Prepared in cooperation with the U.S. Nuclear Regulatory Commission

\title{
Application of At-Site Peak-Streamflow Frequency Analyses for Very Low Annual Exceedance Probabilities
}

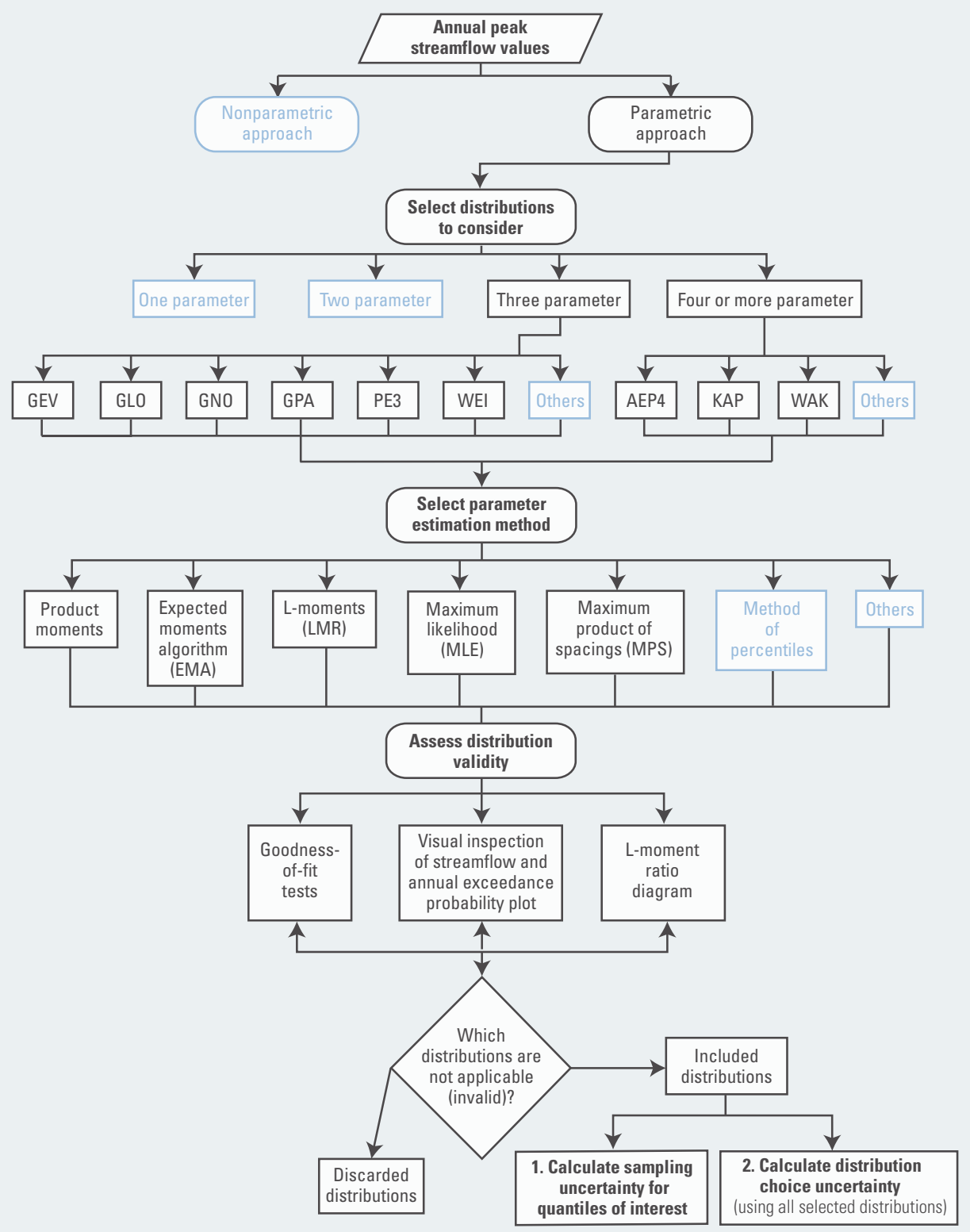

Scientific Investigations Report 2017-5038 
Cover. Schematic diagram showing steps toward estimation of at-site peak-streamflow frequency analyses for low annual exceedance probabilities. Further details are provided in figure 7, herein. 


\section{Application of At-Site Peak-Streamflow Frequency Analyses for Very Low Annual Exceedance Probabilities}

By William H. Asquith, Julie E. Kiang, and Timothy A. Cohn

Prepared in cooperation with the U.S. Nuclear Regulatory Commission

Scientific Investigations Report 2017-5038 


\title{
U.S. Department of the Interior \\ RYAN K. ZINKE, Secretary
}

\section{U.S. Geological Survey William H. Werkheiser, Acting Director}

\author{
U.S. Geological Survey, Reston, Virginia: 2017
}

For more information on the USGS - the Federal source for science about the Earth, its natural and living resources, natural hazards, and the environment-visit https://www.usgs.gov or call 1-888-ASK-USGS.

For an overview of USGS information products, including maps, imagery, and publications,

visit https://store.usgs.gov.

Any use of trade, firm, or product names is for descriptive purposes only and does not imply endorsement by the U.S. Government.

Although this information product, for the most part, is in the public domain, it also may contain copyrighted materials as noted in the text. Permission to reproduce copyrighted items must be secured from the copyright owner.

Suggested citation:

Asquith, W.H., Kiang, J.E., and Cohn, T.A., 2017, Application of at-site peak-streamflow frequency analyses for very low annual exceedance probabilities: U.S. Geological Survey Scientific Investigation Report 2017-5038, 93 p., https:// doi.org/10.3133/sir20175038.

ISSN 2328-0328 (online) 


\section{Author Roles and Acknowledgments}

This report is the product of a coordinated effort by several topical experts. William H. Asquith, U.S. Geological Survey (USGS), provided most of the draft text, computational underpinnings, and provided the material for appendixes 2-5. Julie E. Kiang (USGS) contributed to the report structure and provided much textual enhancement, and Timothy A. Cohn (USGS) contributed early technical comparisons to provisional computations, literature summaries, and nascent report structure. Dan Wagner (USGS) contributed most of appendix 1 with Larry Bohman (USGS) and Kristine Blickenstaff (USGS) providing peer review of that appendix. John F. England, Jr.

(U.S. Army Corps of Engineers) contributed by running a specially compiled version of the USGSPeakFO software for annual exceedance probabilities less than 0.002. Harry Jenter assisted with project scoping and oversight. William H. Asquith and Julie E. Kiang compiled the report; all authors contributed to final editing. Andrea Veilleux (USGS) and Karen Ryberg (USGS) provided technical reviews of all material except appendix 1. This work was funded by the U.S. Nuclear Regulatory Commission (NRC-H0-60-15-I-0006) with Meredith L. Carr acting as the Commission project manager. 



\section{Contents}

Author Roles and Acknowledgments ...........................................................................................ii

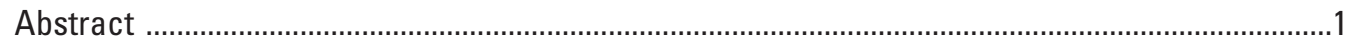

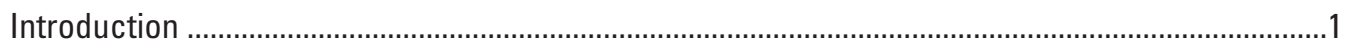

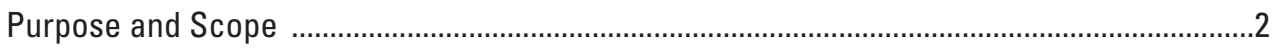

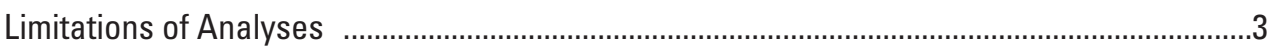

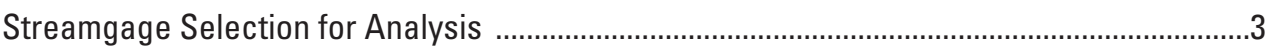

Background on Peak-Streamflow Frequency Estimation ...........................................................

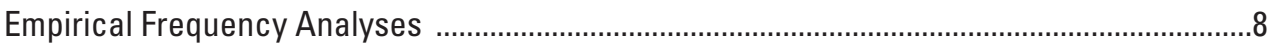

Parametric Frequency Analyses ................................................................................. 10

Other Frequency Methods .............................................................................................. 11

Quantifying Sources of Uncertainty .....................................................................................

Methods of Probability Distribution Selection and Estimation ......................................................12

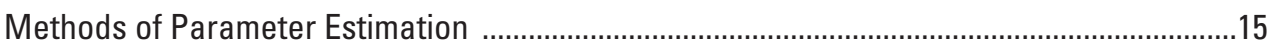

Distribution Validity and Goodness-of-Fit ........................................................................16

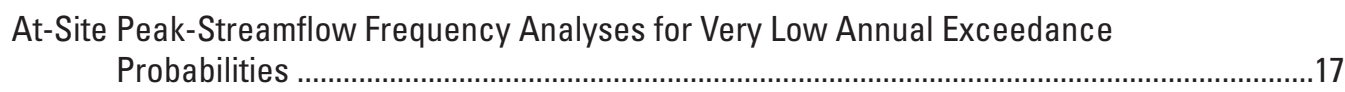

Results for the Raritan River at Manville, New Jersey, Streamgage ....................................18

Comparison of Parameter Estimates .........................................................................18

Frequency Curve Comparisons and Confidence Limits ...............................................18

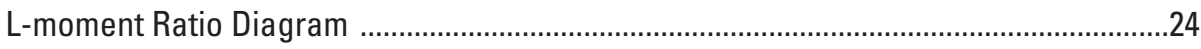

Results for the Potomac River at Point of Rocks, Maryland, Streamgage .............................24

Comparison of Parameter Estimates ...............................................................................24

Frequency Curve Comparisons and Confidence Limits ...................................................24

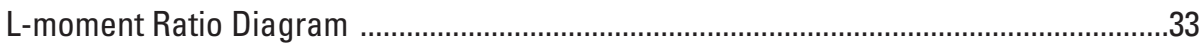

Further Evaluation of Goodness-of-Fit and Uncertainties .......................................................35

Alternative and Visual Representation of Quantile Uncertainty ...............................................37

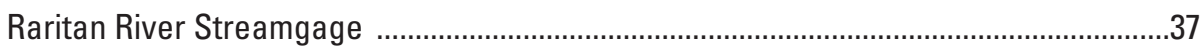

Potomac River Streamgage ................................................................................40

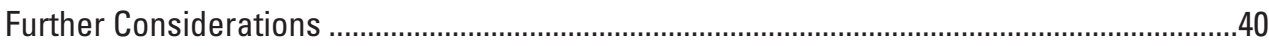

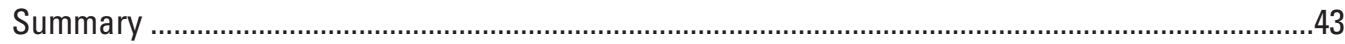

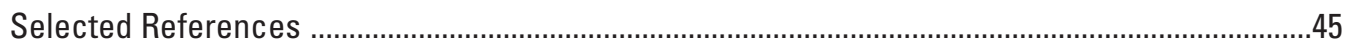

Appendixes

1. U.S. Geological Survey Streamgaging Methods and Annual Peak Streamflow .............52

2. Primer on Product Moment Theory and Plotting Positions as Applicable to

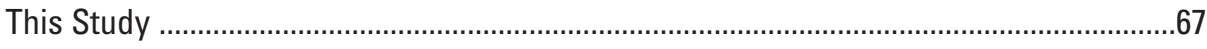

3. Primer on L-moment Theory as Applicable to This Study ...........................................72

4. Primer on Goodness-of-Fit Metrics and Association to the Methods of Maximum Likelihood and Maximum Product of Spacings as Applicable to This Study ..................79

5. Primer on Probability Distributions Applicable to This Study in the Context of L-moments 


\section{Figures}

1. Map showing locations of U.S. Geological Survey streamflow-gaging stations 01400500 Raritan River at Manville, New Jersey, and 01638500 Potomac River at Point of Rocks, Maryland

2. Photograph of river channel at U.S. Geological Survey streamflow-gaging station 01400500 Raritan River at Manville, New Jersey, on September 7, 2016 .5

3. Photograph of river channel at U.S. Geological Survey streamflow-gaging station 01638500 Potomac River at Point of Rocks, Maryland, on May 17, 2014 5

4. Time-series graph of annual peak streamflow data for U.S. Geological Survey streamflow-gaging station 01400500 Raritan River at Manville, New Jersey

5. Time series graph of annual peak streamflow data for U.S. Geological Survey streamflow-gaging station 01638500 Potomac River at Point of Rocks, Maryland

6. Graph showing empirical distribution by means of ranked annual peak streamflow data and Hirsch-Stedinger plotting positions for U.S. Geological Survey streamflow-gaging stations 01400500 Raritan River at Manville, New Jersey, and 01638500 Potomac River at Point of Rocks, Maryland

7. Schematic diagram showing steps toward estimation of at-site peak-streamflow frequency analyses for low annual exceedance probabilities

8. Graph showing comparison of four parameter estimation methods for the Pearson type III probability distribution fit to the logarithms of annual peak streamflow data for U.S. Geological Survey streamflow-gaging station 01400500 Raritan River at Manville, New Jersey

9. Annual nonexceedance probability plot and fitted distributions for U.S. Geological Survey (USGS) streamflow-gaging station 01400500 Raritan River at Manville, New Jersey, based on flood frequency analysis using expected moments algorithm with multiple Grubbs-Beck test (no low outliers detected) and station skew as generated by USGS-PeakFO software

10. L-moment ratio diagram of L-skew and L-kurtosis of annual peak streamflow data for U.S. Geological Survey streamflow-gaging station 01400500 Raritan River at Manville, New Jersey, and comparison to theoretical relations of numerous distributions

11. Graph showing comparison of four parameter estimation methods for the Pearson type III probability distribution fit to logarithms of systematic record of the annual peak streamflow data for U.S. Geological Survey streamflow-gaging station 01638500 Potomac River at Point of Rocks, Maryland

12. Annual nonexceedance probability plot and fitted distributions for U.S. Geological Survey (USGS) streamflow-gaging station 01638500 Potomac River at Point of Rocks, Maryland, based on flood frequency analysis using expected moments algorithm with multiple Grubbs-Beck test (no low outliers detected) and station skew as generated by USGS-PeakF0 software

13. L-moment ratio diagram of L-skew and L-kurtosis of annual peak streamflow data for U.S. Geological Survey streamflow-gaging station 01638500 Potomac River at Point of Rocks, Maryland, and comparison to theoretical relations of numerous distributions

14. Box plots of quantile estimates through Monte Carlo simulation among six threeparameter distributions by the method of L-moments for systematic record for U.S. Geological Survey streamflow-gaging station 01400500 Raritan River at Manville, New Jersey 
15. Box plots of quantile estimates through Monte Carlo simulation among three three-parameter distributions and three methods of parameter estimation for systematic record for U.S. Geological Survey streamflow-gaging station 01400500 Raritan River at Manville, New Jersey

16. Box plots of quantile estimates through Monte Carlo simulation among six three-parameter distributions by the method of L-moments for systematic record for U.S. Geological Survey streamflow-gaging station 01638500 Potomac River at Point of Rocks, Maryland, using systematic record only

17. Box plots of quantile estimates through Monte Carlo simulation among three three-parameter distributions and three methods of parameter estimation for systematic record for U.S. Geological Survey streamflow-gaging station 01638500 Potomac River at Point of Rocks, Maryland

\section{Tables}

1. Identification and ancillary properties of U.S. Geological Survey streamflowgaging stations 01400500 Raritan River at Manville, New Jersey and 01638500 Potomac River at Point of Rocks, Maryland ...

2. Identification of probability distributions referenced in this study

3. Distribution parameters for the Pearson type III distribution by four parameter estimation methods for U.S. Geological Survey streamflow-gaging station 01400500 Raritan River at Manville, New Jersey, using systematic record only

4. Distribution parameters by the methods of L-moments and expected moments algorithm for selected probability distributions for U.S. Geological Survey streamflow-gaging station 01400500 Raritan River at Manville, New Jersey, using systematic record only

5. Confidence limits and quantile fits of peak-streamflow frequency for six threeparameter probability distributions fit by the method of L-moments for U.S. Geological Survey streamflow-gaging station 01400500 Raritan River at Manville, New Jersey, using systematic record only

6. Confidence limits and quantile fits of peak-streamflow frequency using the Pearson type III distribution fit by two methods for U.S. Geological Survey streamflow-gaging station 01400500 Raritan River at Manville, New Jersey, using systematic record only

7. Distribution choice uncertainty computed as logarithmic standard deviation of quantile estimates for five three-parameter probability distributions fit by the method of L-moments for U.S. Geological Survey streamflow-gaging station 01400500 Raritan River at Manville, New Jersey, using systematic record only

8. Distribution parameters for the Pearson type III distribution by four parameter estimation methods for U.S. Geological Survey streamflow-gaging station 01638500 Potomac River at Point of Rocks, Maryland, using systematic record only

9. Distribution parameters by the methods of L-moments and expected moments algorithm for selected probability distributions for U.S. Geological Survey streamflow-gaging station 01638500 Potomac River at Point of Rocks, Maryland

10. Confidence limits and quantile fits of peak-streamflow frequency for six threeparameter probability distributions fit by the method of L-moments for U.S. Geological Survey streamflow-gaging station 01638500 Potomac River at Point of Rocks, Maryland 
11. Confidence limits and quantile fits of peak-streamflow frequency using the Pearson type III distribution fit by two methods for U.S. Geological Survey streamflow-gaging station 01638500 Potomac River at Point of Rocks, Maryland

12. Distribution choice uncertainty computed as logarithmic standard deviation of quantile estimates for five three-parameter probability distributions fit by the method of L-moments for U.S. Geological Survey streamflow-gaging station 01638500 Potomac River at Point of Rocks, Maryland

13. Goodness-of-fit statistics and ranking of selected probability distributions fit to systematic record of annual peak streamflows for U.S. Geological Survey streamflow-gaging stations 01400500 Raritan River at Manville, New Jersey and 01638500 Potomac River at Point of Rocks, Maryland .

\section{Conversion Factors}

Inch/Pound to International System of Units

\begin{tabular}{|c|c|c|}
\hline Multiply & By & To obtain \\
\hline \multicolumn{3}{|c|}{ Length } \\
\hline inch (in.) & 2.54 & centimeter $(\mathrm{cm})$ \\
\hline foot $(\mathrm{ft})$ & 0.3048 & meter (m) \\
\hline mile (mi) & 1.609 & kilometer (km) \\
\hline \multicolumn{3}{|c|}{ Area } \\
\hline square mile $\left(\mathrm{mi}^{2}\right)$ & 2.590 & square kilometer $\left(\mathrm{km}^{2}\right)$ \\
\hline \multicolumn{3}{|c|}{ Volume } \\
\hline cubic foot $\left(\mathrm{ft}^{3}\right)$ & 0.02832 & cubic meter $\left(\mathrm{m}^{3}\right)$ \\
\hline \multicolumn{3}{|c|}{ Flow rate } \\
\hline cubic foot per second $\left(\mathrm{ft}^{3} / \mathrm{s}\right)$ & 0.02832 & cubic meter per second $\left(\mathrm{m}^{3} / \mathrm{s}\right)$ \\
\hline
\end{tabular}

Temperature in degrees Celsius $\left({ }^{\circ} \mathrm{C}\right)$ may be converted to degrees Fahrenheit $\left({ }^{\circ} \mathrm{F}\right)$ as ${ }^{\circ} \mathrm{F}=(1.8 \times$ $\left.{ }^{\circ} \mathrm{C}\right)+32$.

Temperature in degrees Fahrenheit $\left({ }^{\circ} \mathrm{F}\right)$ may be converted to degrees Celsius $\left({ }^{\circ} \mathrm{C}\right)$ as ${ }^{\circ} \mathrm{C}=\left({ }^{\circ} \mathrm{F}-\right.$ 32) / 1.8 .

\section{Datum}

Horizontal coordinate information is referenced to North American Datum of 1983 (NAD 83). 


\section{Abbreviations}

\begin{tabular}{|c|c|}
\hline ADCP & acoustic Doppler current profiler \\
\hline ADV & acoustic Doppler velocimeter \\
\hline AEP & annual exceedance probability \\
\hline AEP4 & asymmetric exponential power distribution (four-parameter probability distribution) \\
\hline AIC & Akaike Information Criterion for assessing goodness-of-fit \\
\hline $\mathrm{CM}$ & Cramér-von Mises statistic for assessing goodness-of-fit \\
\hline CSG & crest-stage gage \\
\hline DCP & data-collection platform (a data logging and telemetry suite used by the USGS) \\
\hline EMA & $\begin{array}{l}\text { expected moments algorithm (a method for parameter estimation related to product } \\
\text { moments but able to include sophisticated and nonstandard historical information) }\end{array}$ \\
\hline GAMLSS & generalized additive models for location, scale, and shape \\
\hline GEV & generalized extreme value distribution (three-parameter probability distribution) \\
\hline GLO & generalized logistic distribution (three-parameter probability distribution) \\
\hline GNO & $\begin{array}{l}\text { generalized normal (three-parameter log-normal) distribution (three-parameter log- } \\
\text { normal probability distribution) }\end{array}$ \\
\hline GOES & Geostationary Operational Environmental Satellite \\
\hline GPA & generalized Pareto distribution (three-parameter probability distribution) \\
\hline GPS & global positioning system \\
\hline HUC & hydrologic unit code \\
\hline IACWD & Interagency Advisory Committee on Water Data \\
\hline KAP & Kappa probability distribution (four-parameter probability distribution) \\
\hline KS & Kolmogorov-Smirnov statistic for assessing goodness-of-fit \\
\hline LMR & $\begin{array}{l}\text { method of L-moments (a method for parameter estimation using the L-moments). } \\
\text { This abbreviation is used very selectively within this report and just the simple term } \\
\text { "L-moments" used elsewhere. }\end{array}$ \\
\hline MD & Moran-Darling statistic for assessing goodness-of-fit \\
\hline MLE & $\begin{array}{l}\text { maximum likelihood (a method for parameter estimation using the probability } \\
\text { density function) }\end{array}$ \\
\hline MPS & $\begin{array}{l}\text { maximum product of spacings (a method for parameter estimation using the } \\
\text { cumulative probability function) }\end{array}$ \\
\hline NESDIS & National Environmental Satellite, Data, and Information Service \\
\hline NOAA & National Oceanic and Atmospheric Administration \\
\hline NRC & U.S. Nuclear Regulatory Commission \\
\hline NWIS & USGS National Water Information System \\
\hline PE3 & Pearson type III distribution (three-parameter probability distribution) \\
\hline PWM & probability-weighted moments (a form of L-moment description and vice versa) \\
\hline USGS & U.S. Geological Survey \\
\hline WAK & Wakeby probability distribution (five-parameter probability distribution) \\
\hline WEI & Weibull probability distribution (three-parameter probability distribution) \\
\hline$\sigma_{\mathrm{s}}$ & $\begin{array}{l}\text { The standard deviation of a quantile estimate for a given AEP based on logarithms. } \\
\text { This is the sampling uncertainty of this report, and such an uncertainty is also } \\
\text { known as aleatoric, irreducible, or stochastic. }\end{array}$ \\
\hline$\sigma_{\mathrm{dc}}$ & $\begin{array}{l}\text { The standard deviation of multiple quantile estimates from selected distributions for } \\
\text { a given AEP based on logarithms. This is the distribution choice uncertainty of this } \\
\text { report, and such an uncertainty is also known as epistemic or reducible. }\end{array}$ \\
\hline
\end{tabular}





\title{
Application of At-Site Peak-Streamflow Frequency Analyses for Very Low Annual Exceedance Probabilities
}

\author{
By William H. Asquith, Julie E. Kiang, and Timothy A. Cohn
}

\section{Abstract}

The U.S. Geological Survey (USGS), in cooperation with the U.S. Nuclear Regulatory Commission, has investigated statistical methods for probabilistic flood hazard assessment to provide guidance on very low annual exceedance probability (AEP) estimation of peak-streamflow frequency and the quantification of corresponding uncertainties using streamgage-specific data. The term "very low AEP" implies exceptionally rare events defined as those having AEPs less than about 0.001 (or $1 \times 10^{-3}$ in scientific notation or for brevity $10^{-3}$ ). Such low AEPs are of great interest to those involved with peak-streamflow frequency analyses for critical infrastructure, such as nuclear power plants. Flood frequency analyses at streamgages are most commonly based on annual instantaneous peak streamflow data and a probability distribution fit to these data. The fitted distribution provides a means to extrapolate to very low AEPs. Within the United States, the Pearson type III probability distribution, when fit to the base-10 logarithms of streamflow, is widely used, but other distribution choices exist. The USGS-PeakFQ software, implementing the Pearson type III within the Federal agency guidelines of Bulletin 17B (method of moments) and updates to the expected moments algorithm (EMA), was specially adapted for an "Extended Output" user option to provide estimates at selected AEPs from $10^{-3}$ to $10^{-6}$. Parameter estimation methods, in addition to product moments and EMA, include L-moments, maximum likelihood, and maximum product of spacings (maximum spacing estimation). This study comprehensively investigates multiple distributions and parameter estimation methods for two USGS streamgages (01400500 Raritan River at Manville, New Jersey, and 01638500 Potomac River at Point of Rocks, Maryland). The results of this study specifically involve the four methods for parameter estimation and up to nine probability distributions, including the generalized extreme value, generalized lognormal, generalized Pareto, and Weibull. Uncertainties in streamflow estimates for corresponding AEP are depicted and quantified as two primary forms: quantile (aleatoric [random sampling] uncertainty) and distribution-choice (epistemic [model] uncertainty). Sampling uncertainties of a given distribution are relatively straightforward to compute from analytical or Monte Carlo-based approaches.
Distribution-choice uncertainty stems from choices of potentially applicable probability distributions for which divergence among the choices increases as AEP decreases. Conventional goodness-of-fit statistics, such as Cramér-von Mises, and L-moment ratio diagrams are demonstrated in order to hone distribution choice. The results generally show that distribution choice uncertainty is larger than sampling uncertainty for very low AEP values.

\section{Introduction}

The U.S. Geological Survey (USGS), in cooperation with the U.S. Nuclear Regulatory Commission (NRC), has investigated probabilistic flood hazard assessment using a statistical perspective with intent to provide guidance for very low annual exceedance probability (exceptionally rare event) estimation of peak-streamflow frequency and corresponding uncertainty quantification. This report is to serve as a resource for NRC technical decisionmakers, collaborators, and other interested parties on the study of the exposure of critical infrastructure, such as nuclear power plant sites to probabilistic flood hazards in the United States (NRC, 2013; O'Connor and others, 2014; Prasad and others, 2011). Probabilistic flood hazard assessment is inherently complex and is but one part of multidisciplinary risk assessment and management for critical infrastructure. For the purposes of this study, critical infrastructure is defined as the infrastructure having components of very large capital investment and (or) substantial risk to public safety as the result of rare hydrologic circumstances. Such infrastructure includes nuclear power plants. Katz (2016, p. 439) notes, "Much economic impact of weather and climate is realized through extreme events," and such extreme events include flood hazards. Similarly, Wang and $\mathrm{Li}(2016$, p. 307) note, "Estimation of tail quantiles is of great interest in many studies of rare events that happen infrequently but have heavy consequences."

Typical hazard levels or annual exceedance probabilities (AEPs) for flood hazard assessments are determined from the right tail of a probability distribution. Especially important for critical infrastructure are annual return intervals associated with very low AEP values that far exceed the length of observational records at individual sites or even within regions 
of interest. The term "very low AEP" implies exceptionally rare events defined as those having AEPs less than about 0.001 (or $1 \times 10^{-3}$ in scientific notation or for brevity $10^{-3}$ ). (Scientific notation is used, hereinafter, for AEPs less than or equal to 0.001 .) The results herein emphatically are not definitive, which is an acknowledgment that various decisions in the processes (steps) in flood hazard assessments have subjective components. Other analysts are expected to produce differing hazard assessments in the details, but likely not in generalizations, of the results herein. Although analyst decisions can affect results, "the unavoidable truth is that structural measures for reducing flood risk need hard numbers to dimension [infrastructure protection]" (Wilby, 2012).

The hydrologic engineering community typically studies instantaneous maximum streamflow (peak streamflow; volume per unit time) as the hazard-producing phenomenon that serves as input for hydraulic and hydrodynamic riverine models used to estimate localized water-surface elevations (stages) (Interagency Advisory Committee on Water Data [IACWD], 1982; National Research Council, 1988). The peak streamflow at a specific AEP is commonly estimated from statistical models, hydrologic models (watershed models), or combinations of the two. For this study, statistical models (probability distributions) are investigated. Estimation methods and uncertainty when translating peak streamflow to river stage, such as using numerical hydraulic models, are not discussed.

When flood hazard assessments are conducted at or near streamflow-gaging stations ("streamgages" hereafter; Lurry, 2011; Olson and Norris, 2007), the observational record of annual peak streamflow forms the information foundation for analysis. This type of analysis is termed an "at-site" analysis; that is, an analysis conducted based on data collected from a specific streamgage. Annual data are most commonly associated with USGS streamgages, and annual peak streamflow data are provided to the public through the USGS National Water Information System (NWIS; USGS, 2016a). Information about streamgaging methods and the USGS database is provided in appendix 1, with emphasis on annual peak streamflow.

Floodplain management in the United States (Federal Emergency Management Agency, 2017) makes wide use of the magnitude of peak streamflow associated with an AEP of 0.01 , sometimes called the 1-percent chance flood or the 100-year flood (Dinicola, 1996). Much infrastructure in the form of culverts, bridges, floodplain management and riverine flood control is dependent on hazard levels that include AEPs commonly ranging from 0.1 to as small as 0.002 . Uncertainty in accuracy and precision exists about the magnitude of peak streamflow for a given AEP. The uncertainty in peakstreamflow frequency estimates (magnitudes) is not ignored, but convention often is to use these peak streamflows as point estimates for the specified AEPs of interest to a design circumstance and deem these sufficient as those hard numbers. Pappenberger and Beven (2006) provide highly cogent arguments concerning uncertainty analysis in hydrologic models (including peak-streamflow frequency) requires greater attention than it currently receives. Nevertheless, it is often sufficient to use point estimates in the design of many bridges and other roadway crossings where the consequences of losses or service interruptions generally are smaller than those associated with critical infrastructure.

For critical infrastructure elements, such as major dams and nuclear power plants, the consequences of exceedance are often much more substantial than for lesser elements, and the uncertainty in the estimated flood hazard is a particularly important component in complex decision- and design-making processes. In fact, the National Research Council (1988, p. 11) states that "a thorough study of low-frequency extreme events requires inclusion of an explicit uncertainty analysis." The AEPs of interest to critical infrastructure flood hazards far transcend the lowest AEP (0.002) of general interest in transportation infrastructure and floodplain management, and the AEPs of $10^{-3}, 10^{-4}$, or even lower are informative. Flood hazard estimates in these distal reaches of the tail of the underlying and unknown probability distribution fundamentally have much uncertainty (El Adlouni and others, 2008). Point estimates for a given AEP might not be sufficient, and quantification of uncertainties is of special interest to critical infrastructure decisionmakers.

\section{Purpose and Scope}

The purpose of this report is to document, using data from two selected USGS streamgages, a framework that can be used to quantify uncertainty in analyses of peakstreamflow frequency attributable to two sources: (1) the choice of the distribution to which the frequency curve is fit and (2) sampling error with respect to a chosen quantile and distribution. Emphasis is placed on the distribution choice uncertainty as a means to express or further explain however much uncertainty in extreme flood quantiles exists. Another purpose of this report is to outline with theoretical sufficiency the associated mathematical statistics in order to provide clarity in complex mathematical definitions.

The study of flood hazard analysis described in this report is restricted to examining the statistical analyses of annual peak streamflow data using probability distributions, which is referred to as peak-streamflow frequency analyses. In brief, a probability distribution is fit to observed data in order to estimate the annual probability of exceeding a specified flood magnitude. The value of the estimated streamflow associated with the $0.001 \mathrm{AEP}$ is a flood quantile (or just "quantile"). A successive sequence of quantiles for different AEPs defines the peak-streamflow frequency curve.

Annual peak streamflow data for USGS streamgages 01400500 Raritan River at Manville, New Jersey, and 01638500 Potomac River at Point of Rocks, Maryland, are used in this report to illustrate methods for estimating very low AEP floods and their uncertainty. Two methods of parameter estimation are primarily utilized: the expected moments algorithm (Cohn and others, 1997; Cohn and 
others, 2001) and L-moments (Hosking, 1990). The expected moments algorithm reduces to product moments in absence of nonstandard flood information. Additionally in a lesser role, the methods of maximum likelihood estimation and maximum product of spacings also are considered. Data are fitted to a total of nine probability distributions, six three-parameter distributions, two four-parameter distributions, and a single five-parameter distribution.

The mathematics associated with this report are provided as four thematic appendixes. A brief review of plotting positions and product moments is provided in appendix 2, and a similar review of L-moments is provided in appendix 3. Maximum likelihood (MLE) and maximum product of spacings (MPS) are described in appendix 4 along with goodness-of-fit statistics. The probability distributions applicable to this study in the context of L-moments are described in appendix 5 . Those appendixes provide succinct mathematics through both independent and co-dependent figures.

\section{Limitations of Analyses}

Although there is one historical flood in the peak streamflow record used for parts of computations involving a streamgage on the Potomac River (see next section), this report focuses almost exclusively on flood quantile estimation using only the systematic record of peak streamflows. Specifically, such record is composed of only data collected during a period of systematic (that is, deliberate) year-to-year data collection, and other types of non-systematic data are not included. Whereas other types of extant information may be informative for extreme quantile or "tail" (National Research Council, 1988, p. 7, 29-31) estimation, it is beyond the scope of this report to research and incorporate such information. This report does not consider the incorporation of information about historical floods and reconstructed flood events using paleohydrology (Baker, 1987; O’Connor and others, 2014), information that may be available from other streamgages in the area, or changes in streamflow generating processes attributable to changes in land use, flood control structures, or anthropogenic climate change (Cohn and Lins, 2005). By extension, the statistical properties of peak streamflow are assumed time invariant and thus stationary (Lins and Cohn, 2011).

\section{Streamgage Selection for Analysis}

The two USGS streamgages (fig. 1) selected for study are located within the eastern United States: 01400500 Raritan River at Manville, New Jersey, and 01638500 Potomac River at Point of Rocks, Maryland (figs. 2 and 3, table 1). The annual peak or annual maximum flood series for these streamgages constitute the data used. The streamgages were not selected to develop definitive peak-streamflow frequencies for design considerations at these streamgages; instead, both streamgages are simply examples used for purposes of illustration.

The streamgages were selected with respect to several general characteristics, including a long period of record (tens of decades), anticipated stationarity of the data, and substantially large watersheds with respect to drainage areas representing upland regions in the humid seaboard of the eastern United States. A final selection criterion was a lack of substantial impacts by flood-flow regulation and urbanization. This is indicated by the absence of the peak streamflow qualification codes (table 1-1) in the USGS peak streamflow database ("peak-flow file" [appendix 1]; USGS, 2016a). The peak streamflows are essentially unregulated in the watersheds and are treated as such for purposes of this study.

The Raritan River streamgage (fig. 1) is located about 33 miles (mi) west-southwest of the New York metropolitan area and has a watershed drainage area of about 490 square miles $\left(\mathrm{mi}^{2}\right.$; table 1$)$. The region lies within the northern New Jersey climate division (National Oceanic and Atmospheric Administration [NOAA], 2016a) and has a mean annual precipitation of about 43 inches (in.) for the period 1903-2015 (NOAA, 2016b). This period corresponds closely to the observational peak streamflow record for the streamgage (table 1-2) shown in figure 4. The USGS reports drainage areas, gage height (stage), streamflow, and precipitation in English units, such as square miles, feet, cubic feet per second, and inches, respectively. These unit conventions are retained for this report.

The peak streamflow data for the Raritan River streamgage show attributes of stationarity based on visual inspection of the data (fig. 4) as well as by examination of peak streamflow data qualification codes associated with the peak streamflow record (USGS, 2016a). None of the annual peaks are flagged in the USGS peak streamflow database as being substantially affected by flood-flow regulation or urbanization. The Kendall's Tau test (Conover, 1999; Helsel and Hirsch, 2002; Hollander and Wolfe, 1973) for temporal trends yields a Tau value of about +0.06 and a corresponding $\mathrm{p}$-value of about 0.38 (table 1 ) from computations made using the USGS-PeakFQ software (Flynn and others, 2006; USGS, 2014), indicating that there is not a statistically significant trend. The Kendall's Tau test is commonly used to detect monotonic trends between streamflow statistics, such as annual peak streamflow, and time. It is therefore reasonable to treat peak streamflows at this streamgage as a stationary time series.

Analyses were restricted only to the systematic record for the Raritan River to allow broadly similar application of different distribution fitting methods. The largest peak in the record is 77,600 cubic feet per second $\left(\mathrm{ft}^{3} / \mathrm{s}\right)$ in 1999 and is the highest since 1896, whereas the smallest peak in the record is $6,660 \mathrm{ft}^{3} / \mathrm{s}$ in 2000 (fig. 4; USGS, 2016a). The period of record for this study is water years 1904-2014, with gaps in the record during 1907-1908 and 1916-1921. A water year is the 12-month period from October 1 through September 30, designated by the calendar year in which it 


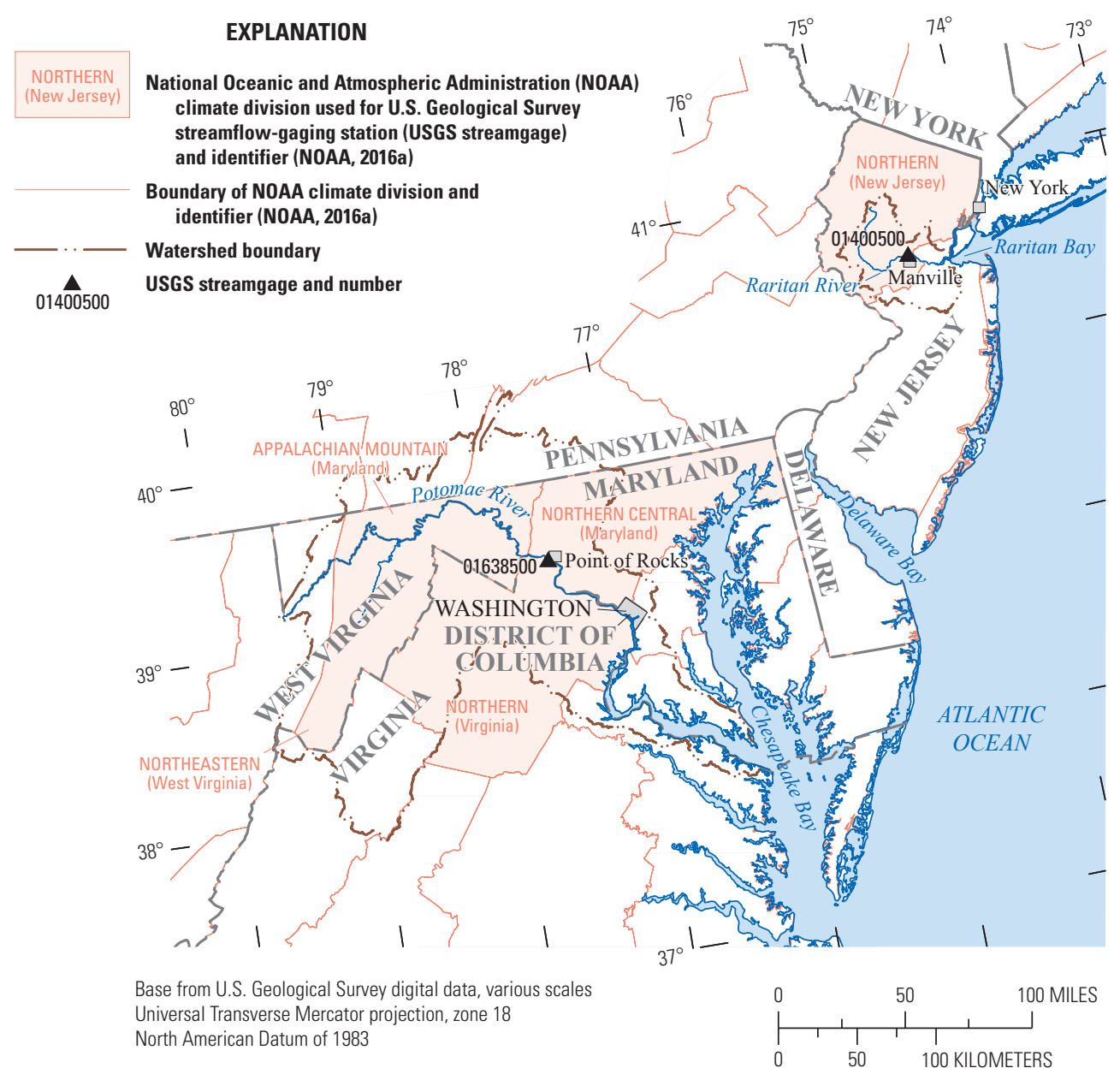

Figure 1. Locations of U.S. Geological Survey streamflow-gaging stations 01400500 Raritan River at Manville, New Jersey, and 01638500 Potomac River at Point of Rocks, Maryland.

ends. The restriction of using only the systematic record ensures a common basis on which to compare methods, because not all methods accommodate non-systematic record information in rigorously identical ways. However, this was not done for the historical streamflow record for the Potomac River at Point of Rocks streamgage.

The Potomac River streamgage (fig. 1) is located about 40 mi northwest of Washington, D.C. and has a watershed drainage area of about 9,651 $\mathrm{mi}^{2}$. The region lies within the north-central Maryland climate division (NOAA, 2016a) and has a mean annual precipitation of about $47 \mathrm{in}$. for the period 1895-2015 (NOAA, 2016b). This period corresponds closely to the observation peak streamflow record shown in figure 5 for this streamgage.

Systematic records of peak streamflows are available for the Potomac River streamgage (table 1-3) for water years 1895-2015; historical information also is available. An annual peak streamflow of $460,000 \mathrm{ft}^{3} / \mathrm{s}$ occurred in 1889 and is the largest peak during the 1889-94 period, which is before systematic operation of the streamgage began. The largest peak in the record (systematic and historical) is $480,000 \mathrm{ft}^{3} / \mathrm{s}$ in 1936 , whereas the smallest peak in the record is $27,800 \mathrm{ft}^{3} / \mathrm{s}$ in 1969 (fig. 5; USGS, 2016a).

The peak streamflow data for the Potomac River streamgage show attributes of stationarity based on a visual inspection of the data (fig. 5) as well as by examination of streamflow qualification codes associated with the peak streamflow record. None of the annual peaks are flagged (identified) in the USGS peak streamflow database as being substantially affected by flood-flow regulation or urbanization. The Kendall's Tau test yields a Tau value of about -0.03 and $p$-value of about 0.64 from computations made using the USGS-PeakFQ software, indicating that there is not a statistically significant trend.

In the context of the background provided herein, the records of peak streamflow for both streamgages are suitable for a study of methods available for peak-streamflow frequency estimation, quantification of uncertainty, and right-tail estimation for low AEP. The peak streamflow data for the streamgages are extensive and provide favorable circumstances for site-specific peak-streamflow frequency computation. 


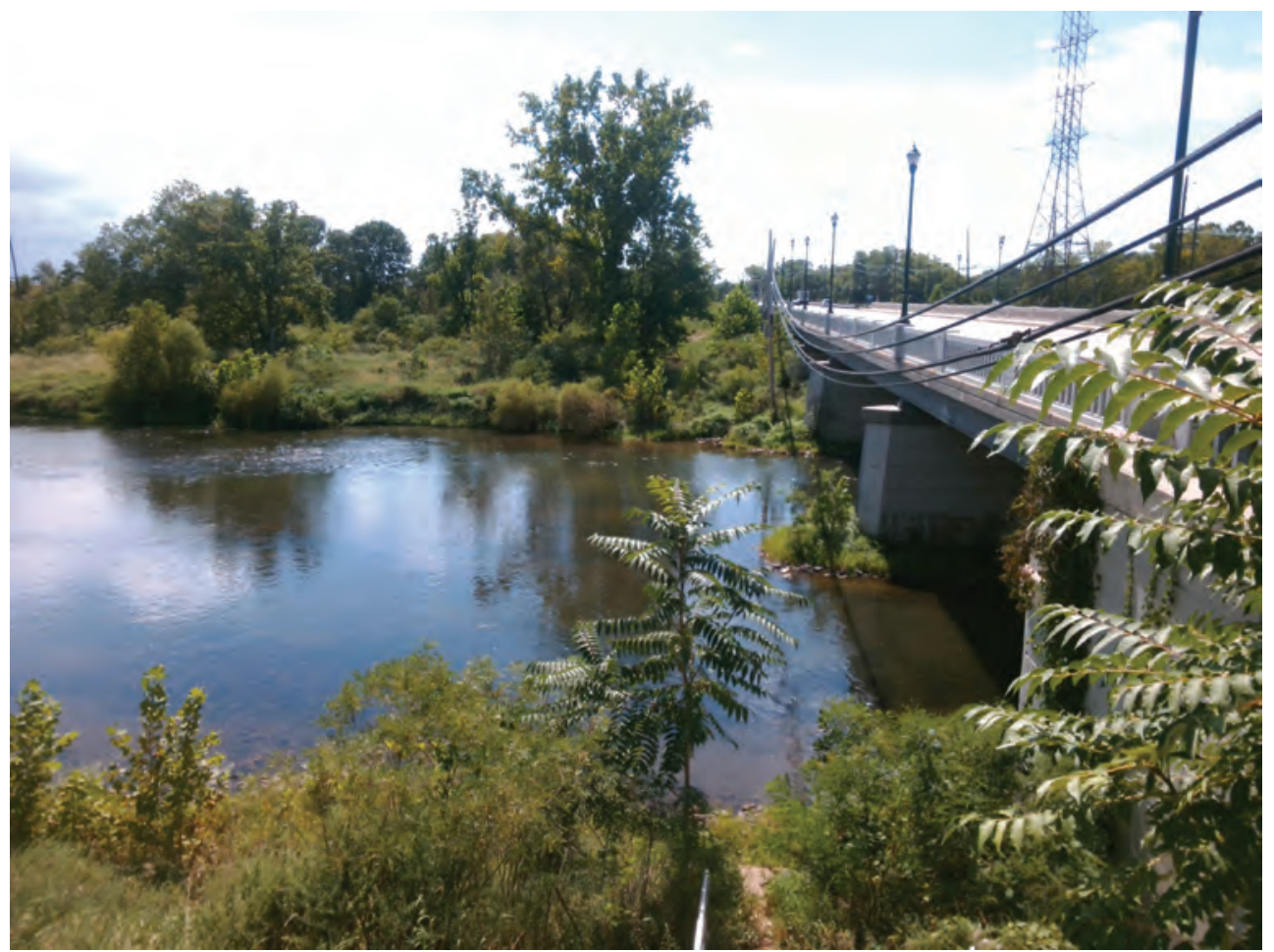

Figure 2. River channel at U.S. Geological Survey streamflow-gaging station 01400500 Raritan River at Manville, New Jersey, on September 7, 2016. Photograph by Brian McDowell, U.S. Geological Survey.

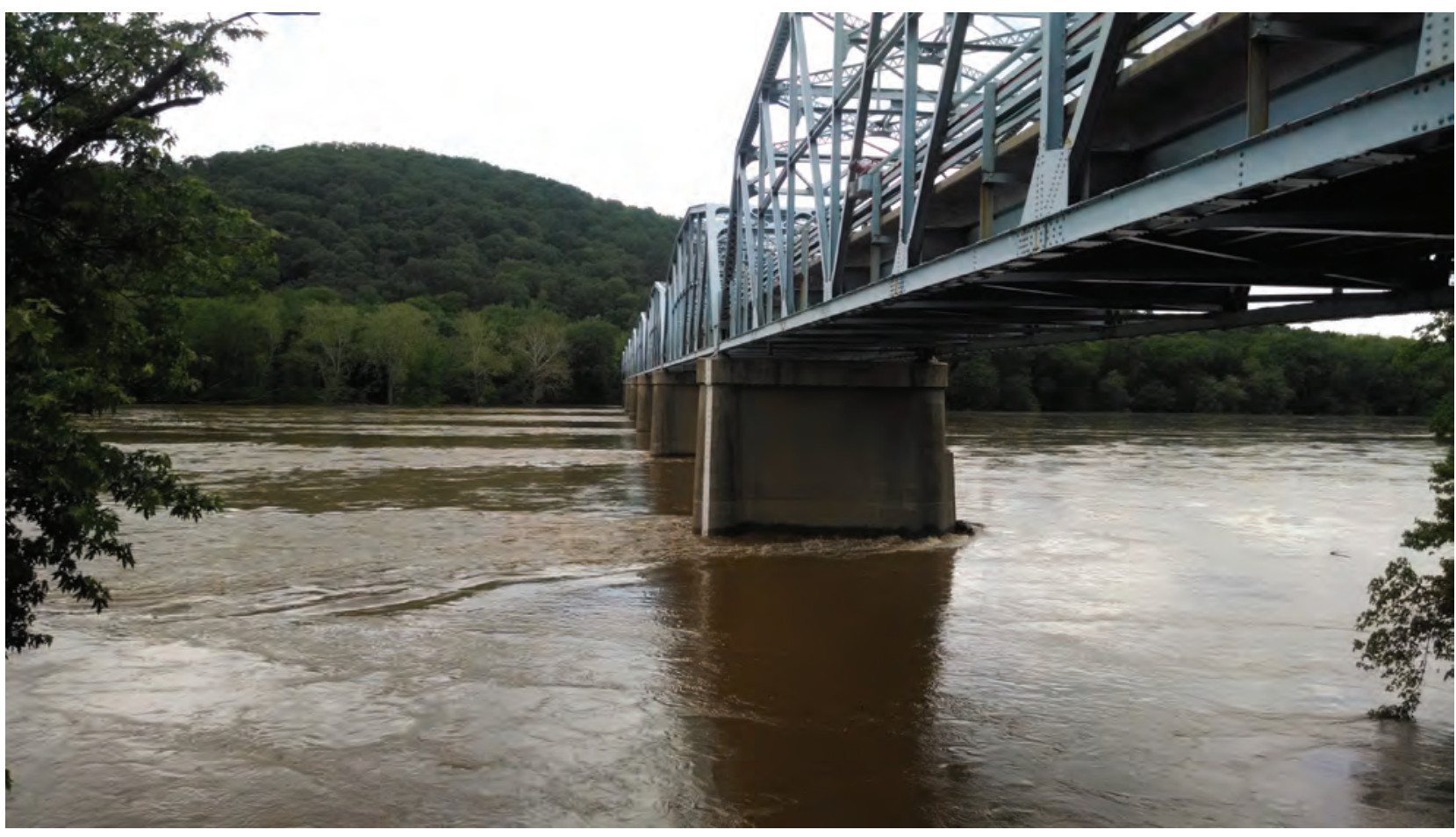

Figure 3. River channel at U.S. Geological Survey streamflow-gaging station 01638500 Potomac River at Point of Rocks, Maryland, on May 17, 2014. Photograph by Eric Vance, U.S. Geological Survey. 
Table 1. Identification and ancillary properties of U.S. Geological Survey streamflow-gaging stations (streamgages) 01400500 Raritan River at Manville, New Jersey and 01638500 Potomac River at Point of Rocks, Maryland.

[USGS, U.S. Geological Survey; NGVD 29, National Geodetic Vertical Datum of 1929; NAVD 88, North American Vertical Datum of 1988; ft, foot; mi², square mile; --, dimensionless. Text in red is referenced directly in the report]

\begin{tabular}{|c|c|c|c|c|c|c|c|c|}
\hline $\begin{array}{l}\text { USGS } \\
\text { station } \\
\text { number }\end{array}$ & Streamgage name & $\begin{array}{l}\text { Latitude } \\
\text { (degrees) }\end{array}$ & $\begin{array}{l}\text { Longitude } \\
\text { (degrees) }\end{array}$ & $\begin{array}{c}\text { Gage datum } \\
\text { (ft) }\end{array}$ & $\begin{array}{l}\text { Period of } \\
\text { systematic } \\
\text { record }\end{array}$ & $\begin{array}{l}\text { Contributing } \\
\text { drainage } \\
\text { area } \\
\left(\mathrm{mi}^{2}\right)\end{array}$ & $\begin{array}{c}\text { Kendall's } \\
\text { Tau } \\
(--)\end{array}$ & $\begin{array}{c}\text { Kendall's } \\
\text { Tau p-value } \\
\text { of analyzed } \\
\text { annual peak } \\
\text { streamflows } \\
(--)\end{array}$ \\
\hline 01400500 & $\begin{array}{l}\text { Raritan River at } \\
\text { Manville, N.J. }\end{array}$ & $40^{\circ} 33^{\prime} 20^{\prime \prime}$ & $74^{\circ} 34^{\prime} 58^{\prime \prime}$ & 20.61 NGVD 29 & $\begin{array}{l}\text { 1904-06, } \\
1909-15, \\
1922-2014\end{array}$ & 490 & +0.06 & 0.38 \\
\hline 01638500 & $\begin{array}{l}\text { Potomac River at Point } \\
\text { of Rocks, Md. }\end{array}$ & $39^{\circ} 16^{\prime} 24.9^{\prime \prime}$ & $77^{\circ} 32^{\prime} 35.2^{\prime \prime}$ & 199.92 NAVD 88 & $1895-2015$ & 9,651 & -0.03 & 0.64 \\
\hline
\end{tabular}

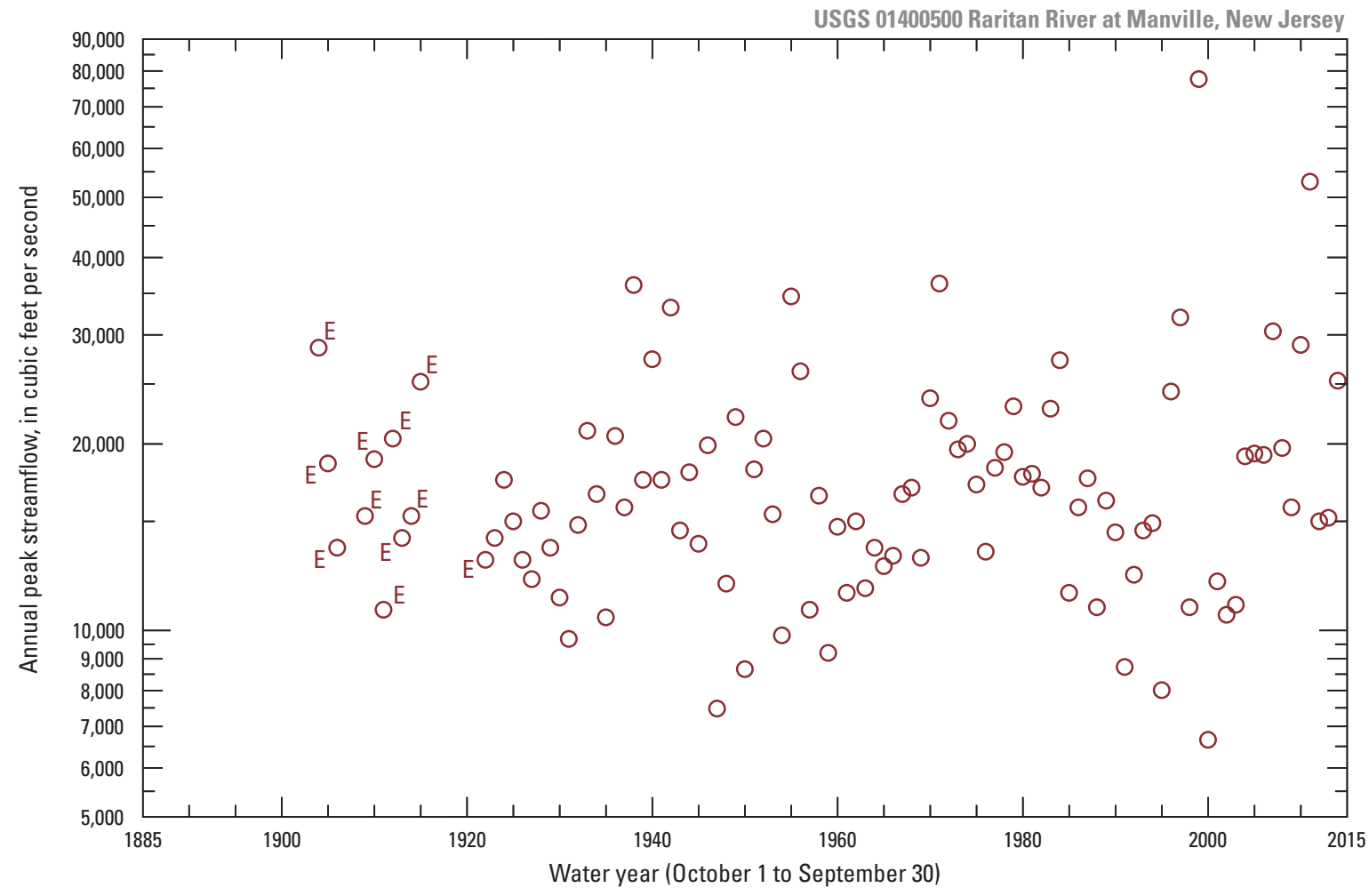

EXPLANATION

$\bigcirc$ Annual peak streamflow with peak streamflow qualification code (appendix 1) if applicable-E, "Only annual peak streamflow available for this year." This qualification code means that no other streamflow information is available and could mean that the streamgage was not operated for continuous record or the streamgage was only operated for acquisition of maximum streamflow

USGS, U.S. Geological Survey

Figure 4. Annual peak streamflow data for U.S. Geological Survey streamflow-gaging station 01400500 Raritan River at Manville, New Jersey. 


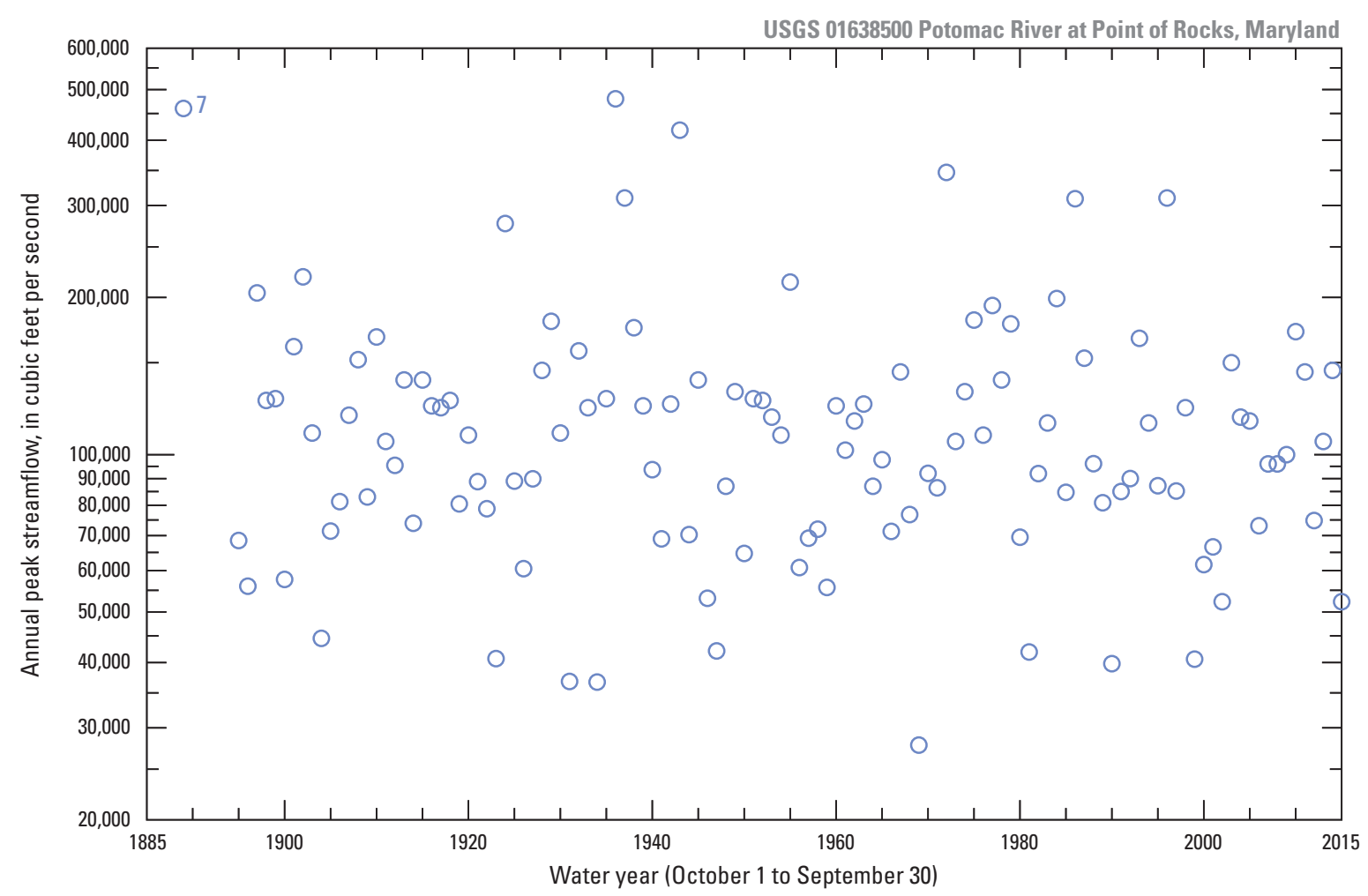

EXPLANATION

$7^{\bigcirc}$ Annual peak streamflow with peak streamflow qualification code (appendix 1) if applicable-7, "Streamflow is an historic peak." This qualification code means that the peak streamflow is outside the period of systematic record

Figure 5. Annual peak streamflow data for U.S. Geological Survey streamflow-gaging station 01638500 Potomac River at Point of Rocks, Maryland.

\section{Background on Peak-Streamflow Frequency Estimation}

Analysis of peak-streamflow frequency (Stedinger and others, 1993) is a type of statistical analysis used to estimate the peak-streamflow frequency curve (commonly also called the flood-frequency curve). Prasad and others (2011, sec. 4.2), in particular, succinctly review the applicable background for those interested in probabilistic flood hazard assessments for nuclear power plants. Specific values for a hazard-level AEP from a peak-streamflow frequency curve are known as flood quantiles. A quantile simply corresponds to a single AEP, and for this study, AEP is the preferred term for hazard level. The frequency curve can be represented in two primary ways. First, the frequency curve can be represented by an empirical distribution function that is often approximated using Hirsch-Stedinger or other plotting positions (Hirsch and Stedinger, 1987; IACWD, 1982; Stedinger and others, 1993). The empirical distribution representation is a nonparametric technique that provides for visualization of the data. Second, parametric methods can be used to fit one or more probability distributions to the data (IACWD, 1982; National Research Council, 1988).
This section first provides some basic information concerning the statistical assumptions used in peak-streamflow frequency analyses. The empirical and parametric approaches to developing peak-streamflow frequency curves are then described. Other possible methods for developing frequency curves are briefly discussed. Lastly, the uncertainties in fitted parametric frequency curves are discussed.

Throughout this report, frequency curves are fit to the base-10 logarithms of the annual peak streamflows, as is common practice in the discipline. The annual peak streamflow series often spans several orders of magnitude (powers of 10), and the logarithmic transformation is used to normalize these values and to keep unusually high values from having an excessive impact on a fitted frequency curve (Stedinger and others, 1993, p. 18.5).

For most at-site frequency analyses, an assumption is that the annual peaks are independent and identically distributed. As a result, the annual peak streamflows are treated as uncorrelated year-over-year (an example of serial correlation [dependency]). Additionally, the approach for peak-streamflow frequency analysis herein implicitly requires that the data be stationary (Lins and Cohn, 2011) for maximum reliability of results. Stationarity implies, for example, that commonly used statistics for time series such as the mean, variability, skew, 
and higher moments do not change over time and thus are time invariant. For this study, an explicit assumption on stationarity is made for the data at both streamgages.

Peak streamflow data are obtained from measurement methods that have finite resolution. For example, a limited number of significant digits can be attributed to the limitations of instrument resolution and limited precision in the stagedischarge rating curve (appendix 1). As a result, ties in the rank order of peak-streamflow data can occur for reasons such as either coarseness of the recorded data or rounding conventions. For example, Raritan River data used for this study consists of 103 values (one for each year of record) but only 85 unique values, and thus many ties in ranking are present. The Raritan River has three $15,000 \mathrm{ft}^{3} / \mathrm{s}$ values in water years 1925, 1962, and 2012; this is a tie run having a length of three (3) for this streamflow magnitude. Such ties in a dataset can hinder statistical inference when the peak streamflows are treated as if they are continuous random variables; for example, the method of maximum product of spacings is particularly sensitive (Cheng and Stephens, 1989 ) to the presence of ties because of its mathematical formulation.

Peak streamflow data might not originate from a purely random process (independence). One case practitioners should be aware of is that of annual peak streamflow occurring at the end of a water year (September 30) and the subsequent year's peak streamflow occurring at the beginning of the next water year on or about October 1 . This situation can occur when the flood hydrograph representing a substantial rainfallrunoff event straddles the water year boundary. Although relatively unimportant for small peaks, very large events can complicate assumptions and computations best illustrated by descriptive example. Suppose the first and second largest annual peak streamflows in a dataset respectively occurred on September 30 of the 1969 water year (September 30, 1969) and October 1 of the 1970 water year (October 1, 1969). To prevent such large events from being oversampled in the data, the analyst might seek to replace the October 1 peak with a peak streamflow from a distinctly different event sometime between October 2, 1969, and September 30, 1970.

Review of the Raritan River data indicates no sequential annual maximum peak streamflows straddling (or nearly so) the September 30-October 1 transition between water years. The same conclusion is made for the Potomac River data; the very large 1897 water year peak was on October 1, 1896 but the previous year peak was on July 26,1896 . Thus, these events are substantially disconnected in time.

\section{Empirical Frequency Analyses}

An important component of frequency analyses is constructing an empirical distribution of the available data. The empirical distribution is defined by the data values without assigning a parametric form of a parent distribution. Empirical distributions are constructed primarily to visualize the distribution of the sample.
To construct an empirical distribution, plotting positions (appendix fig. 2-1) are used to define the nonexceedance probability (cumulative percentages) of individual data points within a sample (Cunnane, 1989; Helsel and Hirsch, 2002; and Stedinger and others, 1993). Plotting positions also can be used to construct probability graph paper (such in USGS-PeakFQ software graphical output [USGS, 2014]) or be used to compare two or more distributions. HirschStedinger plotting positions are used in this study (fig. 2-1) in order to accommodate historical information (Hirsch and Stedinger, 1987). Mathematically, in the absence of historical information, the Hirsch-Stedinger plotting positions are the same as, meaning they collapse to, the more commonly used Weibull plotting positions (IACWD, 1982). Hirsch-Stedinger plotting positions are provided in the USGS-PeakFQ software output.

The empirical distributions of annual peak streamflow data for the Raritan River and Potomac River streamgages are shown in figure 6 . If the annual peak streamflows were to follow a log-normal probability distribution, then the data would generally plot along a straight line, with some variability attributed to sampling error, on the graph such as shown in figure 6 . The steepness of the data in the figure is proportional to the variation or dispersion of the data, such as the standard deviation. The largest data values for both streamgages deflect upward (toward larger magnitude values) from a straight line, which is indicative of positive skewness (right-tail heavy data) for both streamgages.

Concerning the right tail for the Raritan River streamgage, the data have what appears to be a distinct "hinge point" (a distinct change in slope) at approximately 0.20 AEP. This change in the slope may be indicative of high-magnitude flood generation processes occurring about twice per decade. Concerning the right tail for the Potomac River streamgage, the data have a hinge point near approximately 0.10 AEP. A second hinge point is also indicated at approximately 0.30 AEP.

Although beyond the scope of this report, additional investigation of these data might provide insight into important flood-generating processes and thus insight into the interpretation of flood hazards. Factors such as the time of year of annual peak occurrence, moisture conditions just prior to the onset of annual peak-generating rainfall, and weather system (storm) types associated with the annual peaks could be examined. Covariate or conditional probability investigation of annual peak time series could also be explored, such as potential association between peak streamflow and the Palmer Drought Severity Index (Palmer, 1965) for the months in which annual peaks occur. In addition, one could examine the hydraulic characteristics of the stream channel at, and particularly upstream of, a streamgage. For example, channel conveyance or floodplain storage of flood volume can impact the relative growth of instantaneous peak streamflows as AEP diminishes. 


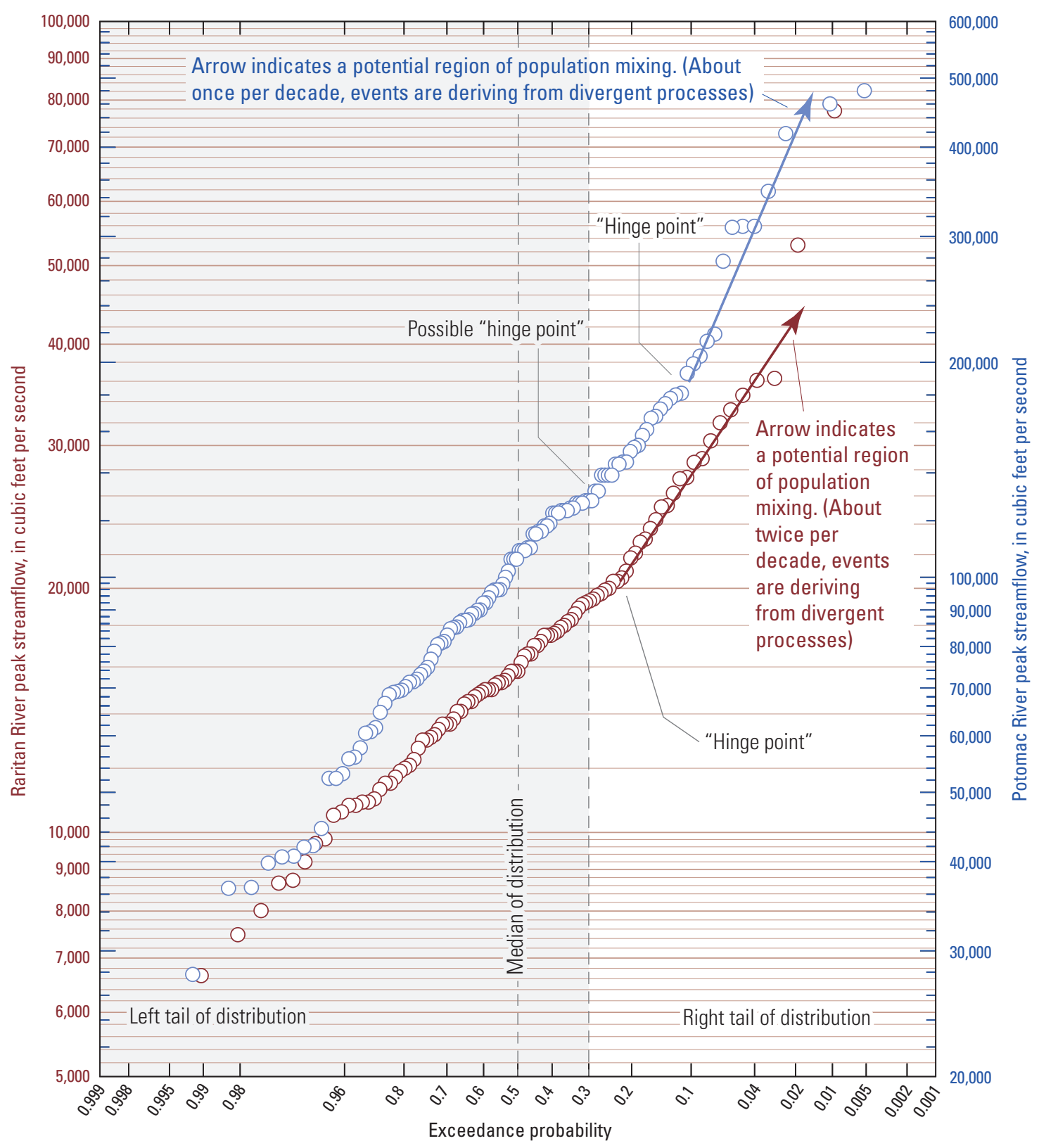

EXPLANATION

Range of exceedance probabilities not shown on other frequency plots in this report

$\bigcirc$ Annual peak streamflow plotted according to Hirsch-Stedinger plotting position for U.S. Geological Survey (USGS) streamgage 01400500 Raritan River at Manville, New Jersey

Annual peak streamflow plotted according to Hirsch-Stedinger plotting position for USGS streamgage 01638500 Potomac River at Point of Rocks, Maryland

Figure 6. Empirical distribution by means of ranked annual peak streamflow data and Hirsch-Stedinger plotting positions for U.S. Geological Survey streamflow-gaging stations 01400500 Raritan River at Manville, New Jersey, and 01638500 Potomac River at Point of Rocks, Maryland. 


\section{Parametric Frequency Analyses}

Parametric methods are used to fit data to a specified statistical distribution, such as the Pearson type III distribution or the generalized extreme value distribution. The parametric approach will not model all of the variability observed in the data, but if the distribution is suitable enough, it provides for extrapolation beyond the exceedance probabilities represented by the data. Defining suitability is a challenging topic, and the following sections about distribution selection attempt to provide some bounds on what distributions may be considered suitable when the estimation requires considerable extrapolation, such as to very low AEPs. First though, common parametric methods for fitting a flood frequency curve are briefly described.

A peak-streamflow frequency curve commonly is fit using a single, usually unimodal, probability distribution (Kite, 1988). Sometimes, mixtures of probability distributions also are used (Karvanen, 2006; Grego and Yates, 2010; Scarrot, 2015; Villarini and others, 2011). In this report, examples pertain only to fitting data to a single probability distribution. For additional information about both simple and complex methods, Dey and Yan (2016) provide a comprehensive treatment of extreme value analysis, including applicable background and mathematics. Kite (1988) and Stedinger and others (1993) discuss specific applications of extreme value analysis with emphasis on annual peak streamflow, and complementarily, Paretti and others (2014) include a useful summary of the large body of literature on peak-streamflow frequency that collectively provides further background.

General guidance for flood frequency computations in the United States follows a parametric approach and is described in Bulletin 17B (IACWD, 1982), which contains Federal agency guidelines that have been widely used in hydrologic education and practice (Stedinger and others, 1993). For example, computations based on Bulletin 17B have commonly been used for the design of transportation infrastructure and floodplain management throughout the United States for more than 30 years. These guidelines specify the use of the log-Pearson type III distribution, as well as relatively unsophisticated methods for using historical data not collected as part of the systematic instrumental record, methods for screening for unusually small annual peak streamflows, and methods for including regional information on skewness into the analysis.

Research on flood frequency analysis has continued since the publication of Bulletin 17B (Cohn and others, 1997; Cohn and others, 2001; Cohn and Stedinger, 1987; Griffis and others, 2004; Griffis and Stedinger, 2007; Stedinger and Griffis, 2008). One of the newer and more sophisticated computational methods includes the expected moments algorithm (EMA), which provides a method of estimation for fitting the frequency curve when nonstandard flood information is available. For example, EMA allows improved representation of nonstandard flood information such as that obtained from historical records or paleoflood hydrology studies (O'Connor and others, 2014; Stedinger and Cohn, 1986, 1987; USGS, 2014; Veilleux and others, 2014). The Bulletin 17B guidance is contemporaneously (2017) being updated to a "Bulletin 17C" version (England and Cohn, 2007; John F. England, Jr., U.S. Army Corps of Engineers, written commun., 2017). The analyses related herein involving EMA are exclusively based on pending Bulletin $17 \mathrm{C}$ extensions, which are already available to practitioners (USGS, 2014; Veilluex and others, 2014). Barth and others (2016) provide extensive details on EMA and a pertinent review of mixed populations in peak-streamflow frequency across more than 1,000 USGS streamgages in the western United States.

Whereas Bulletin 17B provides Federal agency guidance, other statistical methods or hydrologic modeling frameworks also exist that can be used to obtain flood-frequency relations. For example, Villarini and Smith (2010) and Villarini and others (2011) use the generalized extreme value rather than the Pearson type III distribution. Kite (1988) and the National Research Council (1988) include a description of several other distributions that may be considered.

The general purpose for fitting a probability distribution is to represent the magnitude of floods across a wide range of AEP values, and a reasonable probability distribution is especially important when extrapolations of the fitted frequency curve are to be made. Several alternative and complementary methods to fit probability distributions include product moments (IACWD, 1982), maximum likelihood (Hazewinkel, 2001; Jones and others, 2014, p. 349), EMA (Lane and Cohn, 1996; Paretti and others, 2014), and L-moments (Hosking, 1990). Other methods include the percentiles (Karian and Dudewicz, 2011) and maximum product of spacings (Cheng and Stephens, 1989; Dey and others, 2016; Lind, 1994; Wong and Li, 2007).

EMA is an iterative method of solving for the product moments and has been fully developed for the Pearson type III distribution. It also allows flexible handling of different data types, including historical and paleoflood data (Baker, 1987). Extension of EMA, however, to fit other distributions has not yet been fully developed. Thus, the method of L-moments was chosen for primary emphasis in part because extensive though technically demanding code for scripting parallel analyses is available to expand analyses to other distributions beyond the Pearson type III distribution, and such is the case for MLE and MPS. In addition, the use of L-moments (Hosking, 1990) and multiple probability distributions has precedence in regional frequency analysis of extreme rainfall (Hosking and Wallis, 1997), and L-moments, in the precursor form of probabilityweighted moments in earlier studies (National Research Council, 1988). The Precipitation-Frequency Atlas of the United States (NOAA, 2013, p. 18-24; "Atlas 14 volumes") is based prominently on L-moment statistics for computation of depth-duration frequency curves for precipitation (Asquith and Roussel, 2004). 


\section{Other Frequency Methods}

Other methods for estimating peak-streamflow frequency quantiles are also available. For example, rainfall-runoff modeling has been used to model flood response to specific design storms. Nathan and Weinmann (2013) suggest methods for analysis of very rare (AEP less than 0.01 to AEP about 0.005 to $10^{-4}$ ) to extremely rare (AEP less than about $10^{-4}$ ) flood events in Australia, including use of rainfall-based simulation methods and estimation of the probable maximum flood. Methods that emphasize regional information also exist. For example, the index-flood method provides a means of incorporating regional information in peak-streamflow frequency estimation (Hosking and Wallis, 1997; Kite, 1988).

\section{Quantifying Sources of Uncertainty}

Two types of uncertainty in peak-streamflow frequency analyses are considered for this study: epistemic and aleatoric. Epistemic uncertainty (also called reducible uncertainty) is the uncertainty in not knowing the optimal model for probabilistic prediction and thus is related to knowledge of natural and physical world processes. Probabilistic prediction requires a model of probability (a distribution). Kite (1988, p. 28) states, "It is not known which of the many distributions available is the 'true' distribution" and, "It is possible to fit several distributions [to the same data] and end up with several different estimates" of an event of interest. Other authors have called this a model error (or alternatively model error variance) (Bobée and others, 1993, p. 125). The term "distribution choice uncertainty" is adopted for this study.

Aleatory uncertainty is that associated with inherent random chance. This second uncertainty is dependent on the random sample itself and also on the choice of event of interest (hazard level). Kite (1988, p. 28) states, "The statistical parameters of the probability distribution must be estimated from the sample data." Aleatory uncertainty is often referred to as irreducible or stochastic uncertainty. Such uncertainty is also referred to as sampling uncertainty (Bobée and others, 1993, p. 125), and that terminology is the convention adopted in this study. An extensive body of literature concerns this uncertainty owing in part to convenience of mathematical tractability as well as accessibility within designed statistical simulation (Monte Carlo) experiments (Jones and others, 2014; Rizzo, 2008).

Distribution choice uncertainty arises because analyses are conducted using models that are mathematical constructs of the physical world. Better understanding of the true or near-true distribution of peak streamflows would improve the ability to statistically model peak-streamflow frequency. However, the underlying probability distribution used for distal tail estimation will always be unknown in practical circumstances of very low AEP estimation. Decisions on the part of the analyst can greatly impact epistemic uncertainty, and it is not uncommon for decisions to be depicted on "logic trees" (Chevallier, 2016) and reliance on "multiple-expert opinion assessment and aggregation" (National Research Council, 1988, p. 11). Different analysts can legitimately arrive at different quantifications of epistemic uncertainty. Furthermore, even subtle changes in distribution tail behavior can result in widely divergent estimates as AEP decreases. For real-world hydrologic systems and especially for critical infrastructure applications, analytical interests are measured in time scales usually far in excess of the available record (with interests in return periods of major events perhaps greater than 1,000 years or more), limiting the ability to evaluate the chosen model (distribution) or candidate distributions and thereby exacerbating epistemic uncertainty impacts. The probability distribution is used for extrapolation, and Bobée and others (1993, p. 125) note that "the [epistemic uncertainty] is relatively more important in extrapolation." Similarly in a review of methods for tail estimation using covariates or conditional variables, Wang and $\mathrm{Li}(2016$, p. 321) conclude that "parametric methods are sensitive to the misspecification of models."

Sampling uncertainty is attributable to the size of available sample (usually smaller than ideal) under an assumption that a particular distribution is applicable. The sampling uncertainty is dependent to a lesser degree on the properties of the parameter estimation method. Lastly, both the distribution choice uncertainty and sampling uncertainty are themselves dependent on selected AEPs, and both increase as AEP decreases. Specific definitions for this study are now offered:

1. Distribution Choice Uncertainty $\left(\sigma_{\mathrm{dc}}\right)$-This uncertainty is quantified as the standard deviation of the quantile estimates of all distributions considered. Its value is dependent on which distributions are chosen by the analyst for comparison. A different set or ensemble of distributions would yield a different distribution choice uncertainty. For the analyses herein, six three-parameter probability distributions and three higher order distributions have been selected.

2. Sampling Uncertainty $\left(\sigma_{s}\right)$-This uncertainty represents the uncertainty of a given quantile estimate for a specific fitted distribution. For example, this is the sampling uncertainty for a quantile under the condition (assumption) that the chosen distribution is actually correct using the available sample data. This uncertainty can be constructed from analytical results, Monte Carlo simulation, or hybrid techniques dependent on mathematical tractability. The foundation of sampling uncertainty is the mathematical matrix describing the sampling variance-covariance of either the moments (product or L-moment) and (or) the parameters of the distribution based on the data values themselves. The sampling variance-covariance matrix defines the coupling of variation among the moments and parameters. The sampling variance-covariance matrix then provides a key to computing sampling uncertainty and also confidence limits for a given quantile. 
A variance-covariance matrix is a technically complicated topic, but details for specific L-moments are shown in figure $3-3$.

When written, the two uncertainties have inherently complicating syntax that is most accurately described by example. Distribution choice uncertainty is considered first. For example, suppose three 0.01 AEP estimates from three different probabilities distributions are 309,000;331,000; and $794,000 \mathrm{ft}^{3} / \mathrm{s}$. Emphasis is needed that the computations were based on logarithmic transformation. As a result, the uncertainty is best expressed using logarithms, though descriptively, this is best left to numerical examples.

The arithmetic mean of the logarithms (base10 or $\log 10$ ) for the three values is 5.637 , which is $433,000 \mathrm{ft}^{3} / \mathrm{s}$ when retransformed. It is appropriate to use the mean of the logs, because logarithmic transformation is the native basis on which other statistical computations were made. The range in the estimates is 309,000 to $794,000 \mathrm{ft}^{3} / \mathrm{s}$. The standard deviation $\left(\sigma_{\mathrm{dc}}\right)$ of the logarithms for the three values is 0.299. It is suggested that, in the context of distribution choice uncertainty, the estimates of the $0.01 \mathrm{AEP}$ be written as " $433,000 \mathrm{ft}^{3} / \mathrm{s}$ (range 309,000 to $794,000 \mathrm{ft}^{3} / \mathrm{s} ; \sigma_{\mathrm{dc}}=0.229$ $\log 10)$." Note that $\sigma_{\mathrm{dc}}$ is the quantification of distribution choice uncertainty. Because the full range of estimates from the three selected probability distributions are shown, there is no implicit association to an $\mathrm{N}$-percentile confidence interval (such as 90th percentile confidence interval). This is stated because it is in contrast to sampling uncertainty, which is described next.

Sampling uncertainty is best described by example. Suppose the 0.01 AEP estimate for a given probability distribution and given method of parameter estimation is $331,000 \mathrm{ft}^{3} / \mathrm{s}$, which is about $5.520 \log 10$, using a generalized extreme value distribution. In addition, suppose that the standard deviation $\left(\sigma_{\mathrm{s}}\right)$ attributable to sampling error for the 0.01 AEP quantile is computed as $0.082 \log 10$. The lower and upper limits of the 90-percent confidence interval of this quantile can then be computed (assuming about 100 degrees of freedom or about a century of data values) as 5.380 and $5.660 \log 10$, respectively. These limits after retransformation are 240,000 and $457,000 \mathrm{ft}^{3} / \mathrm{s}$, respectively. Lastly, it is suggested that in the context of sampling uncertainty, that the estimates of the $0.01 \mathrm{AEP}$ be written as " $331,000 \mathrm{ft}^{3} / \mathrm{s}$ (90-percent confidence limits 240,000 to $457,000 \mathrm{ft}^{3} / \mathrm{s}$ based on $\left.\sigma_{\mathrm{s}}=0.082 \log 10\right)$."

The authors advise that mention of the logarithmic units of uncertainty (standard deviation) be retained in part because it is location independent (that is, independent in regards to location along the real-number line) to think in terms of log-cycles of uncertainty. For example, the distribution choice uncertainty is 0.147 log-cycles larger than the sampling uncertainty $(0.229-0.082=0.147)$; therefore, it could be inferred that the choice of the distribution is a much greater component to overall uncertainty than the sampling uncertainty stemming from randomness.

\section{Methods of Probability Distribution Selection and Estimation}

Numerous probability distributions are considered in this study, and thus it is important to consider distribution selection and methods of estimation. Because of inherent conceptual complexities, a schematic diagram was created to depict a structure of the analyses provided herein (fig. 7). This schematic embodies the overall logic structure of at-site peakstreamflow frequency as described in this report. In practical circumstances, the logic flow shown is not one-directional, and considerable iterative refinement of the process by an analyst is anticipated. Logic elements not used in the analysis herein are shown in gray. The gray is used to communicate that there is inherently an expansive conceptual breadth and fixed limits are difficult to identify.

Potentially applicable distributions are described in this report, but the identification of distributions to consider is largely based on the findings of others (Rahman and others, 2009; p. 42 and cited references therein). For the analyses provided herein, six three-parameter probability distributions of primary interest were selected because of their previous use in hydrometeorologic frequency analyses (Hosking, 2015a,b; Hosking and Wallis, 1997; Stedinger and others, 1993). The six probability distributions achieve fits by describing the location and spread of the data, as well as the asymmetry of the data about the mean. In addition, three higher-order distributions were selected for comparison.

As shown later in this report, the choice of distribution does not have a substantial effect on flood quantile estimates for AEPs no smaller than 0.04 to 0.005. As AEP is lowered and estimates are made progressively farther into the right tail for AEP $<0.001$, the examples show that the quantile estimates become quite sensitive to the choice of distribution. Multiple distributions were used for this study because of the inherent difficulties in establishing the optimality of one distribution over another to describe extreme flood behavior. Establishing goodness-of-fit criteria of distribution tail properties is difficult when there is an absence of observational data for such extremely rare events.

The primary distributions chosen for this study are listed in table 2 and mathematically described in appendix 5 . Starting first with three-parameter distributions, in alphabetical order these are the generalized extreme value (GEV), generalized logistic (GLO), generalized normal (GNO), generalized Pareto (GPA), Pearson type III (PE3), and Weibull (WEI) distributions. The other, higher-parameter distributions chosen are the asymmetric exponential power (AEP4, four parameter), Kappa (KAP, four parameter), and Wakeby (WAK, five parameter) distributions. The numeral "4" is used to distinguish the AEP4 from a five-parameter version that is not considered for this study, as well as avoiding the obvious conflict with AEP (annual exceedance probability). The analyses reported here are based exclusively on base-10 logarithms of annual peak streamflow data, and as a result, 


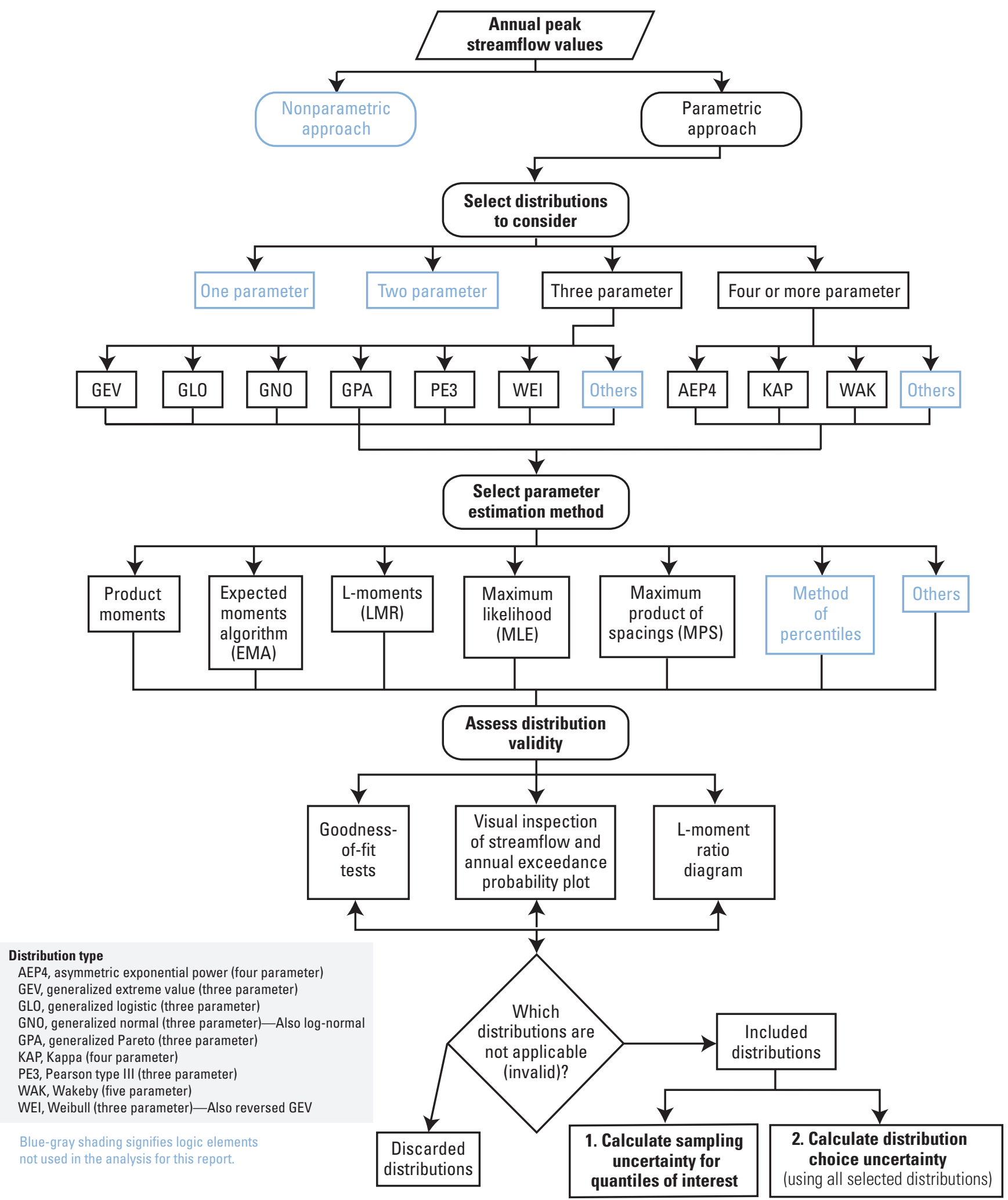

Figure 7. Steps toward estimation of at-site peak-streamflow frequency analyses for low annual exceedance probabilities. 
Table 2. Identification of probability distributions referenced in this study.

[Distribution abbreviations chosen as three characters with exception of AEP4, which is extended to avoid confusion with AEP (annual exceedance probability). The " 4 " in AEP4 reflects four parameters for that distribution]

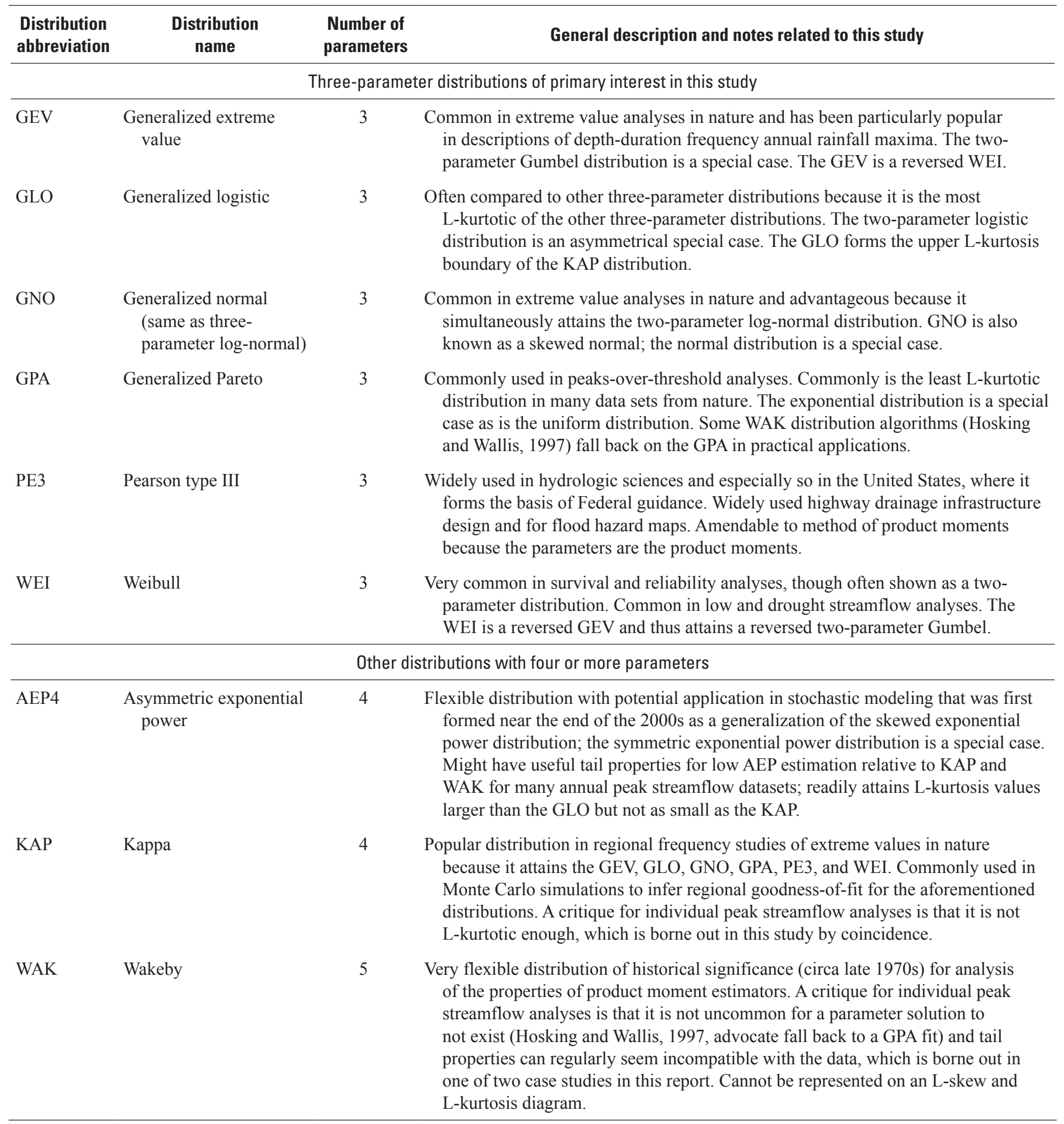


the adjective "log," as in the "log-Pearson type III," is to be inferred as an encompassing adjective of all distribution references herein. It is common for log-PE3 to be abbreviated as LPIII (or something similar) in other literature. It is more convenient for this study to use PE3 as the abbreviation, because logarithms (the "L" in LPIII) are implied and the nomenclature is more consistent with the other abbreviations used herein. The mathematical definitions of these distributions and relations to L-moments are briefly reviewed in appendix 5, and their descriptions are provided in table 2.

The three-parameter distributions receive considerable attention, and often these are preferred over lower-order distributions for magnitude and frequency analyses of skewed datasets. The difficulty in estimating product moment skewness is widely known, and elaborate methods for enhancing shape (skewness) estimation abound in the peakstreamflow frequency literature, mostly reliant on method of moment-like estimators. For example, with the PE3, standard practice in the United States has been to weight the at-site skew with a regional skew and compute a weighted skew for the purpose of fitting the third parameter of the PE3. This regional skew is derived from analyses of peak flows at streamgages throughout the region (Griffis and others, 2004; IACWD, 1982; USGS, 2014; Veilleux and others, 2014) occupied by the streamgage of interest. L-moments can reliably estimate skewness through sample L-skew, and L-moment performance is anticipated to exceed that of product moments and remain competitive with MLE for the sample sizes commonly encountered in peak-streamflow frequency analyses.

Use of PE3 in the United States is common because of its prominence in the Bulletin 17B guidelines. It must be recognized, however, that this distribution may not be optimal. Extreme value theory (Dey and others, 2016; Gumbel, 1958; Salvadori and others, 2007, chap. 1) naturally relates the GEV distribution into the question of hydrologic frequency, and the GEV has long precedence, though not exclusive use, in depth-duration frequency analyses of annual maximum rainfall.

Other distributions commonly used (Hosking and Wallis, 1997) are the GLO, GPA, and GNO. First and at one extreme, the GLO is useful because it is a highly kurtotic distribution and effectively forms an upper bound on attainable kurtosis for the "simple" families of location-scale-shape distributions (fig. 3-5) seen in hydrometeorologic studies. Second and at the other extreme, the GPA is useful because it has some of the least kurtotic tendencies potentially seen in hydrometeorologic studies (Hosking and Wallis, 1997; Kjeldsen and others, 2002). The GPA also is popular for peaks-over-threshold analyses (Stedinger and others, 1993, p. 18.37-18.39; Dey and others, 2016, p. 16), which are used occasionally in hydrometeorologic applications. Third, the GNO is useful, because it is a generalization of the normal distribution into skewness and is closely related - that is, equivalent through alternative parameterization - to the log-normal distribution. The GNO resides between the GLO and the GEV for near- symmetrical distributions and is less L-kurtotic than the GLO and GEV (for instance) for large L-skew.

The WEI distribution, which commonly is applied in survival and reliability studies, often is seen as having suitable tail behavior for estimation of low-magnitude (left tail) hydrometeorologic processes. The WEI is a reverse of the GEV, in that the negation or sign change of the data reverses the data. As an aside, some aspects of existing L-moment theory require reversing in order to accommodate censored data herein.

Distributions having four or more parameters (also called high-parameter distributions or four-plus parameter distributions) are not used as often as the lower-order distributions having three or fewer parameters, described elsewhere in this report. High-parameter distributions have inherent promise for mimicking the geometry of heavytailed distributions when used with adequate sample sizes to reliably estimate the parameters. The parameter estimation method and sample size become progressively more important as the number of parameters to fit increases. The number of distribution parameters used in this study (five or less) implicitly mitigate concerns for model over fit.

The four-plus parameter distributions conventionally are fit to the mean, variance (dispersion), skewness, and at least the next general moment of kurtosis (conceptually just the next higher-order measure of shape) of a dataset. These high-order distributions are flexible, and for some types of distributional analyses they might provide useful fits that are not attainable by lower-order distributions. Lastly, as a rule, parameter estimation for higher-order distributions is considerably more complex than for lower-order parameter distributions because numerical methods for minimization or direct root-solving typically are required.

\section{Methods of Parameter Estimation}

This study focuses primarily on parameter estimation using product moments (EMA) and L-moments, described in more detail next. Limited attention is also given to MLE and MPS. Thus, combined, four different methods of parameter estimation are reviewed.

The Bulletin 17B guidelines use (in logarithms) the product moments of sample mean, variance, and skew. A sequence of prescriptive procedures is used to make adjustments to the sample moments in order to account for any historical record and zero flows. The Bulletin $17 \mathrm{C}$ guidelines, already implemented in software (USGS, 2014; Veilleux and others, 2014), also suggest the use of product moments estimated using EMA, which uses an iterative approach to solve for the product moments when nonstandard flood information is available. EMA is flexible and allows vastly more versatility in representing nonstandard data, such as historical data or flood peaks that are imprecisely known, than currently available within the theory of L-moments and MPS. 
The Bulletin 17C guidelines, again already implemented in software (USGS, 2014; Veilleux and others, 2014), also call for screening for potentially influential low floods, which are small values in the time series of annual peak streamflow that can strongly influence the fit of the frequency curve. Because these small peak streamflows are not relevant to fitting the right tail of the distribution, it is desirable to identify them. A single Grubbs-Beck test (Bulletin 17B) or a multiple Grubbs-Beck test (Bulletin 17C) is used to identify smaller floods that do not fit the bulk of the distribution. Implementation of these screening procedures and the subsequent treatment of identified peaks can greatly influence distribution fit but are not considered further in this report.

The USGS-PeakFQ software (USGS, 2014; Veilleux and others, 2014) can be used to fit the peak-streamflow frequency curve using the PE3 and product moments and EMA. The software is not readily extensible to other distributions, and hence the PE3 is the only distribution using EMA and the Grubbs-Beck test or the multiple GrubbsBeck test. Specifically for this study, the USGS-PeakFQ software was specially adapted for an "Extended Output" user option to provide estimates at selected AEPs from $10^{-3}$ to $10^{-6}$.

L-moments (Hosking, 1990) are an "attractive alternative system of moment-like quantities" (Jones, 2004, p. 98) and thus are an alternative to product moments. Like other statistical moments, L-moments characterize the geometry of distributions and summarize samples. L-moments have similar interpretations as the product moments and thus are analogs of those statistics, which makes L-moments conceptually accessible to practical circumstances already involving product moments.

L-moments (appendix 3) are based on linear combinations of differences between the expectations of order statistics as opposed to the product moments, which are based on powers (exponents) of differences (appendix 2). For example, the product moment definition of skew, which is based on differences to a third power, can result in poor sampling performance for distributions characterized by heavy tails, asymmetry, and outliers. The performance of kurtosis, which is based on differences to the fourth power, is usually worse. Partly because of favorable sampling performance, Hosking (1992) concludes that "L-moments can provide good summary measures of distributional shape and may be preferable to [product] moments for this purpose."

Probability-weighted moments and L-moments are so closely related to each other that the choice of one over the other is often determined by or based on mathematical convenience and tractability as opposed to fundamental differences in sampling properties. Deng and Pandey (2009) explore the estimation of probability-weighted moments for conditions of left-tail censoring using "partial probabilityweighted moments" for which several other studies of these moments are referenced therein. For this study, a form of censored L-moment computation (Wang and others, 2010 ) is made in a framework anticipated as more adaptable to mixed censoring involving complex historical flood information.

The two additional methods of parameter estimation involved in this study, MLE and MPS, are closely related to goodness-of-fit metrics (appendix 4). In brief, MLE estimates the parameters of a distribution by maximizing the summation of logarithms of the probability density computed for each of the data values. MPS is similar in the sense that maximization of a summation also is involved, but for MPS, the quantities summed are the successive differences of probability estimates obtained from the cumulative distribution function for each of the data values. Markiewicz and Strupczewski (2009) study dispersion measures in peakstreamflow frequency analyses and acknowledge that MLE loses applicability if an inappropriate distributional model has been selected when probability densities become infinite or exactly zero (or numerically near zero) in a tail. MPS is sensitive to ties between data values and close groupings (clusters) of them.

\section{Distribution Validity and Goodness-of-Fit}

Distribution selection is a critically important component of parametric frequency analyses and a difficult task (Gingras and Adamowski, 1994, p. 856). The problem is compounded when events far into the right tail are needed, and in practice, such information is extremely scarce. Methods for fit assessment are often based on distribution fit in the "central area" (Gringas and Adamowski, 1994) or "bulk of the distribution" (Apipattanavis and others, 2010) rather than the tails. Bobée and others (1993, p. 122) state, "Although attempts have been made to give some statistical justification for the use of asymptotic extreme value distributions [and others] $* * *$ there is no solid theoretical basis for justifying one specific type of distribution for modeling flood data."

Methods for assessing distribution validity include goodness-of-fit tests. Goodness-of-fit describes the extent to which observed data match the values expected by theory. For the application here, a fitted distribution of a given form (distribution choice) serves as the theory. Goodness-of-fit in the context of peak-streamflow frequency analyses can be qualitative and guided by expert opinion using methods such as graphical visualization when the dimension of the problem is small (univariate). Goodness-of-fit can also be evaluated using a quantitative reference frame and can be based on one or more numerical measures of fit. Many goodness-of-fit methods result in p-values from which statistical inference can be made. Such methods include the nonparametric Kolmogorov-Smirnov or parametric Chi-squared tests (Conover, 1999). Mathematical details of goodness-of-fit applicable to this study are provided in appendix 4. Again, note that these traditional methods of assessing goodness-of-fit 
have unknown utility when extrapolation far beyond the observed data is needed.

L-moments provide more secure inference of distribution shape than product (conventional) moments (Sankarasubramanian and Srinivasan, 1999), and L-moment ratio diagrams are convenient for this purpose. These diagrams express relations between high measures of distribution shape, such as L-skew and the next higher moment (L-kurtosis). Two diagrams that provide results specific to this study are introduced later. A template of the L-moment ratio diagram requires detailed explanation, and readers are directed to the discussion associated with figure $3-5$ for additional background details.

Probability distributions are distinguished according to their formal mathematical definition, L-moments based on fundamental theory, and perhaps more obviously by their respective parameter values. Distributions, as a general result, have specific and typically unique intrarelations (that is, within the distribution) between moments and parameters (fig. 3-5). The intramoment relations between the moments of a distribution (theoretical or sample) provide a means to judge the potential suitability of candidate distributions. Because L-moments are a convenient and powerful tool for discriminating distribution shape (Hosking, 1992; Royston, 1992), L-moment ratio diagrams, in turn, are useful for discriminating between distributional forms (Hosking, 1990; Hosking and Wallis, 1997; Vogel and Fennessey, 1993). However, as conceptually set up in L-moment ratio diagrams, Pandey and others (2001) conducted experiments on using L-kurtosis to assess goodness-of-fit by choosing "that distribution whose L-kurtosis is the closest to that of the sample data" (Pandey and others, 2001, p. 288). Compared to other procedures used to assess goodness-of-fit, Pandey and others (2001, p. 291) conclude that "L-kurtosis is a good indicator of distribution shape and its use in quantile estimation is effective." Other contextual sources about L-skew and L-kurtosis joint distribution and goodness-of-fit are Ben-Zvi and Azmon (1997) and Liou and others (2007). Recently, Hosking (2015c) explored joint confidence regions of L-moment ratio diagrams.

L-moment ratio diagrams are one of the standard tools used in the regional analyses of hydrologic phenomena (Asquith and others, 2006; Liou and others, 2007; Peel and others, 2001). In fact, Sankarasubramanian and Srinivasan (1999, p. 26) conclude, "One of the main applications of L-moments is in the identification of the probability distribution of the observed phenomena using the L-moment ratio diagram."

L-moment ratio diagrams are information dense and require considerable explanation. To begin, an L-moment ratio diagram, such as figure $3-5$, is most often a depiction of the two-dimensional domain of L-skew and L-kurtosis (third and fourth L-moments), because emphasis on hydrologic frequency analyses continues to be oriented toward threeparameter distributions. Diagrams of L-skew and L-kurtosis are especially useful for evaluating distributional form in a framework that is largely independent of the location and scale (dispersion, variation) characteristics of the distribution. Other L-moment diagram variants exist. For example, Hosking and others $(2000$, p. 3$)$ suggest that the L-moment ratio diagram of L-kurtosis (the fourth L-moment ratio) and the unnamed sixth L-moment ratio (not otherwise referenced in this study) can be used to distinguish different families of symmetric distributions.

L-moment ratio diagrams address, but cannot completely solve, the nontrivial problem of selecting a distributional form for arbitrary data. The diagrams, however, provide a convenient tool to use when considering or distinguishing distributional form. Distributions can have unique points, lines, or regions on an L-moment ratio diagram; the diagram can be used to evaluate the portion of the L-skew and L-kurtosis domain occupied by the distribution that is most similar to the sample estimates of L-skew and L-kurtosis from the data. The difficulty in estimating sample L-skew and L-kurtosis from relatively small samples makes this evaluation inexact, and this partly explains why regional analyses are considered in order to provide clarity on distributional form (Asquith and others, 2006; Hosking and Wallis, 1997, numerous references therein; NOAA, 2013).

\section{At-Site Peak-Streamflow Frequency Analyses for Very Low Annual Exceedance Probabilities}

This section presents results of the analysis of data from two streamgages chosen for this study. The results are shown in parallel sections for each streamgage. The peakstreamflow frequency curves for the four multiple parameter estimation methods for the PE3 are presented, and such curves are followed by a review of the multiple frequency curves. Tables specific to each streamgage of numerical results including quantiles, 90-percent confidence limits, distribution choice uncertainty, and sampling uncertainty are identified. L-moment ratio diagrams specific to each streamgage are shown, and attendant discussion concerning distribution validity is made. Two additional sections discuss (1) goodnessof-fit using several approaches in an effort to semi-quantify relative distribution fits, and (2) the distribution of the 0.01 and 0.001 AEP quantiles by both method and distribution using Monte Carlo simulation. Lastly, the results are highly parallel and discussion comparably written, and hence results are similar in generalities and even in some specifics. This is quite by coincidence and not deliberate design in the selection of the two streamgages for this study. Readers are asked to not over-interpret the similarities in the L-moment diagram results of this report as general representations applicable to other circumstances. 


\section{Results for the Raritan River at Manville, New Jersey, Streamgage}

\section{Comparison of Parameter Estimates}

The parameters for a selected distribution for a given dataset are simultaneously dependent on the choice of parameter estimation method. Results for the Raritan River data, respectively, for the parameters (mean, standard deviation, skew) of the PE3 distribution using methods of EMA (product moments), L-moments, MLE, and MPS are listed in table 3. Of special note concerning results for the Raritan River data in table 3 are the small differences in the means and standard deviations (the first and second parameters of the PE3 distribution). The four fitted PE3 curves to these four ensembles of parameter estimates are shown in figure 8 in comparison to the data. The largest differences in table 3 are in the third parameter, skew, indicated by the curvature of the line. Visible curvature indicates that skew is measurably different from zero.

Figure 8 shows the four fits for the PE3 are similar, and divergence among them increases as AEP diminishes. For these data, the two methods of L-moments and MPS produce nearly identical parameter estimates; however, inference that these two methods always produce nearly identical quantile estimates is not intended. The product moment estimate has the most positive skew, and hence, the trajectory for its PE3 curves up and away from the other three. The larger skew might be attributable, in part, to the influence of the two largest peaks, which seem to be outliers relative to other large values. Product moments are more sensitive to potential outliers than the L-moments (Hosking, 1990; Stedinger and others, 1993). Lastly, the quantile estimates produced by MLE are the lowest of the four; interpretation, however, that

Table 3. Distribution parameters for the Pearson type III distribution by four parameter estimation methods for U.S. Geological Survey streamflow-gaging station (streamgage) 01400500 Raritan River at Manville, New Jersey, using systematic record only.

[PE3, Pearson type III distribution. PE3 is fit to logarithms of the annual peak streamflow data for respective streamgage. PE3(mean, standard deviation, skew) represents the respective parameters of the distribution in the same ordering as in mathematics of figure 5-5]

\begin{tabular}{|c|c|}
\hline $\begin{array}{l}\text { Distribution abbreviation } \\
\text { and parameter values }\end{array}$ & $\begin{array}{c}\text { Parameter } \\
\text { estimation method }\end{array}$ \\
\hline PE3( $4.2204,0.1734,0.748)$ & $\begin{array}{l}\text { Method of product moments } \\
\quad \text { (expected moments algorithm) }\end{array}$ \\
\hline PE3( $4.2204,0.1696,0.5741)$ & Method of L-moments \\
\hline PE3( $4.2204,0.1708,0.4604)$ & Method of maximum likelihood \\
\hline PE3( $4.2202,0.1701,0.5686)$ & $\begin{array}{l}\text { Method of maximum product of } \\
\text { spacings }\end{array}$ \\
\hline
\end{tabular}

this method (MLE) always produces the smallest quantile estimates in other practical applications is not intended. Similarly, product moments do not always produce the largest quantiles.

The top five largest annual peak streamflows are all associated with late summer tropical cyclones in the region, and all have occurred within about a 5-week interval (August 19 through September 22) over approximately the past century. Other associations with tropical storm systems seem to exist for smaller peaks, but further study of population mixing (Barth and others, 2016; Grego and Yates, 2010; Karvanen, 2006; Scarrott, 2016; Scarrott and Yang, 2015) within the annual peak streamflow series is outside the scope of this paper. Villarini and others (2014) provide a topical review of tropical system impacts for most of the eastern United States.

\section{Frequency Curve Comparisons and Confidence Limits}

A visual comparison of the selected probability distributions for this study applied to the annual peak streamflow data for the Raritan River streamgage is shown in figure 9. (The Kappa distribution is not shown or discussed further because it lacks solutions for both the Raritan River and Potomac River data.) The far right tail is of interest in this study, and thus the horizontal axis on a probability scale that starts at the $0.30 \mathrm{AEP}$ and is carried through to the $10^{-6} \mathrm{AEP}$ (one part in 1 million). Peak streamflows from the systematic record are shown in figure 9, plotted using Hirsch-Stedinger plotting positions (fig. 2-1). For these systematic-record-only data, these plotting positions are the same as the Weibull plotting positions (fig. 2-1). The numerical values for the parameter estimates by L-moments for the Raritan River are listed in table 4.

The respective trends or trajectories of the fitted probability distributions as AEP decreases are especially important (fig. 9). All of the distributions have similar fits to the underlying data within the range of empirical probabilities of the data. The exception is the GPA, which shows a fit having an upper support (boundary) less than the two largest values. This is an important point, because the fitted GPA to these data represents a physically implausible situationa great and inappropriate underestimation of the right tail is self-evident.

Another point evident in figure 9 is that as distance into the right tail increases (AEP decreases), divergence between distributions becomes progressively larger. The two highparameter distributions shown are the AEP4 and WAK. Both distributions are more flexible than the six three-parameter distributions, because these are fit through L-kurtosis (AEP4 and WAK) and the unnamed fifth L-moment (WAK only). In particular, the WAK distribution, by having five parameters, can be lauded as a highly flexible distribution capable of mimicking subtle details in the data. A downside of flexible distributions, however, is that they can have large variance in 


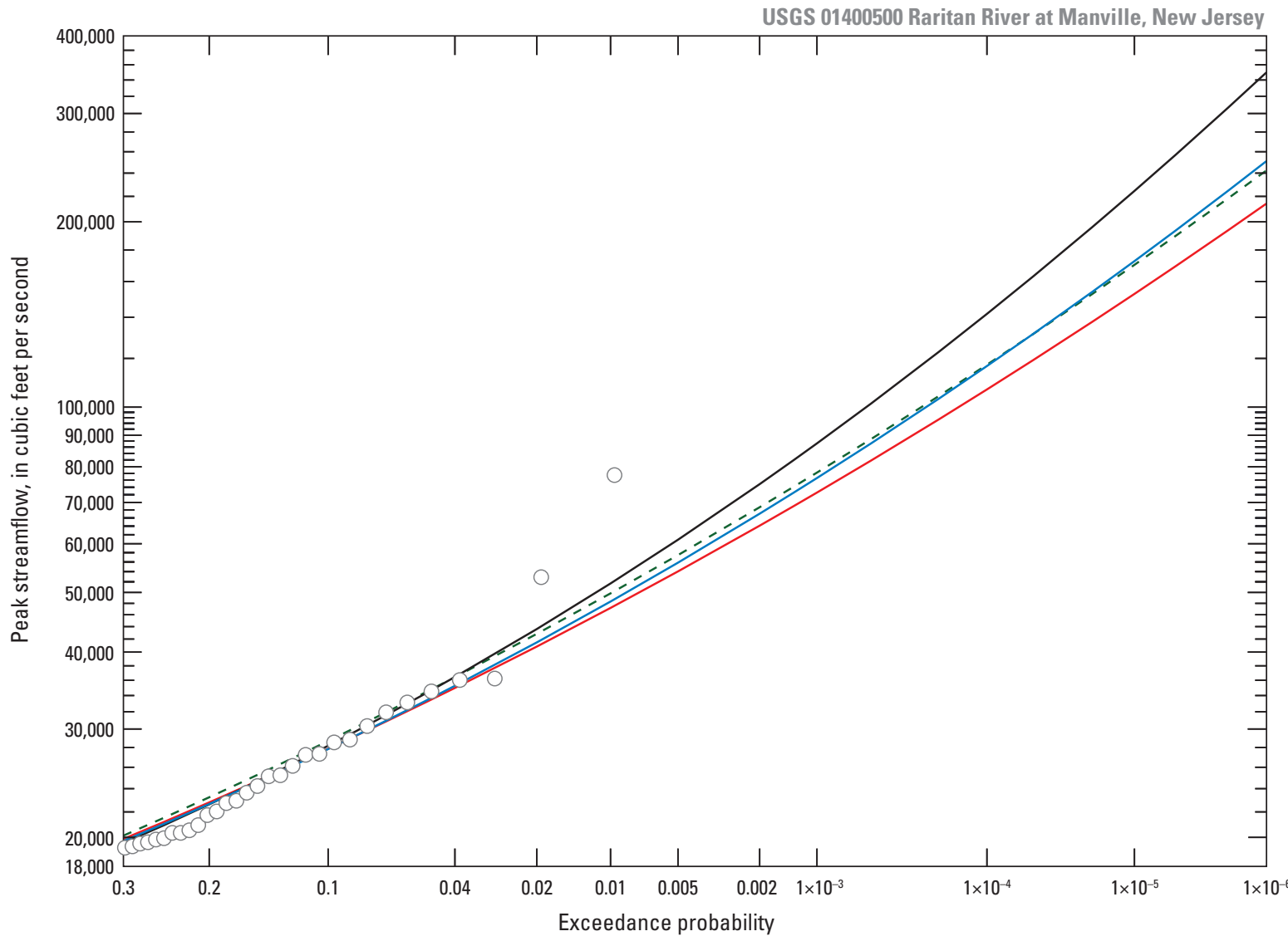

EXPLANATION

Pearson type III probability distribution fit to logarithms of systematic record, by parameter estimation method

Product moments

L-moments

Maximum likelihood

Maximum product of spacings

Annual peak streamflow from systematic record plotted according to Hirsch-Stedinger plotting position

USGS, U.S. Geological Survey

Note: For clarity, exceedance probabilities less than 0.002 are shown in scientific notation.

Figure 8. Comparison of four parameter estimation methods for the Pearson type III probability distribution fit to the logarithms of annual peak streamflow data for U.S. Geological Survey streamflow-gaging station 01400500 Raritan River at Manville, New Jersey.

the distribution tails for sample sizes common in streamflow data. Regional studies could aid in higher moment estimation, such as L-skew or L-kurtosis. The two distributions (AEP4 and WAK) have quite similar trajectories and collectively reside between the GLO and GNO fits. The two fits for the PE3 are different as in figure 8; the PE3-EMA lies above the L-moment PE3 fit. In part, because the L-skew for these data is not particularly large, the GEV and WEI have similar fits, although these distributions are reversed relative to each other. Only in the very distant tail at the right-hand side of the figure does the tail difference between the GEV and WEI begin appearing. There is much vertical variation for a given
AEP shown in the figure, and thus is a visual portrayal of distribution choice uncertainty.

The estimated 90-percent confidence intervals for the two solutions of the PE3 are shown to provide a visual reference of sampling uncertainty. The two PE3 fits increasingly diverge from each other as AEP decreases. As anticipated, the confidence limits of the two PE3 fits differ, and the differences between them are attributed to different methods of parameter estimation and mathematical approach to computation of the confidence limits. The analytical 90-percent confidence limits for the PE3-EMA are obtained from the USGSPeakFQ software and are mathematically correct if the parent 


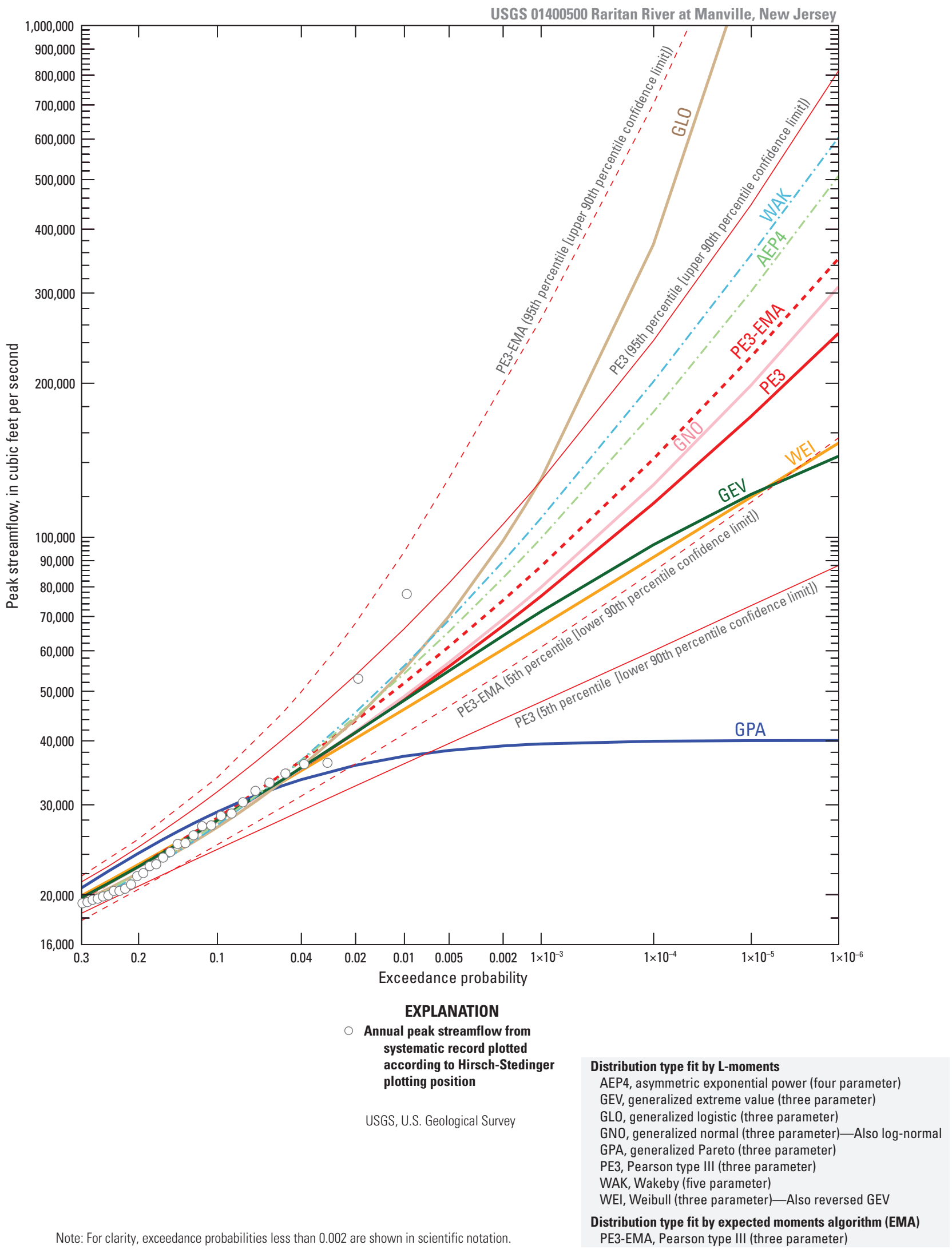

Figure 9. Annual nonexceedance probability plot and fitted distributions for U.S. Geological Survey (USGS) streamflowgaging station 01400500 Raritan River at Manville, New Jersey, based on flood frequency analysis using expected moments algorithm with multiple Grubbs-Beck test (no low outliers detected) and station skew as generated by USGS-PeakF0 software (USGS, 2014). 
Table 4. Distribution parameters by the methods of L-moments and expected moments algorithm for selected probability distributions for U.S. Geological Survey streamflow-gaging station (streamgage) 01400500 Raritan River at Manville, New Jersey, using systematic record only.

[Each distribution is fit by the method of L-moments to logarithms of the annual peak streamflow data for respective streamgage and parameter values listed in the same ordering as in the mathematics in appendix 5; for example, PE3(mean, standard deviation, skew) represents the respective parameters of the distribution in the same ordering as in mathematics of figure 5-5. EMA, expected moments algorithm. PE3-EMA, Pearson type III fit by EMA. Only three significant figures are available for skew from PE3-EMA]

\begin{tabular}{|c|c|c|c|c|}
\hline & $\begin{array}{l}\text { Distribution abbreviation } \\
\text { and parameter values }\end{array}$ & $\begin{array}{l}\text { Distribution } \\
\text { name }\end{array}$ & $\begin{array}{l}\text { Number of } \\
\text { parameters }\end{array}$ & $\begin{array}{c}\text { Applicable } \\
\text { appendix } 5 \\
\text { figure }\end{array}$ \\
\hline AEP4( 4.1674, & $0.1614, \quad 0.8096,1.2416)^{1}$ & Asymmetric exponential power & 4 & Figure 5-7 \\
\hline GEV( 4.1496, & $0.1512, \quad 0.1220)^{2}$ & Generalized extreme value & 3 & Figure 5-1 \\
\hline GLO( 4.2059 , & $0.0934,-0.0939)^{2}$ & Generalized logistic & 3 & Figure 5-2 \\
\hline GNO( 4.2044, & $0.1653,-0.1925)^{2}$ & Generalized normal & 3 & Figure $5-3$ \\
\hline PE3( 4.2204, & $0.1696,0.5741)^{2}$ & Pearson type III & 3 & Figure 5-5 \\
\hline PE3-EMA( 4.2204, & $0.1734, \quad 0.748)^{2}$ & Pearson type III by EMA & 3 & Figure 5-5 \\
\hline WAK( 3.8570 , & $1.8585, \quad 7.5700,0.1514,-0.0330)^{3}$ & Wakeby & 5 & Figure 5-9 \\
\hline WEI(-3.8735, & $0.3917,2.1735)^{2}$ & Weibull & 3 & Figure $5-6$ \\
\hline
\end{tabular}

${ }^{1}$ For the AEP distribution (four parameters), the order of parameters shown is "location," "scale," "shape1," and "shape2."

${ }^{2}$ For a three parameter distribution, the order of parameters shown is "location," "scale," and "shape."

${ }^{3}$ For the Wakeby distribution (five parameters), the order of parameters shown is "location," "scale1," "scale2," "shape1," and "shape2."

distribution is in fact a log-Pearson type III distribution. In contrast, the confidence limits stemming from Monte Carlo simulation of the PE3 by L-moments are based on the distribution-free exact variance-covariance structure (fig. 3-3) of the sample L-moments (fig. 3-2). The variance-covariance structure of the sample L-moments permits Monte Carlo simulation to be used to generate a large number of sequences (number of simulations $=5,000$; sample size $=103$ [systematic record]) of sample L-moments, successively fit the PE3 to these, and compute simulated quantiles for a given AEP. The distribution of these simulated quantiles for a given AEP is then used to compute the 5th and 95th percentiles to form the 90-percent confidence interval. This discussion is provided to explain visible differences between the EMA and L-moment PE3 quantiles and confidence limits in figure 9 and to indicate that exact matching of results is not anticipated. The quantile fits and 90-percent confidence intervals associated with the six three-parameter distributions fit by the method of L-moments are listed in table 5. The quantile fits and 90-percent confidence intervals restricted to the PE3 are listed in table 6.

Concerning table 5, it is useful to provide two examples of syntax stating the estimate for $10^{-4} \mathrm{AEP}$ using the GEV, which are "The $10^{-4}$ AEP streamflow estimate based on the GEV distribution is $96,800 \mathrm{ft}^{3} / \mathrm{s}$ (90-percent confidence interval 44,910 to $361,800 \mathrm{ft}^{3} / \mathrm{s}$ based on $\sigma_{\mathrm{s}}=0.2788 \log 10$ )" or "The $10^{-4}$ AEP streamflow estimate based on the GEV distribution is $96,800 \mathrm{ft}^{3} / \mathrm{s}\left(\sigma_{\mathrm{s}}=0.2788 \log 10\right)$."

Distribution choice uncertainty can now be quantified, and the results are listed in table 7. Distribution choice uncertainty for a given AEP is computed by the standard deviation of quantile estimates for the models (distributions) selected. It is established visually in figure 9 that the GPA is obviously not an acceptable fit to the Raritan River data. For brevity, only the remaining five three-parameter distributions were used to compute the uncertainty. The AEP4 and WAK distributions were not included. The five quantiles for selected AEP from the distributions are listed in table 7 . The standard deviation of the logarithms of these is also listed, below which the mean of the logarithms is expressed in the originating units (cubic feet per second).

Inspection of the values listed in table 7 indicates that the range of the quantiles is exceptional for the lowest AEP of $10^{-6}$. For example, the range 153,000 to $7,069,000 \mathrm{ft}^{3} / \mathrm{s}$, measured in logarithms, is almost 1.7 log-cycles for $10^{-6} \mathrm{AEP}$ and the standard deviation of the logarithms $\left(\sigma_{\mathrm{dc}}\right)$ is 0.7034 for $10^{-6} \mathrm{AEP}$. It is particularly important to stress that quantiles not too far into the right tail ( 0.1 or $0.01 \mathrm{AEP})$ are relatively insensitive to distribution choice. To clarify, these two AEPs correspond, respectively, to cumulative percentiles of 90 and 99 percent of the unknown parent distribution, and the insensitivity to distribution choice is shown by $\sigma_{\mathrm{dc}}$ being less than about a tenth of a log-cycle for AEP $>0.01$.

Two examples of syntax are now provided, each stating the estimate for $10^{-4} \mathrm{AEP}$ based on the transformed mean of logarithms (table 7). These examples are "The $10^{-4} \mathrm{AEP}$ streamflow estimate when acknowledging uncertainty in the probability model is $137,400 \mathrm{ft}^{3} / \mathrm{s}$ (range 91,530 to $373,600 \mathrm{ft}^{3} / \mathrm{s} ; \sigma_{\mathrm{dc}}=0.2497 \log 10$ )" or "The $10^{-4} \mathrm{AEP}$ 
Table 5. Confidence limits and quantile fits of peak-streamflow frequency for six three-parameter probability distributions fit by the method of L-moments for U.S. Geological Survey streamflow-gaging station 01400500 Raritan River at Manville, New Jersey, using systematic record only.

$\left[\mathrm{ft}^{3} / \mathrm{s}\right.$, cubic foot per second; GEV, generalized extreme value; GLO, generalized logistic; GNO, generalized normal; GPA, generalized Pareto; PE3, Pearson type III; WEI, Weibull; lower, the lower limit of the 90th percentile confidence interval. The lower limit is the 5th percentile of the quantile distribution; upper, the upper limit of the 90th percentile confidence interval. The upper limit is the 95 th percentile of the quantile distribution. Computations were made on the basis of logarithmic transformation, and hence the standard deviation of a quantile $\left(\sigma_{\mathrm{s}}\right)$ is reported in logarithms. Text in red is referenced directly in the report]

\begin{tabular}{|c|c|c|c|c|c|c|c|}
\hline \multirow{2}{*}{$\begin{array}{c}\text { Distribution } \\
\text { abbreviation }\end{array}$} & \multirow[b]{2}{*}{ Statistic } & \multicolumn{6}{|c|}{ Quantile (ft $\mathrm{ft}^{3} / \mathrm{s}$ ) or standard deviation for annual exceedance probability (AEP) } \\
\hline & & $\begin{array}{c}\text { AEP }=0.1 \\
\left(\mathrm{ft}^{3} / \mathrm{s}\right)\end{array}$ & $\begin{array}{c}\text { AEP }=0.01 \\
\left(\mathrm{ft}^{3} / \mathrm{s}\right)\end{array}$ & $\begin{array}{c}\text { AEP }=1 \times 10^{-3} \\
\left(\mathrm{ft}^{3} / \mathrm{s}\right)\end{array}$ & $\begin{array}{c}\text { AEP }=1 \times 10^{-4} \\
\left(\mathrm{ftt}^{3} / \mathrm{s}\right)\end{array}$ & $\begin{array}{c}\text { AEP }=1 \times 10^{-5} \\
\left(\mathrm{ft}^{3} / \mathrm{s}\right)\end{array}$ & $\begin{array}{c}\text { AEP=1 } \times 10^{-6} \\
\left(\mathrm{ft}^{3} / \mathrm{s}\right)\end{array}$ \\
\hline \multirow[t]{4}{*}{ GEV } & Lower & 24,660 & 34,690 & 41,030 & 44,910 & 47,070 & 48,250 \\
\hline & Fit & 28,000 & 48,060 & 71,650 & 96,800 & 121,500 & 144,200 \\
\hline & Upper & 31,600 & 69,190 & 154,900 & 361,800 & 871,300 & $2,158,000$ \\
\hline & $\sigma_{\mathrm{s}}$ & 0.0323 & 0.0909 & 0.1757 & 0.2788 & 0.3982 & 0.5352 \\
\hline \multirow[t]{4}{*}{ GLO } & Lower & 24,240 & 39,770 & 63,990 & 103,600 & 168,700 & 275,500 \\
\hline & Fit & 27,150 & 55,240 & 129,800 & 373,600 & $1,387,000$ & $7,069,000$ \\
\hline & Upper & 30,420 & 79,510 & 328,400 & $2,793,000$ & $70,850,000$ & $9,280,000,000$ \\
\hline & $\sigma_{\mathrm{s}}$ & 0.0305 & 0.0910 & 0.2159 & 0.4423 & 0.8316 & 1.4870 \\
\hline \multirow[t]{4}{*}{ GNO } & Lower & 24,530 & 36,190 & 47,550 & 59,790 & 72,760 & 86,850 \\
\hline & Fit & 27,840 & 48,930 & 79,890 & 126,700 & 198,400 & 309,100 \\
\hline & Upper & 31,480 & 68,040 & 151,200 & 354,600 & 882,400 & $2,385,000$ \\
\hline & $\sigma_{\mathrm{s}}$ & 0.0325 & 0.0835 & 0.1517 & 0.2339 & 0.3301 & 0.4404 \\
\hline GPA & Lower & 25,230 & 28,440 & 28,800 & 28,840 & 28,850 & 28,850 \\
\hline \multirow{3}{*}{$\begin{array}{l}\text { (distribution } \\
\text { rejected for } \\
\text { right tail } \\
\text { performance) }\end{array}$} & Fit & 29,090 & 37,390 & 39,520 & 40,010 & 40,120 & 40,140 \\
\hline & Upper & 33,170 & 51,390 & 61,270 & 65,640 & 67,500 & 68,220 \\
\hline & $\sigma_{\mathrm{s}}$ & 0.0364 & 0.0784 & 0.1012 & 0.1117 & 0.1166 & 0.1189 \\
\hline \multirow[t]{4}{*}{ PE3 } & Lower & 24,580 & 36,140 & 47,740 & 60,080 & 73,630 & 88,190 \\
\hline & Fit & 27,900 & 48,390 & 76,760 & 116,600 & 172,500 & 250,700 \\
\hline & Upper & 31,840 & 66,320 & 129,000 & 242,400 & 447,000 & 816,500 \\
\hline & $\sigma_{\mathrm{s}}$ & 0.0340 & 0.0805 & 0.1324 & 0.1865 & 0.2420 & 0.2985 \\
\hline \multirow[t]{4}{*}{ WEI } & Lower & 24,650 & 34,990 & 44,460 & 53,590 & 62,500 & 71,370 \\
\hline & Fit & 28,090 & 46,180 & 67,090 & 91,530 & 120,000 & 153,000 \\
\hline & Upper & 31,970 & 62,450 & 108,800 & 178,700 & 279,400 & 423,700 \\
\hline & $\sigma_{\mathrm{s}}$ & 0.0341 & 0.0758 & 0.1177 & 0.1583 & 0.1975 & 0.2353 \\
\hline
\end{tabular}

streamflow estimate when acknowledging uncertainty in the probability model is $137,400 \mathrm{ft}^{3} / \mathrm{s}\left(\sigma_{\mathrm{dc}}=0.2497 \log 10\right)$." Although statements such as these quantify distribution choice uncertainty, it is necessary to emphasize that the uncertainty is somewhat semi-quantitative in that it is controlled by the choices an analyst makes concerning which distributions to incorporate. This last observation is not unique to this study, because the National Research Council (1988) states in this same context that "assessment of relative weights (degrees of belief) on alternative distributions may be needed."

Sampling uncertainty is now reconsidered in comparison to distribution choice uncertainty. A rough comparison of the numerical entries for $\sigma_{\mathrm{s}}$ and $\sigma_{\mathrm{dc}}$ listed in tables 5 and 7 , respectively, is informative. The authors conclude that for about $10^{-3} \mathrm{AEP}$ and greater (toward the left), the $\sigma_{\mathrm{s}}$ values among the distributions appear larger than $\sigma_{\mathrm{dc}}$; however, for about $10^{-4} \mathrm{AEP}$ and lower (toward the right), $\sigma_{\mathrm{dc}}$ is larger than $\sigma_{s}$. The comparison is said to be rough or imprecise, because there is inherent dependency on the sampling data and particularly on the probability distributions involved. For example, the GLO has considerably larger $\sigma_{\mathrm{s}}$ than any of the other corresponding values for the other distributions as AEP decreases beyond $0.01 \mathrm{AEP}$ (table 5) because the GLO fit curves up and away from the bulk of the remaining distributions (fig. 9). 
Table 6. Confidence limits and quantile fits of peak-streamflow frequency using the Pearson type III distribution fit by two methods for U.S. Geological Survey streamflow-gaging station 01400500 Raritan River at Manville, New Jersey, using systematic record only.

[ft 3 s, cubic foot per second; PE3, Pearson type III and PE3 fit by method of L-moments; EMA, expected moments algorithm (product moments); lower, the lower limit of the 90th percentile confidence interval. The lower limit is the 5th percentile of the quantile distribution; upper, the upper limit of the 90th percentile confidence interval. The upper limit is the 95 th percentile of the quantile distribution. Computations were made on the basis of logarithmic transformation, and hence the standard deviation of a quantile $\left(\sigma_{\mathrm{s}}\right)$ is reported in logarithms]

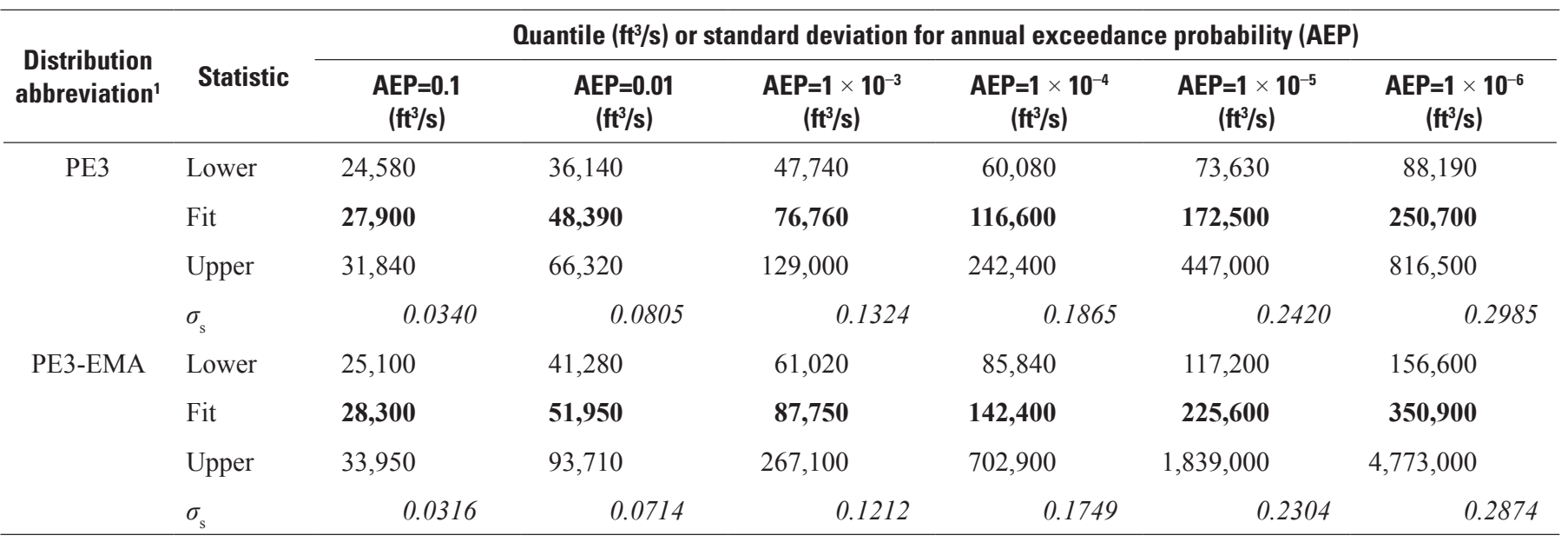

${ }^{1}$ Notes concerning distribution parameters: PE3(mean, standard deviation, skew) parameters by method are listed below and mimic nomenclature of tables 3 and 4. Only three significant figures are available for skew from PE3-EMA, Pearson type III distribution fit by expected moments algorithm:

PE3-EMA PE3( $4.2204,0.1734,0.748)$

PE3 PE3( 4.2204, 0.1696, 0.5741)

Table 7. Distribution choice uncertainty computed as logarithmic standard deviation of quantile estimates for five three-parameter probability distributions fit by the method of L-moments for U.S. Geological Survey streamflow-gaging station 01400500 Raritan River at Manville, New Jersey, using systematic record only.

[ft 3 s, cubic foot per second; GEV, generalized extreme value; GLO, generalized logistic; GNO, generalized normal; PE3, Pearson type III; WEI, Weibull; $\sigma_{\mathrm{dc}}$, distribution choice uncertainty computed by standard deviation of base-10 logarithms of the listed quantiles. The $\sigma_{\mathrm{dc}}$ values are shaded to emphasize the product of this table; the quantiles are also listed in table 5. Text in red is referenced directly in the report]

\begin{tabular}{|c|c|c|c|c|c|c|c|}
\hline \multirow{2}{*}{$\begin{array}{l}\text { Distribution } \\
\text { abbreviation }\end{array}$} & \multirow[b]{2}{*}{ Statistic } & \multicolumn{6}{|c|}{ Quantile $\left(\mathrm{ft}^{3} / \mathrm{s}\right.$ ) for annual exceedance probability (AEP) and distribution choice uncertainty } \\
\hline & & $\begin{array}{c}\text { AEP }=0.1 \\
\left(\mathrm{ftt}^{3} / \mathrm{s}\right)\end{array}$ & $\begin{array}{c}\text { AEP }=0.01 \\
\left(\mathrm{ftt}^{3} / \mathrm{s}\right)\end{array}$ & $\begin{array}{c}\text { AEP }=1 \times 10^{-3} \\
\left(f^{3} / \mathbf{s}\right)\end{array}$ & $\begin{array}{c}\text { AEP }=1 \times 10^{-4} \\
\left(\mathrm{ft}^{3} / \mathrm{s}\right)\end{array}$ & $\begin{array}{c}\text { AEP }=1 \times 10^{-5} \\
\left(\mathrm{ft}^{3} / \mathrm{s}\right)\end{array}$ & $\begin{array}{c}\text { AEP }=1 \times 10^{-6} \\
\left(\mathrm{ftt}^{3} / \mathbf{s}\right)\end{array}$ \\
\hline GEV & Fit & 28,000 & 48,060 & 71,650 & 96,800 & 121,500 & 144,200 \\
\hline GLO & Fit & 27,150 & 55,240 & 129,800 & 373,600 & $1,387,000$ & $7,069,000$ \\
\hline GNO & Fit & 27,840 & 48,930 & 79,890 & 126,700 & 198,400 & 309,100 \\
\hline PE3 & Fit & 27,900 & 48,390 & 76,760 & 116,600 & 172,500 & 250,700 \\
\hline \multirow[t]{2}{*}{ WEI } & Fit & 28,090 & 46,180 & 67,090 & 91,530 & 120,000 & 153,000 \\
\hline & $\sigma_{\mathrm{dc}}$ & 0.0059 & 0.0293 & 0.1137 & 0.2497 & 0.4430 & 0.7034 \\
\hline \multicolumn{2}{|c|}{ Transformed mean of logarithms } & 27,790 & 49,270 & 82,520 & 137,400 & 233,400 & 413,500 \\
\hline
\end{tabular}




\section{L-moment Ratio Diagram}

L-moment ratio diagrams of L-skew and L-kurtosis are thoroughly described in the context of figure 3-5 ahead of superposition of data for this study. The sample L-skew and L-kurtosis for the systematic record of the Raritan River streamgage are shown in figure 10, along with results from a Monte Carlo simulation experiment (number of simulations $=3,000$; sample size $=103$ years [systematic record]). The simulation facilitates exploration of the joint distribution potential between sample L-skew and L-kurtosis.

The L-skew and L-kurtosis for the Raritan River streamgage plot as a single point above the trajectory for the GLO shown in figure 10. Several conclusions can be made. This point lies above the accessible domain of the KAP distribution, and thus, the distribution cannot be fit to these data. The AEP4 distribution includes L-skew and L-kurtosis domain not covered by the KAP, and the AEP4 can be fit to these data. Lastly, the GLO is the closest three-parameter distribution to the point; thus, the GLO is most consistent with these data. Sample variability, however, affects the precise plotted location of this point, because the sample L-skew and L-kurtosis are obviously dependent on the respective data.

Simulation through Monte Carlo methods can be used for evaluation outside the context of regional information, such as is the case here. Simulation based on the variance-covariance structure (fig. 3-3) may be used. Using the variancecovariance matrix of the sample L-moments of Raritan River streamgage data, 3,000 simulations of these L-moments from a multivariate normal distribution were made. For each simulation, the L-skew and L-kurtosis were computed and are scattered around the L-skew and L-kurtosis of the data (fig. 10). The 90th-confidence level (ellipse) shown is based on the covariance structure of the 3,000 simulated values. The plotting of these simulation results provides a visual and inferential depiction of inherent variation. The general scatter of the simulated points is spread (distributed) near the GLO, and as a result, the GLO might be more favorable than other three-parameter distributions. The GEV, GNO, and PE3 all pass through the ellipse for the L-skew of the data and the trajectories are close to one another. The frequency curves should thus show considerable similarity with each other. The trajectories for the GPA and WEI pass outside the ellipse, and as a result, these distributions are less likely to be applicable. Moreover, the GPA is divergent from the simulation results and thus should show the least favorable fit to the Raritan River data.

\section{Results for the Potomac River at Point of Rocks, Maryland, Streamgage}

\section{Comparison of Parameter Estimates}

Numerical and graphical comparisons of parameter estimates were made for the Potomac River data for the
PE3 distribution (fig. 11 and table 8). The four methods of parameter estimation are represented. Only the systematic record for the Potomac River was used to form a common base on which to compare the methods of parameter estimation. As a result, only data for the systematic record are shown in the figure. As in table 3 for the Raritan River data, the largest differences in table 8 are for the third parameter, skew. The skew values, however, are measurably similar to zero (meaning becoming close to zero) and hence the four distributions in figure 11 appear quite straight, thus indicating a nearly log-normal distribution.

The similarity among the four fits for the PE3 distribution is indicated by figure 11, which also shows that divergence among them increases as AEP diminishes. For these data, the two methods of product moments and MPS produce nearly identical parameter estimates, and these two estimates are the most positive of the four.

\section{Frequency Curve Comparisons and Confidence Limits}

Selected probability distributions for this study as applied to annual peak streamflow data for the Raritan River streamgage are shown for comparison in figure 9. The Kappa distribution is not shown or discussed further, because its PE3 lacks a solution for the Potomac River data. Peak streamflows from the systematic and historical record are also shown in figure 9 and were plotted using Hirsch-Stedinger plotting positions (fig. 2-1). The numerical values for the parameter estimates by L-moments for the Potomac River are listed in table 9.

The top half of table 9 lists the parameters using only the systematic record. The bottom half of the table lists the parameters using a censoring approach in an effort to accommodate the historical information available for this streamgage. Historical information was included for the L-moments using a censoring approach that required distributional reversal by flipping the data first, whereas historical information inclusion for PE3-EMA did not. However, a notable comparison can be made. Using historical information, the PE3-EMA estimates mean, standard deviation, and skewness as 5.0233, 0.2303, and 0.311 , respectively. (The units for the mean and standard deviation are logarithms.) The L-moments similarly estimates a reversed PE3 having a mean, standard deviation, and skewness of $1.2263,0.2241$, and -0.1963 , respectively, with a flip of 6.249365. The two estimates of standard deviation can be compared, because this statistic is always positive: 0.2303 versus 0.2241 . The two skews can be compared after sign reversal for the L-moments value: 0.311 versus 0.1963 . The two estimates of the mean can be compared after flipping: 5.0233 versus $6.249365-1.2263=$ 5.0231 . 


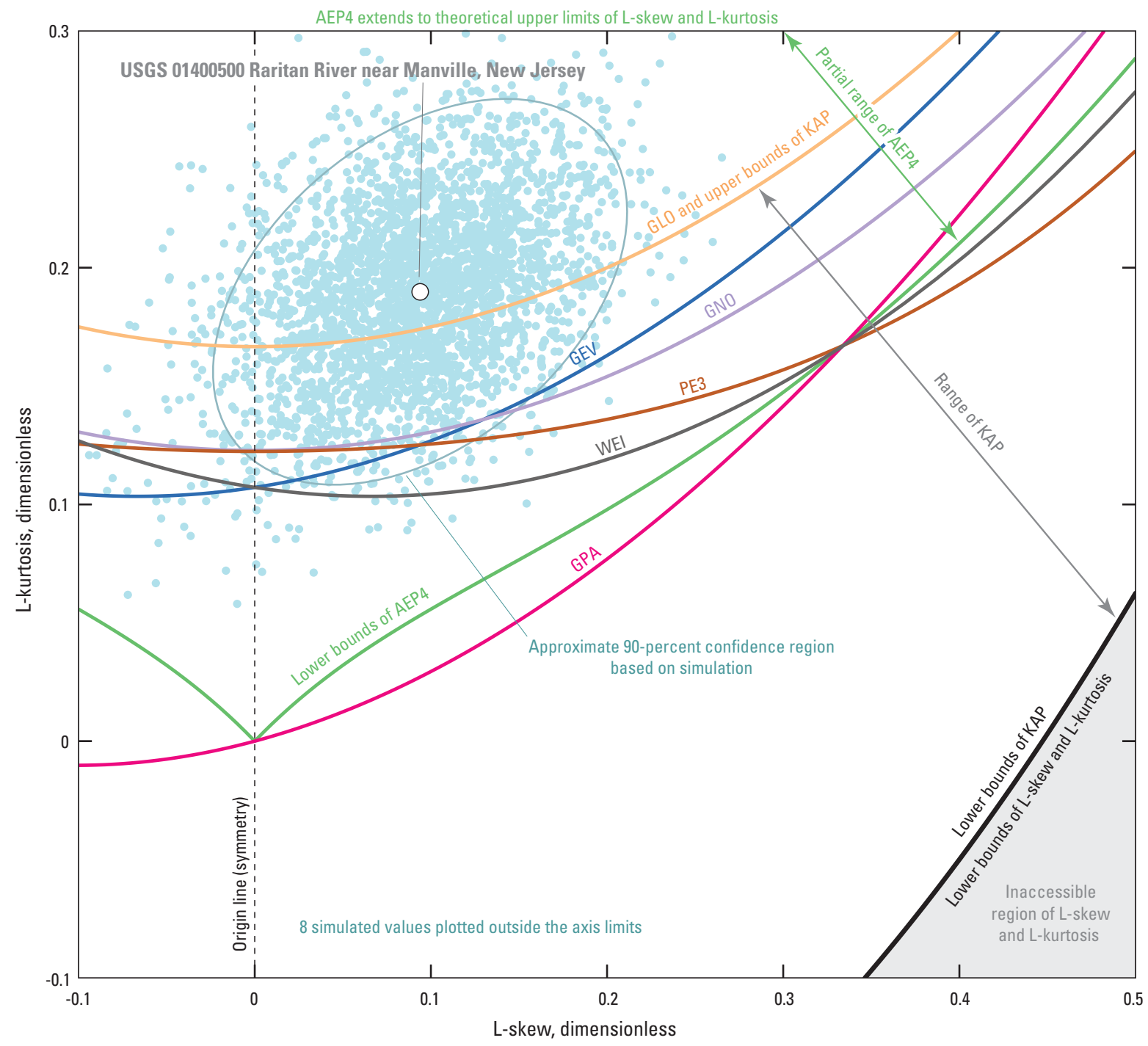

\section{EXPLANATION}

Systematic record (1904-6, 1909-15, and 1922-2014)—L-moments computed for the systematic record

Simulated value based on systematic record-Sample variance-covariance matrix of L-moments used in multivariate-normal simulation of size 3,000 with some values not shown as indicated by note

USGS, U.S. Geological Survey

\author{
Distribution type \\ AEP4, asymmetric exponential power (four parameter) \\ GEV, generalized extreme value (three parameter) \\ GLO, generalized logistic (three parameter) \\ GNO, generalized normal (three parameter)—Also log-normal \\ GPA, generalized Pareto (three parameter) \\ KAP, Kappa (four parameter) \\ PE3, Pearson type III (three parameter) \\ WEI, Weibull (three parameter)—Also reversed GEV
}

Figure 10. L-moment ratio diagram of L-skew and L-kurtosis of annual peak streamflow data for U.S. Geological Survey streamflow-gaging station 01400500 Raritan River at Manville, New Jersey, and comparison to theoretical relations of numerous distributions. 


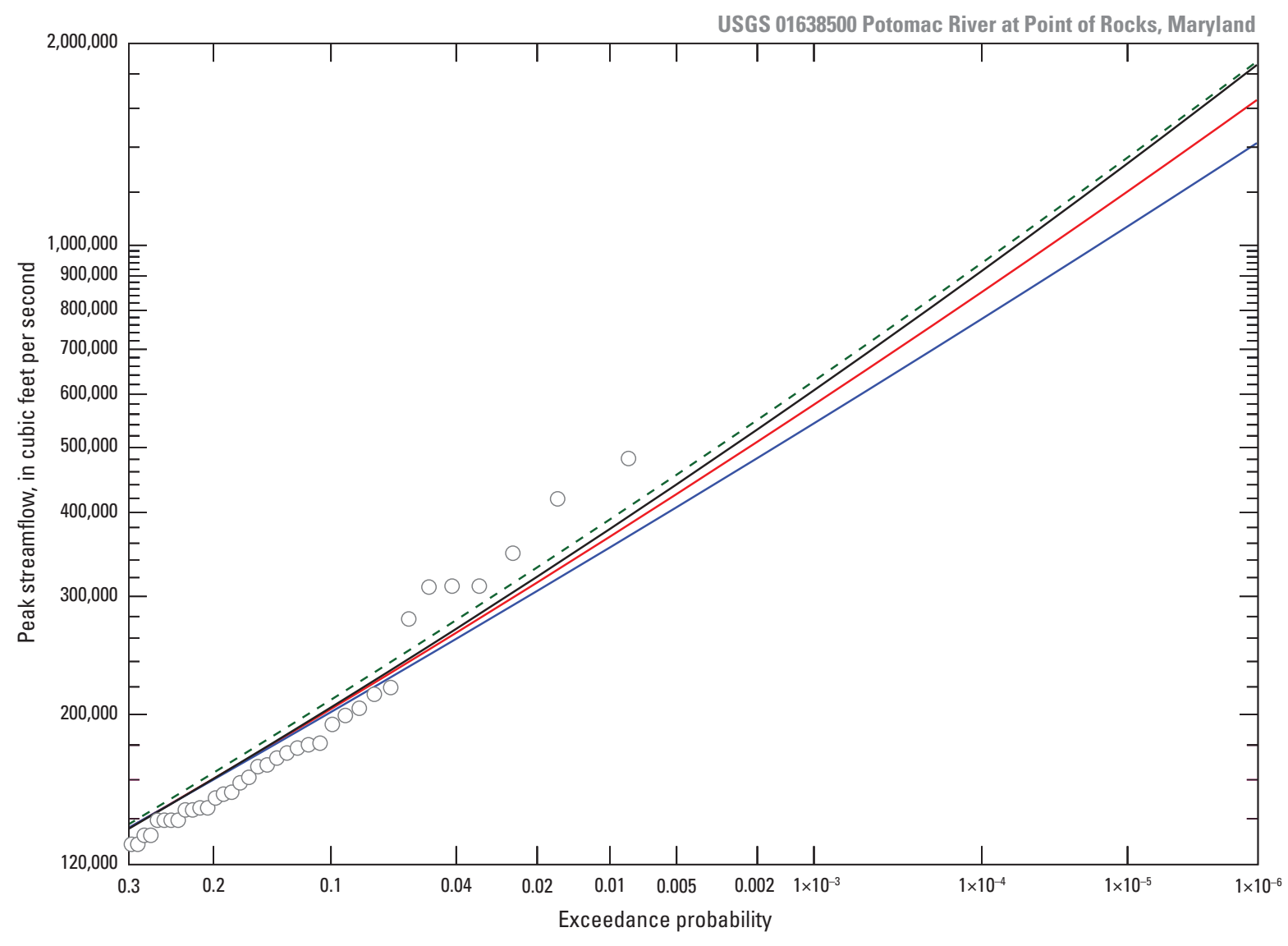

EXPLANATION

Pearson type III probability distribution fit to logarithms of systematic record, by parameter estimation method

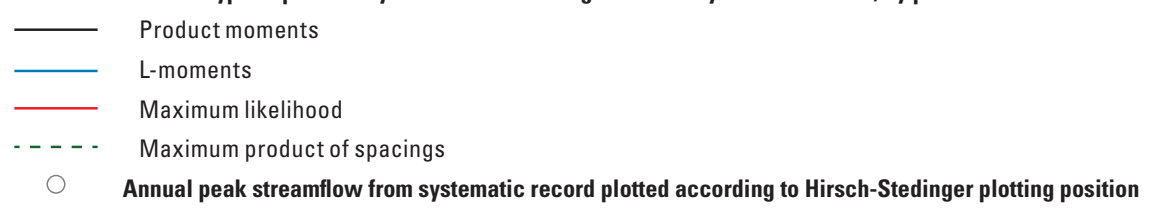

USGS, U.S. Geological Survey

Note: For clarity, exceedance probabilities less than 0.002 are shown in scientific notation.

Figure 11. Comparison of four parameter estimation methods for the Pearson type III probability distribution fit to logarithms of systematic record of the annual peak streamflow data for U.S. Geological Survey streamflow-gaging station 01638500 Potomac River at Point of Rocks, Maryland.

The parameters including historical information (table 9, bottom half) were used to draw the distributions shown in figure 12. An exception is made for the PE3 distribution in which the curves for the systematic record only by EMA and L-moments are also shown. The primary emphasis should be those PE3 curves by EMA and L-moments incorporating the historical information as well.

The GPA distribution for the Potomac River data has an unacceptable fit (fig. 12) for the same reason indicated for the Raritan River data (fig. 9). The distribution has an upper limit that is less than one or more of the largest data values.
The high-parameter distributions AEP4 and WAK also are shown; however, these do not have a similar fit into the tail, which is unlike that shown in figure 9 for the Raritan River. For the Potomac River data, the WAK distribution has an upper limit comparable to the largest data value, and this is an unacceptable fit relative to the other distributions. The WAK does bend upwards to mimic the eight largest values that do plot above the trajectories of all the distributions. The AEP4 distribution lies between the GLO and PE3-EMA and accommodates the L-kurtosis of these data. 
Table 8. Distribution parameters for the Pearson type III distribution by four parameter estimation methods for U.S. Geological Survey streamflow-gaging station (streamgage) 01638500 Potomac River at Point of Rocks, Maryland, using systematic record only.

[PE3, Pearson type III distribution. PE3 is fit to logarithms of the annual peak streamflow data for respective streamgage. PE3(mean, standard deviation, skew) represents the respective parameters of the distribution in the same ordering as in the mathematics provided in figure 5-5]

\begin{tabular}{|c|c|}
\hline $\begin{array}{l}\text { Distribution abbreviation } \\
\text { and parameter values }\end{array}$ & $\begin{array}{c}\text { Parameter } \\
\text { estimation method }\end{array}$ \\
\hline PE3( $5.0182,0.2240,0.222)$ & $\begin{array}{l}\text { Method of product moments } \\
\text { (expected moments algorithm) }\end{array}$ \\
\hline PE3( $5.0182,0.2204,0.1052)$ & Method of L-moments \\
\hline PE3( $5.0182,0.2229,0.1671)$ & Method of maximum likelihood \\
\hline PE3( $5.0187,0.2329,0.1703)$ & $\begin{array}{l}\text { Method of maximum product of } \\
\text { spacings }\end{array}$ \\
\hline
\end{tabular}

Sampling uncertainty can now be reviewed. The estimated 90-percent confidence intervals for the PE3 are shown to visually portray sampling uncertainty. The analytical 90-percent confidence limits for the PE3-EMA are obtained from the USGS-PeakFQ software and are mathematically correct if the parent distribution is in fact a (log-)Pearson type III distribution. In contrast, the confidence limits obtained from Monte Carlo simulation of the PE3 by L-moments are based on the distribution-free exact variance-covariance structure of the sample L-moments. Again, as made for the Raritan River streamgage, the variance-covariance structure of the sample L-moments permits a Monte Carlo simulation to be used to generate a large number of sequences (simulation size $=5,000$; sample size $=121$ [systematic record]) of sample L-moments, successively fit the PE3 to these, and compute simulated quantiles for a given AEP. The distribution of these simulated quantiles for a given AEP is then used to compute the 5th and 95th percentiles to form the 90-percent confidence interval. The quantile fits and 90-percent confidence intervals associated with the six three-parameter distributions fit by the method of L-moments are listed in table 10. The quantile files and 90-percent confidence intervals restricted to the PE3 are listed in table 11.

Note that the inclusion of historical information can increase or decrease the sampling uncertainty and associated confidence limits for the quantile estimates, depending on how much the historical information extends the record and whether it is consistent with the fit indicated by the systematic record. A more complete examination of the use of nonsystematic data for peak-streamflow frequency analysis is left for future inquiry.
Concerning table 10 for historical plus systematic record, it is useful to provide two examples of syntax stating the estimate for $10^{-4} \mathrm{AEP}$ using the GEV, which are "The $10^{-4}$ AEP streamflow estimate based on the GEV distribution is $721,100 \mathrm{ft}^{3} / \mathrm{s}$ (90th percentile confidence limit of 439,800 to $1,290,000 \mathrm{ft}^{3} / \mathrm{s}$ based on $\sigma_{\mathrm{s}}=0.1407 \log 10$ )" or "The $10^{-4}$ AEP streamflow estimate based on the GEV distribution is $721,100 \mathrm{ft}^{3} / \mathrm{s}\left(\sigma_{\mathrm{s}}=0.1407 \log 10\right)$."

Distribution choice uncertainty can now be quantified, and the results are listed in table 12. Distribution choice uncertainty for a given AEP is computed by the standard deviation of quantile estimates for the models (distributions) selected. As in figure 12, the GPA is obviously not an acceptable fit to the Potomac River data. For brevity, only the remaining five three-parameter distributions were used to compute the uncertainty. The AEP4 and WAK distributions were not included. The five quantiles for selected AEPs from the distributions are listed in table 12.

Inspection of the values listed in table 12 indicates that the range of the quantiles for historical plus systematic record is exceptional for the lowest AEP $\left(10^{-6}\right)$. For example, the range of 705,400 to $16,070,000 \mathrm{ft}^{3} / \mathrm{s}$ measured in logarithms is almost $1.4 \log$-cycles for $10^{-6} \mathrm{AEP}$, and the standard deviation of the logarithms $\left(\sigma_{\mathrm{dc}}\right)$ is 0.5190 for $10^{-6} \mathrm{AEP}$. As for the Raritan River streamgage, the quantiles for 0.1 or $0.01 \mathrm{AEP}$ are relatively insensitive to distribution choice, which is shown by the $\sigma_{\mathrm{dc}}$ being less than about a $1 / 10$ of log-cycle.

Two examples of syntax are now provided, stating the estimate for $10^{-4} \mathrm{AEP}$ based on the transformed mean of logarithms (table 12). These examples are "The $10^{-4} \mathrm{AEP}$ streamflow estimate when acknowledging uncertainty in the probability model is $957,100 \mathrm{ft}^{3} / \mathrm{s}$ (range 592,000 to 2,325,000 $\left.\mathrm{ft}^{3} / \mathrm{s} ; \sigma_{\mathrm{dc}}=0.2284 \log 10\right)$ " or "The $10^{-4}$ AEP streamflow estimate when acknowledging uncertainty in the probability model is $957,100 \mathrm{ft}^{3} / \mathrm{s}\left(\sigma_{\mathrm{dc}}=0.2284 \log 10\right) . "$

Sampling uncertainty is now reconsidered in comparison to distribution choice uncertainty. A rough comparison of the numerical entries for $\sigma_{\mathrm{s}}$ and $\sigma_{\mathrm{dc}}$ listed in tables 10 and 12 is informative. The authors conclude that for about $10^{-3}$ AEP and greater, the $\sigma_{\mathrm{s}}$ values among the distributions are larger than the choice of distribution. For about $10^{-4} \mathrm{AEP}$ and lower, however, $\sigma_{\mathrm{dc}}$ is larger than $\sigma_{\mathrm{s}}$. The comparison is said to be rough or imprecise, because there is inherent dependency on the sampling data and particularly on the probability distributions involved. For example, the GLO has considerably larger $\sigma_{\mathrm{s}}$ than any of the other corresponding values for the other distributions as AEP decreases beyond 0.01 AEP (table 5). As for the Raritan River streamgage, the GLO curves up and away from the bulk of the remaining distributions (fig. 12). 
Table 9. Distribution parameters by the methods of L-moments and expected moments algorithm for selected probability distributions for U.S. Geological Survey streamflow-gaging station (streamgage) 01638500 Potomac River at Point of Rocks, Maryland.

[Each distribution is fit by the method of L-moments to logarithms of the annual peak streamflow data for respective streamgage and parameter values listed in the same ordering as in the mathematics in appendix 5-for example, PE3(mean, standard deviation, skew) represents the respective parameters of the distribution in the same ordering as in mathematics of figure 5-5; flip is the value used to reverse (mirror or "flip") a distribution; for example, flip - PE3(1AEP; mean, standard deviation, skew) would be the quantile for annual exceedance probability (AEP; itself reversed on 1 [unity]) for the PE3 having those respective parameters; EMA, expected moments algorithm; PE3-EMA, Pearson type III fit by EMA. Only three significant figures are available for skew from PE3-EMA]

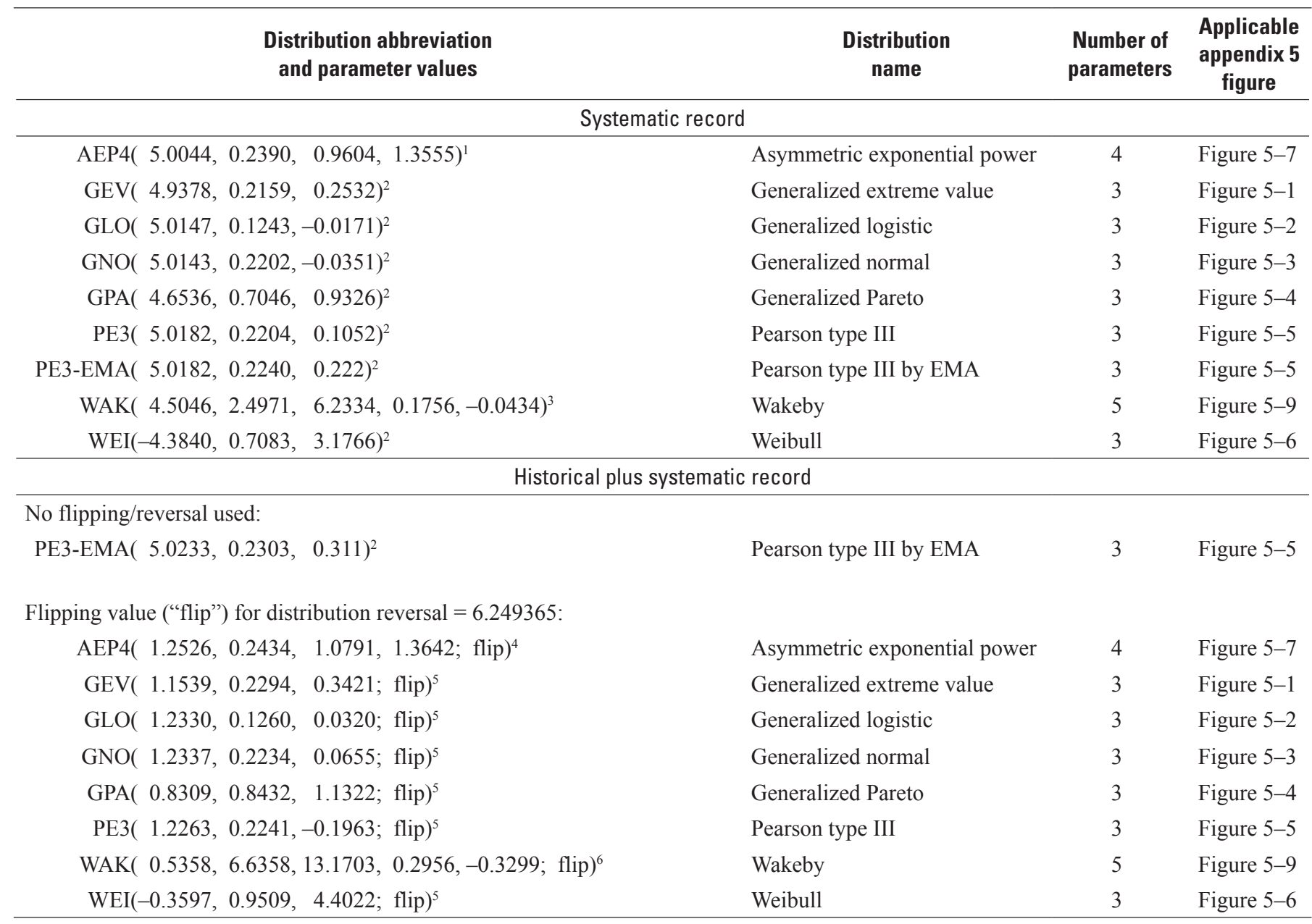

${ }^{1}$ For the AEP4 distribution (four parameters) the order of parameters shown is "location," "scale," "shape1," and "shape2."

${ }^{2}$ For a three parameter distribution, the order of parameters shown is "location," "scale," and "shape."

${ }^{3}$ For the Wakeby distribution (five parameters), the order of parameters shown is "location," "scale1," "scale2," "shape1," and "shape2."

${ }^{4}$ For the AEP4 distribution (four parameters), the order of parameters shown is "location," "scale," "shape1," and “shape2," and the flip.

${ }^{5}$ For a three parameter distribution, the order of parameters shown is "location," "scale," "shape," and the flip.

${ }^{6}$ For the Wakeby distribution (five parameters), the order of parameters shown is "location," “scale1," "scale2," "shape1,” and “shape2," and the flip. 


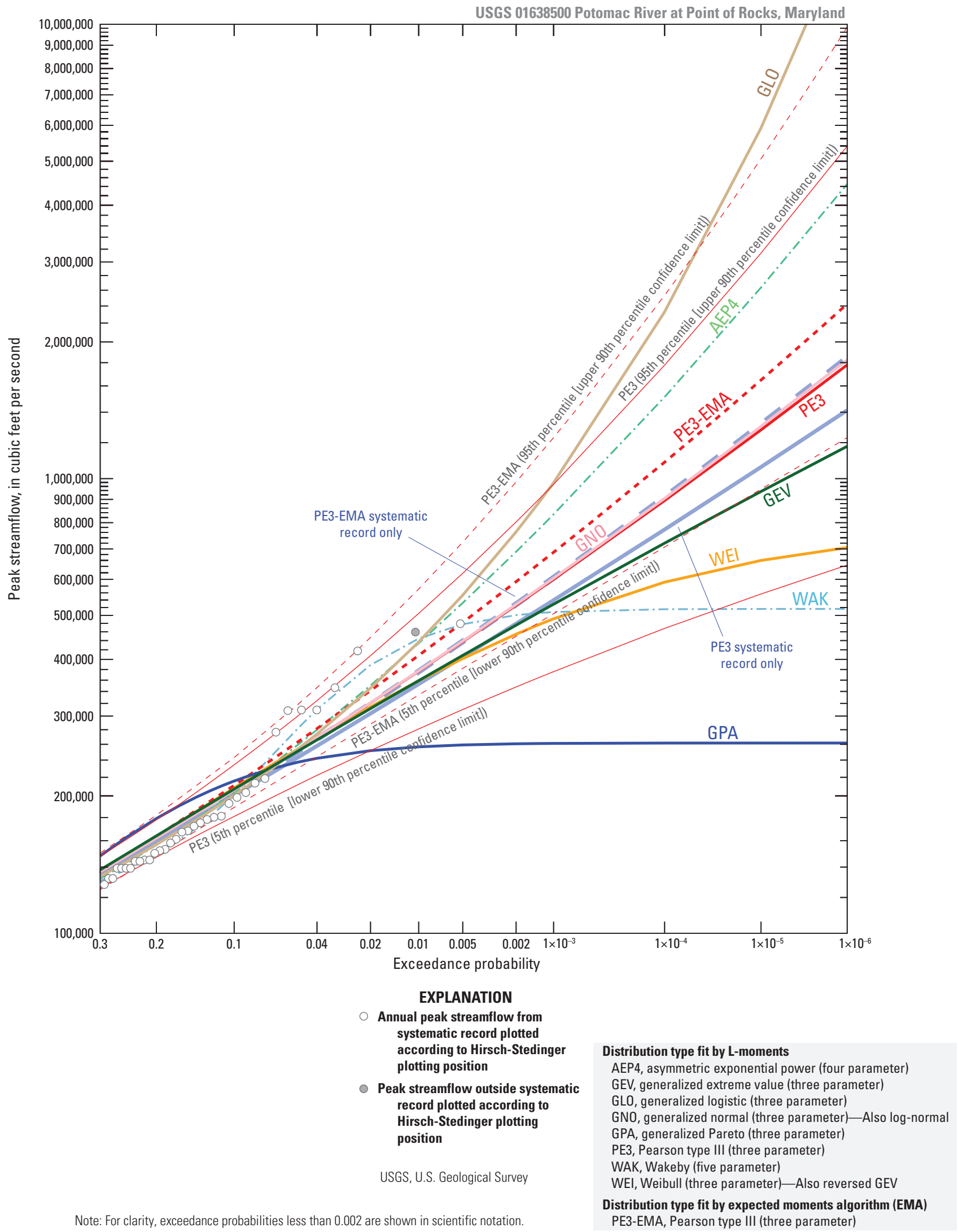

Figure 12. Annual nonexceedance probability plot and fitted distributions for U.S. Geological Survey (USGS) streamflowgaging station 01638500 Potomac River at Point of Rocks, Maryland, based on flood frequency analysis using expected moments algorithm with multiple Grubbs-Beck test (no low outliers detected) and station skew as generated by USGS-PeakFO software (USGS, 2014). 
Table 10. Confidence limits and quantile fits of peak-streamflow frequency for six three-parameter probability distributions fit by the method of L-moments for U.S. Geological Survey streamflow-gaging station 01638500 Potomac River at Point of Rocks, Maryland.

[ft³/s, cubic foot per second; GEV, generalized extreme value; GLO, generalized logistic; GNO, generalized normal; GPA, generalized Pareto; PE3, Pearson type III; WEI, Weibull; lower, the lower limit of the 90th percentile confidence interval. The lower limit is the 5th percentile of the quantile distribution; upper, the upper limit of the 90th percentile confidence interval. The upper limit is the 95th percentile of the quantile distribution; computations were made on the basis of logarithmic transformation and hence the standard deviation of a quantile $\left(\sigma_{\mathrm{s}}\right)$ is reported in logarithms. Text in red is referenced directly in the report]

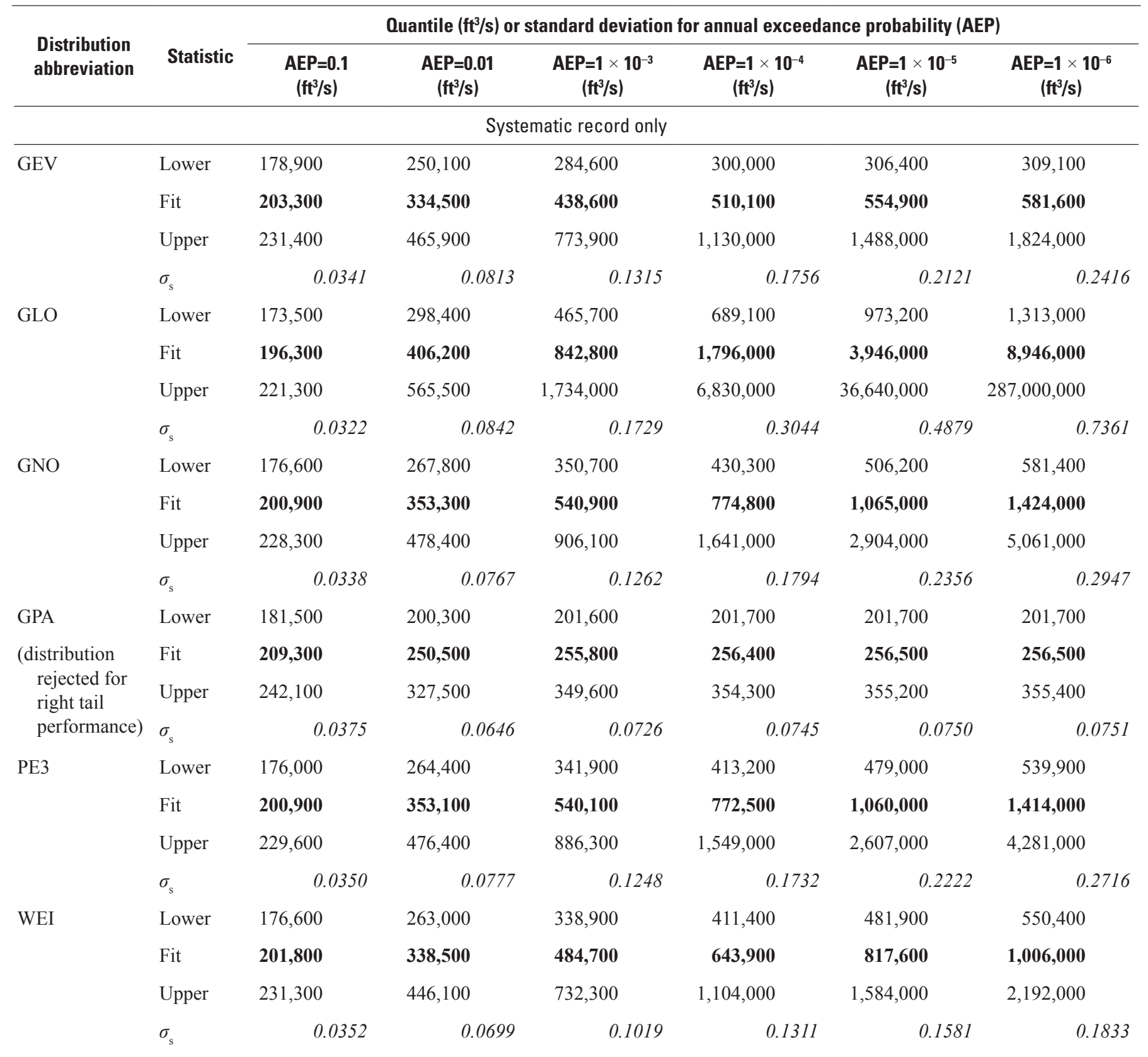


Table 10. Confidence limits and quantile fits of peak-streamflow frequency for six three-parameter probability distributions fit by the method of L-moments for U.S. Geological Survey streamflow-gaging station 01638500 Potomac River at Point of Rocks,

Maryland.-Continued

[ft³/s, cubic foot per second; GEV, generalized extreme value; GLO, generalized logistic; GNO, generalized normal; GPA, generalized Pareto; PE3, Pearson type III; WEI, Weibull; lower, the lower limit of the 90th percentile confidence interval. The lower limit is the 5th percentile of the quantile distribution; upper, the upper limit of the 90th percentile confidence interval. The upper limit is the 95th percentile of the quantile distribution; computations were made on the basis of logarithmic transformation and hence the standard deviation of a quantile $\left(\sigma_{\mathrm{s}}\right)$ is reported in logarithms. Text in red is referenced directly in the report]

\begin{tabular}{|c|c|c|c|c|c|c|c|}
\hline $\begin{array}{l}\text { Distribution } \\
\text { abbreviation }\end{array}$ & Statistic & \multicolumn{6}{|c|}{ Quantile $\left(\mathrm{ft}^{3} / \mathbf{s}\right)$ or standard deviation for annual exceedance probability (AEP) } \\
\hline \multirow[t]{2}{*}{ GEV } & Lower & 180,900 & 273,500 & 358,400 & 439,800 & 519,600 & 599,100 \\
\hline & $\sigma_{\mathrm{s}}$ & 0.0364 & 0.0736 & 0.1085 & 0.1407 & 0.1706 & 0.1986 \\
\hline \multirow[t]{2}{*}{ GLO } & Lower & 177,000 & 316,000 & 518,200 & 795,100 & $1,175,000$ & $1,673,000$ \\
\hline & Fit & 201,100 & 436,800 & 978,600 & $2,325,000$ & $5,899,000$ & $16,070,000$ \\
\hline \multirow[t]{4}{*}{ GNO } & Lower & 180,200 & 281,900 & 378,700 & 476,800 & 575,800 & 676,700 \\
\hline & Fit & 206,200 & 377,600 & 603,700 & 904,400 & $1,302,000$ & $1,825,000$ \\
\hline & Upper & 234,700 & 518,800 & $1,051,000$ & $2,054,000$ & $3,956,000$ & $7,635,000$ \\
\hline & $\sigma_{\mathrm{s}}$ & 0.0350 & 0.0801 & 0.1338 & 0.1927 & 0.2559 & 0.3233 \\
\hline GPA & Lower & 186,100 & 212,200 & 215,000 & 215,300 & 215,300 & 215,300 \\
\hline \multirow{3}{*}{$\begin{array}{l}\text { (distribution } \\
\text { rejected for } \\
\text { right tail } \\
\text { performance) }\end{array}$} & Fit & 216,100 & 257,100 & 261,600 & 262,100 & 262,100 & 262,100 \\
\hline & Upper & 251,300 & 314,000 & 321,400 & 322,100 & 322,200 & 322,200 \\
\hline & $\sigma_{\mathrm{s}}$ & 0.0395 & 0.0510 & 0.0522 & 0.0524 & 0.0524 & 0.0524 \\
\hline \multirow{3}{*}{ WEI } & Fit & 208,600 & 359,100 & 491,700 & $\mathbf{5 9 2 , 0 0 0}$ & 660,900 & 705,400 \\
\hline & Upper & 236,400 & 498,800 & 898,100 & $1,428,000$ & $2,033,000$ & $2,670,000$ \\
\hline & $\sigma_{\mathrm{s}}$ & 0.0344 & 0.0841 & 0.1407 & 0.1936 & 0.2400 & 0.2799 \\
\hline
\end{tabular}




\section{Application of At-Site Peak-Streamflow Frequency Analyses for Very Low Annual Exceedance Probabilities}

Table 11. Confidence limits and quantile fits of peak-streamflow frequency using the Pearson type III distribution fit by two methods for U.S. Geological Survey streamflow-gaging station 01638500 Potomac River at Point of Rocks, Maryland.

[ft 3 s, cubic foot per second; PE3, Pearson type III and PE3 fit by method of L-moments; EMA, expected moments algorithm (product moments); lower, the lower limit of the 90th percentile confidence interval. The lower limit is the 5th percentile of the quantile distribution; upper, the upper limit of the 90th percentile confidence interval. The upper limit is the 95th percentile of the quantile distribution. Computations were made on the basis of logarithmic transformation; hence, the standard deviation of a quantile $\left(\sigma_{\mathrm{s}}\right)$ is reported in logarithms]

\begin{tabular}{|c|c|c|c|c|c|c|c|}
\hline \multirow{2}{*}{$\begin{array}{c}\text { Distribution } \\
\text { abbreviation' }\end{array}$} & \multirow[b]{2}{*}{ Statistic } & \multicolumn{6}{|c|}{ Quantile (ft $3 / \mathbf{s}$ ) or standard deviation for annual exceedance probability (AEP) } \\
\hline & & $\begin{array}{c}\text { AEP }=0.1 \\
\left(f^{3} / s\right)\end{array}$ & $\begin{array}{c}\text { AEP }=0.01 \\
\left(\mathrm{ft}^{3} / \mathrm{s}\right)\end{array}$ & $\begin{array}{c}\text { AEP }=1 \times 10^{-3} \\
\left(\mathrm{ftt}^{3} / \mathbf{s}\right)\end{array}$ & $\begin{array}{c}\text { AEP=1 } \times 10^{-4} \\
\left(\mathbf{f t t}^{3} / \mathbf{s}\right)\end{array}$ & $\begin{array}{c}\text { AEP }=1 \times 10^{-5} \\
\left(\mathrm{ftt}^{3} / \mathbf{s}\right)\end{array}$ & $\begin{array}{c}\text { AEP }=1 \times 10^{-6} \\
\left(\mathrm{ftt}^{3} / \mathbf{s}\right)\end{array}$ \\
\hline \multicolumn{8}{|c|}{ Systematic record only } \\
\hline \multirow[t]{4}{*}{ PE3 } & Lower & 176,000 & 264,400 & 341,900 & 413,200 & 479,000 & 539,900 \\
\hline & Fit & 200,900 & 353,100 & 540,100 & 772,500 & $1,060,000$ & $1,414,000$ \\
\hline & Upper & 229,600 & 476,400 & 886,300 & $1,549,000$ & $2,607,000$ & $4,281,000$ \\
\hline & $\sigma_{\mathrm{s}}$ & 0.0350 & 0.0777 & 0.1248 & 0.1732 & 0.2222 & 0.2716 \\
\hline \multirow[t]{4}{*}{ PE3-EMA } & Lower & 180,600 & 304,800 & 437,200 & 581,400 & 739,300 & 910,800 \\
\hline & Fit & 204,200 & 376,300 & 605,000 & 910,600 & $1,316,000$ & $1,846,000$ \\
\hline & Upper & 241,300 & 565,900 & $1,218,000$ & $2,499,000$ & $4,987,000$ & $9,749,000$ \\
\hline & $\sigma_{\mathrm{s}}$ & 0.0300 & 0.0608 & 0.0975 & 0.1371 & 0.1780 & 0.2195 \\
\hline \multicolumn{8}{|c|}{ Historical plus systematic record } \\
\hline \multirow[t]{4}{*}{ PE3 } & Lower & 180,200 & 280,700 & 375,200 & 469,000 & 561,700 & 653,700 \\
\hline & Fit & 206,300 & 377,000 & 600,400 & 894,700 & $1,280,000$ & $1,780,000$ \\
\hline & Upper & 234,000 & 503,400 & 967,900 & $1,755,000$ & $3,094,000$ & $5,319,000$ \\
\hline & $\sigma_{\mathrm{s}}$ & 0.0345 & 0.0773 & 0.1254 & 0.1752 & 0.2261 & 0.2775 \\
\hline \multirow[t]{4}{*}{ PE3-EMA } & Lower & 185,500 & 324,400 & 482,900 & 666,800 & 880,100 & $1,125,000$ \\
\hline & Fit & 211,300 & 408,300 & 688,300 & $1,087,000$ & $1,647,000$ & $2,424,000$ \\
\hline & Upper & 251,300 & 627,500 & $1,465,000$ & $3,293,000$ & $7,227,000$ & $15,570,000$ \\
\hline & $\sigma_{\mathrm{s}}$ & 0.0316 & 0.0656 & 0.1058 & 0.1493 & 0.1944 & 0.2402 \\
\hline
\end{tabular}

${ }^{1}$ Notes concerning distribution parameters: PE3(mean, standard deviation, skew) parameters by method are listed below and mimic nomenclature of tables 8 and 9. Only three significant figures are available for skew from PE3-EMA, Pearson type III distribution fit by expected moments algorithm:

01638500 Potomac River at Point of Rocks, Maryland (systematic record only)

PE3 PE3( 5.0182, 0.2204, 0.1052)

PE3-EMA PE3( 5.0182, 0.2240, 0.222)

01638500 Potomac River at Point of Rocks, Maryland (historical plus systematic record)

PE3 PE3( $1.2263,0.2241,-0.1963$; flip=6.249365) $\quad$ (see table 9 for description of flip)

PE3-EMA PE3( 5.0233, 0.2303, 0.311) 
Table 12. Distribution choice uncertainty computed as logarithmic standard deviation of quantile estimates for five three-parameter probability distributions fit by the method of L-moments for U.S. Geological Survey streamflow-gaging station 01638500 Potomac River at Point of Rocks, Maryland.

[ft³/s, cubic foot per second; GEV, generalized extreme value; GLO, generalized logistic; GNO, generalized normal; PE3, Pearson type III; WEI, Weibull; $\sigma_{\mathrm{dc}}$, distribution choice uncertainty computed by standard deviation of base-10 logarithms of the listed quantiles. The $\sigma_{\mathrm{dc}}$ values are shaded to emphasize the product of this table; the quantiles are also listed in table 10. Text in red is referenced directly in the report]

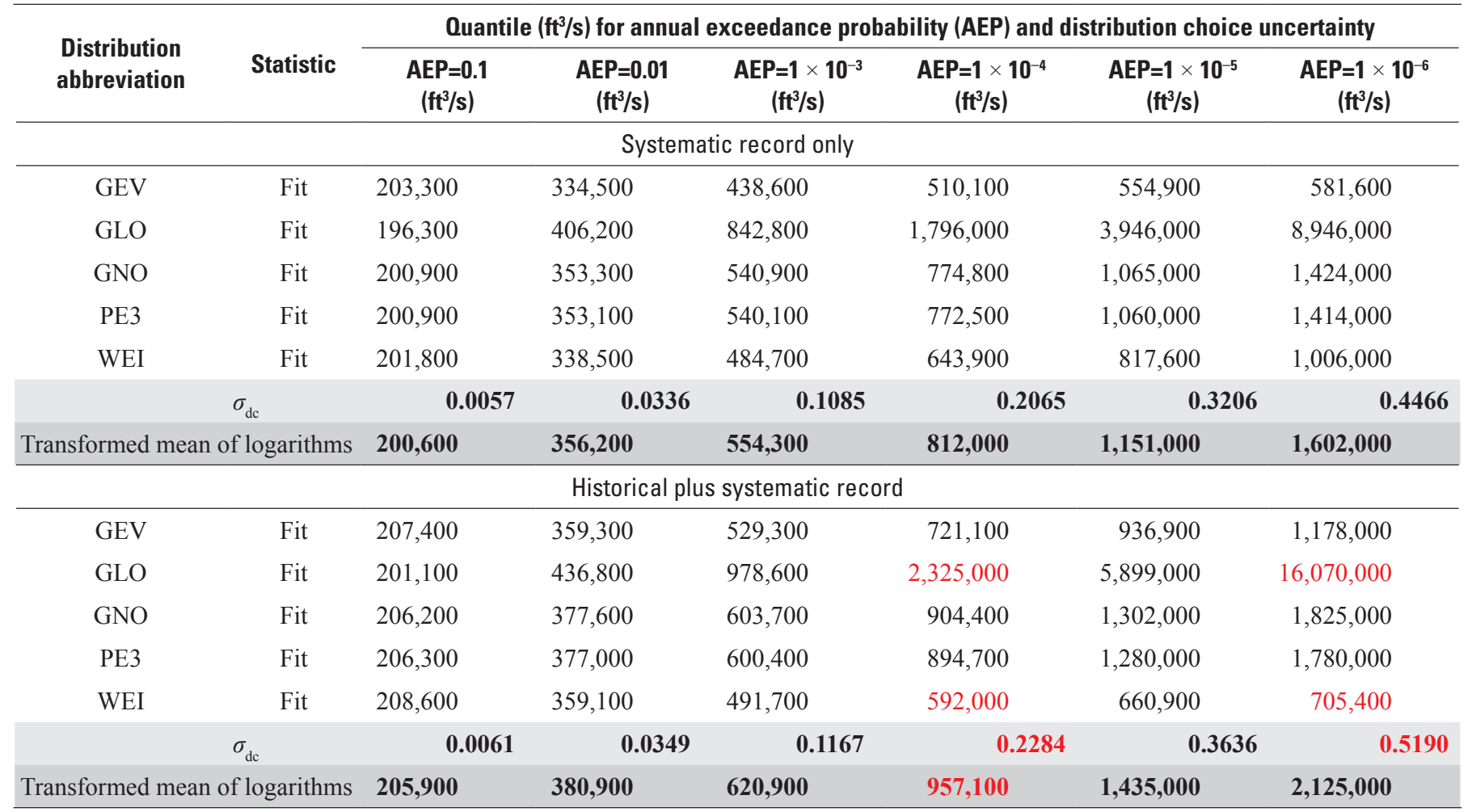

\section{L-moment Ratio Diagram}

The sample L-skew and L-kurtosis for the systematic record of the Potomac River streamgage are shown in figure 13, which depicts another L-moment ratio diagram. The results of a simulation experiment (number of simulations $=3,000$; sample size $=121$ years [systematic record]) are also shown in the figure to facilitate the exploration of the joint distribution potential between sample L-skew and L-kurtosis.

The L-skew and L-kurtosis for the Potomac River streamgage plot as a single point; however, two circles are used to show the properties of the Potomac River data (fig. 13). One circle simply represents sample L-skew for the systematic record only and the other represents the magnitude of L-skew computed for censored L-moments for the flipped data. This L-skew technically is negative and would plot on the opposite side of the vertical zero line. However, the L-skew is plotted with a sign change (to make it positive) only for ease of comparison to L-skew magnitude of the systematic data.

As with the Raritan River streamgage (fig. 10), the L-skew and L-kurtosis point for the Potomac River streamgage plots above the trajectory for the GLO in figure 13. The KAP cannot be fit to these data because the point is above the GLO. The GLO is the closest threeparameter distribution to the point, and thus, the GLO is most consistent with these data. Sample variability, however, affects the precise location of the point, because the sample L-skew and L-kurtosis are obviously dependent on the respective data.

Monte Carlo simulation can be used for evaluation outside the context of regional information, as is the case here. The simulated values through Monte Carlo simulation based on systematic record and the associated 90-percent confidence region shown in figure 13 are based on the sample variance-covariance structure (fig. $3-3$ ). The ellipse indicating the 90-percent confidence level is also shown. The GLO line passes through the points, and as a result, the GLO might be more favorable than other three-parameter distributions. The GEV, GNO, and PE3 all pass outside but the ellipse for the L-skew of the data. The frequency curves should thus show considerable similarity with each other. The trajectories for the GPA and WEI pass outside the ellipse, and as a result, these distributions are less likely to be applicable. In particular, the GPA is divergent from the simulation results and thus should show the least favorable fit to the Raritan River data. 


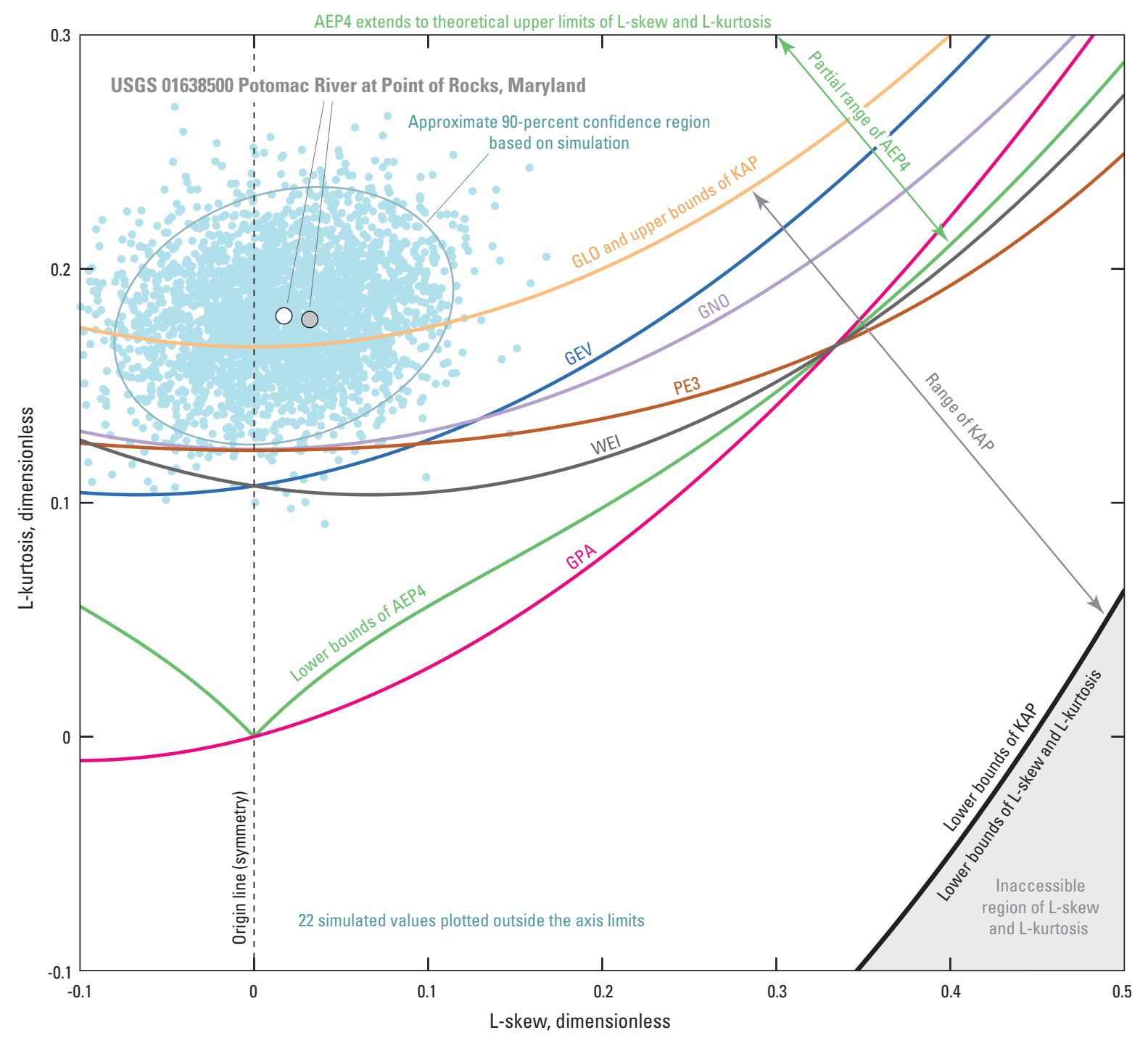

\section{EXPLANATION}

Systematic record (1895-2015) — L-moments computed for the systematic record using conventional approach

Historical record plus systematic record (1889-94 and 1895-2015) - L-moments computed for the record using a left-censored approach by censoring the indicator variable and reflection/flipping required so L-skew has been negated (plotted to the right of origin line) to be more readily compared to that for the systematic record

Simulated value based on systematic record-Sample variance-covariance matrix of L-moments used in multivariate-normal simulation of size 3,000 with some values not shown as indicated by note

USGS, U.S. Geological Survey
Distribution type
AEP4, asymmetric exponential power (four parameter)
$\mathrm{GEV}$, generalized extreme value (three parameter)
$\mathrm{GLO}$, generalized logistic (three parameter)
GNO, generalized normal (three parameter)—Also log-normal
GPA, generalized Pareto (three parameter)
KAP, Kappa (four parameter)
PE3, Pearson type III (three parameter)
WEI, Weibull (three parameter)—Also reversed GEV

Figure 13. L-skew and L-kurtosis of annual peak streamflow data for U.S. Geological Survey streamflow-gaging station 01638500 Potomac River at Point of Rocks, Maryland, and comparison to theoretical relations of numerous distributions. 


\section{Further Evaluation of Goodness-of-Fit and Uncertainties}

As noted in the "Distribution Validity and Goodness-ofFit" section, goodness-of-fit is difficult to reliably evaluate for peak-streamflow frequency. This is true because the primary interest is in the far right tail of the unknown distribution. There are no observed data available, and reliable evaluation is further confounded, because ultimately the sample sizes are too few in practical applications of low AEP. By focusing on the higher moments, the L-moment ratio diagrams are used to help address the difficulty in evaluating goodnessof-fit just described. As discussed previously, the L-moment ratio diagrams (figs. 10 and 13) allow a visual evaluation of goodness-of-fit on the premise that superior fit is achieved when the higher L-moments exhibit good fit. Achieving a close match to L-kurtosis is favorable, and much of the thinking behind this view is described by Hosking and Wallis (1997). Sampling variation, however, exists around any L-kurtosis computed from a random sample. L-moment ratio diagrams can be used for statistical inference, such as represented by the elliptical regions depicted through Monte Carlo simulation. The difference between the observed L-kurtosis of the data and the L-kurtosis for the fitted distribution is a measure of goodness-of-fit. For purposes of reference to other goodness-of-fit measures, this difference is identified in this report as "Delta L-kurtosis." Liou and others (2008) discuss goodness-of-fit in the context of L-moments.

For this study, four conventional goodness-of-

fit measures were selected, but their ability to quantify goodness-of-fit for the unobserved far right tail is unknown. Nevertheless, goodness-of-fit does inform distribution choice. The measures investigated are the Cramér-von Mises statistic (CM), Kolmogorov-Smirnov statistic (KS), Moran-Darling statistic (MD), and Akaike Information Criterion (AIC).

The CM statistic (Csörgö and Faraway, 1996; Faraway and others, 2015) is based on the integrated square distance between an empirical cumulative distribution function of the data and a fitted cumulative distribution function. The KS statistic (Hollander and Wolfe, 1973; Marsaglia and others, 2003 ) is based on the supremum (greatest lower bound) of a set of absolute differences between an empirical distribution function of the data and a fitted cumulative distribution function. The MD statistic (Cheng and Stephens, 1989) is based on the summation of logarithms of the cumulative probabilities of an ordered sample, computed through a fitted cumulative distribution function. The MD statistic naturally arises from MPS, and this statistic is closely related to the Anderson-Darling statistic (not included in this report). The AIC statistic is based on the log-likelihood of the fitted probability density function, which conveniently arises from MLE, though AIC can be computed for other fitting methods. Other factors being equal, such as sample size and number of parameters in a distribution, smaller values of CM, KS, DM, and AIC are desirable when comparing fits.
The goodness-of-fit statistics just described qualify the overall fit of a probability distribution to the bulk of the data because in practical applications of peak-streamflow frequency analyses, the true form of the parent distribution is unknown. As a result, the p-values for these statistics can be misleading in the single-sample versions of hypothesis tests involving these statistics. Thus when fit by parameters from the sample, the test statistic is nearly always smaller than the statistic for a prespecified set of parameters. For this important line of reasoning, p-values are not reported here and only the relative magnitudes of the statistics are reported and should be compared. Finally, it must be stressed that these metrics do not answer the fundamental question about whether a given fit is in fact adequate.

For the six three-parameter probability distributions and the AEP4 fit using the method of L-moments, five goodnessof-fit measures were computed and are listed in table 13 (top half). The table presents results for both the Raritan River and Potomac River streamgages. Only the systematic record for the Potomac River was used, which means that the historical information, though used for some parts of this study, was not used to compute or assess goodness-of-fit for this study. Also listed in the table (bottom half) are relative ranks of preference for distribution fit. These ranks provide the most effective means for scrutiny.

The CM, KS, DM, and AIC statistics, along with Delta L-kurtosis, all provide similar relative ranks (table 13). Rank similarity mostly reflects the fundamental fact that these statistics measure somewhat similar information. For the application here for the Potomac River data, KS does not show as much sensitivity as the others as evidenced by the ranges of ranks listed in table 13. Considering the six threeparameter distributions, the relative ranks of the CM, KS, DM, and AIC all generally indicate a favoring of the GLO, followed by the GNO, PE3, GEV, WEI, and GPA. Such ranking is thought to be consistent with visual comparison of the frequency curves to the data in figures 9 and 12. The AEP4, however, is often the second most favorable distribution, between the GLO and the GNO, which is consistent with how the AEP4 plots relative to these two distributions in figures 9 and 12.

It is notable that the first ranked distribution is the GLO for the CM, KS, DM, and AIC statistics, and the AEP4 for the Delta L-kurtosis statistic (table 13). The Delta L-kurtosis measure automatically favors the AEP4 because, of the distributions listed, only the AEP4 directly fits, that is matches, the L-kurtosis of the data. It could be reasoned by that fact alone that the AEP4 has superior fit. Each statistic is computed using all of the data values; however, the KS statistic ultimately depends only on the single largest difference between the empirical probabilities of the data and the fitted cumulative distribution. This largest value could exist in applied circumstances in the left tail of the distribution, which is not of interest in this study. 
Table 13. Goodness-of-fit statistics and ranking of selected probability distributions fit to systematic record of annual peak streamflows for U.S. Geological Survey streamflow-gaging stations 01400500 Raritan River at Manville, New Jersey and 01638500 Potomac River at Point of Rocks, Maryland.

[AEP4, four-parameter asymmetric exponential power (not to be confused with AEP, which is used elsewhere in this report for annual exceedance probability); GEV, generalized extreme value; GLO, generalized logistic; GNO, generalized normal; GPA, generalized Pareto; PE3, Pearson type III; WEI, Weibull (reversed GEV); CDF, cumulative distribution function; PDF, probability density function; QDF, quantile distribution function. Delta L-kurtosis represents the difference between the observed L-kurtosis of the data and that for the fitted distribution and "zero" is deliberate and indicates that AEP4 is fit to L-kurtosis. --, not applicable because of degeneration in underlying mathematics caused by finite support of the distribution. Ties between statistics are shown as a range (" $1-2$ "). Rank among statistics for a given test is determined by ascending sort, because the smallest numerical value of each of the tests is favorable]

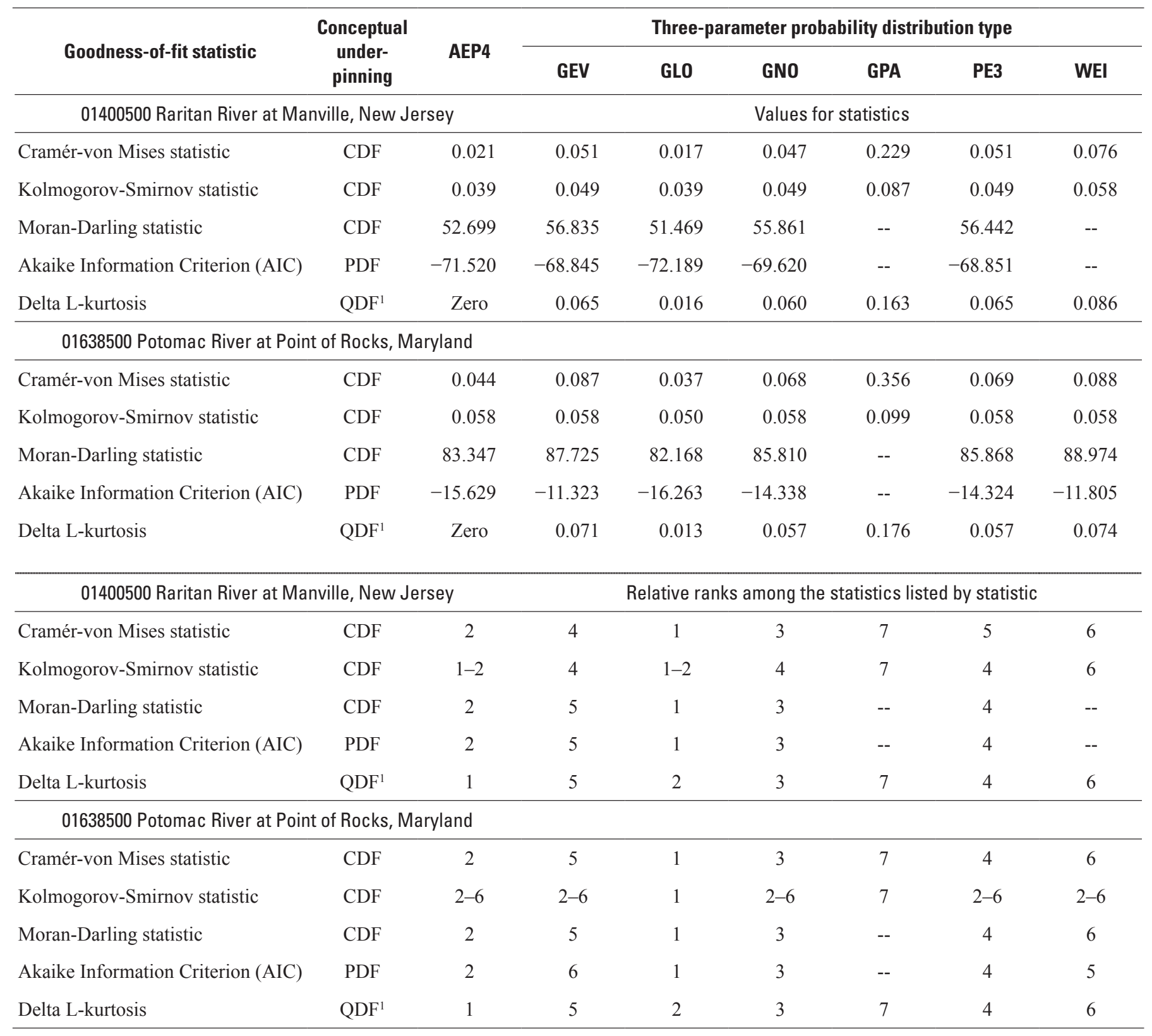

${ }^{1}$ The L-moments are defined in terms of the quantile (distribution) function of the probability distribution. A three-parameter distribution is fit through to the third L-moment where L-kurtosis is the next higher measure of distributional geometry and the Delta L-kurtosis represents such departure of sequentially higher fit. 
Among three-parameter distributions, the GLO provides the best fit to data from both streamgages (table 13). The marked upward curvature of the GLO indicates that it estimates much larger streamflows for very low AEP than estimated by the other distributions. The GLO's $\sigma_{\mathrm{s}}$ (sampling uncertainty, tables 5 and 10) is the largest among the distributions for AEPs less than 0.01. The $\sigma_{\mathrm{dc}}$ (distribution choice uncertainty, tables 7 and 12) is smaller than $\sigma_{\mathrm{s}}$ if the unknown true distribution is close to the GLO, but as a general rule, scrutiny of $\sigma_{\mathrm{dc}}$ and $\sigma_{\mathrm{s}}$ in tabulated results shows that $\sigma_{\mathrm{dc}}$ is the largest of the two for about $10^{-3}$ to $10^{-4} \mathrm{AEP}$ and remains so for lower AEP. Hence for very low AEP, it is likely that decisions associated with probability model selection constitute greater uncertainty than that associated with the data sample.

\section{Alternative and Visual Representation of Quantile Uncertainty}

Alternative and visual representations of quantile uncertainty for both streamgages are presented in this section. For simplification, only the systematic records for the Raritan River and Potomac River streamgages were used.

Confidence limits, as well as the standard deviation of a quantile, are a means to express sampling uncertainty (tables 5,6,10,11). These confidence limits can be considered a quantification of uncertainty in conjunction with the standard deviation of the quantile distribution $\left(\sigma_{\mathrm{s}}\right.$ in tables $5,6,10$, and 11). Considering only the method of L-moments, a reminder is provided that the distribution-free variance-covariance matrix (fig. 3-3) of the sample L-moments was used to repeatedly simulate L-moments. In succession for each simulation, the respective distribution was fit and quantiles for selected AEPs computed. The confidence limits estimated for each AEP were estimated from the distribution of the simulated quantiles. This technique is computationally complex.

A less complicated method was used to express sampling uncertainty in a semi-quantitative manner. The method is considered semi-quantitative, because box plots were used to depict variation in the distribution of the 0.01 and $0.001 \mathrm{AEP}$ quantiles. This less complicated method for depicting variation was selected because of algorithmic efficiency to explore potential differences or similarities in distribution between the parameter estimation methods of L-moments (LMR), maximum likelihood (MLE), and maximum product of spacings (MPS). (Reiteration of acronyms and the specific use of LMR for purposes here is deliberate.)

The less complicated method is based on the premise that the LMR (or MLE or MPS) of the systematic record can be used to compute an appropriate parent probability distribution for a given distribution. A logarithmic transformation of the data was used to be consistent throughout this report. Next, a parent distribution was used for Monte Carlo simulation for sample sizes equal to that of the systematic record for the streamgage to generate many repeated random samples (the number of simulations was set to 2,000 to be suitably large enough). For each of these random samples, LMR (or MLE or MPS) was used to fit a chosen distribution. From many fits of the chosen distribution, up to 2,000 quantile estimates at the $0.01 \mathrm{AEP}$ and 0.001 AEP were made. These estimates for a given method, distribution, and AEP were then used to create a box plot showing the distribution of these simulated quantiles.

\section{Raritan River Streamgage}

Box plots of the simulated distribution of 2,000 random samples were created by distribution type for the six threeparameter distributions and are shown in figure 14 for the 0.01 and $0.001 \mathrm{AEP}$ quantiles. These quantiles were retransformed to units of volume per time and the box plots computed. The simulation size is shown as 2,000 for each of the box plots, because the L-moments guarantee a fit to these distributions. The mean and median of the simulated quantiles are shown in order to highlight central tendency. These two statistics are generally close to those listed for the fit in table 5 .

Considerable differences in the uncertainties expressed through the box plots between distributions are shown in figure 14. In particular, the GLO distribution shows the widest variation, which is consistent with the larger L-kurtosis of this distribution for a given L-skew than that of the other distributions. Visually, this means that more frequently in the simulation, the right tail of the GLO bends upwards toward larger streamflow values than for the other five distributions. The GPA distribution conversely shows the narrowest variation, which is consistent with the smallest L-kurtosis and flattest right tail (upper limit of fit as AEP diminishes). Lastly, it is evident that the variation of all the boxes increases (vertically lengthens) for 0.001 AEP relative to $0.01 \mathrm{AEP}$.

The box plots in figure 14 semi-quantitatively show the uncertainty by distribution using L-moments. A comparison between parameter estimation methods was made using the same Monte Carlo simulation framework described in relation to figure 14 . For parameter estimation comparison, the GEV, GNO, and PE3 distributions were chosen, and the methods of LMR, MLE, and MPS were used. Box plots for the simulations are shown in figure 15. The simulation counts above the box plots are not all equal to 2,000 because MLE and MPS, being numerical optimization techniques, can fail occasionally for technically complex reasons. Results for both 0.01 and $0.001 \mathrm{AEP}$ are shown. A potentially striking result is the comparative insensitivity of the quantiles to the choice of parameter estimation method. The sample size is large, however, being 103 years of record for this study, so performance benefits of L-moments and MPS in small samples relative to MLE are small. Close inspection suggests that MPS estimates slightly larger quantiles across the board than LMR and MLE, whose boxes appear quite similar for a given distribution. 


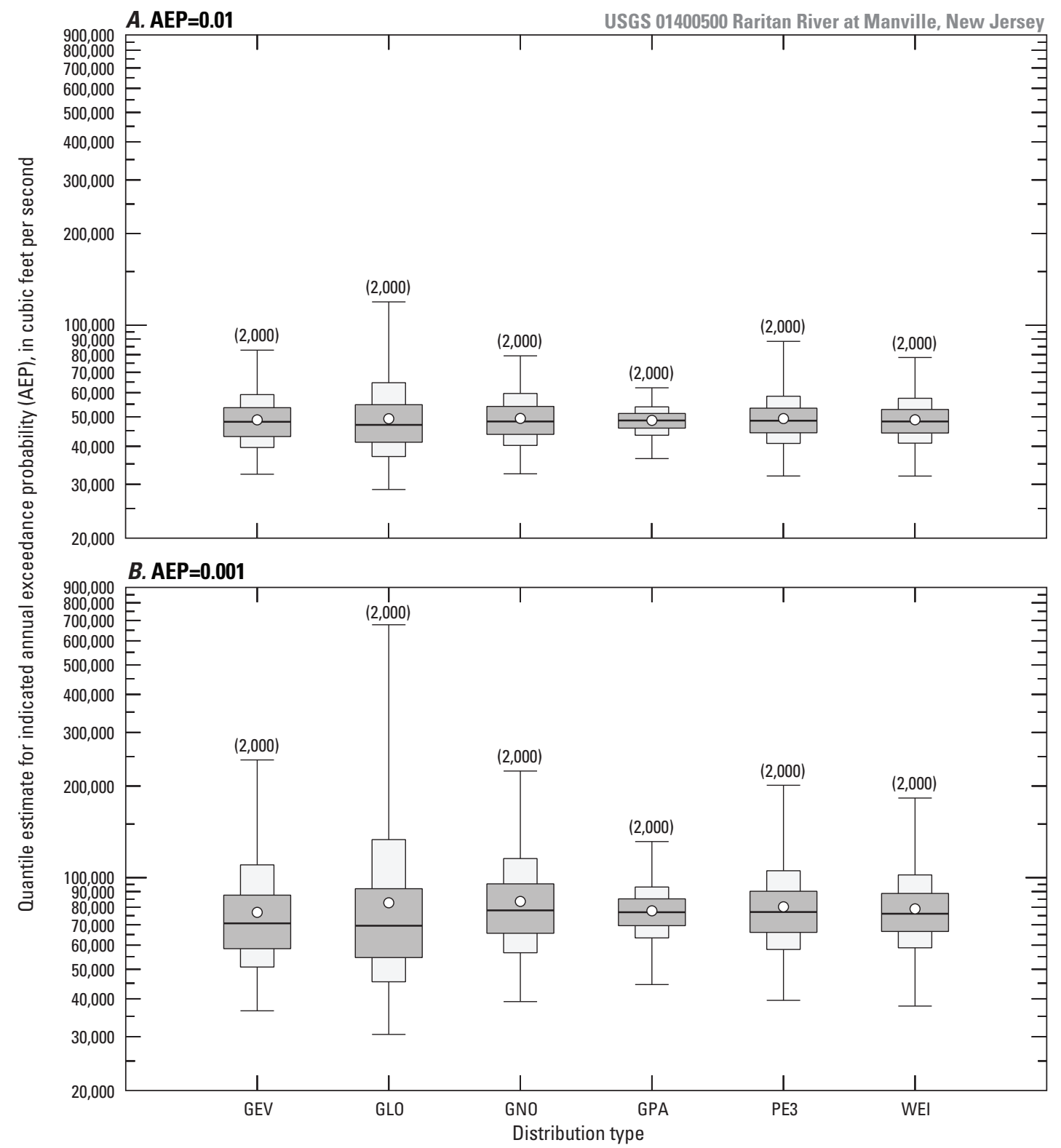

EXPLANATION

Distribution of quantile estimates through Monte Carlo simulation-The Monte Carlo simulation was based on a "parent distribution" unique to each distribution type fit by the method of L-moments

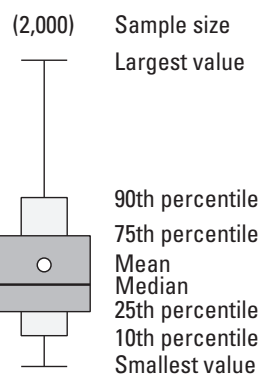

USGS, U.S. Geological Survey
Distribution type

GEV, generalized extreme value (three parameter)

GLO, generalized logistic (three parameter)

GNO, generalized normal (three parameter)-Also log-normal GPA, generalized Pareto (three parameter)

PE3, Pearson type III (three parameter)

WEI, Weibull (three parameter)—Also reversed GEV

Figure 14. Quantile estimates through Monte Carlo simulation among six three-parameter distributions by the method of L-moments for systematic record for U.S. Geological Survey streamflow-gaging station 01400500 Raritan River at Manville, New Jersey. 


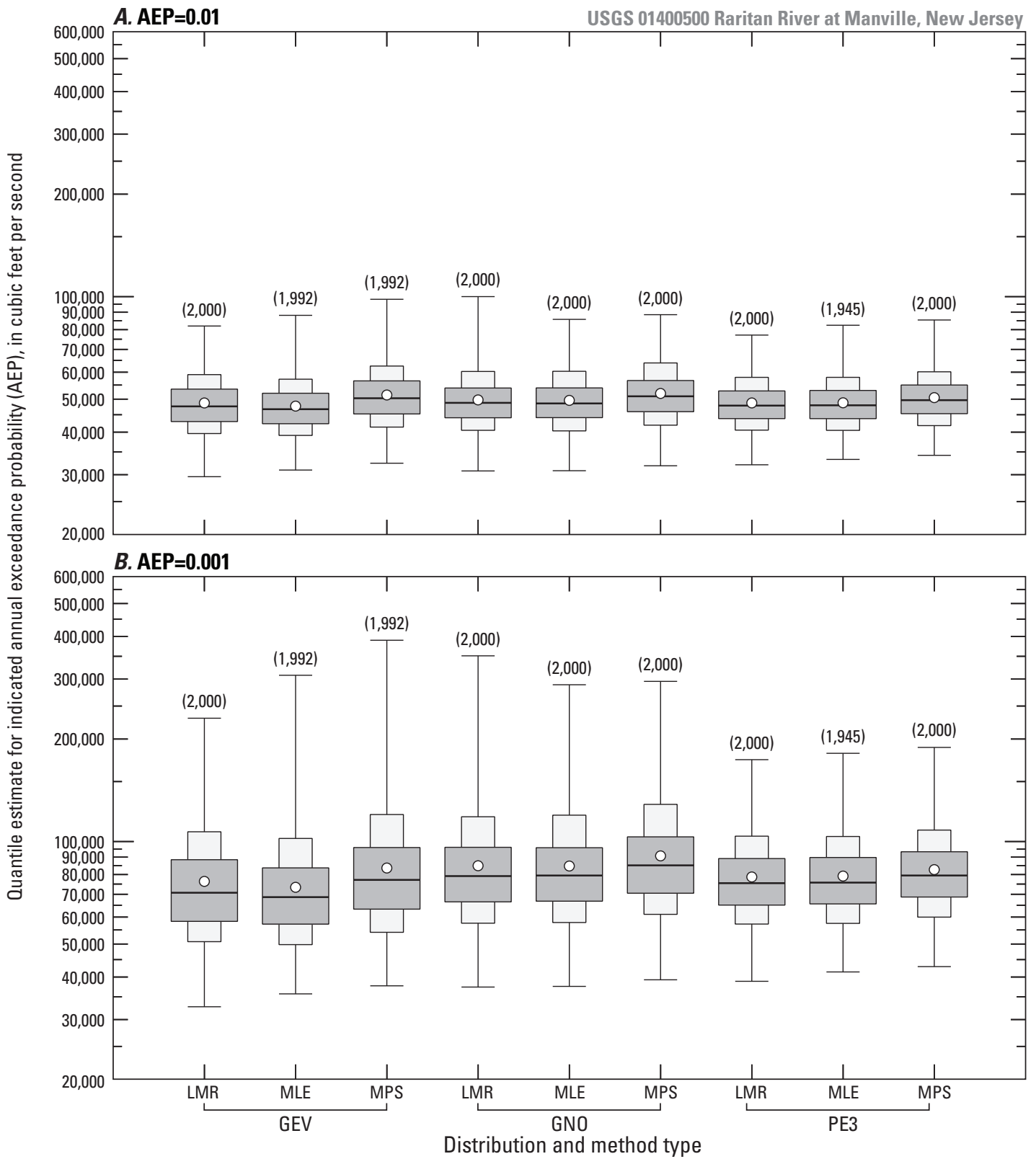

EXPLANATION

Distribution of quantile estimates through Monte Carlo simulation-Sample sizes less than 2,000 indicate a small percentage of failures in the optimization algorithm related to degeneracy of underlying mathematics. The Monte Carlo simulation was based on a "parent distribution" unique to each distribution type fit by the method of L-moments

$(2,000) \quad$ Sample size

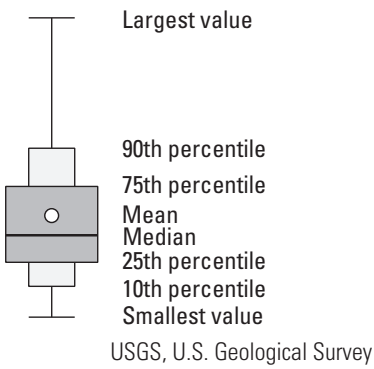

Distribution type

GEV, generalized extreme value (three parameter) GNO, generalized normal (three parameter)

PE3, Pearson type III (three parameter)

Method type

LMR, L-moments

MLE, maximum likelihood

MPS, maximum product of spacings

Figure 15. Quantile estimates through Monte Carlo simulation among three three-parameter distributions and three methods of parameter estimation for systematic record for U.S. Geological Survey streamflow-gaging station 01400500 Raritan River at Manville, New Jersey. 


\section{Potomac River Streamgage}

Box plots of the simulated distribution for the Potomac River streamgage are shown in figure 16. As a reminder, the mean and median of the simulated quantiles are generally similar to those listed for the fit in table 10. The similarity shows the simulation is consistent with the data analysis. Considerable differences exist in the uncertainties expressed through the box plots between distributions. In particular, the GLO distribution shows the widest variation, which is consistent with the larger L-kurtosis of this distribution for a given L-skew than the other distributions. Visually, this means that more frequently in the simulation, the right tail of the GLO bends upwards toward larger streamflow values than for the other five distributions. The GPA distribution conversely shows the narrowest variation, which is consistent with the smallest L-kurtosis and flattest right tail (upper limit of fit as AEP diminishes). Lastly, it is evident that the variation of all the boxes increases (vertically lengthens) for 0.001 AEP relative to $0.01 \mathrm{AEP}$.

A comparison between parameter estimation methods using the same Monte Carlo simulation framework as for the Raritan River box plots (fig. 15) is shown for the Potomac River streamgage in figure 17. Again, the simulation counts above the box plots are not all equal to 2,000 because MLE and MPS can fail occasionally, and again, results for both 0.01 and 0.001 AEP are shown. A potentially striking result is the comparative insensitivity of the quantiles to the choice of parameter estimation method. The sample size is large, however, being 121 years of record for this study, so performance benefits of L-moments and MPS in small samples relative to MLE are small. Close inspection suggests that MPS estimates slightly larger quantiles across the board than LMR and MLE, whose boxes appear quite similar for a given distribution.

\section{Further Considerations}

This section discusses examples of analyst end-products used to estimate at-site peak-streamflow frequency for very low AEP. Peak-streamflow frequency analysis for a very low AEP requires both the estimate as well as the associated uncertainties. Distribution choice uncertainty is abbreviated as $\sigma_{\mathrm{dc}}$, and sampling uncertainty is abbreviated as $\sigma_{\mathrm{s}}$. Assuming the generalized logistic distribution (GLO) is singularly the most applicable (best fit) three-parameter distribution for the data at both streamgages, estimates for the $10^{-4}$ AEP streamflow based on the method of L-moments can be stated as follows: (1) "For the systematic record at Raritan River at Manville, the $10^{-4}$ AEP streamflow estimate based on the GLO distribution is $373,600 \mathrm{ft}^{3} / \mathrm{s}$ (90-percent confidence interval 103,600 to $2,793,000 \mathrm{ft}^{3} / \mathrm{s}$ based on $\sigma_{\mathrm{s}}=0.4423 \log 10$ ) with $\sigma_{\mathrm{dc}}=0.2497 \log 10$ "; and (2) "For the systematic and historical record at Potomac River at Point of Rocks, the $10^{-4}$ AEP streamflow estimate based on the GLO distribution is $2,325,000 \mathrm{ft}^{3} / \mathrm{s}$ (90-percent confidence interval 795,100 to
$10,140,000 \mathrm{ft}^{3} / \mathrm{s}$ based on $\left.\sigma_{\mathrm{s}}=0.3338 \log 10\right)$ with $\sigma_{\mathrm{dc}}=0.2284$ $\log 10$." The numerical values shown are from tables 5 and 7 (Raritan River) and tables 10 and 12 (Potomac River).

The remaining discussion is not all encompassing but identifies topics considered especially applicable to the documentation of uncertainty associated with the estimation of events of low AEP for which virtually no information exists.

Quantile Dependency — An almost universal problem in the estimation of peak-streamflow frequency for low AEP is an incomplete understanding of the processes used to determine the magnitude and shape of the right tail. This is not a new observation and was certainly clear to the National Research Council (1988). Further, some processes potentially affecting the tail may not be evident and thus not evident in the data because of insufficient record length; such cases are a form of mixed population effects. Wang and Li (2016, p. 315) state, "To estimate extreme conditional quantiles in the very far tails [low AEP] with few or no observations available, additional conditions or models for the tails are needed." Wang and $\mathrm{Li}$ (2016) provide a contemporaneous summary of the various methods of quantile dependency analysis, including quantile regression. Succinctly, Wang and Li (2016) consider what causative variables or conditions affect the slope and shape of the right tail. Many examples exist.

For example, is the right tail directly caused by tropical storm systems or in other regions of the United States rainon-snow events (Cohen and others, 2015). Another for the western United States is the impact of atmospheric rivers on extreme quantiles (Barth and others, 2016). As another example, under physically applicable circumstances, does storage of runoff volume in very large floodplains cause a near finite upper limit to instantaneous peak streamflow? This question implies a contrast to the continued growth by some distributions, such as the GLO, shown in this study. An alternative approach for examining tail dependency might be in the form of generalized additive models for location, scale, and shape (GAMLSS; Rigby and Stasinopoulos, 2005; Stasinopoulos and others, 2016) using combinations of predictor variables (covariates) including those such as month of annual peak, climate indices, or other potentially statistically significant predictor variables or bivariate copulas (Nelsen, 2006; Salvadori and others, 2007).

Parameter Estimation-Different parameter estimation methods exist, and four are used in this report. In practical applications, it is not always clear whether a single method should be preferred over all others. Whereas uncertainty about parameter estimation methods did not appear to be as dominant as distribution choice uncertainty in this study, the use of multiple parameter estimation methods does have the obvious potential to provide documentation of a component of epistemic uncertainty. The model itself is dependent on the methods chosen for parameter estimation. Perhaps in practical applications in which nonstandard peak streamflow information is not used, the methods of EMA (if extended to more three-parameter distributions than the PE3), L-moments (or variants), MLE, and MPS could all be used. 


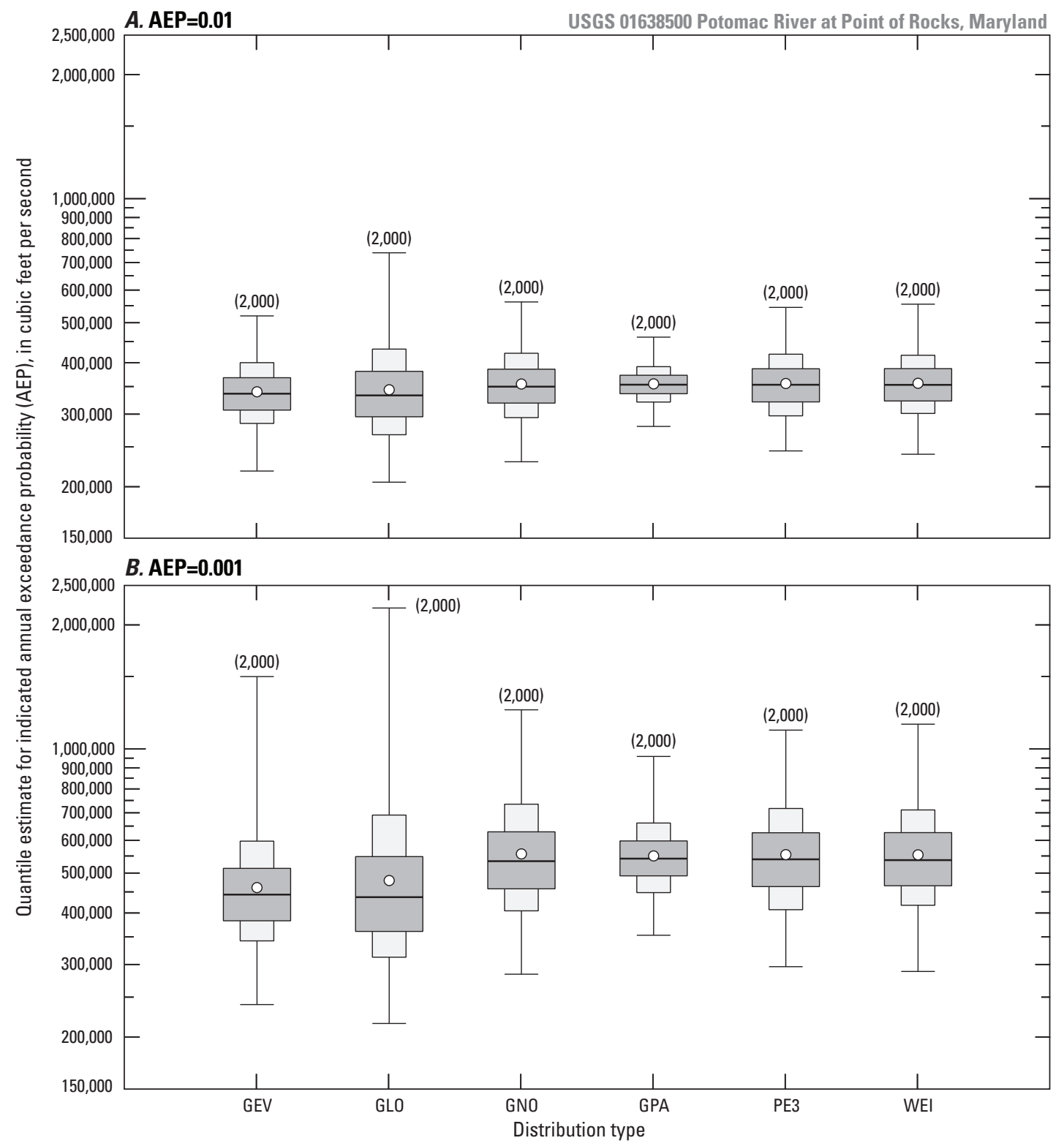

EXPLANATION

Distribution of quantile estimates through Monte Carlo simulation-The Monte Carlo simulation was based on a "parent distribution" unique to each distribution type fit by the method of L-moments

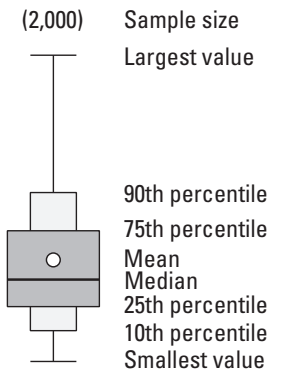

USGS, U.S. Geological Survey

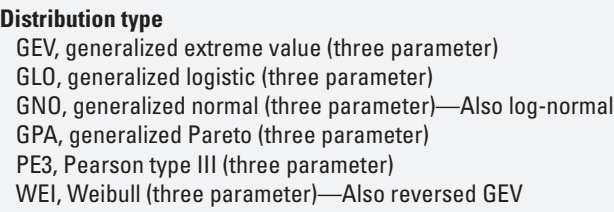

Figure 16. Quantile estimates through Monte Carlo simulation among six three-parameter distributions by the method of L-moments for systematic record for U.S. Geological Survey streamflow-gaging station 01638500 Potomac River at Point of Rocks, Maryland, using systematic record only. 


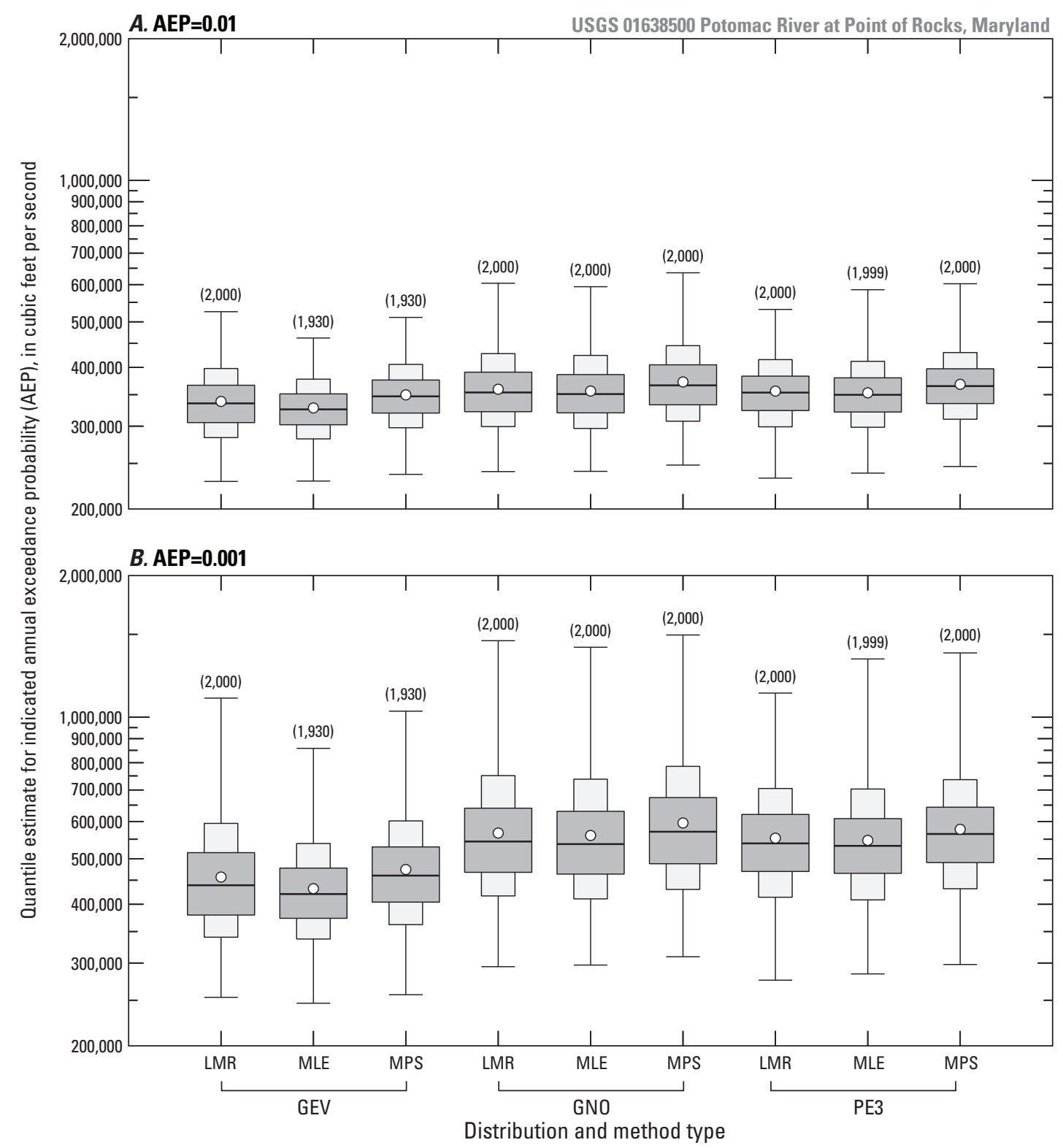

EXPLANATION

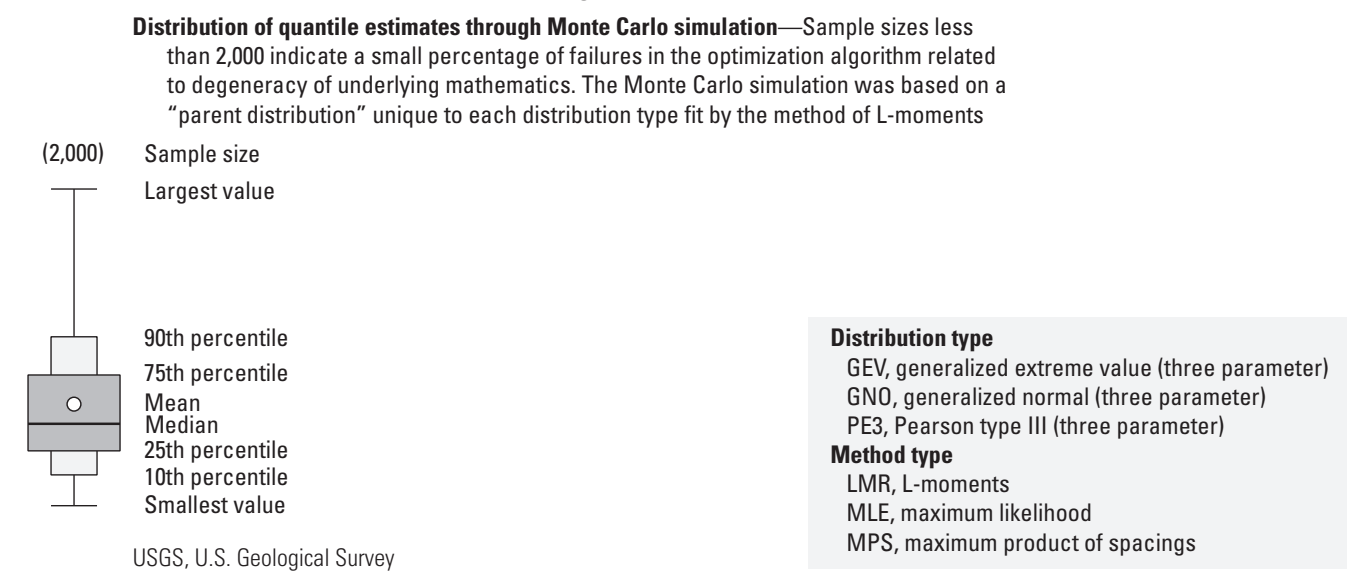

Figure 17. Quantile estimates through Monte Carlo simulation among three three-parameter distributions and three methods of parameter estimation for systematic record for U.S. Geological Survey streamflow-gaging station 01638500 Potomac River at Point of Rocks, Maryland. 
Regional Information - Regional information is a conceptual and practical means to incorporate or add information to the problem of peak-streamflow frequency estimation. Perhaps most often information about skewness is added from regional studies. Potentially higher moments could also be regionalized, which would have a benefit towards identification of more preferential distributions than other distributions for purposes of very low AEP estimation. Regional or generalized skew (IACWD, 1982) is a widely known conceptual example. To expand knowledge of distribution choice, regional study of L-skew and more importantly L-kurtosis could be highly informative in the context of this study. Regional information also can be used to extend or further interpret peak streamflow data for a given USGS streamgage. Other regional information could inform analyses of quantile dependency and constrain the development of mixed population models (Barth and others, 2016).

Physical Processes and Potential ConstraintsIncluding confidence limits as well, the supports of positively skewed distributions tend to have effectively infinite upper bounds. Moreover, even negatively skewed distributions can have asymptotic upper limits so large that such estimates might conflict with physical (deterministic) constraints of instantaneous peak streamflow for some riverine settings. Another potentially open problem is how the probable maximum flood (Stedinger and others, 1993, p. 9.37-9.38), which is the result of a deterministic analysis, can be used to inform distal tail behavior of probability distributions to provide a type of holistic perspective.

Asymmetric Exponential Power and Kappa Distribution Mixture-For this study and the data used in it, the AEP4 and the WAK are the only distributions considered that simultaneously matched both the L-skew and L-kurtosis of the data. Hence, both distributions provided a higher moment fit than any of the three-parameter distributions for conditions that a sufficient sample size (not judged for this study) is available for fourth-moment estimation. The AEP4 has lower L-kurtosis bounds (fig. 3-5) that might be too close to potential regions of L-skew and L-kurtosis for universal application within annual peak streamflow (logarithmic as well as untransformed) analyses, although this was not observed in this study. The KAP exists for L-kurtosis below the AEP4, but the AEP4 exists for L-kurtosis above the KAP (figs. 10, 13, and 3-5). Asquith (2014, p. 955) makes "a proposal $* * *$ for AEP4 implementation in conjunction with the [four-parameter KAP] distribution to create a mixeddistribution framework encompassing the [entire] joint L-skew and L-kurtosis domains" for which a proration between distribution form in the shared region (Asquith, 2014, fig. 6) could be made. The proration could be based on L-kurtosis as an overlap percentage between the distributions, and the quantile functions of separately fit AEP4 and KAP and mixed by a prorated weight factor.

In conclusion as this study shows, the estimation of at-site peak-streamflow frequency for very low AEP is a profoundly difficult problem. A broad computational and statistical skill set is required to address or discern the profoundly complex details, such as parameter estimation and multiple probability distributions. Estimation of very low AEPs is complicated further because suboptimal circumstances exist in the presence of tail estimates for which extremely limited information is available to analysts. That is, event rarity may be so extreme that the actual presence of such events in observational datasets will be exceedingly small. The results generally show that distribution choice uncertainty is larger than sampling uncertainty for very low AEP values.

\section{Summary}

The U.S. Geological Survey (USGS), in cooperation with the U.S. Nuclear Regulatory Commission, has investigated probabilistic flood hazard assessments using a statistical perspective with intent to provide guidance for very low annual exceedance probability (exceptionally rare event) estimation of peak-streamflow frequency and corresponding uncertainty quantification. This report serves as a resource to Nuclear Regulatory Commission (NRC) technical decisionmakers, collaborators, and other interested parties in the study of the exposure of critical infrastructure, such as nuclear power plant sites, to flood hazards in the United States. Probabilistic flood-hazard assessment is inherently complex and is but one part of multidisciplinary risk assessment and management for critical infrastructure. For the purposes of this study, critical infrastructure is defined as infrastructure having components of very large capital investment and (or) substantial risk to public safety as a result of rare hydrologic circumstances. Such infrastructure includes nuclear power plants.

The typical hazard level or annual exceedance probability (AEP) for probabilistic flood-hazard assessments is determined in the right tail of a probability distribution. Especially important for critical infrastructure are annual return intervals associated with very low AEP values that far exceed the length of observational records at individual sites or even within regions of interest. The term "very low AEP" implies exceptionally rare events defined as those having AEPs less than about 0.001 (or $1 \times 10^{-3}$ in scientific notation or for brevity $10^{-3}$ ). When assessments are conducted at or near streamflow-gaging stations ("streamgages" hereafter), the observational record of annual peak streamflow is the fundamental information used for the analysis. This type of analysis is termed an "at-site" analysis; that is, analysis conducted based on data for a specific streamgaging site. Annual data for these analyses are most commonly associated with USGS streamgages. Information about streamgaging methods and the USGS National Water Information System (NWIS) database is provided in an appendix to this report.

Annual peak streamflow data for the USGS streamgage 01400500 Raritan River at Manville, New Jersey, and 01638500 Potomac River at Point of Rocks, Maryland, are 
used in this report to illustrate methods for estimating very low AEP floods and their uncertainty. The Raritan River streamgage is located about 33 miles west southwest of the New York metropolitan area and has a watershed drainage area of about 490 square miles. The period of record for this study of the Raritan River streamgage is water years 19042014, though with gaps in the record from 1907-1908 and 1916-1921. The Potomac River streamgage is located about 40 miles northwest of Washington, D.C., has a watershed drainage area of about 9,651 square miles, and the systematic record of peak streamflow is available for water years 1895-2015.

Peak-streamflow frequency analyses are a type of statistical analysis used to estimate the peak-streamflow frequency curve (commonly also called the flood-frequency curve). The frequency curve can be represented in two primary ways. First, the frequency curve can be represented by an empirical distribution function that is often approximated using Hirsch-Stedinger or other plotting positions. Second, parametric methods can be used to fit one or more probability distributions to the data. The empirical distributions of the annual peak streamflow data for the Raritan River and Potomac River streamgages are shown.

Parametric methods are used to fit data to a specified statistical distribution (for example, the Pearson type III distribution or the generalized extreme value distribution). The parametric approach will not model all of the variability observed in the data, but if the distribution is suitable enough, it provides for extrapolation beyond the exceedance probabilities represented by the data.

The general purpose for fitting a probability distribution is to represent the magnitude of floods across a wide spread of AEP values, and a reasonable probability distribution is especially important when extrapolations of the fitted frequency curve are to be made. Several alternative and complementary methods to fit probability distributions include product moments, maximum likelihood (MLE), expected moments algorithm (EMA), L-moments, and maximum product of spacings (MPS).

Technically complex mathematics applicable to this study are provided in thematic appendixes. A brief review of product moments and a similar primer on L-moments are provided. MLE and MPS are described, along with goodnessof-fit statistics. The probability distributions applicable to this study in the context of L-moments are also described. The appendixes provide succinct mathematics through both independent and co-dependent figures.

The EMA is an iterative method of solving for the product moments and has been fully developed for the Pearson type III distribution. Extension of EMA, however, to fit other distributions has not yet been fully developed. Thus, the method of L-moments was chosen for primary emphasis, in part, because extensive though technically demanding code for scripting parallel analyses is available to expand analyses to other distributions beyond the Pearson type III distribution, and such is the case for MLE and MPS.
Two core types of uncertainty in peak-streamflow frequency analyses are considered for this study. The first uncertainty is often referred to as either epistemic or reducible, whereas the second uncertainty is often referred as aleatoric, irreducible, or stochastic. Epistemic uncertainty is the uncertainty in not knowing the optimal model for probabilistic prediction, and thus is related to knowledge of natural and physical world processes. Aleatory uncertainty is that associated with inherent random chance (hence the adjectives "irreducible" or "stochastic"). This second uncertainty is dependent on the random sample itself and on the choice of the event of interest (hazard level). An extensive body of literature concerns this uncertainty, owing in part to conveniences of mathematical tractability and accessibility of the designed statistical simulation (Monte Carlo). Both variances are themselves dependent on selected AEPs and both increase as AEP decreases.

Numerous probability distributions are considered in this study. The three-parameter distributions considered are generalized extreme value (GEV), generalized logistic (GLO), generalized normal (GNO), generalized Pareto (GPA), Pearson type III (PE3), and Weibull (WEI). Other, higher-parameter distributions considered are the asymmetric exponential power (AEP4, four parameter), Kappa (KAP, four parameter), and Wakeby (WAK, five parameter). The analyses are exclusively based on base-10 logarithms of annual peak streamflow data, and as a result, the adjective "log" as in the "log-Pearson type III" is to be inferred as an encompassing adjective of all distribution references.

This study focuses primarily on parameter estimation using product moments (EMA, USGS-PeakFQ software) and L-moments, and frequency curves for the distributions are depicted for both of the streamgages. L-moments are based on linear combinations of differences of the expectations of order statistics as opposed to the product moments, which are based on powers (exponents) of differences.

The two additional methods of parameter estimation used in this study of MLE and MPS are closely related to goodnessof-fit metrics. Succinctly, MLE estimates the parameters of a distribution by maximizing the summation of logarithms of the probability density computed for each of the data values. MPS is similar in that maximizing a summation also is involved, but for MPS, the quantities summed are the successive differences of probability estimates through the cumulative distribution function for each of the data values.

Distribution selection is a difficult and critically important component of parametric frequency analyses. The problem is compounded when events far into the right tail of a distribution are needed, and in practice, such information is extremely scarce. One method for assessing distribution validity is the goodness-of-fit test. Goodness-of-fit describes the extent to which observed data match the values expected by theory. In this study, a fitted distribution of a given form (distribution choice) serves as the theory. Goodness-of-fit in the context of peak-streamflow frequency analyses can be qualitative and guided by expert opinion using methods such 
as graphical visualization when the dimension of the problem is small (univariate). Goodness-of-fit can also be evaluated using a quantitative reference frame and can be based on one or more numerical measures of fit.

Probability distributions are distinguished according to their formal mathematical definition, moments, and respective parameter values. Distributions, as a general result, have specific and typically unique intrarelations (that is within the distribution) between moments and parameters. The intramoment relations between the moments of a distribution (theoretical or sample) have been considered as a means to judge the potential suitability of candidate distributions. Because L-moments are a convenient and powerful tool for discriminating distribution shape, L-moment ratio diagrams in turn are useful for discriminating between distributional forms.

The results are shown in parallel for each streamgage within which the peak-streamflow frequency curves for the four multiple parameter estimation methods for the PE3 are shown. These curves are followed by a review of the multiple frequency curves restricted to PE3-EMA as well as the PE3 and other distributions fit by the method of L-moments. Tables specific to each streamgage of numerical results including quantiles, 90-percent confidence limits, distribution choice uncertainty, and sampling uncertainty are identified. L-moment ratio diagrams specific to each streamgage are shown and attendant discussion concerning distribution validity is made. Two further sections are given concerning (1) goodness-of-fit using several approaches in an effort to semi-quantify and rank relative fits for the distributions, and (2) the distribution of the 0.01 and 0.001 AEP quantiles by both method and distribution using Monte Carlo simulation. General discussion describing further considerations of estimation of at-site peak-streamflow frequency for low AEP concludes.

Peak-streamflow frequency analysis for a very low AEP requires both the estimate as well as the associated uncertainties. Distribution choice uncertainty is abbreviated as $\sigma_{\mathrm{dc}}$, and sampling uncertainty is abbreviated as $\sigma_{\mathrm{s}}$. Assuming GLO is singularly the most applicable (best fit) three-parameter distribution for the data at both streamgages, estimates for the $10^{-4} \mathrm{AEP}$ streamflow based on the method of L-moments can be stated as follows: (1) "For the systematic record at Raritan River at Manville, the $10^{-4}$ AEP streamflow estimate based on the GLO distribution is 373,600 cubic feet per second $\left(\mathrm{ft}^{3} / \mathrm{s}\right)(90$-percent confidence interval 103,600 to $2,793,000 \mathrm{ft}^{3} / \mathrm{s}$ based on $\left.\sigma_{\mathrm{s}}=0.4423 \log 10\right)$ with $\sigma_{\mathrm{dc}}=0.2497$ $\log 10$ "; and (2) "For the systematic and historical record at Potomac River at Point of Rocks, the $10^{-4}$ AEP streamflow estimate based on the GLO distribution is $2,325,000 \mathrm{ft}^{3} / \mathrm{s}$ (90-percent confidence interval 795,100 to $10,140,000 \mathrm{ft}^{3} / \mathrm{s}$ based on $\sigma_{\mathrm{s}}=0.3338 \log 10$ ) with $\sigma_{\mathrm{dc}}=0.2284 \log 10$." The $\sigma_{\mathrm{dc}}$ is smaller than $\sigma_{\mathrm{s}}$ if the unknown true distribution is close to the GLO, but as a general rule scrutiny of $\sigma_{\mathrm{dc}}$ and $\sigma_{\mathrm{s}}$ in tabulated results shows that $\sigma_{\mathrm{dc}}$ is the largest of the two for about $10^{-3}$ AEP to about $10^{-4}$ AEP and remains so for lower
AEP. Hence for very low AEP, it is likely that decisions on probability model constitute larger uncertainty than the uncertainty stemming from the data sample.

The estimation of at-site peak-streamflow frequency for very low AEP is a difficult problem, as this study demonstrates. A broad computational and statistical skill set is required to address or discern the profoundly complex details, such as parameter estimation and multiple probability distributions. Estimation of very low AEPs is complicated further because suboptimal circumstances exist in the presence of tail estimates for which limited information is available to the analyst. That is, event rarity may be so extreme that the actual presence of such events in observational datasets will be extremely unusual. The results generally show that distribution choice uncertainty is considerably larger than sampling uncertainty for very low AEP values.

\section{Selected References}

Anderson, T.W., 1962, On the distribution of the two-sample Cramér-von Mises Criterion: Annals of Mathematical Statistics. Institute of Mathematical Statistics: v. 33, no. 3, p. $1148-1159$.

Apipattanavis, Somkiat, Rajagopalan, Balaji, and Lall, Upmanu, 2010, Local polynomial based flood frequency estimator for mixed population: Journal of Hydrologic Engineering, v. 15, no. 9, p. 1-12.

Asquith, W.H., 2007, L-moments and TL-moments of the generalized lambda distribution: Computational Statistics and Data Analysis, v. 51, no. 9, p. 4484-4496.

Asquith, W.H., 2011a, Distributional analysis with L-moment statistics using the R environment for statistical computing: Texas Tech University, Ph.D. dissertation, accessed June 3, 2016, at https://ttu-ir.tdl.org/ttu-ir/handle/2346/ETD-

TTU-2011-05-1319.

Asquith, W.H., 2011b, Distributional analysis with L-moment statistics using the R environment for statistical computing: CreateSpace ISBN 978-1463508418. [Print-on-demand; reprinting of Asquith, 2011a, with errata.]

Asquith, W.H., 2014, Parameter estimation for the 4-parameter asymmetric exponential power distribution by the method of L-moments using R: Computational Statistics \& Data Analysis, v. 71, p. 955-970.

Asquith, W.H., 2016, lmomco-L-moments, trimmed L-moments, L-comoments, censored L-moments, and many distributions: R package version 2.2.5 (September 9, 2016), accessed February 21, 2017, at http://cran.r-project.org/web/ packages/lmomco/index.html. 
Asquith, W.H., and Roussel, M.C., 2004, Atlas of depthduration frequency of precipitation annual maxima for Texas: U.S. Geological Survey Scientific Investigations Report 2004-5041, 106 p. [Also available at http://pubs. usgs.gov/sir/2004/5041/.]

Asquith, W.H., Roussel, M.C., Cleveland, T.G., Fang, Xing, and Thompson, D.B., 2006, Statistical characteristics of storm interevent time, depth, and duration for eastern New Mexico, Oklahoma, and Texas: U.S. Geological Survey Professional Paper 1725, 299 p. [Also available at http:// pubs.usgs.gov/pp/pp1725/.]

Baker, V.R., 1987, Paleoflood hydrology and extraordinary flood events: Journal of Hydrology, v. 96, p. 79-99.

Barth, N.A., Villarini, Gabriele, Nayak, M.A., and White, Kathleen, 2016, Mixed populations and annual flood frequency estimates in the western United States-The role of atmospheric rivers: Water Resources Research, v. 53, p. $257-269$.

Benson, M.A., and Dalrymple, Tate, 1967, General field and office procedures for indirect measurements: U.S. Geological Survey Techniques of Water-Resources Investigations, book 3, chap. Al, $30 \mathrm{p}$. [Also available at http://pubs.usgs.gov/twri/twri3-a1/.]

Ben-Zvi, Arie, and Azmon, Benjamin, 1997, Joint use of L-moment diagram and goodness-of-fit test-A case study of diverse series: v. 198, nos. 1-4, p. 245-259.

Bobée, B., Cavadias, G., Ashkar, F., Bernier, J., and Rasmussen, P., 1993, Towards a systematic approach to comparing distributions used in flood frequency analysis: Journal of Hydrology, v. 142, nos. 1-4, p. 121-136.

Bodhaine, G.L., 1968, Measurement of peak discharge at culverts by indirect methods: U.S. Geological Survey Techniques of Water-Resources Investigations, book 3, chap. A3, 60 p. [Also available at http://pubs.usgs.gov/twri/ twri3-a3/.]

Cheng, R.C.H., and Stephens, M.A., 1989, A goodness-offit test using Moran's statistic with estimated parameters: Biometrika, v. 76, no. 2, p. 385-392.

Chevallier, Arnaud, 2016, Strategic thinking in complex problem solving: Oxford, U.K., Oxford University Press, $47 \mathrm{p}$.

Cohen, Judah, Ye, Hengchun, and Jones, Justin, 2015, Trends and variability in rain-on-snow events: Geophysical Research Letters, v. 42, p. 7115-7122.

Cohn, T.A., Lane, W.L., and Baier, W.G., 1997, An algorithm for computing moments-based flood quantile estimates when historical flood information is available: Water Resources Research, v. 33, no. 9, p. 2089-2096.
Cohn, T.A., Lane, W.L., and Stedinger, J.R., 2001, Confidence intervals for expected moments algorithm flood quantile estimates: Water Resources Research, v. 37, no. 6, p. 16951706.

Cohn, T.A., and Lins, H.F., 2005, Nature's style-Naturally trendy: Geophysical Research Letters, v. 32, no. 23, L23402.

Cohn, T.A., and Stedinger, J.R., 1987, Use of historical information in a maximum-likelihood framework: Journal of Hydrology, v. 96, no. 1, p. 215-223.

Conover, W.J., 1999, Practical nonparametric statistics (3d ed.): New York, John Wiley.

Csörgö, S., and Faraway, J.J., 1996, The exact and asymptotic distributions of Cramér-von Mises statistics: Journal of the Royal Statistical Society, Series B, v. 58, p. 221-234.

Cunnane, C., 1989, Statistical distributions for flood frequency analysis: Geneva, Secretariat of the World Meteorological Organization, World Meteorological Organization Operational Hydrology Report No. 33.

Dalrymple, Tate, and Benson, M.A., 1967, Measurement of peak discharge by the slope-area method: U.S. Geological Survey Techniques of Water-Resources Investigations, book 3, chap. A2, 12 p. [Also available at http://pubs.usgs.gov/ twri/twri3-a2/.]

Deng, Jian, and Pandey, M.D., 2009, Using partial probability weighted moments and partial maximum entropy to estimate quantiles from censored samples: Probabilistic Engineering Mechanics, v. 24, no. 3, p. 407-417.

Dey, D.K., Roy, Dooti, and Yan, Jun, 2016, Univariate extreme value analysis, chap 1 of Dey, D.K., and Yan, Jun, eds., Extreme value modeling and risk analysis-Methods and applications: Boca Raton, Fla., CRC Press, p. 1-22.

Dey, D.K., and Yan, Jun, 2016, Extreme value modeling and risk analysis - Methods and applications: Boca Raton, Fla., CRC Press, 520 p.

Dinicola, Karen, 1996, The "100-year flood": U.S. Geological Survey Fact Sheet 229-96, 2 p. [Also available at https:// pubs.usgs.gov/fs/FS-229-96/.]

Elamir, E.A.H., and Seheult, A.H., 2003, Trimmed L-moments: Computational Statistics and Data Analysis, v. 43 , p. $299-314$.

Elamir, E.A.H., and Seheult, A.H., 2004, Exact variance structure of sample L-moments: Journal of Statistical Planning and Inference, v. 124, p. 337-359.

El Adlouni, S., Bobée, B., and Ouarda, T.B.M.J., 2008, On the tails of extreme event distributions in hydrology: Journal of Hydrology, v. 355, p. 16-33. 
England, J.F., and Cohn, T.A., 2007, Scientific and practical considerations related to revising Bulletin 17B-The case for improved treatment of historical information and low outliers: American Society of Civil Engineers, EWRI World Water \& Environmental Resources Congress, p. 1-9.

Evans, Merran, Hastings, N.A.J., and Peacock, B.J., 2000, Statistical distributions (3d ed.): New York, John Wiley, $221 \mathrm{p}$.

Faraway, J.J., Marsaglia, George, Marsaglia, John, and Baddeley, Adrian, 2015, goftest - Classical goodness-of-fit tests for univariate distributions: $\mathrm{R}$ package version 1.0-4, accessed February 21, 2017, at https://cran.r-project.org/ package $=$ goftest.

Feaster, T.D., Gotvald, A.J., and Weaver, J.C., 2009, Magnitude and frequency of rural floods in the southeastern United States, 2006-Volume 3, South Carolina: U.S. Geological Survey Scientific Investigations Report 2009$5156,226 \mathrm{p}$.

Federal Emergency Management Agency, 2017, The National Flood Insurance Program: Accessed March 9, 2017, at https://www.fema.gov/national-flood-insurance-program.

Flynn, K.M., Kirby, W.H., and Hummel, P.R., 2006, User's manual for program PeakFQ annual flood-frequency analysis using Bulletin 17B guidelines: U.S. Geological Survey Techniques and Methods, book 4, chap. B4, 42 p.

Gingras, Denis, and Adamowski, Kaz, 1994, Performance of L-moments and nonparametric flood frequency analysis: Canadian Journal of Civil Engineering, v. 21, p. 856-862.

Gotvald, A.J., Feaster, T.D., and Weaver, J.C., 2009, Magnitude and frequency of rural floods in the southeastern United States, 2006-Volume 1, Georgia: U.S. Geological Survey Scientific Investigations Report 2009-5043, 120 p.

Grego, J.M., and Yates, P.A., 2010, Point and standard error estimation for quantiles of mixed flood distributions: Journal of Hydrology, v. 391, p. 289-301.

Griffis, V.W., and Stedinger, J.R., 2007, Evolution of flood frequency analysis with Bulletin 17: Journal of Hydrologic Engineering, v. 12, no. 3, p. 283-297.

Griffis, V.W., Stedinger, J.R., and Cohn, T.A., 2004, Log Pearson type 3 quantile estimators with regional skew information and low outlier adjustments: Water Resources Research, v. 40, no. 7, 17 p.

Gumbel, E.J., 1958, Statistics of extremes: New York, Columbia University Press, 375 p. [Print-on-demand, Dover Publications, Mineola, New York.]

Harwell, G.R., and Asquith, W.H., 2011, Annual peak streamflow and ancillary data for small watersheds in central and western Texas: U.S. Geological Survey Fact Sheet 2011-3082, 4 p. [Also available at http://pubs.usgs. gov/fs/2011/3082/.]
Hazewinkel, Michiel, ed., 2001, Maximum-likelihood method: Encyclopedia of Mathematics, Springer.

Helsel, D.R., and Hirsch, R.M., 2002, Statistical methods in water resources: U.S. Geological Survey Techniques of Water-Resources Investigations book 4, chap. A3. [Also available at http://pubs.usgs.gov/twri/twri4a3.]

Hirsch, R.M., and Stedinger, J.R., 1987, Plotting positions for historical floods and their precision: Water Resources Research, v. 23, no. 4, p. 715-727.

Hollander, Myles, and Wolfe, D.A., 1973, Nonparametric statistical methods: New York, John Wiley, 503 p.

Hosking, J.R.M., 1990, L-moments-Analysis and estimation of distributions using linear combinations or order statistics: Journal of Royal Statistical Society, series B, v. 52, no. 1, p. 105-124.

Hosking, J.R.M., 1992, Moments or L moments?—An example comparing two measures of distributional shape: American Statistician, v. 46, no. 3, p. 186-189.

Hosking, J.R.M., 2015a, lmom-L-moments: R package version 2.5 (February 2, 2015), accessed February 21, 2017, at http://cran.r-project.org/package=1mom.

Hosking, J.R.M., 2015b, lmomRFA—Regional frequency analysis using L-moments: $\mathrm{R}$ package version 3.0-1 (February 2, 2015): Accessed February 21, 2017, at http:// cran.r-project.org $/$ package $=$ lmomRFA.

Hosking, J.R.M., 2015c, Nonparametric confidence regions for L-moments, in Ordered data analysis, modeling and health research models: Springer Proceedings in Mathematics and Statistics, v. 139, p. 39-53, accessed February 21, 2017 at http://dx.doi.org/10.1007/978-3-31925433-3_3.

Hosking, J.R.M., and Wallis, J.R., 1997, Regional frequency analysis-An approach based on L-moments: Cambridge, Cambridge University Press, 224 p.

Hosking, J.R.M., Bonti, Gabriel, and Siegel, Dirk, 2000, Beyond the lognormal-Accurate estimation of the frequency of rare events in VaR calculations: Risk, v. 13, no. 5 , p. 59-62.

Hulsing, Harry, 1967, Measurement of peak discharge at dams by indirect methods: U.S. Geological Survey Techniques of Water-Resources Investigations, book 3, chap. A5, 29 p. [Also available at http://pubs.usgs.gov/twri/twri3-a5/.]

Interagency Advisory Committee on Water Data [IACWD], 1982, Guidelines for determining flood flow frequency: Bulletin 17B of the Hydrology Subcommittee, Office of Water Data Coordination, U.S. Geological Survey, Reston, Va., $183 \mathrm{p}$. 
Jones, M.C., 2004, On some expressions for variance, covariance, skewness and L-moments: Journal of Statistical Planning and Inference, v. 126, p. 97-106.

Jones, O.D., Maillardet, R.J., and Robinson, A.P., 2014, Introduction to scientific programming and simulation using R, (2d ed.): Boca Raton, Fla., CRC Press, 582 p.

Kandeel, A.F., 2015, Linear moments-An overview: International Journal of Business and Statistical Analysis, v. 2 , no. 2 , p. $85-90$.

Karian, Z.A., Dudewicz, E.J., 2011, Handbook of fitting statistical distributions with R: Boca Raton, Fla., CRC Press, 1,672 p.

Karvanen, Juha, 2006, Estimation of quantile mixtures via L-moments and trimmed L-moments: Computational Statistics and Data Analysis, v. 51, no. 2, p. 947-959.

Karvanen, Juha, 2016, Lmoments-L-moments and quantile mixtures: R package version 1.2-3 (February 22, 2016), accessed February 21, 2017, at https://cran.r-project.org/ web/packages/Lmoments/index.html.

Katz, R.W., 2016, Weather and climate disasters, chapter 21, in Dey, D.K., and Yan, Jun, eds., Extreme value modeling and risk analysis-Methods and applications: Boca Raton, Fla., CRC Press, p. 439-460.

Kennedy, E.J., 1984, Discharge ratings at gaging stations: U.S. Geological Survey Techniques of Water-Resources Investigations, book 3, chap. A10, 59 p. [Also available at http://pubs.usgs.gov/twri/twri3-a10/.]

Kite, G.W., 1988, Frequency and risk analyses in hydrology: Littleton, Colo., Water Resources Publications, 257 p.

Kjeldsen, T.R., Smithers, J.C., and Schulze, R.E., 2002, Regional flood frequency analysis in the KwaZulu-Natal Province, South Africa, using the index-flood method: Journal of Hydrology, v. 255, nos. 1-4, p. 194-211.

Lane, W.L., and Cohn, T.A., 1996, Expected moments algorithms for flood frequency analysis, in Bathala, C., ed., American Society of Civil Engineers, North American Water and Environment Congress and Destructive Water, p. 2185-2190.

Lind, N.C., 1994, Information theory and maximum product of spacings estimation: Journal Royal Statistical Society, Series B (Methodological), v. 56, no. 2, p. 341-343.

Lins, H.F., and Cohn, T.A., 2011, Stationarity-Wanted dead or alive? 1: Journal of the American Water Resources Association, v. 47, no. 3, p. 475-480.

Liou, Jun-Jih, Wu, Yii-Chen, and Cheng, Ke-Sheng, 2008, Establishing acceptance regions for L-moments based goodness-of-fit tests by stochastic simulation: Journal of Hydrology, v. 355, p. 49-62.
Liou, Jun-Jih, Wu, Yii-Chen, Chiang, Jie-Lun, and Cheng, Ke-Sheng, 2007, Assessing power of test for goodness-offit test using L-moment-ratios diagram: Journal of Chinese Agricultural Engineering, v. 53, no. 4, p. 80-91.

Lurry, D.L., 2011, How does a U.S. Geological Survey streamgage work?: U.S. Geological Survey Fact Sheet 2011-3001, 2 p. [Also available at http://pubs.usgs.gov/ fs/2011/3001/.]

Markiewicz, Iwona, and Strupczewski, W.G., 2009, Dispersion measures for flood frequency analysis: Physics and Chemistry of the Earth, Parts A/B/C, v. 34, no. 10-12, p. $670-678$.

Marsaglia, George, Tsang, W.W., and Wang, Jingbo, 2003, Evaluating Kolmogorov's distribution: Journal of Statistical Software, v. 8 , no. 18,4 p.

Matthai, H.F., 1967, Measurement of peak discharge at width contractions by indirect methods: U.S. Geological Survey Techniques of Water-Resources Investigations, book 3, chap. A4, 44 p. [Also available at http://pubs.usgs.gov/twri/ twri3-a4/.]

Mueller, D.S., and Wagner, C.R., 2009, Measuring discharge with acoustic Doppler current profilers from a moving boat: U.S. Geological Survey Techniques and Methods, book 3, chap. A22, 95 p. [Also available at http://pubs.water.usgs. gov/tm3a22.]

Nair, N.U., and Vineshkumar, B., 2010, L-moments of residual life: Journal of Statistical Planning and Inference, v. 140, no. 9, p. 2618-2631.

Nathan, R.J., and Weinmann, Erwin, 2013, Very to extreme flood estimation, Book 8 of Australian Rainfall \& Runoff-A guide to flood estimation: Australian Government, Geoscience Australia, Commonwealth of Australia, accessed February 21, 2017, at http://book.arr. org.au.s3-website-ap-southeast-2.amazonaws.com/.

National Oceanic and Atmospheric Administration [NOAA], 2013, Precipitation-frequency atlas of the United States, Southeastern States: NOAA Atlas 14, v. 9, accessed May 3, 2016, at http://www.nws.noaa.gov/oh/hdsc/PF_documents/ Atlas14_Volume9.pdf.

National Oceanic and Atmospheric Administration [NOAA], 2016a, Get climate division boundaries: National Oceanic and Atmospheric Administration, Earth System Research Laboratory Web site, accessed June 3, 2016, at http://www. esrl.noaa.gov/psd/data/usclimdivs/boundaries.html.

National Oceanic and Atmospheric Administration [NOAA], 2016b, Climate at a glance: National Oceanic and Atmospheric Administration Web site, accessed June 3, 2016, at http://www.ncdc.noaa.gov/cag/time-series/us. 
National Research Council, 1988, Estimating probabilities of extreme floods-Methods and recommended research: Washington, D.C., National Academy Press, 141 p.

Nelsen, R.B., 2006, An introduction to copulas: New York, Springer, $269 \mathrm{p}$.

Nielsen, J.P., and Norris, J.M., 2007, From the river to youUSGS real-time streamflow information: U.S. Geological Survey Fact Sheet 2007-3043, 4 p. [Also available at http:// pubs.usgs.gov/fs/2007/3043/.]

Nuclear Regulatory Commission [NRC], 2013, Workshop on probabilistic flood hazard assessment: U.S. Nuclear Regulatory Commission Headquarters, Rockville, MD, January 29-31, 2013, accessed February 21, 2017, at https:// www.nrc.gov/docs/ML1327/ML13277A074.pdf.

Oberg, K.A., and Mueller, D.S., 2007, Validation of streamflow measurements made with acoustic Doppler current profilers: Journal of Hydraulic Engineers, v. 133, no. 12 , p. $1421-1432$.

O'Connor, J.E., Atwater, B.F., Cohn, T.A., Cronin, T.M., Keith, M.K., Smith, C.G., and Mason, R.R., 2014, Assessing inundation hazards to nuclear powerplant sites using geologically extended histories of riverine floods, tsunamis, and storm surges: U.S. Geological Survey Scientific Investigations Report 2014-5207, 65 p.

Olson, S.A., and Norris, J.M., 2007, U.S. Geological Survey streamgaging - from the National Streamflow Information Program: U.S. Geological Survey Fact Sheet 2005-3131, 4 p. [Also available at http://pubs.usgs.gov/fs/2005/3131/.]

Palmer, W.C., 1965, Meteorological drought: U.S. Department of Commerce, Weather Bureau Research Paper 45, 58 p. [Also available at https://www.ncdc.noaa.gov/temp-andprecip/drought/docs/palmer.pdf.]

Pandey, M.D., van Gelder, P.H.A.J.M., and Vrijling, J.K., 2001, Assessment of an L-kurtosis-based criterion for quantile estimation: Journal of Hydrologic Engineering, v. 6 , no. 4, p. 284-292.

Pappenberger, F., and Beven, K.J., 2006, Ignorance is blissOr seven reasons not to use uncertainty analysis: Water Resources Research, v. 42, W05302, 8 p.

Paretti, N.V., Kennedy, J.R., and Cohn, T.A., 2014, Evaluation of the expected moments algorithm and a multiple lowoutlier test for flood frequency analysis at streamgaging stations in Arizona: U.S. Geological Survey Scientific Investigations Report 2014-5026, 61 p. [Also available at http://pubs.usgs.gov/sir/2014/5026/.]

Peel, M.C., Wang, Q.J., Vogel, R.M., and McMahon, T.A., 2001, The utility of L-moment ratio diagrams for selecting a regional probability distribution: Hydrological Sciences, v. 46 , no. 1 , p. $147-155$.
Prasad, Rajiv, Hibler, L.F., Coleman, A.M., and Ward, D.L., 2011, Design-basis flood estimation for site characterization at nuclear power plants in the United States of America: U.S. Nuclear Regulatory Commission, Office of Nuclear Regulatory Research Report NUREG/CR-7046 [variously paged], accessed on October 26, 2016, at http://www.nrc. gov/docs/ML1132/ML11321A195.pdf.

R Core Team, 2016, R-A language and environment for statistical computing, version 3.2.4: Vienna, Austria, R Foundation for Statistical Computing.

Rahman, Ataur, Haddad, Khaled, Kuczera, George, and Weinmann, Erwin, 2009, Australian rainfall and runoff revision: Project 5-Regional flood methods: Barton, ACT, Australia, Engineers Australia, Stage 1 Report P5/S1/003, $181 \mathrm{p}$.

Rigby, R.A., and Stasinopoulos, D.M., 2005, Generalized additive models for location, scale and shape (with discussion): Applied Statistics, v. 54, part 3, p. 507-554.

Rizzo, M.L., 2008, Statistical computing with R: Boca Raton, Fla., CRC Press, 399 p.

Royston, Patrick, 1992, Which measures of skewness and kurtosis are best?: Statistics in Medicine, v. 11, no. 3, p. 333-343.

Salvadori, G., De Michele, C., Kottegoda, N.T., and Rosso, R., 2007, Extremes in nature-An approach using copulas: Dordrecht, Netherlands, Springer, Water Science and Technology Library 56.

Sankarasubramanian, A., and Srinivasan, K., 1999, Investigation and comparison of sampling properties of L-moments and conventional moments: Journal of Hydrology, v. 218, p. 13-34.

Sauer, V.B., and Turnipseed, D.P., 2010, Stage measurement at gaging stations: U.S. Geological Survey Techniques and Methods, book 3, chap. A7, 45 p. [Also available at http:// pubs.usgs.gov/tm/tm3-a $7 /$.

Scarrott, Carl, 2016, Univariate extreme value mixture modeling, chap. 3 of Dey, D.K., and Yan, Jun, eds., Extreme value modeling and risk analysis-Methods and applications: Boca Raton, Fla., CRC Press, p. 41-67.

Scarrot, Carl, and Hu, Yang, 2015, evmix - Extreme value mixture modelling: R package version 2.6 (May 27, 2015), accessed February 21, 2017, at https://cran.r-project.org/ web/packages/evmix/index.html.

SonTek/YSI Corporation, 2002, SonTek/YSI FlowTracker Handheld ADV technical documentation: San Diego, Calif., SonTek/YSI Corporation, $2 \mathrm{p}$. 
Stasinopoulos, D.M., Rigby, R.A., Voudouris, V., Akantziliotou, C., Enea, M., Kiose, D., 2016, gamlssGeneralised additive models for location scale and shape: R package version 4.4-0 (November 21, 2016), accessed February 21, 2017, at http://cran.r-project.org/web/ packages/gamlss/index.html.

Stedinger, J.R., and Cohn, T.A., 1986, Flood frequency analysis with historical and paleoflood information: Water Resources Research, v. 22, no. 5, p. 785-793.

Stedinger, J.R., and Cohn, T.A., 1987, Historical flood frequency data - Its value and use: International Symposium on Flood Frequency and Risk Analyses.

Stedinger, J.R., and Griffis, V.W., 2008, Flood frequency analysis in the United States-Time to update: Journal of Hydrologic Engineering, v. 13, no. 4, p. 199-204.

Stedinger, J.R., Vogel, R.M., and Foufoula-Georgiou, Efi, 1993, Frequency analysis of extreme events, chap. 18 of D.A. Maidment, ed., Handbook of hydrology: New York, McGraw-Hill, p. 18.1-18.66.

Turnipseed, D.P., and Sauer, V.B., 2010, Discharge measurements at gaging stations: U.S. Geological Survey Techniques and Methods, book 3, chap. A8, 87 p. [Also available at http://pubs.usgs.gov/tm/tm3-a8/.]

U.S. Geological Survey [USGS], 2014, PeakFQFlood frequency analysis based on Bulletin 17B and recommendations of the Advisory Committee on Water Information (ACWI) Subcommittee on Hydrology (SOH) Hydrologic Frequency Analysis Work Group (HFAWG): Accessed October 4, 2014, at http://water.usgs.gov/ software/PeakFQ/.

U.S. Geological Survey [USGS], 2016a, Peak streamflow for the Nation: National Water Information System Web interface, Accessed June 2, 2016, at http://nwis.waterdata. usgs.gov/nwis/peak.

U.S. Geological Survey [USGS], 2016b, USGS current water data for the Nation: National Water Information System Web interface: Accessed November 3, 2016, at http:// waterdata.usgs.gov/nwis/rt.

U.S. Geological Survey [USGS], 2016c, USGS water data for the Nation: National Water Information System Web interface: Accessed November 3, 2016, at http://waterdata. usgs.gov/nwis.

Veilleux, A.G., Cohn, T.A., Flynn, K.M., Mason, R.R., Jr., and Hummel, P.R., 2014, Estimating magnitude and frequency of floods using the PeakFQ 7.0 program: U.S. Geological Survey Fact Sheet 2013-3108, 2 p. [Also available at http:// pubs.usgs.gov/fs/2013/3108/.]
Villarini, Gabriele, Goska, Radoslaw, Smith, J.A., and Vecchi, G.A, 2014, North Atlantic tropical cyclones and U.S. flooding: Bulletin American Meteorological Society, v. 95, no. 9, p. 1381-1388.

Villarini, Gabriele, and Smith, J.A., 2010, Flood peak distributions for the eastern United States: Water Resources Research, v. 46, no. 6, W06504, 17 p.

Villarini, Gabriele, Smith, J.A., Baeck, M.L., and Krajewski, W.F., 2011, Examining flood frequency distributions in the Midwest U.S.: Journal of the American Water Resources Association, v. 47, no. 3, p. 447-463, accessed February 21, 2017, at http://dx.doi.org/10.1111/j.17521688.2011.00540.x.

Vogel, R.M., and Fennessey, N.M., 1993, L moment diagrams should replace product moment diagrams: Water Resources Research, v. 29, no. 6, p. 1745-1752.

Wahl, K.L., Thomas, W.O. Jr., and Hirsch, R.M., 1995, Stream-gaging program of the U.S. Geological Survey: U.S. Geological Survey Circular 1123, 22 p. [Also available at http://pubs.er.usgs.gov/publication/cir1123.]

Wang, Dongliang, Hutson, A.D., and Miecznikowski, J.C., 2010, L-moment estimation for parametric survival models given censored data: Statistical Methodology, v. 7, no. 6, p. 655-667.

Wang, H.J., and Li, Deyuan, 2016, Estimation of extreme conditional quantiles, chapter 15, in Dey, D.K., and Yan, Jun, eds., Extreme value modeling and risk analysisMethods and applications: Boca Raton, Fla., CRC Press, p. 307-324.

Weaver, J.C., Feaster, T.D., and Gotvald, A.J., 2009, Magnitude and frequency of rural floods in the Southeastern United States, through 2006-Volume 2, North Carolina: U.S. Geological Survey Scientific Investigations Report 2009-5158, $111 \mathrm{p}$.

Wilby, R.L., 2012, Forward, in Mujumdar, P.P., and Kumar, D.N., eds., Floods in a Changing Climate: Cambridge University Press, $177 \mathrm{p}$.

Wong, T.S.T., and Li, W.K., 2007, A note on the estimation of extreme value distributions using maximum product of spacings: IMS Lecture Notes-Monograph Series, v. 52, p. 272-283. 
Appendixes 


\title{
Appendix 1. U.S. Geological Survey Streamgaging Methods and Annual Peak Streamflow
}

\author{
By Dan Wagner, Julie E. Kiang, and William H. Asquith
}

\section{U.S. Geological Survey Streamgaging Methods}

\section{Introduction}

Streamflow information is a vital national asset of the United States that is used extensively to safeguard lives, protect property, manage water supplies, and conduct scientific investigations. The U.S. Geological Survey (USGS) operates streamflow-gaging stations ("streamgages" hereafter; Lurry, 2011; Olson and Norris, 2007) throughout the Nation to provide quantitative information about flow in rivers and streams. Streamflow, or discharge (used herein when usage requires), is defined as the volumetric rate of water flow (volume per unit time) in an open channel, including any sediment or other solids that may be dissolved in (or mixed with) it that adhere to the Newtonian physics of open-channel hydraulics of water (Turnipseed and Sauer, 2010).

The majority of USGS streamgages are referred to as continuous-record streamgages, because they provide a continuous time series of streamflow data. These streamgages provide comprehensive information about normal flow conditions as well as extreme high flows and extreme low flows. The USGS operates a network of more than 8,000 streamgages nationwide (USGS, 2016b) and delivers data through the USGS National Water Information System (NWIS; USGS, 2016c). Other streamgage types include those monitoring only low flows or high flows, known as partial record streamgages. Yet other types include those monitoring tidal flow or those recording only peak flow for water-surface elevations. Different types of streamgages exist to meet specific needs. This appendix describes continuousrecord streamgages with emphasis on annual peak streamflow, although gages recording only peak streamflows, also known as crest-stage gages, are also described.

Streamgages typically contain instruments that automatically measure and record stage at a regular time interval (typically every 15 minutes). The instrumentation commonly is housed in unobtrusive structures along bridge crossings, such as the metal structure with antenna shown in figure 1-1. Others are more substantial structures, such as the one schematically depicted in figure 1-2. Commonly through satellite telemetry, stage data are transmitted hourly from streamgages to USGS computers for further processing.

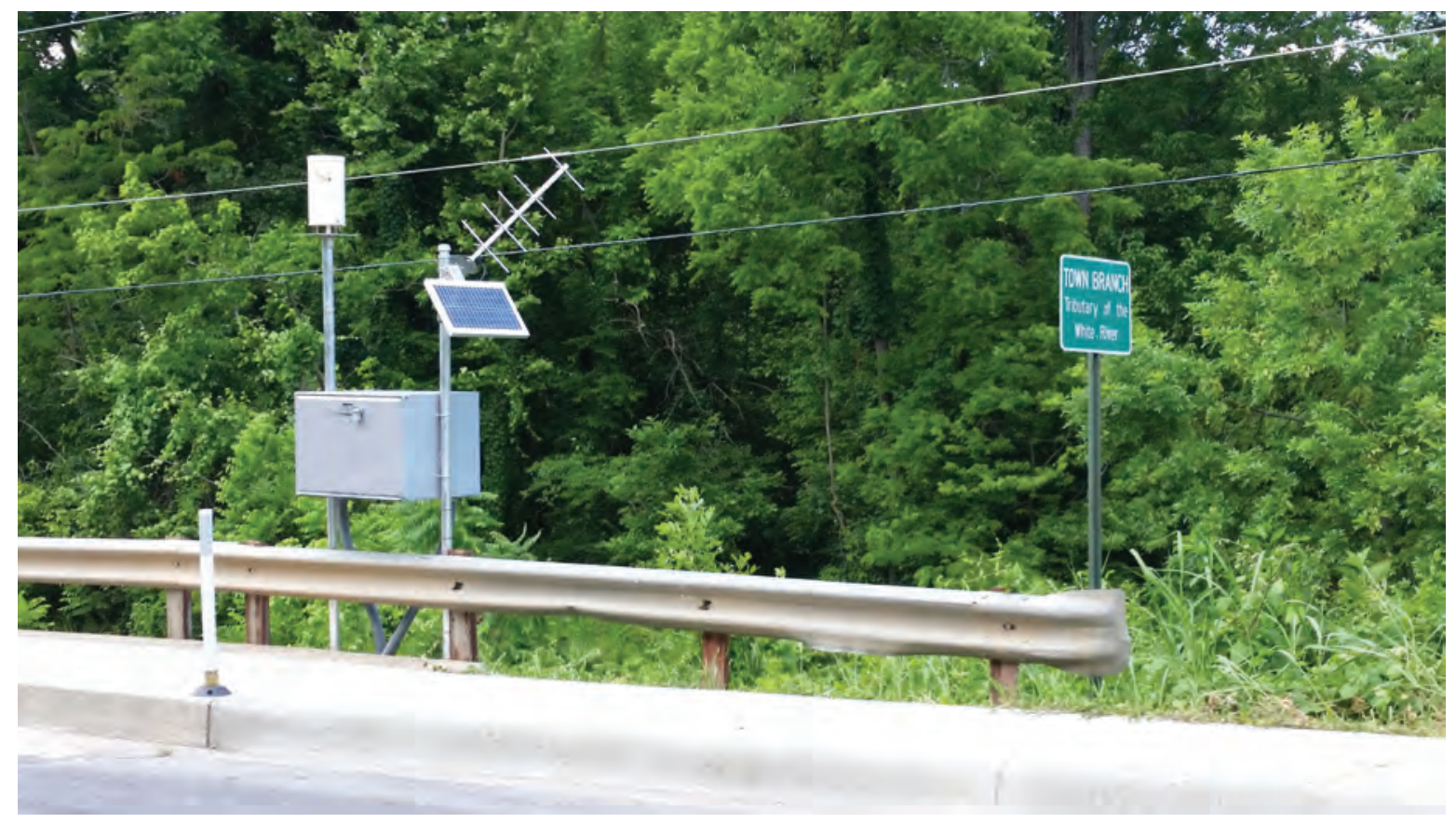

Figure 1-1. U.S. Geological Survey streamflow-gaging station 07048495 Town Branch at Armstrong Road at Fayetteville, Arkansas, on July 15, 2016. Photograph by Dan Wagner, U.S. Geological Survey. 


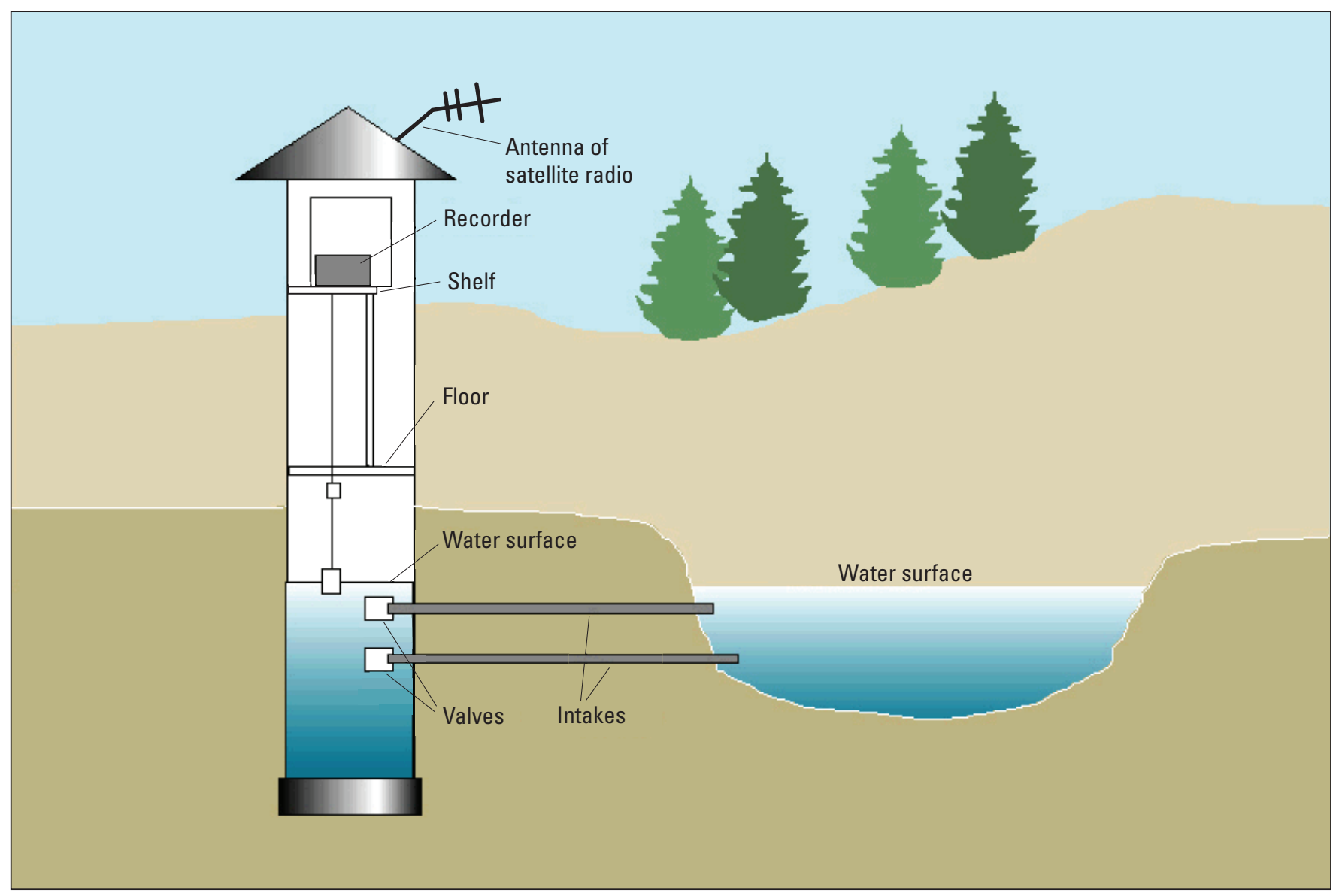

Figure 1-2. Traditional stilling-well style of U.S. Geological Survey streamflow-gaging station after Nielsen and Norris (2007).

The most critical processing step is the development of a relation between stage and streamflow. This relation, known as a stage-discharge rating and often referred to as a rating curve for its graphical appearance, is developed using paired observations of stage and streamflow collected in the field. At some sites, a third parameter is needed to compute streamflow, such as index velocity, stream slope, or the rate of change in stage at a site. Such complex ratings are not presented herein but compose about 5 to 10 percent of the USGS streamgaging network. Regardless of whether simple or complex rating methods are used, the measured stage and computed streamflow data are made available to the public (USGS, 2016c); by convention, the USGS expresses streamflow in units of cubic feet per second and water-surface elevation in feet.

Annual peak streamflow represents the maximum instantaneous peak flow experienced during a given year at a streamgage. Such streamflows are also referred to as annual maximum peaks or annual peak streamflows. These peak streamflow data are among the most important data produced by the USGS streamgaging program and are a product of nearly every continuous-record streamgage. Similarly, highflow partial-record streamgages and peak-streamflow-only streamgages are designed and operated to record peak streamflows.

Annual peak streamflow data are important because they are often used for analyses supporting floodplain management (including establishment of zones requiring flood insurance) and infrastructure design (dams, highway drainage, and bridges). These data, as exemplified by the statistical analyses described in the main body of this report, are used to develop peak-streamflow frequency. Typically, such analyses fit time series of annual peak streamflows to the Pearson type III distribution and a risk-level is specified as an exceedance probability (or recurrence interval) associated with a particular streamflow magnitude.

\section{Creating Continuous Records of Streamflow}

The majority of streamgages produce continuous record because doing so provides a high degree of temporal data resolution, making the information obtained at a given location suitable for a wide variety of scientific, engineering, recreational, and resource-management uses. Under most circumstances, it is not practical to directly measure streamflow continuously. River stage is, however, easier to 
measure continuously. Because of this, most streamgages are located in riverine settings that exhibit a strong physical and thus mathematical relation between stage and streamflow. A continuous record of streamflow is computed from the continuous record of the "surrogate" parameter (stage) using a stage-discharge rating.

The creation and maintenance of reliable continuous records of streamflow involves several steps, including (1) measuring and recording stage (automatically) and processing stage data for quality-control and assurance (both automatic and human-supervised); (2) making periodic discrete (that is, unique in time) measurements of river streamflow at various stage levels to represent the full range of streamflow occurring at a given location; (3) developing the mathematical relation between stage and streamflow, known as a stage-discharge rating, and (4) applying the stagedischarge rating to the continuous record of stage in order to compute streamflow. These steps are described in more detail in the sections that follow.

\section{Measurement of Stage}

Sauer and Turnipseed (2010) describe stage measurement methods and equipment in detail. Measurement of stage has evolved considerably since the USGS began collecting such data over a century ago. Stage is typically recorded every 15 minutes at USGS streamgages using one or more of several different styles or types of water-level sensors, with a single sensor being the most common setup. Whereas most streamgages record information at a 15-minute interval during normal operations, some streamgages are set up using different time intervals to meet specific purposes. For example, a streamgage in a very small watershed characterized by flashy (short-duration) peaks might require a 5 -minute data interval to sufficiently define the flood hydrograph (that is, a graphical plot of stage versus time). A traditional style of stage measurement is shown in figure 1-2, which depicts a streamgage constructed with a stilling well.

A streamgage with a stilling well is hydraulically connected to the river such that the water level in the stilling well matches that of the river. The stilling well acts to physically minimize water-level fluctuations by calming the water surface where it is monitored by equipment such as (1) a float and tape coupled with a shaft encoder or (2) a pressure transducer measuring hydrostatic head.

In newer streamgages (fig. 1-1), stage measurements are made by physically locating the pressure measuring apparatus in the riverine environment. Alternatively, noncontact radar can be mounted above the water surface and stage recorded using the beam distance between the radar and the water. For these newer types of streamgages, a smaller footprint for construction can be used to house the streamgaging equipment.

Figure 1-2 shows a recorder inside the streamgage structure. (The recorder is not visible in figure 1-1.) The recorder is a special-purpose onsite computer, referred to as a data-collection platform (DCP), that automates the operation of stage sensors, auxiliary stage sensors, and other sensors such as water quality or weather instruments. The type of equipment and sensors used are dependent upon the physical conditions at the site and the specific needs of the cooperative funding agency. Stage measurements are stored in the DCP memory and transmitted hourly on a preset schedule to USGS computers using the National Oceanic and Atmospheric Administration (NOAA), National Environmental Satellite, Data, and Information Service (NESDIS), Geostationary Operational Environmental Satellite (GOES) (fig. 1-3). During emergency situations, such as when intense rainfall and runoff cause a river or stream to exceed a predetermined high stage or a rapid rate of change in stage, the DCP can be programmed to acquire auxiliary measurements of stage more often - every 5 minutes or less, depending on the instrumentation used to measure stage - and auxiliary data can be transmitted by satellite more often than under normal operating conditions to provide timely data.

The accuracy and precision of stage measurements is influenced by many factors, such as the type of instrumentation (instrument error), methods of field verification (comparison of recorder readings to reference gages such as staff plates or wire-weight gages) during visits to the streamgages by USGS personnel, and the complex, site-specific nature of localized hydraulics affecting the water surface near stage measuring devices. The USGS utilizes instrumentation capable of reporting stage to the nearest hundredth of a foot. During regularly scheduled site visits, concurrent readings of stage from the reference gage (a manual measurement of stage independent of the automated equipment) and stage sensor are made, and the reading of the stage sensor corrected to that of the reference gage, if necessary. Differential leveling techniques are used every 1 to 3 years to ensure changes to the (vertical) gage datum and the reference gage are not occurring at the site. The largest uncertainty associated with stage measurement is usually the local hydraulics of the river. Uncertainty associated with stage measurement typically is greatest for fast moving water and turbulent flow associated with annual peak streamflow.

\section{Measurement of Streamflow}

As with stage measurement, methods for measuring streamflow have evolved. Until the late 20th century, mechanical current meters measured flow by using the force of moving water to spin the rotating cups on the meter. These meters are still used, but are increasingly being replaced by equipment that uses acoustic Doppler methods to measure water velocity (Turnipseed and Sauer, 2010). Other methods used less frequently include portable weirs and flumes, floats, volumetric tanks, tracers, and indirect methods (Benson and Dalrymple, 1967). Of these alternative methods, only indirect methods for computing peak streamflow are discussed here because of their relevance to the statistical computations in this report. 


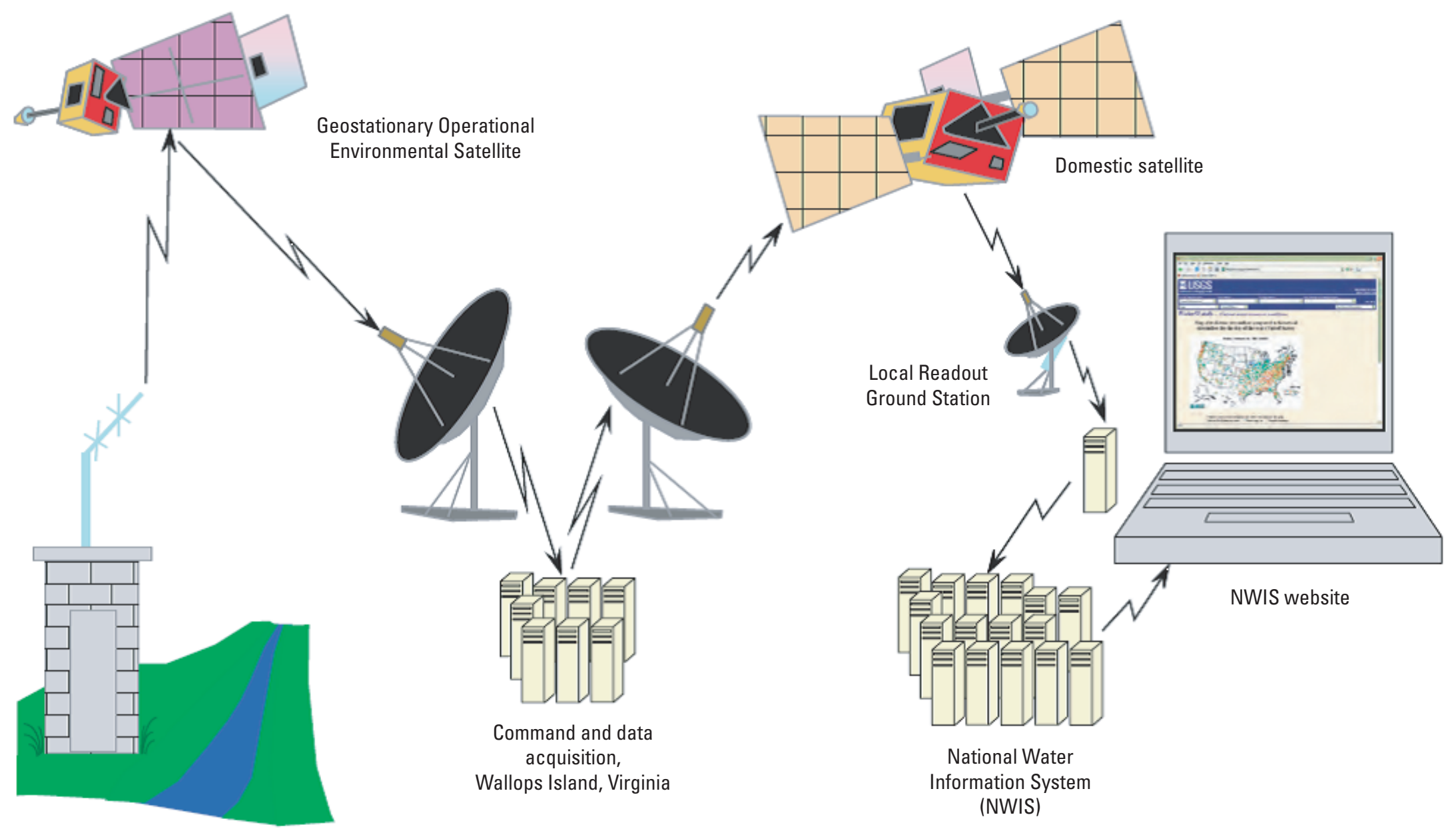

Streamgage

Figure 1-3. General workflow of hydrological data for a data-collection platform (DCP) transmission from a U.S. Geological Survey streamflow-gaging station to the Internet (from Sauer and Turnipseed, 2010, fig. 48). 
The most traditional method of streamflow measurement is the velocity-area method, whereby streamflow is computed by subdividing a cross section of the stream into segments, measuring the depth and velocity at selected vertical locations, and summing the products of the partial areas of the stream cross section and their respective mean velocities (Turnipseed and Sauer, 2010). USGS application of the velocity-area method typically involves dividing a cross section of the stream channel into 25 to 30 rectangular sections. The width of each section is determined by using a marked line (commonly referred to as a tag line), cableway, or bridge rail to measure the distance from an initial point from either bank. A wading rod or sounding reel is used to measure depth and a current meter is used to measure velocity for a predetermined amount of time (typically 40 seconds) at one or more locations in the water column, depending on depth and other conditions. For each of the 25 to 30 rectangular subsections, the width, depth, and velocity are multiplied to compute discharge within that subsection. The subsection discharges are then summed to compute total streamflow. Either mechanical current meters or acoustic Doppler velocimeters (ADVs; SonTek/ YSI Corporation, 2002) are commonly used for this type of measurement. Acoustic Doppler current profilers (ADCPs; Oberg and Mueller, 2007; Mueller and Wagner, 2009) are occasionally used in this manner as well.

More commonly, ADCPs are used to make "moving boat" measurements. ADCPs are capable of measuring velocity every $2-10$ inches (in.) (5-25 centimeters) in a given stream cross section to create a detailed velocity profile (Turnipseed and Sauer, 2010). ADCPs are commonly used to make velocity measurements in large rivers or in streams exceeding water depths that can be safely waded (Mueller and Wagner, 2009). ADCPs can be used on manned, tethered, or remote-control boats, and when coupled with an onboard, global positioning system (GPS), yield accurate positional and velocity data.

During flooding, it may be impossible, impractical, or unsafe to measure peak streamflows within some streams. The peak may not occur when personnel resources are available. For example, small rivers may crest for such short periods of time, that is, are so "flashy," that a measurement, even if it could be safely performed, cannot be made when the peak occurs. As a result, the vast majority of annual peak streamflows are not obtained through direct measurements of streamflow. Instead, the peak streamflows are computed using the stage-discharge rating and the measured peak stage.

Sometimes river streamflows during flood events can be determined using indirect methods (Benson and Dalrymple, 1967), either for purposes of defining the stage-discharge rating or to provide the actual annual peak. Indirect measurements are performed after the event itself by collecting information in the stream reach or at a hydraulic structure (such as a bridge, culvert, or dam) in order to construct a numerical model of streamflow. Indirect techniques for determining peak streamflow include slopearea (Dalrymple and Benson, 1967), contracted-opening
(Matthai, 1967), flow-through-culvert (Bodhaine, 1968), and flow-over-dam (Hulsing, 1967) methods. These methods have specific requirements for locating and surveying highwater marks, structure geometry (if applicable), and cross sections of the stream channel. Many indirect methods also require determining the roughness (boundary friction) of a representative reach of the stream channel or the structure used in the computation. Furthermore, structures must closely resemble standard configurations, because discharge coefficients, which represent hydraulic efficiency, are determined from limited empirical laboratory experiments. The uncertainty associated with indirect methods is typically greater than that for direct measurement methods. The exact uncertainty depends on the quality of information available and the nature of the channel.

After a streamflow measurement is made, the hydrologic technician rates the measurement as either "excellent," "good," "fair," or "poor." A measurement rated as excellent is considered to have 2-percent error or less; a good measurement 5-percent error or less; a fair measurement 8-percent error or less; and a poor measurement greater than 8-percent error (Turnipseed and Sauer, 2010). Despite these numerical assignments, however, the measurement quality ratings are subjective. The ratings are based on stream conditions and limitations of the equipment used during the measurement that affect data quality, which include but are not limited to (1) low or conversely high water velocities relative to the measurement performance (operational limitations) of the equipment; (2) shallow water in the cross section; (3) a large flow-direction angle relative to crosssection orientation; (4) substantial two- and three-dimensional flow components relative to the downstream direction; (5) rapidly changing stage; and (6) other limitations of the equipment, such as a low signal-to-noise ratio for ADVs or loss of bottom-tracking or GPS signal for ADCPs (Turnipseed and Sauer, 2010).

\section{Relating Stage to Streamflow}

The continuous record of stage is converted to a continuous record of streamflow by developing and applying a stage-discharge rating. This rating is developed for each streamgage from numerous physical measurements of streamflow made at that streamgage over a wide range of stage values (from low to flood stage). Stage-discharge ratings change over time for various reasons, such as natural riverine processes causing erosion or deposition of sediments or natural vegetation growth and succession. In other words, changes in channel morphology or frictional resistance cause the relation between stage and streamflow to vary with time. Considerable resources within the USGS are expended to maintain stage-discharge ratings. An example stage-discharge rating for an arbitrary USGS streamgage is shown in figure $1-4$.

The relation between stage and streamflow depends on the shape, size, slope, and roughness of a section or channel 


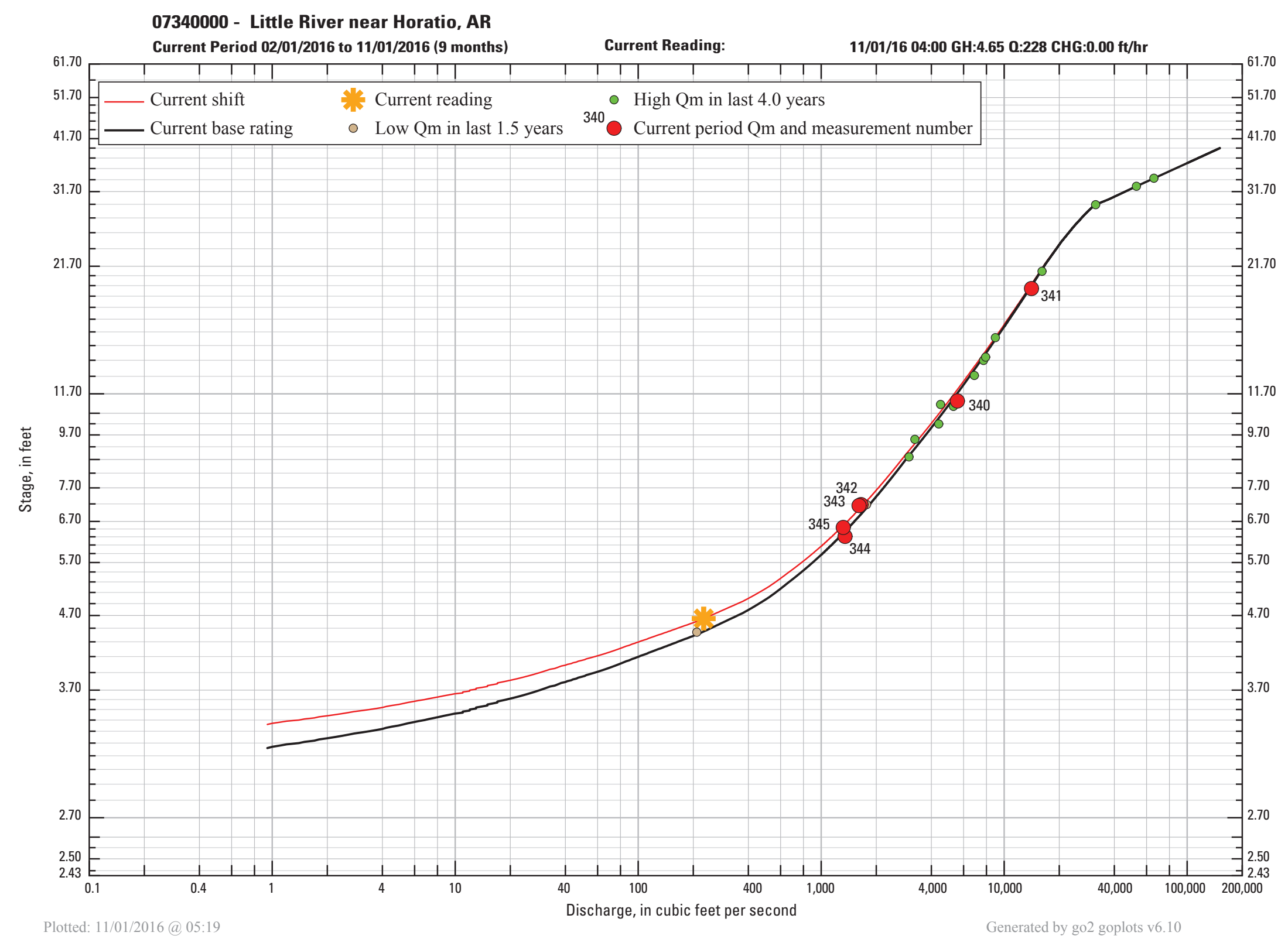

Figure 1-4. Example diagram of stage-discharge rating from internal U.S. Geological Survey National Water Information System record-processing software for USGS streamflow-gaging station 07340000 Little River near Horatio, Arkansas, showing the current shifted and base ratings as well as recent and other informative streamflow measurements as of November 1, 2016. ( 0 is discharge, in cubic feet per second; GH is gage height [stage], in feet; $\mathrm{CHG}$ is gage-height change, in feet per hour; and $\mathrm{Qm}$ is discharge measurement.) 
reach downstream of the gaging station and is different for every streamgage. A section or reach of the stream channel downstream of the streamgage, known as the control, eliminates the effect of all other downstream conditions on the velocity of flow at the streamgage (Kennedy, 1984). A feature at a single point in the stream channel downstream of the streamgage that affects the relation between stage and discharge at low flow is called the section control. The section control is recognized by a clear break in the water surface across the entire width of the channel. Such controls may be a bedrock ledge, a riffle, or other natural or man-made feature that becomes submerged at medium to high flows. At medium flows (up to bankfull stage), the physical features of the channel reach downstream of the streamgage, such as obstructions and (or) vegetation, bedrock outcrops, irregular banks, and constrictions and expansions in the width of the channel all affect the relation between stage and streamflow and constitute what is known as the channel control.

Above bankfull stage, the effects of vegetation or structures on the floodplain begin to dominate the relation between stage and streamflow and are known as overbank control. The graphical appearance of the stage-discharge rating is typically a compound curve with multiple inflection points and consists of two to three segments. These segments correspond to the ranges of stage and streamflow affected by each of the controls present in the reach of stream near the gaging station, with transitional curves connecting the segments.

Stage-discharge ratings, especially within the ranges affected by the section and channel controls, often change after floods, when the physical force of floodwater and suspended material can alter the dimensions of the streambed or stream channel. To keep stage-discharge ratings accurate and up-todate, USGS personnel visit each streamgage approximately once every 6 to 8 weeks to directly measure streamflow. Additional unscheduled measurements of streamflow are often made during high flows to verify the overbank range of the stage-discharge rating and afterward to assess changes in the streambed or channel that affect the section and channel controls. For streams having unstable channels, such as sandbed streams, the frequency of streamflow measurements may be made as often as once per week, depending upon the level of accuracy needed.

\section{Computation of Continuous Record of Streamflow}

After a site visit and streamflow measurement are made at a streamgage, USGS personnel check the plotting of the measurement to assess whether or not it either conforms to the current stage-discharge rating or indicates that a shift to part of the rating may be needed so that streamflow computed by means of the stage-discharge rating matches the measured streamflow. Shifts are temporary changes to the stage-discharge rating that result from the natural alteration of section or channel controls during storm events or floods, such as scour or aggradation of gravel riffles or mass wasting of cut banks. Such changes typically affect only the lowerto-middle range of streamflow. Appreciable changes to the floodplain occur less frequently and, therefore, the high ranges of stage-discharge ratings affected by overbank control tend to change infrequently and require few shifts. Shifts in the stage-discharge rating are temporal in nature but the duration of a given shift is a highly site-specific component of USGS discharge record computations.

If a streamflow measurement indicates that a shift to part of a stage-discharge rating may be necessary, the hydrologic technician will verify whether obvious changes to the section or channel controls occurred that might explain the shift or if recent measurements have all indicated a similar shift. If deemed appropriate, the technician computes the required shift and applies it to the appropriate period of record.

Streamflows corresponding to periods of missing stage record are estimated using various techniques that take into account the streamflow at other streamgages along the stream or, if none are available, at streamgages in adjacent basins. Estimated streamflows are flagged in the NWIS database with a code " $\mathrm{e}$ " to alert the end-user about the quality of the data (USGS, 2016b).

In developing and updating stage-discharge ratings, the rated quality of streamflow measurements is considered. Ratings are developed (drawn) with a goal of minimizing differences between the rating and the measurements used to develop the rating. As part of rating development, the differences between the rated discharges - those predicted by the rating - and measured discharges do not exceed the percent errors assigned to the measured discharges. This is not always possible to achieve, and as such, it is important that quality ratings assigned to streamflow measurements are appropriate and account for all possible sources of error. To ensure the quality of stage-discharge ratings, they are generally updated, checked, and reviewed on a regular basis as part of rigorous USGS records processing. That is, the hydrologic technician's work for the period for which the streamflow record is being computed is checked for accuracy and completeness by a fellow technician, sent back for revision and rechecked if necessary, and finally reviewed and approved by a senior-level technician or supervisor.

As with individual streamflow measurements, hydrologic technicians assign a qualitative rating of "excellent," "good," "fair," or "poor," to records computed from the stage-discharge rating for each water year. A water year is the 12-month period from October 1 through September 30, designated by the calendar year in which it ends. The rating is assigned on the basis of factors such as the amount of missing data, the degree to which stage corrections were required, the adequacy of measurements used to verify the stage-discharge rating, and the frequency with which shifts were used to compute streamflow. Thus, a record obtained from a stable channel might receive an excellent rating if no equipment malfunctions occurred and measurements were made to verify 
the stage-discharge rating over the full range of stage values observed during the year. In contrast, a record assigned a poor rating might have extended periods of missing stage record requiring estimation of both low and high flows, numerous corrections to the continuous stage record because of drift in the stage sensor, poor coverage over the range of stage experienced owing to few measured streamflows, or numerous shifts required for the stage-discharge rating that are not easily attributed to channel changes or particular high-flow events.

In practice, the quality rating of streamflow records is subjective. USGS records include notes if a portion of the record is particularly problematic; for example, a 120-day period might be rated good except for a 2 -week period that is rated poor because of intermittent or missing stage data owing to a malfunctioning stage sensor that ultimately required estimation of streamflow during the period. The USGS is pursuing methods for quantitative estimation of uncertainty in the stage-discharge rating and streamflow records. This has been a difficult research problem to address because of the unstable nature of the stage-discharge rating, along with the subjective nature of the accuracy assigned to discharge measurements and the intermittent frequency of those measurements.

\section{Crest-Stage Gages and Peak Verification}

Crest-stage gages (CSGs) are a simple type of device used to passively record maximum stages associated with floods or small stormflow events. A CSG-only streamgage is purposed to acquire peak stages, such as annual peak stage from which peak streamflow can be computed. At other streamgages, CSGs are often used as a complementary backup device for continuously recording sensors. For example, should the recording equipment at a streamgage malfunction or be damaged during a flood event, the CSG can provide valuable information for estimation of streamflow record. Many continuous-record streamgages have one or more CSGs functioning for such a purpose, and CSGs are used to verify peak stage even when equipment malfunction is not suspected. Where CSGs are not available or overtopped/damaged, gaged peaks can be verified by high-water marks and other apparatus, such as minimum and maximum clips indicating such stages on float and tape devices.

CSG-only streamgages are purposed for annual peak streamflow collection, and in fact, entire subnetworks of USGS streamgages can be composed of CSGs (Harwell and Asquith, 2011) used to collect data of particular interest to those involved with the design of transportation infrastructure in small watersheds. Streamflows associated with CSGs can often be exclusively based on indirect methods rather than direct measurements of streamflow.

A CSG is a simple way to passively record maximum stage after an event. A wooden stick (typically 0.75 in. thick by $1.50 \mathrm{in}$. wide in various lengths) is placed within a 2-in.diameter galvanized steel pipe that is mounted vertically in the path of flow either in the gage pool, channel, or upstream of the drawdown zone of any structure. At the bottom of the wooden stick, a mesh basket is secured and filled with a supply of granulated cork. The steel pipe has end caps on the top and bottom that are each vented with predrilled holes to allow water to enter and air to escape. The bottom of the stick rests on a pin in the bottom cap of the pipe, and the elevation of the pin is surveyed and referenced to the (vertical) gage datum. As the stage rises, the cork floats up inside the pipe, and when the stage falls, a cork line is left on the wooden stick indicating the peak stage during the event. The stick is removed during a visit and the water level is recorded. In preparation for the next stormflow event, the cork line is brushed away from the stick, and the mesh basket is recharged with new cork.

\section{Data Delivery}

Through the USGS National Water Information System Web interface (NWIS; USGS, 2016c), continuous records of stage and streamflow data from streamgages are made available to water-data users in near-real time to meet the needs of water resource managers, emergency management agencies, and others (Wahl and others, 1995). NWIS also provides access to streamflow statistics - such as daily, monthly, and annual mean streamflows, and annual peak streamflows - for the period of record for all active and discontinued streamgages operated by the USGS. These statistics are derived from the continuous records of streamflow. Although the data immediately available in NWIS are typically provisional and subject to revision, when the data become approved, they are flagged as such when viewed through or retrieved from the database.

\section{Annual Peak Streamflow and the Peak-Flow File}

Annual peak streamflow represents the highest streamflow experienced at a streamgage during a given water year, and the value is recorded in a peak-flow file in the USGS database associated with that streamgage. The peak-flow file for one or more streamgages can be acquired from NWIS (USGS, 2016a). The annual time series of peak streamflows contained in the peak-flow file is used to conduct peakstreamflow frequency analyses at individual streamgages.

The vast majority of peak streamflows are collected as part of the systematic streamgaging program, whereby peak streamflow information is systematically collected each year at a streamgage location. At some locations, historical information about extraordinarily large floods is used to supplement the peak-flow file. The term "historical information" is intended to reflect flood information that is outside the period of record but available in general historical records, such as newspapers, from the time of earliest settlers to modern times. When and where available, historical peaks may be included in the peak-flow file. 
Paleoflood information is another type of information outside the period of systematic record that may be available for a streamgage or within the surrounding locale. Paleoflood hydrology is used to reconstruct information about unobserved floods through careful analysis of long-lasting traces of past floods (Baker, 1987; O'Connor and others, 2014). For example, information can be derived from careful analysis of sediment deposits, erosional features on the landscape, and scars left on trees. Currently (2017), paleoflood information is not stored in the peak-flow file and must be accessed through individual reports or other reference material.

In contrast to annual peak streamflows, secondary peaks, that is, large peaks that are not the maximum for the year, are also recorded in the peak-flow file at some streamgages. Such data can be used to construct a dataset of "peaks above base," that is, all peaks that were observed at a streamgage above a specified streamflow threshold. Unfortunately, secondary peaks have been stored somewhat inconsistently, meaning that, although an uncommon case, historical data may exist but a digital storage equivalent might not be available. Different thresholds were sometimes used in different years, and the way in which thresholds were set for different streamgages may not allow regional analysis. As a general rule, only annual maximum peak streamflows are used for flood frequency analysis of extreme events.
The peak-flow file for a streamgage contains all annual peak streamflows associated with the streamgage. Ancillary information about the streamgage is also contained in the text file and includes the latitude and longitude of the gaging station, the drainage area of the watershed at the location of the streamgage, the 8-digit hydrologic unit code (HUC), and the (vertical) gage datum. For each entry, the year, month, day, and time of occurrence (if available); the magnitude of the annual peak streamflow (in cubic feet per second); the stage associated with the annual peak streamflow; and the discharge qualification codes assigned to the peak are provided. If the gage height associated with the peak streamflow is not the highest for the year (attributable to backwater or other factors), the peak gage height for the year is entered in a separate field in addition to the value associated with the peak streamflow.

\section{Discharge Qualification Codes}

Qualification codes are used to document watershed or environmental conditions that may affect the accuracy of the annual peak streamflows or other information deemed potentially useful in statistical analyses and interpretive studies (table 1-1). Every annual peak does not necessarily require a qualification code, and annual peaks can be assigned multiple codes. Codes used to qualify gage heights in the

Table 1-1. Qualification codes used by the U.S. Geological Survey in the archival of peak streamflow data for streamflow-gaging stations (streamgages).

\begin{tabular}{|c|c|}
\hline $\begin{array}{l}\text { Qualification } \\
\text { code }\end{array}$ & $\begin{array}{l}\text { Verbatim definition from U.S. Geological Survey (USGS) } \\
\text { National Water Information System database (USGS, 2016a) }\end{array}$ \\
\hline \multicolumn{2}{|r|}{ Peak discharge (streamflow) } \\
\hline 1 & Streamflow is a maximum daily average. \\
\hline 3 & Streamflow affected by dam failure. \\
\hline 4 & Streamflow is less than indicated value, which is the minimum recordable value at this site. \\
\hline 7 & Streamflow is a historical peak. \\
\hline 8 & Streamflow is actually greater than the indicated value. \\
\hline 9 & Streamflow is affected by snowmelt, hurricane, ice-jam, or debris-dam breakup. \\
\hline A & Year of occurrence is unknown or not exact. \\
\hline $\mathrm{B}$ & Month or day of occurrence is unknown or not exact. \\
\hline $\mathrm{E}$ & Only annual peak streamflow available for this year. \\
\hline \multicolumn{2}{|r|}{ Gage height } \\
\hline 1 & Gage height affected by backwater. \\
\hline 2 & Gage height not the maximum for the year. \\
\hline 3 & Gage height at different site and(or) datum. \\
\hline 4 & Gage height below minimum recordable elevation. \\
\hline 5 & Gage height is an estimate. \\
\hline 6 & Gage datum changed during this year. \\
\hline
\end{tabular}


peak-flow file are available but not presented in this report. Peak streamflow qualification codes and their meanings are listed in table 1-1.

Qualification codes 5, 6, 7, C, and combinations of these with other codes are of particular interest and are referred to as primary peak qualification codes. Code 5 is assigned to annual peak streamflows at streamgages that have some degree of regulation or diversion in the watershed upstream of the gage but likely not enough to affect the magnitude of peak streamflows. Code 6 is assigned to annual peak streamflows at a streamgage for which 10 percent or more of the upstream drainage area is regulated by reservoirs. Code 6 also is used to indicate that regulation in the watershed upstream of the streamgage might be enough to substantially affect the magnitude of flow and, consequently, the interpretation of the data for practical purposes such as statistical computations. Code $\mathrm{C}$ is assigned to annual peak streamflows from watersheds that have extensive anthropogenic channel alteration or are affected by substantial urbanization; typically such watersheds contain at least 10 percent impervious surface (Feaster and others, 2009; Gotvald and others, 2009; Weaver and others, 2009).

Code 7 is intended to be assigned to annual peak streamflows that represent historically notable, highmagnitude peaks that were observed or inferred outside the period of systematic record, commonly referred to as historic peaks. These peaks may be inferred from old newspaper articles, letters, anecdotal evidence, other historical sources, or by analysis of geological, botanical, or other paleoflood information. Code 7 streamflows may also have been physically measured during a noteworthy flood event or computed by post-event indirect methods to provide better areal coverage of the hydrology of the flood. Such annual peak streamflows, although often subject to considerable uncertainty, are useful in peak-streamflow frequency analysis because they allow the analyst to define thresholds for historic periods that otherwise could not be considered. Occasionally, annual peak streamflows assigned a code 7 are simply opportunistic, meaning that they were observed during a storm event that was otherwise not particularly great in magnitude or otherwise of notable historical importance. It is up to the analyst to determine whether or not historical peaks are truly historic or merely opportunistic and to properly apply historical peak streamflows to perception thresholds for time periods outside the systematic record when using the expected moments algorithm (EMA) or other data-censoring techniques for peak-streamflow frequency analyses such as described in this report.

The remaining qualification codes provide information about the individual annual peak streamflows. Code 1 is assigned to peaks that are maximum daily mean streamflows, rather than annual maximum instantaneous peak streamflows. Often a maximum daily mean streamflow value is recorded in the peak-flow file when the maximum instantaneous streamflow was unavailable because the stage-discharge rating was exceeded or the stage recording equipment was over ranged (a term meaning that stage was higher than instrumentation could handle) during the actual peak, but enough stage readings were recorded to compute daily mean streamflow. Code 1 has also been applied to peaks from periods when stage and streamflow were noted only once daily. The degree to which the maximum daily mean differs from the maximum instantaneous peak streamflow depends on the nature of the river system. Some rivers and streams respond quickly to storm events, resulting in rapid changes in the streamflow hydrographs from hour to hour or minute to minute. In such cases, it is possible for the maximum instantaneous peak to far exceed maximum daily mean streamflow. For other river systems, increases and decreases in flow are much more gradual, and in terms of percentage, the difference between the daily mean flow and the maximum instantaneous flow may be so small as to be negligible for practical applications. As a result, annual maximum daily means can be aggregated with annual peak streamflow into a common sample for statistical analysis.

Code 2 indicates that the annual peak streamflow is an estimate. This code may be used for several reasons, generally to indicate that the accuracy of such peak streamflows is less than the others but the accuracy cannot be quantified. Code 3 indicates annual peak streamflow that resulted from, or was affected by, dam failure; these are unique, nonrecurring events that are not representative of future flood risk. Code 4 indicates that the annual peak streamflow is less than the value stored in the database, which is the minimum recordable value at a streamgage; this code is most often applied to annual peaks from crest-stage gaging stations when the annual peak streamflow was not great enough to register a mark on the crest-stage gage. Code 8 indicates that the annual peak streamflow is greater than the value shown in the database. Code 9 indicates that the streamflow resulted from, or was affected by, snowmelt, a hurricane, or ice-jam or debris-dam breakup; code 9 is used to identify circumstances that may differ from the predominant flood-generating mechanism at the streamgage.

Lettered codes A and B indicate the year, month, or day of occurrence is unknown or not exact; code $\mathrm{D}$ indicates that the base streamflow changed during the coded year; and code $E$ is used to indicate those years in which no secondary peaks exceeded the base. Specifically, code E is needed to document that the absence of secondary peaks from the record means that, other than the annual peak (which may be above or below the base streamflow), all remaining flows were below the base streamflow. This code is not used unless a search for the secondary peaks was made and none were found to be greater than the partial-duration base value.

Reliable qualifications of annual peak streamflows are important for end-user application using the data. For example, codes 5, 6, and $\mathrm{C}$ are useful for peak-streamflow frequency analysis, because they document anthropogenic activities that could substantially affect annual peak streamflows. In many cases, however, the percentage of drainage area regulated by reservoirs or covered by an 
impervious surface has not been explicitly determined, nor has the effect of these characteristics on the numerical value of peak streamflow been quantified. Furthermore, analyst-toanalyst variability in the interpretation and application of the coding system remains in the peak-flow file, despite efforts to standardize application.

\section{Uncertainty of Annual Peak Streamflows}

Although quantitative estimates of the uncertainty of individual peaks are not available, some information can be inferred from information in the peak-flow file or the streamflow records. When qualification codes $1,2,4$, or 8 are applied to a peak, larger than normal uncertainty then exists for the peak in question, as discussed in the previous section.

The largest peaks at a streamgage location may define the upper end of the stage-discharge rating, as there are very few measurements available for these rare events. In such cases, the uncertainty of the individual measurements will strongly affect the uncertainty associated with the peak in the streamflow record. Annual peak streamflow databases of the USGS do not include information about measurement uncertainty or measurement methods for these streamflow measurements. Additional consultation with USGS personnel familiar with the streamgage in question may be useful.

In general, the uncertainty of an individual peak is far smaller than the range of peak streamflows observed at a streamgage. Consequently, the uncertainties of peaks within the systematic record typically are not explicitly accounted for in flood frequency analysis. Where historical information or paleoflood information is used, attempts are often made to assign an upper and lower bound to the peak streamflow to reflect the greater uncertainty associated with this type of information.

\section{Annual Peak Streamflow Data Used for Example in This Study}

The annual peak streamflow data on which the computations and results of this study are based for very low annual exceedance probability (AEP) estimation were acquired from NWIS (USGS, 2016a), and these data simultaneously serve as example data from the USGS peakflow file for purposes of this appendix. The annual peak streamflow data for streamgage 01400500 Raritan River at Manville, New Jersey, are listed in table 1-2 and the data for 01638500 Potomac River at Point of Rocks, Maryland, are listed in table 1-3. Several columns of information (almost exclusively null values) unrelated to the annual peak streamflow and its corresponding gage height are not shown for brevity. 
Table 1-2. Annual peak streamflow data for U.S. Geological Survey streamflow-gaging station 01400500 Raritan River at Manville, New Jersey.

[Discharge and gage-height qualification codes are listed in table 1-1, and only a small fraction are listed with these data. Text in red is referenced directly in the report. $\mathrm{ft}^{3} / \mathrm{s}$, cubic foot per second; ft, foot; --, no entry or not available]

\begin{tabular}{|c|c|c|c|c|c|c|c|c|c|c|c|c|c|}
\hline $\begin{array}{c}\text { Water } \\
\text { year }\end{array}$ & $\begin{array}{c}\text { Peak } \\
\text { stream- } \\
\text { flow } \\
\text { date }\end{array}$ & $\begin{array}{c}\text { Peak } \\
\text { stream- } \\
\text { flow } \\
\left(\mathrm{ft}^{3} / \mathrm{s}\right)\end{array}$ & $\begin{array}{c}\text { Dis- } \\
\text { charge } \\
\text { qualifi- } \\
\text { cation } \\
\text { code }\end{array}$ & $\begin{array}{c}\text { Gage } \\
\text { height } \\
\text { (ft) }\end{array}$ & $\begin{array}{l}\text { Gage- } \\
\text { height } \\
\text { qualifi- } \\
\text { cation } \\
\text { code }\end{array}$ & $\begin{array}{c}\text { Highest } \\
\text { since } \\
\text { year }\end{array}$ & $\begin{array}{c}\text { Water } \\
\text { year }\end{array}$ & $\begin{array}{c}\text { Peak } \\
\text { stream- } \\
\text { flow } \\
\text { date }\end{array}$ & $\begin{array}{c}\text { Peak } \\
\text { stream- } \\
\text { flow } \\
\left(\mathrm{ft}^{3} / \mathrm{s}\right)\end{array}$ & $\begin{array}{c}\text { Dis- } \\
\text { charge } \\
\text { qualifi- } \\
\text { cation } \\
\text { code }\end{array}$ & $\begin{array}{c}\text { Gage } \\
\text { height } \\
\text { (ft) }\end{array}$ & $\begin{array}{l}\text { Gage- } \\
\text { height } \\
\text { qualifi- } \\
\text { cation } \\
\text { code }\end{array}$ & $\begin{array}{c}\text { Highest } \\
\text { since } \\
\text { year }\end{array}$ \\
\hline 1904 & 1903-10-10 & 28,600 & $\mathrm{E}$ & 18.50 & -- & -- & 1964 & 1964-01-10 & 13,600 & -- & 14.52 & -- & -- \\
\hline 1905 & $1905-01-07$ & 18,600 & E & 15.40 & -- & -- & 1965 & 1965-02-08 & 12,700 & -- & -- & -- & -- \\
\hline 1906 & 1906-03-04 & 13,600 & E & 13.30 & -- & -- & 1966 & $1966-02-14$ & 13,200 & -- & 14.63 & -- & -- \\
\hline 1911 & 1911-09-01 & 10,800 & E & 12.00 & -- & -- & 1969 & 1969-07-29 & 13,100 & -- & 14.23 & -- & -- \\
\hline 1912 & 1912-03-13 & 20,400 & E & 16.00 & -- & -- & 1970 & 1970-04-03 & 23,700 & -- & 18.22 & -- & -- \\
\hline 1913 & $1912-12-31$ & 14,100 & E & 13.50 & -- & -- & 1971 & $1971-08-28$ & 36,300 & -- & 23.80 & -- & -- \\
\hline 1914 & 1914-03-18 & 15,300 & E & 14.00 & -- & -- & 1972 & $1972-06-23$ & 21,800 & -- & 17.89 & -- & -- \\
\hline 1915 & 1915-02-02 & 25,200 & E & 17.50 & -- & -- & 1973 & 1973-08-02 & 19,600 & -- & 17.47 & -- & -- \\
\hline 1922 & 1922-02-02 & 13,000 & E & 13.00 & -- & -- & 1974 & $1973-12-21$ & 20,000 & -- & 18.42 & -- & -- \\
\hline 1926 & $1926-02-26$ & 13,000 & -- & 13.00 & -- & -- & 1978 & $1978-01-26$ & 19,400 & -- & 17.77 & -- & -- \\
\hline 1927 & 1927-08-01 & 12,100 & -- & 12.60 & -- & -- & 1979 & $1979-01-25$ & 23,000 & -- & -- & -- & -- \\
\hline 1928 & 1927-10-19 & 15,600 & -- & 14.10 & -- & -- & 1980 & $1980-03-22$ & 17,700 & -- & 16.63 & -- & -- \\
\hline 1929 & 1929-02-27 & 13,600 & -- & 13.34 & -- & -- & 1981 & $1981-05-12$ & 17,900 & -- & 15.99 & -- & -- \\
\hline 1930 & 1930-03-08 & 11,300 & -- & 11.93 & -- & -- & 1982 & $1982-01-05$ & 17,000 & -- & 16.60 & -- & -- \\
\hline 1931 & 1931-07-11 & 9,690 & -- & 11.30 & -- & -- & 1983 & 1983-04-16 & 22,800 & -- & 18.39 & -- & -- \\
\hline 1932 & $1932-03-28$ & 14,800 & -- & 13.76 & -- & -- & 1984 & 1984-07-07 & 27,300 & -- & 19.95 & -- & -- \\
\hline 1933 & 1933-08-24 & 21,000 & -- & 16.22 & -- & -- & 1985 & 1985-09-28 & 11,500 & -- & 13.33 & -- & -- \\
\hline 1934 & 1934-03-05 & 16,600 & -- & 14.52 & -- & -- & 1986 & $1986-01-26$ & 15,800 & -- & 14.65 & -- & -- \\
\hline 1935 & $1935-02-15$ & 10,500 & -- & 11.60 & -- & -- & 1987 & 1987-04-04 & 17,600 & -- & 16.17 & -- & -- \\
\hline 1936 & 1936-01-03 & 20,600 & -- & 16.10 & -- & -- & 1988 & 1988-07-27 & 10,900 & -- & 12.86 & -- & -- \\
\hline 1937 & $1936-12-20$ & 15,800 & -- & 14.23 & -- & -- & 1989 & 1989-09-21 & 16,200 & -- & 16.24 & -- & -- \\
\hline 1946 & 1946-06-02 & 19,900 & -- & 17.76 & -- & -- & 1998 & 1998-04-10 & 10,900 & -- & 12.26 & 2 & -- \\
\hline 1947 & 1947-04-05 & 7,480 & -- & 10.89 & -- & -- & 1999 & 1999-09-16 & 77,600 & -- & 27.10 & 2 & 1896 \\
\hline 1948 & 1947-11-09 & 11,900 & -- & 13.57 & -- & -- & 2000 & $2000-02-14$ & 6,660 & -- & 9.23 & 2 & \\
\hline 1949 & $1948-12-31$ & 22,100 & -- & 19.80 & -- & -- & 2001 & 2001-01-19 & 12,000 & -- & 12.19 & -- & -- \\
\hline 1950 & 1950-03-23 & 8,660 & -- & 11.59 & -- & -- & 2002 & 2002-05-14 & 10,600 & -- & 11.97 & -- & -- \\
\hline 1951 & $1950-11-26$ & 18,200 & -- & 16.17 & -- & -- & 2003 & 2003-06-04 & 11,000 & -- & 12.83 & 2 & -- \\
\hline 1952 & 1951-11-07 & 20,400 & -- & 17.17 & -- & -- & 2004 & 2003-12-11 & 19,100 & -- & 16.53 & -- & -- \\
\hline 1953 & 1953-04-07 & 15,400 & -- & 14.70 & -- & -- & 2005 & 2005-04-03 & 19,300 & -- & 16.90 & -- & -- \\
\hline 1954 & $1953-12-14$ & 9,820 & -- & 12.10 & -- & -- & 2006 & $2005-10-12$ & 19,200 & -- & 16.44 & -- & -- \\
\hline 1955 & 1955-08-19 & 34,600 & -- & 21.80 & 2 & -- & 2007 & $2007-04-16$ & 30,400 & -- & -- & -- & -- \\
\hline 1956 & $1955-10-15$ & 26,200 & -- & 19.60 & 2 & -- & 2008 & 2008-03-09 & 19,700 & -- & 16.71 & -- & -- \\
\hline 1957 & 1957-04-05 & 10,800 & -- & 13.10 & -- & -- & 2009 & $2008-12-12$ & 15,800 & -- & 16.00 & -- & -- \\
\hline 1958 & $1958-02-28$ & 16,500 & -- & 16.10 & -- & -- & 2010 & 2010-03-14 & 28,900 & -- & 21.54 & -- & -- \\
\hline 1959 & 1958-10-26 & 9,200 & -- & 11.96 & -- & -- & 2011 & $2011-08-28$ & 53,000 & -- & 26.24 & -- & -- \\
\hline 1960 & 1960-09-13 & 14,700 & -- & 15.30 & -- & -- & 2012 & 2011-12-08 & 15,000 & -- & 14.85 & -- & -- \\
\hline 1961 & 1961-03-24 & 11,500 & -- & 13.55 & -- & -- & 2013 & 2013-06-08 & 15,200 & -- & 15.23 & -- & -- \\
\hline 1962 & 1962-03-13 & 15,000 & -- & 15.40 & -- & -- & 2014 & 2014-05-01 & 25,300 & -- & 19.99 & -- & -- \\
\hline 1963 & 1963-03-07 & 11,700 & -- & 13.57 & -- & -- & -- & -- & -- & -- & -- & -- & -- \\
\hline
\end{tabular}


Table 1-3. Annual peak streamflow data for U.S. Geological Survey streamflow-gaging station 01638500 Potomac River at Point of Rocks, Maryland.

[Discharge and gage-height qualification codes are listed in table 1-1, and only a small fraction are listed with these data. Text in red is referenced directly in the report. $\mathrm{ft}^{3} / \mathrm{s}$, cubic foot per second; $\mathrm{ft}$, foot; --, no entry or not available]

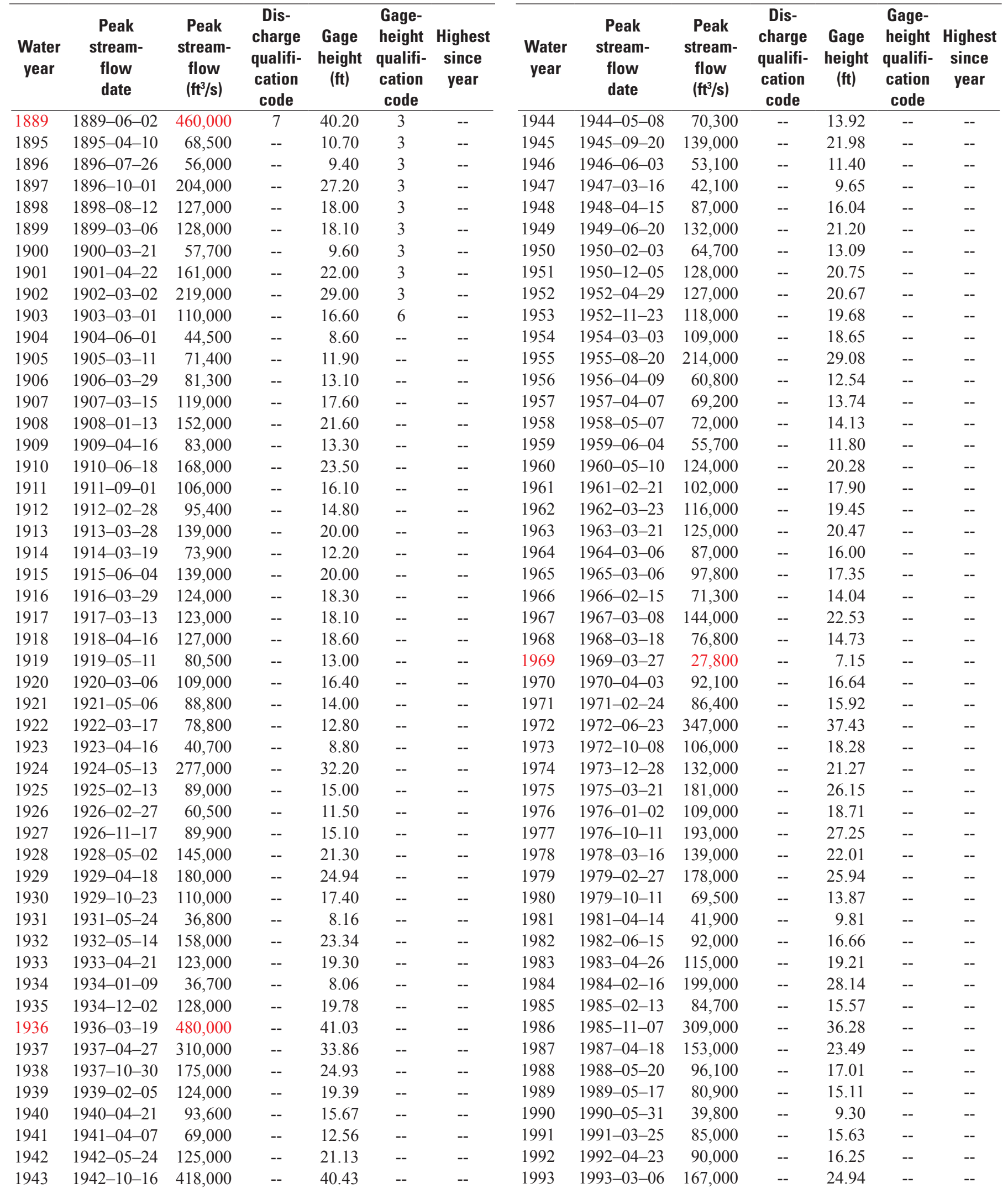


Table 1-3. Annual peak streamflow data for U.S. Geological Survey streamflow-gaging station 01638500 Potomac River at Point of Rocks, Maryland.-Continued

[Discharge and gage-height qualification codes are listed in table 1-1, and only a small fraction are listed with these data. Text in red is referenced directly in the report. $\mathrm{ft}^{3} / \mathrm{s}$, cubic foot per second; ft, foot; --, no entry or not available]

\begin{tabular}{|c|c|c|c|c|c|c|c|c|c|c|c|c|c|}
\hline $\begin{array}{c}\text { Water } \\
\text { year }\end{array}$ & $\begin{array}{c}\text { Peak } \\
\text { stream- } \\
\text { flow } \\
\text { date }\end{array}$ & $\begin{array}{c}\text { Peak } \\
\text { stream- } \\
\text { flow } \\
\left(\mathrm{ft}^{3} / \mathrm{s}\right)\end{array}$ & $\begin{array}{c}\text { Dis- } \\
\text { charge } \\
\text { qualifi- } \\
\text { cation } \\
\text { code }\end{array}$ & $\begin{array}{c}\text { Gage } \\
\text { height } \\
\text { (ft) }\end{array}$ & $\begin{array}{l}\text { Gage- } \\
\text { height } \\
\text { qualifi- } \\
\text { cation } \\
\text { code }\end{array}$ & $\begin{array}{c}\text { Highest } \\
\text { since } \\
\text { year }\end{array}$ & $\begin{array}{c}\text { Water } \\
\text { year }\end{array}$ & $\begin{array}{c}\text { Peak } \\
\text { stream- } \\
\text { flow } \\
\text { date }\end{array}$ & $\begin{array}{c}\text { Peak } \\
\text { stream- } \\
\text { flow } \\
\left(\mathrm{ft}^{3} / \mathrm{s}\right)\end{array}$ & $\begin{array}{c}\text { Dis- } \\
\text { charge } \\
\text { qualifi- } \\
\text { cation } \\
\text { code }\end{array}$ & $\begin{array}{c}\text { Gage } \\
\text { height } \\
\text { (ft) }\end{array}$ & $\begin{array}{l}\text { Gage- } \\
\text { height } \\
\text { qualifi- } \\
\text { cation } \\
\text { code }\end{array}$ & $\begin{array}{c}\text { Highest } \\
\text { since } \\
\text { year }\end{array}$ \\
\hline 1994 & 1993-11-29 & 115,000 & -- & 19.25 & -- & -- & 2005 & $2005-03-30$ & 116,000 & -- & 19.37 & -- & -- \\
\hline 1995 & 1995-01-17 & 87,200 & -- & 15.90 & -- & -- & 2006 & $2005-12-01$ & 73,100 & -- & 14.10 & -- & -- \\
\hline 1996 & 1996-01-21 & 310,000 & -- & 36.34 & -- & -- & 2007 & 2007-04-17 & 96,000 & -- & 17.00 & -- & -- \\
\hline 1999 & 1999-03-20 & 40,600 & -- & 9.42 & -- & -- & 2010 & $2010-03-15$ & 172,000 & -- & 25.52 & -- & -- \\
\hline 2000 & $2000-02-20$ & 61,600 & -- & 12.54 & -- & -- & 2011 & 2011-04-18 & 144,000 & -- & 22.52 & -- & -- \\
\hline 2001 & $2001-03-23$ & 66,600 & -- & 13.23 & -- & -- & 2012 & 2011-12-09 & 74,800 & -- & 14.32 & -- & -- \\
\hline 2002 & 2002-04-24 & 52,300 & -- & 11.21 & -- & -- & 2013 & $2012-10-31$ & 106,000 & -- & 18.19 & -- & -- \\
\hline 2003 & $2003-09-21$ & 150,000 & -- & 23.12 & -- & -- & 2014 & 2014-05-17 & 145,000 & -- & 22.62 & -- & -- \\
\hline
\end{tabular}

\section{Appendix 1 References Cited}

Baker, V.R., 1987, Paleoflood hydrology and extraordinary flood events: Journal of Hydrology, v. 96, p. 79-99.

Benson, M.A., and Dalrymple, Tate, 1967, General field and office procedures for indirect measurements: U.S. Geological Survey Techniques of Water-Resources Investigations, book 3, chap. Al, 30 p. [Also available at http://pubs.usgs.gov/twri/twri3-a1/.]

Bodhaine, G.L., 1968, Measurement of peak discharge at culverts by indirect methods: U.S. Geological Survey Techniques of Water-Resources Investigations, book 3, chap. A3, 60 p. [Also available at http://pubs.usgs.gov/twri/ twri3-a3/.]

Dalrymple, Tate, and Benson, M.A., 1967, Measurement of peak discharge by the slope-area method: U.S. Geological Survey Techniques of Water-Resources Investigations, book 3, chap. A2, 12 p. [Also available at http://pubs.usgs. gov/twri/twri3-a2/.]

Feaster, T.D., Gotvald, A.J., and Weaver, J.C., 2009, Magnitude and frequency of rural floods in the southeastern United States, 2006-Volume 3, South Carolina: U.S. Geological Survey Scientific Investigations Report 20095156, 226 p.

Gotvald, A.J., Feaster, T.D., and Weaver, J.C., 2009, Magnitude and frequency of rural floods in the southeastern United States, 2006-Volume 1, Georgia: U.S. Geological Survey Scientific Investigations Report 2009-5043, 120 p.

Harwell, G.R., and Asquith, W.H., 2011, Annual peak streamflow and ancillary data for small watersheds in central and western Texas: U.S. Geological Survey Fact Sheet 2011-3082, 4 p. [Also available at http://pubs.usgs. gov/fs/2011/3082/.]

Hulsing, Harry, 1967, Measurement of peak discharge at dams by indirect methods: U.S. Geological Survey Techniques of Water-Resources Investigations, book 3, chap. A5, 29 p. [Also available at http://pubs.usgs.gov/twri/twri3-a5/.]

Kennedy, E.J., 1984, Discharge ratings at gaging stations: U.S. Geological Survey Techniques of Water-Resources Investigations, book 3, chap. A10, 59 p. [Also available at http://pubs.usgs.gov/twri/twri3-a10/.]

Lurry, D.L., 2011, How does a U.S. Geological Survey streamgage work?: U.S. Geological Survey Fact Sheet 2011-3001, 2 p. [Also available at http://pubs.usgs.gov/ fs/2011/3001/.]

Matthai, H.F., 1967, Measurement of peak discharge at width contractions by indirect methods: U.S. Geological Survey Techniques of Water-Resources Investigations, book 3, chap. A4, 44 p. [Also available at http://pubs.usgs.gov/twri/ twri3-a4/.]

Mueller, D.S., and Wagner, C.R., 2009, Measuring discharge with acoustic Doppler current profilers from a moving boat: U.S. Geological Survey Techniques and Methods, book 3, chap. A22, 95 p. [Also available at http://pubs.water.usgs. gov/tm3a22.] 
Nielsen, J.P., and Norris, J.M., 2007, From the river to youUSGS real-time streamflow information: U.S. Geological Survey Fact Sheet 2007-3043, 4 p. [Also available at http:// pubs.usgs.gov/fs/2007/3043/.]

Oberg, K.A., and Mueller, D.S., 2007, Validation of streamflow measurements made with acoustic Doppler current profilers: Journal of Hydraulic Engineers, v. 133, no. 12 , p. 1421-1432.

O’Connor, J.E., Atwater, B.F., Cohn, T.A., Cronin, T.M., Keith, M.K., Smith, C.G., and Mason, R.R., 2014, Assessing inundation hazards to nuclear powerplant sites using geologically extended histories of riverine floods, tsunamis, and storm surges: U.S. Geological Survey Scientific Investigations Report 2014-5207, 65 p.

Olson, S.A., and Norris, J.M., 2007, U.S. Geological Survey streamgaging - from the National Streamflow Information Program: U.S. Geological Survey Fact Sheet 2005-3131, 4 p. [Also available at http://pubs.usgs.gov/fs/2005/3131/.]

Sauer, V.B., and Turnipseed, D.P., 2010, Stage measurement at gaging stations: U.S. Geological Survey Techniques and Methods, book 3, chap. A7, 45 p. [Also available at http:// pubs.usgs.gov/tm/tm3-a7/.]

SonTek/YSI Corporation, 2002, SonTek/YSI FlowTracker Handheld ADV technical documentation: San Diego, Calif., SonTek/YSI Corporation, 2 p.
Turnipseed, D.P., and Sauer, V.B., 2010, Discharge measurements at gaging stations: U.S. Geological Survey Techniques and Methods, book 3, chap. A8, 87 p. [Also available at http://pubs.usgs.gov/tm/tm3-a8/.]

U.S. Geological Survey [USGS], 2016a, Peak streamflow for the Nation: National Water Information System Web interface, Accessed June 2, 2016, at http://nwis.waterdata. usgs.gov/nwis/peak.

U.S. Geological Survey [USGS], 2016b, USGS current water data for the Nation: National Water Information System Web interface: Accessed November 3, 2016, at http:// waterdata.usgs.gov/nwis/rt.

U.S. Geological Survey [USGS], 2016c, USGS water data for the Nation: National Water Information System Web interface: Accessed November 3, 2016, at http:/waterdata. usgs.gov/nwis.

Wahl, K.L., Thomas, W.O. Jr., and Hirsch, R.M., 1995, Stream-gaging program of the U.S. Geological Survey: U.S. Geological Survey Circular 1123, 22 p. [Also available at http://pubs.er.usgs.gov/publication/cir1123.]

Weaver, J.C., Feaster, T.D., and Gotvald, A.J., 2009, Magnitude and frequency of rural floods in the Southeastern United States, through 2006-Volume 2, North Carolina: U.S. Geological Survey Scientific Investigations Report 2009-5158, 111 p. 


\section{Appendix 2. Primer on Product Moment Theory and Plotting Positions as Applicable to This Study}

This appendix summarizes the theory of plotting positions and the mathematical theory related to product moments used for probability distribution fitting. Product moments are used by the USGS-PeakFQ software with two options for parameter estimation - those described in Bulletin 17B (Interagency Advisory Committee on Water Data [IACWD], 1982) and the expected moments algorithm (EMA) (England and Cohn, 2007; John F. England, Jr., U.S. Army
Corps of Engineers, written commun., 2017). The mathematics of the EMA fitting process are complex (USGS, 2014;

Veilluex and others, 2014). For this report, the lesser complex product moments are presented in three compartmentalized figures. Plotting positions as used in this study are reviewed in figure $2-1$. The theoretical product moments (centered on the arithmetic mean) are shown in figure 2-2, whereas the sample versions are shown in figure $2-3$. 


\section{Plotting Positions for Graphical Display of the Empirical Distribution}

\section{Weibull Plotting Positions}

Plotting positions can be used to define the exceedance probabilities $S$ of individual data points from the order statistics $x_{1: n} \geq x_{2: n} \geq \cdots \geq x_{n: n}$ of sample size $n$ when no historical information is present. Plotting positions are used for graphical display of the empirical distribution in this report. $S_{i} \equiv$ AEP is annual exceedance probability as used elsewhere in this report. An elementary formula to compute $S$ for the $i$ th largest flood is

$$
S_{i}=\frac{i-a}{n+1-2 a}
$$

where $i$ is an ascending rank and $a$ is a coefficient and treated as $a=0$ in this report (the Weibull plotting positions; Asquith (2011a,b, 2016)). The true probability associated with the largest (and smallest) observation is a random variable with mean $1 /(n+1)$ and a standard deviation of nearly $1 /(n+1)$. The formula gives rough estimates of the unknown AEP and particularly rough estimates associated with largest and smallest events. As $n$ becomes large, the choice of $a$ becomes relatively unimportant. To reiterate, equation 2.1.1 holds for a complete flood sample lacking historical information.

\section{Hirsch-Stedinger Plotting Positions}

The more complex Hirsch-Stedinger plotting positions (Hirsch and Stedinger, 1987) provide a generalization to historical information. Plotting positions for systematic record floods below a threshold must be adjusted to reflect the additional information provided by the historical flood record. The mathematic nomenclature herein closely follows that of John F. England, Jr. (U.S. Army Corps of Engineers, written commun., 2017). The number of thresholds of the historic record is defined as $j \in 1, \cdots, m$ that is to read " $j$ in the integer sequence 1 to $m$," where the discharge thresholds $Q_{j} \in 1, \cdots, m$ are ordered (sorted) from largest to smallest such that $Q_{1}>Q_{2}>\cdots>Q_{m}$. The probability of exceedance $S_{e_{j}}$ for each threshold $j$ is computed as

$$
S_{e_{j}}=S_{e_{j-1}}+\left(1-S_{e_{j-1}}\right) \times q_{e_{j}},
$$

where $q_{e_{j}}$ is the conditional probability that a flood falls between the $j$ th and $(j-1)$ th threshold and is

$$
q_{e_{j}}=\frac{k_{j}}{n_{j}-\sum_{m=1}^{j-1} k_{m}},
$$

where $k_{j}$ is the number of floods that exceed threshold $j$ but also not any higher thresholds $(j-1)$, and the denominator represents the number of years $\left(n_{j}\right)$ that threshold $Q_{j}$ applies minus the sum of all floods $k_{m}$ that exceed any higher $(j-1, j-2, \cdots)$ thresholds during period $n_{j}$. The above-threshold floods can be plotted by

$$
S_{i}=S_{e_{j-1}}+\left(1-S_{e_{j-1}}\right) \times q_{e_{j}}\left(\frac{i-a}{k_{j}+1-2 a}\right),
$$

and the below-threshold floods can be plotting using

$$
S_{r}=S_{e_{j}}+\left(1-S_{e_{j}}\right)\left(\frac{r-a}{n_{s}-e_{s}+1-2 a}\right),
$$

where $r \in 1, \cdots,\left(n_{s}-e_{s}\right) ; e_{s}$ is the number of systematic-record floods that exceed a threshold; and $n_{s}$ is the length of the systematic record.

Figure 2-1. Definition of plotting positions in context of empirical distributions after Asquith (2011a,b, 2016) and Hirsch and Stedinger (1987). 


\section{Theoretical Central Product Moments}

Theoretical product moments (centered on the arithmetic mean) of random variable $X$ are defined by centering differences on the arithmetic mean. The first product moment is the mean, which measures the location of the distribution on the real-number line, and is defined as the expectation $(\mathrm{E}[\cdots])$

$$
\mu=\mathrm{E}[X]=\int_{-\infty}^{\infty} x f(x) \mathrm{d} x
$$

The higher-order product moments $\left(M_{r}\right)$ for moment order $r$ are defined in terms of expectations of powers of differences from the mean $\mu$ :

$$
M_{r}=\mathrm{E}\left[(X-\mu)^{r}\right]=\int_{-\infty}^{\infty}(x-\mu)^{r} f(x) \mathrm{d} x \quad \text { for } r \geq 2,
$$

where $M_{2}$ is known as the variance $\sigma^{2}$ and the standard deviation is $\sigma=\sqrt{\sigma^{2}}$. In practice, dimension is often removed for $r \geq 2$ to form the well-known ratios that represent the coefficient of variation, skew, and kurtosis:

$$
\begin{aligned}
C V & =\sigma / \mu=\text { coefficient of variation, } \\
G & =M_{3} / M_{2}^{3 / 2}=\text { skew, and } \\
K & =M_{4} / M_{2}^{2}=\text { kurtosis. }
\end{aligned}
$$

Figure 2-2. Definition of theoretical product moments centered on the arithmetic mean from definitions of the probability density function of a given distribution after Asquith (2011a,b; 2016) and references therein. 


\section{Sample Central Product Moments}

Sample product moments (centered on the arithmetic mean) for a random sample $x_{1}, x_{2}, \cdots, x_{n}$ of size $n$ are ubiquitous sample statistics. The sample mean and higher sample moments for moment order $r$ are

$$
\hat{\mu}=\frac{1}{n} \sum_{i=1}^{n} x_{i} \quad \text { and } \quad \bar{M}_{r}=\frac{1}{n} \sum_{i=1}^{n}\left(x_{i}-\hat{\mu}\right)^{r} \quad \text { for } r \geq 2,
$$

but the $\bar{M}_{r}$ are biased. An unbiased estimator for $\bar{M}_{2}$ is computed as

$$
\hat{\sigma}^{2}=\frac{1}{n-1} \sum_{i=1}^{n}\left(x_{i}-\hat{\mu}\right)^{2},
$$

and note the division by $n-1$ instead of $n$. The sample standard deviation and sample coefficient of variation thus are

$$
\hat{\sigma}=\sqrt{\hat{\sigma}^{2}} \text { and } \quad \hat{C V}=\hat{\sigma} / \hat{\mu} .
$$

Although $\hat{\sigma}^{2}$ is an unbiased estimator of variance, $\sqrt{\hat{\sigma}^{2}}$ is not an fully an unbiased estimator of $\hat{\sigma}$. Nearly unbiased estimators of sample skew and sample kurtosis are

$$
\begin{aligned}
& \hat{G}=\frac{\bar{M}_{3}}{\hat{\sigma}^{3}} \times \frac{n^{2}}{(n-1)(n-2)} \text { and } \\
& \hat{K}=\frac{1}{\hat{\sigma}^{4}} \times \frac{n^{2}}{(n-2)(n-3)} \times\left[\left(\frac{n+1}{n-1}\right) \bar{M}_{4}-3 \bar{M}_{2}^{2}\right]+3,
\end{aligned}
$$

care is needed with $\hat{K}$, because its definition can vary between software packages, including the addition of +3 because $K=3$ is the kurtosis of the Normal distribution. $\hat{K}$ is not used for fitting of probability distributions having three or fewer parameters.

Figure 2-3. Definition of sample product moments centered on the arithmetic mean from definitions of the probability density function of a given distribution after Asquith (2011a,b; 2016) and references therein. 


\section{Appendix 2 References Cited}

Asquith, W.H., 2011a, Distributional analysis with L-moment statistics using the R environment for statistical computing: Texas Tech University, Ph.D. dissertation, accessed June 3, 2016, at https://ttu-ir.tdl.org/ttu-ir/handle/2346/ETD-

TTU-2011-05-1319.

Asquith, W.H., 2011b, Distributional analysis with L-moment statistics using the R environment for statistical computing: CreateSpace ISBN 978-1463508418. [Print-on-demand; reprinting of Asquith, 2011a, with errata.]

Asquith, W.H., 2016, lmomco-L-moments, trimmed L-moments, L-comoments, censored L-moments, and many distributions: R package version 2.2.5 (September 9, 2016), accessed February 21, 2017, at http://cran.r-project.org/web/ packages/lmomco/index.html.

England, J.F., and Cohn, T.A., 2007, Scientific and practical considerations related to revising Bulletin 17B-The case for improved treatment of historical information and low outliers: American Society of Civil Engineers, EWRI World Water \& Environmental Resources Congress, p. 1-9.
Hirsch, R.M., and Stedinger, J.R., 1987, Plotting positions for historical floods and their precision: Water Resources Research, v. 23, no. 4, p. 715-727.

Interagency Advisory Committee on Water Data [IACWD], 1982, Guidelines for determining flood flow frequency: Bulletin 17B of the Hydrology Subcommittee, Office of Water Data Coordination, U.S. Geological Survey, Reston, Va., $183 \mathrm{p}$.

U.S. Geological Survey [USGS], 2014, PeakFQFlood frequency analysis based on Bulletin 17B and recommendations of the Advisory Committee on Water Information (ACWI) Subcommittee on Hydrology (SOH) Hydrologic Frequency Analysis Work Group (HFAWG): Accessed October 4, 2014, at http://water.usgs.gov/ software/PeakFQ/.

Veilleux, A.G., Cohn, T.A., Flynn, K.M., Mason, R.R., Jr., and Hummel, P.R., 2014, Estimating magnitude and frequency of floods using the PeakFQ 7.0 program: U.S. Geological Survey Fact Sheet 2013-3108, 2 p. [Also available at http:// pubs.usgs.gov/fs/2013/3108/.] 


\section{Appendix 3. Primer on L-moment Theory as Applicable to This Study}

This appendix summarizes the theory related to L-moments applicable to this study. A sequence of four compartmentalized figures is presented, each constructed with the intent of presenting an absolutely minimal summary of technically demanding mathematics. Many references are provided in the main body of the text, and for clarity, only the most pertinent references are listed here.

The core mathematics of L-moments shown in this appendix are thoroughly reviewed by Hosking (1990), Hosking and Wallis (1997), Kandeel (2015), Stedinger and others (1993), and Nair and Vineshkumar (2010), and extensions available in Asquith (2011a,b), Karian and Dudewicz (2011), and Elamir and Seheult (2003, 2004). In particular, the mathematics herein are listed in near verbatim from typesetting sources of Asquith (2011a,b) and Asquith (2016). Readers are directed to the research packages by Asquith (2016) [R package lmomco], Hosking (2015a) [R package lmom], and Karvanen (2016) [R package Lmoments], which describe the computation of L-moments in the R language (R Core Team, 2016). Much more limited support for L-moment computation is provided by a few other packages, including some for other programming languages, which can be found by Internet keyword search.

Theoretical L-moments are defined for probability distributions and summarized in figure 3-1. The L-moments of samples are defined in figure 3-2, which provides definitions for whole samples (Hosking, 1990) and for a type of censored data germane to this study (Wang and others, 2010). The variance-covariance structure of the sample L-moments used for this study is defined in figure 3-3 following the definitions of Elamir and Seheult (2004) and implementations by Asquith (2016) and Karvanen (2016). Lastly, the sample variancecovariance computations are dependent on probabilityweighted moments (PWMs, defined in fig. 3-4), which are linearly related to L-moments. Also defined in figure 3-4 are the concepts of L-skew and L-kurtosis and other L-moment ratios that are analogs to product moments of similar name and concept.

A template of an L-moment ratio diagram (Asquith, 2014; Vogel and Fennessey, 1993) is shown in figure 3-5 depicting theoretical relations between L-skew and L-kurtosis for distributions considered or referenced in this study. These distributions and the mathematics of their L-moments are summarized in appendix 5. Figure 3-5 functioned as the template for figures 10 and 13 in the report. An L-moment ratio diagram contains a copious amount of information, and considerable discussion is required.

First, the horizontal and vertical axes depict L-skew and L-kurtosis, respectively, with the axis limits being chosen narrower than the theoretical joint L-skew and L-kurtosis domain for convenience. The lower bounds of the joint relation between these two statistics is labeled as "lower bounds of L-skew and L-kurtosis" and is shown in the lower right part of the figure. The choice of the limits for the horizontal axis shows that primary interest is in positive L-skew, which is indicative of right-tail heavy (right-skewed) distributions, as is common in hydrology. The vertical origin line represents the boundary between left and right distributional asymmetry.

Second, two-parameter distributions having location and scale formulations plot as points in an L-moment ratio diagram (Hosking and Wallis, 1997), though none are shown in figure 3-5. The mathematics of these three two-parameter distributions are not shown in this report. The normal distribution is symmetrical and would plot as a point at an L-skew of zero and L-kurtosis of about 0.123 . The Gumbel is a special case of the generalized extreme value (GEV) distribution and thus would plot as a point at L-skew about 0.170 and L-kurtosis about 0.150 on the trajectory of the GEV. Similarly, the exponential distribution is a special case of several other distributions (generalized Pareto distribution [GPA], Pearson type III distribution [PE3], Weibull probability distribution [WEI], and lower boundary of the asymmetric exponential power distribution [AEP4]). The exponential would plot as a point at L-skew about 0.333 and L-kurtosis about 0.167 .

Third, the trajectories of the distributions require further discussion. The GEV, by having a mutable third parameter controlling shape, spans a range in L-skew but simultaneously is bound to a joint value of L-kurtosis, meaning that there is a specific conversion between the L-skew of the GEV and its next higher L-moment (L-kurtosis). Hence, the GEV can be represented as a line on the diagram. Other three-parameter distributions are also shown. The WEI is a reversed form of the GEV and vice versa; thus, the trajectories for these are mirror images of each other, centered about the origin line. This explains why they intersect just above an L-kurtosis of 0.1 , precisely at an L-skew of zero. Other distributional crossing might or might not be coincident with other distribution forms. The intersection of the AEP4 and GPA at an L-skew of zero corresponds to the uniform distribution (unlabeled in fig. 3-5). The generalized logistic distribution (GLO) is generally regarded in the hydrologic literature as the most L-kurtotic of the three-parameter distributions. Conversely, the GPA distribution is usually the least L-kurtotic of the three-parameter distributions until L-skew surpasses that of the exponential, at which point the PE3 becomes the least L-kurtotic of the three-parameter distributions shown. 


\section{Theoretical L-moments}

Theoretical L-moments of order $r$ for a real-valued random variable $X$ with quantile function $x(F)$ for nonexceedance probability $F$ are defined from the theoretical expectations of order statistics (the ascending order $X_{1: n} \leq X_{2: n} \leq \cdots \leq X_{j: n} \leq \cdots \leq X_{n: n}$ for sample size $n$ ):

$$
\lambda_{r}=\frac{1}{r} \sum_{k=0}^{r-1}(-1)^{k}\left(\begin{array}{c}
r-1 \\
k
\end{array}\right) \mathrm{E}\left[X_{j: n}\right]
$$

where $r$ is the integer order of the L-moment, and $\mathrm{E}\left[X_{r-k: r}\right]$ is the expectation of the $r-k$ order statistic of a sample of size $r$ :

$$
\mathrm{E}\left[X_{j: n}\right]=\frac{n !}{(j-1) !(n-j) !} \int_{0}^{1} x(F) \times F^{j-1} \times(1-F)^{n-j} \mathrm{~d} F,
$$

where the quantity to the left of the integral is

$$
\frac{n !}{(j-1) !(n-j) !}=n\left(\begin{array}{c}
n-1 \\
j-1
\end{array}\right) \quad \text { for which notationally } \quad\left(\begin{array}{l}
a \\
b
\end{array}\right)=\frac{a !}{(a-b) ! b !} \quad \text { for } b \leq a .
$$

L-moments also are formulated from $r$ th-shifted Legendre polynomials (the term in brackets):

$$
\lambda_{r}=\int_{0}^{1} x(F)\left[\sum_{k=0}^{r}(-1)^{r-k}\left(\begin{array}{l}
r \\
k
\end{array}\right)\left(\begin{array}{c}
r+k \\
k
\end{array}\right) F^{k}\right] \mathrm{d} F .
$$

The $\lambda_{r}$ for $r \geq 2$ in terms of the cumulative distribution function $F(x)$ are

$$
\lambda_{r}=\frac{1}{r} \sum_{j=0}^{r-2}(-1)^{j}\left(\begin{array}{c}
r-2 \\
j
\end{array}\right)\left(\begin{array}{c}
r \\
j+1
\end{array}\right) \int_{-\infty}^{\infty}[F(x)]^{r-j-1} \times[1-F(x)]^{j+1} \mathrm{~d} x,
$$

or alternatively

$$
\lambda_{r}=\int_{-\infty}^{\infty} F(x) \times[1-F(x)] \times L_{r}(F(x)) \mathrm{d} x,
$$

where the $L_{r}(u)$ is computed as

$$
L_{r}(u)=\frac{1}{1-r} \sum_{j=0}^{r-2}(-1)^{j}\left(\begin{array}{c}
r-1 \\
j
\end{array}\right)\left(\begin{array}{c}
r-1 \\
j+1
\end{array}\right) u^{r-2-j}(1-u)^{j} .
$$

The $\lambda_{r}$ can be written in terms of the derivatives of the quantile function $x^{(r)}(F)$ (for example, $x^{(0)}(F) \equiv x(F)$ and $x^{(1)}(F)$ is the first derivative):

$$
\lambda_{r+1}=\frac{1}{r !} \int_{0}^{1} F^{r}(1-F)^{r} \times x^{(r)}(F) \mathrm{d} F
$$

This form helps interpretation of $\lambda_{2}$ (L-scale), which is a measure of distribution variability or spread. Variability is proportional to the rate of change (the first derivative) of $x(F)$-the greater the rate of change, the larger distance between successively ordered samples.

Figure 3-1. Definition of theoretical L-moments from definitions of the quantile function and cumulative distribution functions of a given distribution after Asquith (2011a,b; 2016) and references therein. 


\section{Sample L-moments}

\section{Uncensored Sample Version}

Sample L-moments of order $r$ are computed from the sample order statistics

$x_{1: n} \leq x_{2: n} \leq \cdots \leq x_{j: n} \leq \cdots \leq x_{n: n}$ for sample size $n$ and are

$$
\hat{\lambda}_{r}=\frac{1}{r}\left(\begin{array}{c}
n \\
r
\end{array}\right)^{-1} \sum_{i=1}^{n}\left[\sum_{j=0}^{r-1}(-1)^{j}\left(\begin{array}{c}
r-1 \\
j
\end{array}\right)\left(\begin{array}{c}
i-1 \\
r-1-j
\end{array}\right)\left(\begin{array}{c}
n-i \\
j
\end{array}\right)\right] x_{i: n} .
$$

\section{Right-Censored Sample Version}

Right-censored data can be accommodated by using $\hat{\lambda}_{r}$ based on a right-censoring indicator. For indicator censoring each of the $x_{j: n}$, it is known that $x_{j: n}=\min \left(X_{j: n}, T_{j}\right)$ for a threshold $T$ that can be mutable as assigned to the $j$ th order statistic. The threshold is unknown, is not explicitly needed, and $T_{j}$ is itself possibly a random variable generated along side each realization of the random variable $X$. Let $\delta_{j: n}$ be indicators of censoring: $\delta_{j: n}=0$ indicates that $x_{j: n}$ is uncensored, $\delta_{j: n}=1$ indicates that $x_{j: n}$ is right censored (" $R C$ ").

The $\hat{\lambda}_{r}^{(R C)}$ by right-censoring indictor variable are computed by

$$
\begin{aligned}
& \hat{\lambda}_{r}=\sum_{j=1}^{n} w_{j: n}(r) \times x_{j: n}, \quad \text { where } w_{j: n}(r) \text { is a weight factor function computed by } \\
& w_{j: n}(r)=\frac{1}{r} \sum_{k=0}^{r-1}(-1)^{k}\left(\begin{array}{c}
r-1 \\
k
\end{array}\right)\left[B^{\star}(p ; a, b)-B_{\star}(q ; a, b)\right],
\end{aligned}
$$

where $\mathrm{B}(q ; a, b)$ is the Beta distribution for quantiles $p$ and $q$ and parameters $a$ and $b$. The two Beta distributions $B^{\star}$ and $B_{\star}$ are computed by

$$
\begin{aligned}
& B^{\star}(p ; a, b)=\mathrm{B}\left(1-\hat{S}_{j: n}\left(x_{j: n}\right) ; \quad r-k, k+1\right), \text { and } \\
& B_{\star}(q ; a, b)=\mathrm{B}\left(1-\hat{S}_{j-1: n}\left(x_{j-1: n}\right) ; r-k, k+1\right),
\end{aligned}
$$

for parameters $r-k$ and $k+1$ and empirical survival function $\hat{S}$ (an exceedance probability), which is defined as

$$
\hat{S}_{j: n}(x)= \begin{cases}1 & j=0, \\ \prod_{x_{j: n} \leq x}\left(\frac{n-j}{n-j+1}\right)^{1-\delta_{j: n}} & x_{1: n} \leq x<x_{n: n}, \text { and } \\ 0 & x \geq X_{n: n},\end{cases}
$$

where $1-\hat{S}$ represent conversion to nonexceedance probability.

\section{Left-Censored Sample Version}

The L-moments for left censoring by indicator variable $\hat{\lambda}^{(L C \phi)}$ as yet are not rigorously studied but left censoring can be accommodated by variable flipping and using $\hat{\lambda}^{(R C)}$ of the right-censoring version. Let $Y$ be a random variable having left censoring, flipping is made by transforming

$$
X=\phi-Y,
$$

where $\phi$ is an arbitrary constant greater than or equal to the maximum $\max (Y)$, forming the sample order statistics $x_{j: n}$ and then computing the $\hat{\lambda}_{r}^{(R C)}$. Distributions fit to the $\hat{\lambda}_{r}^{(R C)}$ require retransformation by unflipping.

Figure 3-2. Definition of sample L-moments for whole samples and for two types of censoring after Asquith (2011a,b; 2016) and references therein. 


\section{Sample Variance-Covariance of L-moments}

A distribution-free, variance-covariance matrix ( $\widehat{\operatorname{var}}(\lambda)$ ) of the sample L-moments $\left(\hat{\lambda}_{r}\right)$ for $r \in 1: r$ (up to $r$ th moment order [number of L-moments involved]) is defined by the matrix product

$$
\widehat{\operatorname{var}}(\lambda)=\mathbf{C} \hat{\Theta} \mathbf{C}^{\mathrm{T}},
$$

where the $r \times r$ matrix $\mathbf{C}$ for number of L-moments $r$ represents the coefficients of the linear combinations responsible for converting $\hat{\beta}_{k}$ (sample probability-weighted moments) to $\hat{\lambda}_{r}$ and the $r$ th row in the matrix (row notation $C[r$,$] , meaning "whole row") is defined as$

$$
\mathbf{C}[r,]_{k=0:(r-1)}=(-1)^{(r-1-k)}\left(\begin{array}{c}
r-1 \\
k
\end{array}\right)\left(\begin{array}{c}
r-1+k \\
k
\end{array}\right),
$$

where the row is padded from the right with zeros for $k<r$ to form the required lower triangular structure. Letting the falling factorial be defined as

$$
a^{(b)}=\Gamma(b+1)\left(\begin{array}{l}
a \\
b
\end{array}\right)
$$

an entry in the $\hat{\Theta}$ matrix is denoted as $\hat{\theta}_{k l}$, defined as

$$
\hat{\theta}_{k l}=\hat{\beta}_{k} \hat{\beta}_{l}-\frac{A}{n^{(k+l+2)}},
$$

where $\hat{\beta}_{k}$ or $\hat{\beta}_{l}$ are the sample probability-weighted moments for subscripted moment order $(k, l \in[0:(r-1)])$, and $A$ is defined as

$$
A=\sum_{i=1}^{n-1} \sum_{j=i+1}^{n}\left[(i-1)^{(k)}(j-k-2)^{(l)}+(i-1)^{(l)}(i-l-2)^{(k)}\right]\left(x_{i: n} \times x_{j: n}\right),
$$

where $x_{i: n}$ are the sample order statistics for a sample of size $n$. Incidentally, the matrix $\hat{\Theta}$ is the variancecovariance structure of $\hat{\beta}$, thus $\widehat{\operatorname{var}}(\beta)=\hat{\Theta}$.

A Taylor-series-based approximation can be used to estimate the variance of an L-moment ratio $\left(\tau_{r}\right.$ for $\left.r \geq 3\right)$ is based on structure of the variance of the ratio of two uniform variables in which the numerator is the $r$ th $\mathrm{L}$-moment and the denominator is $\lambda_{2}$ :

$$
\operatorname{var}\left(\tau_{r}\right) \cong\left[\frac{\operatorname{var}\left(\lambda_{r}\right)}{\mathrm{E}\left(\lambda_{r}\right)^{2}}+\frac{\operatorname{var}\left(\lambda_{2}\right)}{\mathrm{E}\left(\lambda_{2}\right)^{2}}-\frac{2 \operatorname{cov}\left(\lambda_{r}, \lambda_{2}\right)}{\mathrm{E}\left(\lambda_{r}\right) \mathrm{E}\left(\lambda_{2}\right)}\right]\left[\frac{\mathrm{E}\left(\lambda_{r}\right)}{\mathrm{E}\left(\lambda_{2}\right)}\right]^{2}
$$

where $\operatorname{var}(\cdots)$ are the along the diagonal of $\widehat{\operatorname{var}}(\lambda)$ and $\operatorname{cov}(\cdots)$ are the off-diagonal covariances. The expectations $\mathrm{E}(\cdots)$ are replaced with the sample estimates of the L-moments.

Figure 3-3. Definition of sample variance-covariance of L-moments for whole samples after Asquith (2016) and Karvanen (2016) and references therein. 


\section{Probability-Weighted Moments, Relation to L-moments, and L-moment Ratios}

\section{Theoretical Probability-Weighted Moments}

Theoretical probability-weighted moments $\beta_{r}$ of random variable $X$ with a cumulative distribution function of $F(x)$ and quantile function of $x(F)$ are defined by the expectations

$$
M_{p, r, s}=\mathrm{E}\left[x(F)^{p} F(x)^{r}(1-F(x))^{s}\right],
$$

where for the probability-weighted moment $M$, the $p, r$, and $s$ are integers. By historical convention, $\beta_{r}=$ $M_{1, r, 0}=\mathrm{E}\left[x(F) F^{r}\right]$, and so for a $x(F)$, the $\beta_{r}$ for $r \geq 0$ are

$$
\beta_{r}=\int_{0}^{1} x(F) F^{r} \mathrm{~d} F
$$

\section{Sample Probability-Weighted Moments}

Unbiased sample probability-weighted moments $\hat{\beta}_{r}$ are computed from the sample order statistics $x_{1: n} \leq$ $x_{2: n} \leq \cdots \leq x_{j: n} \leq \cdots \leq x_{n: n}$ by

$$
\hat{\beta}_{r}=n^{-1} \sum_{j=1}^{n}\left(\begin{array}{c}
j-1 \\
r
\end{array}\right) x_{j: n}
$$

and the so-called plotting-position estimators of $\hat{\beta}_{r}$ are computed by

$$
\tilde{\beta}_{r}=\frac{1}{n} \sum_{j=1}^{n}\left(\frac{j+A}{n+B}\right)^{r} x_{j: n},
$$

where $A$ and $B$ are plotting-position coefficients $A>B>-1$.

\section{Relation to L-moments}

The $\beta_{r}$ and L-moments $\lambda_{r}$ are linear combinations of each other. Methods based on one can be based on the other, and choice is often by mathematical and interpretive convenience. The system of linear equations relating $\lambda_{r}$ to $\beta_{r}$ and sample versions $\hat{\lambda}_{r}$ to $\hat{\beta}_{r}$ is

$$
\lambda_{r+1}=\sum_{k=0}^{r}(-1)^{r-k}\left(\begin{array}{l}
r \\
k
\end{array}\right)\left(\begin{array}{c}
r+k \\
k
\end{array}\right) \beta_{k} \quad \text { and } \quad \hat{\lambda}_{r+1}=\sum_{k=0}^{r}(-1)^{r-k}\left(\begin{array}{l}
r \\
k
\end{array}\right)\left(\begin{array}{c}
r+k \\
k
\end{array}\right) \hat{\beta}_{k} \quad \text { for } r \geq 0 .
$$

\section{L-moment Ratios}

Although $\beta_{0}$ is the arithmetic mean, the individual $\beta_{r}$ for $r \geq 2$ are difficult to interpret in terms of the geometry of a probability distribution or a sample. L-moments however have direct interpretations. The L-moment ratios (often just termed "L-moments") are

$$
\begin{array}{llll}
\tau_{2}=\lambda_{2} / \lambda_{1} & \text { and } & \hat{\tau}_{2}=\hat{\lambda}_{2} / \hat{\lambda}_{1} \equiv \text { coefficient of L-variation, } \\
\tau_{3}=\lambda_{3} / \lambda_{2} & \text { and } & \hat{\tau}_{3}=\hat{\lambda}_{3} / \hat{\lambda}_{2} \equiv \mathrm{L} \text {-skew, and } \\
\tau_{4}=\lambda_{4} / \lambda_{2} & \text { and } & \hat{\tau}_{4}=\hat{\lambda}_{4} / \hat{\lambda}_{2} \equiv \text { L-kurtosis }
\end{array}
$$

and for $r \geq 5$, which are unnamed, are

$$
\lambda_{r}=\lambda_{r} / \lambda_{2} \quad \text { and } \quad \hat{\lambda}_{r}=\hat{\lambda}_{r} / \hat{\lambda}_{2}
$$

Figure 3-4. Definition of probability-weighted moments, their relation to L-moments, and L-moment ratios after Asquith (2011a,b; 2016) and references therein. 


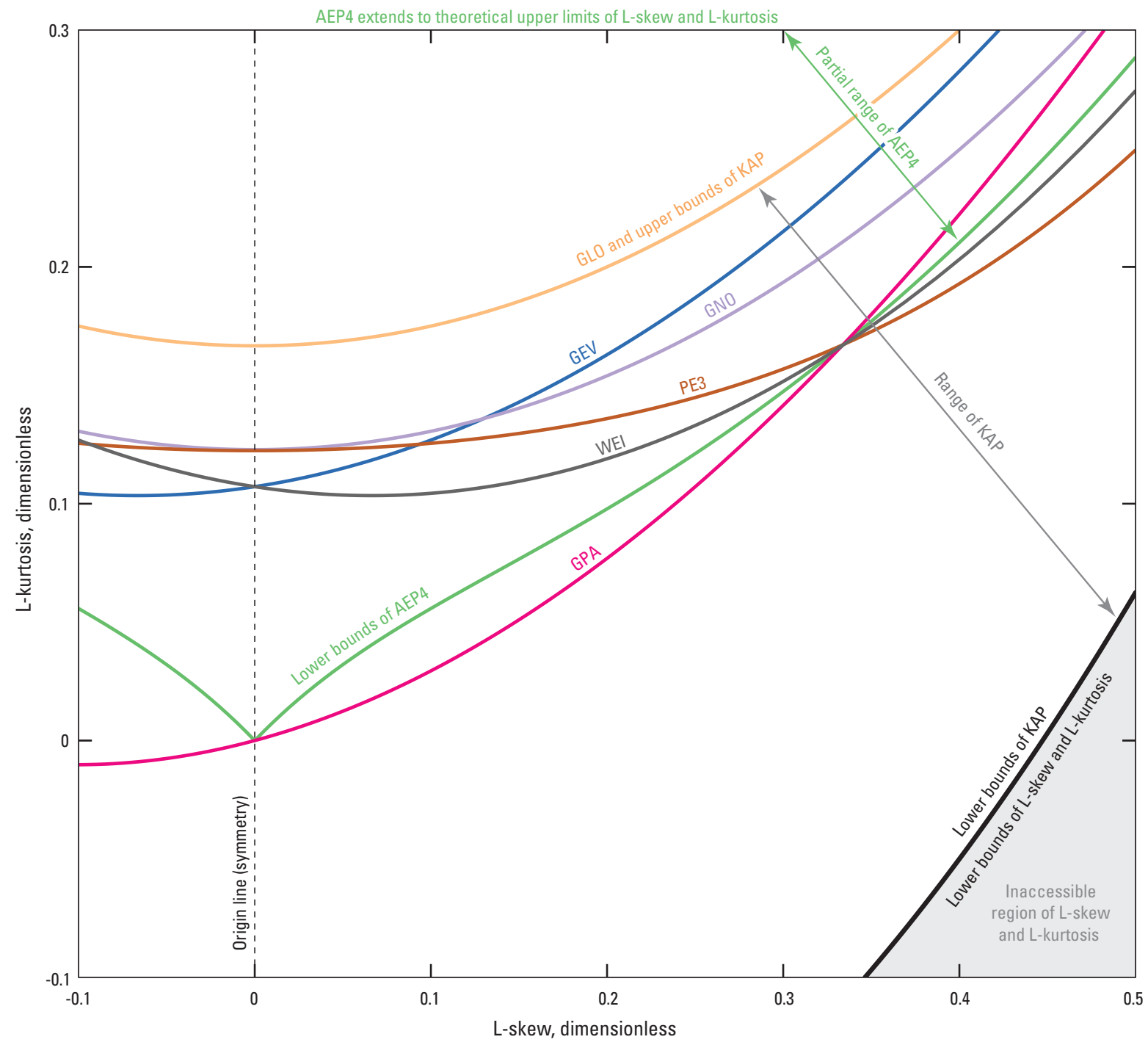

Distribution type

AEP4, asymmetric exponential power (four parameter)

GEV, generalized extreme value (three parameter)

$\mathrm{GLO}$, generalized logistic (three parameter)

GNO, generalized normal (three parameter)—Also log-normal

GPA, generalized Pareto (three parameter)

KAP, Kappa (four parameter)

PE3, Pearson type III (three parameter)

WEI, Weibull (three parameter)—Also reversed GEV

Figure 3-5. Template of an L-moment ratio diagram depicting theoretical relations between L-skew and L-kurtosis for distributions considered or referenced in this study. 
Fourth, the AEP4 is a four-parameter distribution and thus occupies an area or region in figure 3-5. The AEP4 does have a lower bound, however, indicating that the exponential distribution is a limiting form of the AEP4 for a certain L-skew, but otherwise the AEP4 has its own unique lower boundary of L-skew and L-kurtosis. The theoretical upper limit of the AEP4 is not germane to this study but does extend well beyond the upper limit of the vertical axis (Asquith, 2014). The partial range of the AEP4 shown in figure 3-5 indicates that the distribution spans many three-parameter distributions except for the PE3 and WEI for L-skew beyond the exponential. Incidentally, the Kappa (KAP) is a fourparameter distribution, and its upper and lower L-skew and L-kurtosis boundaries are shown in figure $3-5$. The domain of the KAP extends from the theoretical lower bounds of L-skew and L-kurtosis up to the trajectory of the GLO. Lastly, the other high-parameter distribution, the Wakeby (WAK), has much more complicated L-skew and L-kurtosis relations than the other distributions listed. The WAK is not depicted in figure 3-5 (and cannot readily be) because it occupies complex areas within the diagram.

\section{Appendix 3 References Cited}

Asquith, W.H., 2011a, Distributional analysis with L-moment statistics using the $\mathrm{R}$ environment for statistical computing: Texas Tech University, Ph.D. dissertation, accessed June 3, 2016, at https://ttu-ir.tdl.org/ttu-ir/handle/2346/ETDTTU-2011-05-1319.

Asquith, W.H., 2011b, Distributional analysis with L-moment statistics using the $\mathrm{R}$ environment for statistical computing: CreateSpace. [Print-on-demand; reprinting of Asquith, 2011a, with errata.]

Asquith, W.H., 2014, Parameter estimation for the 4-parameter asymmetric exponential power distribution by the method of L-moments using R: Computational Statistics \& Data Analysis, v. 71, p. 955-970.

Asquith, W.H., 2016, lmomco-L-moments, trimmed L-moments, L-comoments, censored L-moments, and many distributions: R package version 2.2.5 (September 9, 2016), accessed February 21, 2017, at http://cran.r-project.org/web/ packages/lmomco/index.html.

Elamir, E.A.H., and Seheult, A.H., 2003, Trimmed L-moments: Computational Statistics and Data Analysis, v. 43, p. 299-314.
Elamir, E.A.H., and Seheult, A.H., 2004, Exact variance structure of sample L-moments: Journal of Statistical Planning and Inference, v. 124, p. 337-359.

Hosking, J.R.M., 1990, L-moments-Analysis and estimation of distributions using linear combinations or order statistics: Journal of Royal Statistical Society, series B, v. 52, no. 1, p. $105-124$.

Hosking, J.R.M., and Wallis, J.R., 1997, Regional frequency analysis-An approach based on L-moments: Cambridge, Cambridge University Press, 224 p.

Hosking, J.R.M., 2015a, lmom-L-moments: R package version 2.5 (February 2, 2015), accessed February 21, 2017, at http://cran.r-project.org/package=lmom.

Kandeel, A.F., 2015, Linear moments-An overview: International Journal of Business and Statistical Analysis, v. 2 , no. 2 , p. $85-90$.

Karian, Z.A., Dudewicz, E.J., 2011, Handbook of fitting statistical distributions with R: Boca Raton, Fla., CRC Press, 1,672 p.

Karvanen, Juha, 2016, Lmoments-L-moments and quantile mixtures: R package version 1.2-3 (February 22, 2016), accessed February 21, 2017, at https://cran.r-project.org/ web/packages/Lmoments/index.html.

Nair, N.U., and Vineshkumar, B., 2010, L-moments of residual life: Journal of Statistical Planning and Inference, v. 140, no. 9, p. 2618-2631.

R Core Team, 2016, R—A language and environment for statistical computing, version 3.2.4: Vienna, Austria, $\mathrm{R}$ Foundation for Statistical Computing.

Stedinger, J.R., Vogel, R.M., and Foufoula-Georgiou, Efi, 1993, Frequency analysis of extreme events, chap. 18 of D.A. Maidment, ed., Handbook of hydrology: New York, McGraw-Hill, p. 18.1-18.66.

Vogel, R.M., and Fennessey, N.M., 1993, L moment diagrams should replace product moment diagrams: Water Resources Research, v. 29 , no. 6, p. 1745-1752.

Wang, Dongliang, Hutson, A.D., and Miecznikowski, J.C., 2010, L-moment estimation for parametric survival models given censored data: Statistical Methodology, v. 7, no. 6, p. 655-667. 


\section{Appendix 4. Primer on Goodness-of-Fit Metrics and Association to the Methods of Maximum Likelihood and Maximum Product of Spacings as Applicable to This Study}

This appendix summarizes the theory for selected metrics of goodness-of-fit applicable to this study through presentation of two compartmentalized figures of associated mathematics and discussion. In addition, this appendix documents the formulation for the two methods of maximum likelihood (MLE) and maximum product of spacings (MPS) considered for parts of this study to also estimate distribution parameters. The first two goodness-of-fit measures as hypothesis tests are the Cramér-von Mises (fig. 4-1, top section) and Kolmogorov-Smirnov (fig. 4-1, bottom section). These two tests are shown together in a common figure, because there is some mathematical similarity between the two. The principal commonality is that both are based on differences between the empirical cumulative distribution function that stems from the data and the theoretical cumulative distribution function. The latter function is usually taken as the final form of a fitted distribution to the data by a parameter estimation method, such as MLE. The mathematics in figure 4-1 show that Cramérvon Mises fundamentally is based on a square difference between two functions for the cumulative distribution, whereas Kolmogorov-Smirnov is based on the largest absolute difference. Further details are shown within the figure.

The next two goodness-of-fit measures as just a value or hypothesis test, respectively, are the Akaike Information Criterion (AIC; fig. 4-2, top section) and Moran-Darling (fig. 4-2, bottom section). Both are shown in a common figure, because their close association to MLE and MPS provides a concise means to compare and contrast the two tests. The AIC is simply a shift in the value for the objective function involved in the method of maximum likelihood. AIC and MLE are both based on the probability density function. The Moran-Darling test is oriented around Moran's M, which is a summation of the logarithmic spacings between ordered probabilities for the sample from the cumulative distribution function. Maximization of Moran's M is the method of maximum product of spacings. Further details are shown within the figure. 


\section{Goodness-of-Fit Statistics (Cramér-von Mises Test and Kolmogorov-Smirnov Test)}

\section{Cramér-von Mises Test}

The Cramér-von Mises test for goodness-of-fit is defined on the cumulative distribution function by the squared distance $\omega^{2}$ computed as

$$
\omega^{2}=\int_{-\infty}^{\infty}\left[F_{n}(x)-F_{\theta}(x)\right]^{2} \mathrm{~d} F(x)
$$

where $F_{\theta}(x)$ is a continuous cumulative distribution function for some distribution having parameters $\theta$ and $F_{n}(x)$ is the empirical cumulative distribution function defined as

$$
F_{n}(x)=\frac{1}{n} \sum_{i=1}^{n} \mathbf{I}_{[-\infty, x]} x_{i: n},
$$

where $\mathbf{I}_{[-\infty, x]}$ is an indicator function equal to 1 if $x_{i: n} \leq x$ and equal to 0 otherwise. The test is implemented for the sample order statistics $x_{1: n} \leq x_{i: n} \leq x_{n: n}$ of a sample of size $n$. The test statistic $\omega_{n}^{2}$ is defined (Anderson, 1962; Csörgö and Faraway, 1996) as

$$
\omega_{n}^{2}=\frac{1}{12 n}+\sum_{i=1}^{n}\left[\frac{2 i-1}{2 n}-F_{\theta}\left(x_{i}\right)\right]
$$

If the value for $\omega^{2}$ is larger than some critical value, reject the null hypothesis. The null hypothesis is that $F$ is the function specified by $\theta$, whereas the alternative hypothesis is that $F$ is some other function. A null distribution of $\omega_{n}^{2}$ is required, is technically rigorous, and discussed by Faraway and others (2015). The significance level will be smaller than intended. Compared to Moran-Darling (fig. 4-2), Cramér-von Mises places more weight on observations in the tails of the distribution.

\section{Kolmogorov-Smirnov Test}

The Kolmogorov-Smirnov test for goodness-of-fit (Faraway and others, 2015; Hollander and Wolfe, 1973; Marsaglia and others, 2003) also is based on the cumulative distribution function for which the test statistic is the distance

$$
D_{n}=\sup _{x}\left|F_{n}(\theta)-F_{\theta}(x)\right|,
$$

where $\sup _{x}$ is the supremum of the set of absolute distances. If the value for $D_{n}$ is larger than some critical value, reject the null hypothesis. The required null distribution of $D_{n}$ is defined as

$$
F_{D_{n}}(x)=\frac{\sqrt{2 \pi}}{x} \sum_{k=1}^{\infty} \exp \left[-(2 k-1)^{2} \pi^{2} /\left(8 x^{2}\right)\right] .
$$

Figure 4-1. Definition of goodness-of-fit tests (measures) Cramér-von Mises and Kolmogorov-Smirnov after Anderson (1962), Csörgö and Faraway (1996), and Faraway and others (2015), Hollander and Wolfe (1973), Marsaglia and others (2003), and references therein. 


\section{Goodness-of-Fit Statistics (Akaike Information Criterion and Moran-Darling Test)}

Akaike Information Criterion - A Relative of the Method of Maximum Likelihood

The Akaike Information Criterion (AIC) is based on the probability density function transformed into the likelihood function, and AIC is defined as

$$
\mathrm{AIC}=2 k-2 \log \left(L_{n}\right),
$$

where $\log (a)$ is the natural $\log$ arithm and $L_{n}$ is defined as the maximum value of likelihood, and $k$ is the number of parameters in the probability density function. The quantity $\log \left(L_{n}\right)$ is readily obtained from the method of maximum likelihood (MLE), but for any fitted distribution, it computed as

$$
\log \left(L_{n}\right)=\sum_{i=1}^{n} \log \left(f\left(x_{i} ; \theta\right)\right),
$$

where $n$ is the sample size, $x_{i}$ is the $i$ th value, and $f(x ; \theta)$ is the probability density function given the $k$ parameters in the vector $\theta$. Maximization of $\log \left(L_{n}\right)$ for candidate $\theta$ constitutes MLE.

\section{Moran-Darling Test - A Relative of the Method of Maximum Product of Spacings}

The Moran-Darling test is readily obtained from the method of maximum product of spacings (MPS). Let the cumulative distribution function be $F(x ; \theta)$ and let $U_{i}(\theta)=F\left(x_{i: n} ; \theta\right)$ be a nonexceedance probability of the sample order statistics $x_{i: n}$ for a sample of size $n$, now define the differences

$$
D_{i}(\Theta)=U_{i}(\theta)-U_{i-1}(\theta) \text { for } i=1, \ldots, n+1, \text { and }
$$

with the inclusions of $U_{0}(\theta)=0$ and $U_{n+1}(\theta)=1$. The MPS objective function is

$$
M_{n}(\theta)=\sum_{i=1}^{n+1} \log \left[D_{i}(\theta)\right] .
$$

Maximization of $M_{n}$ for candidate $\theta$ constitutes MPS. If all $U$ are equally spaced, then the absolute value $|M(\theta)|=I_{o}=(n+1) \log (n+1)$ and establishes the concepts towards goodness-of-fit. The $M_{n}(\theta)$ is a form of the Moran-Darling statistic for goodness-of-fit. The $M_{n}(\theta)$ is a normal distribution with

$$
\begin{aligned}
& \mu_{M} \approx(n+1)[\log (n+1)+\gamma]-\frac{1}{2}-\frac{1}{12(n+1)} \text { for the mean, and } \\
& \sigma_{M} \approx(n+1)\left(\frac{\pi^{2}}{6}-1\right)-\frac{1}{2}-\frac{1}{6(n+1)} \text { for the standard deviation, }
\end{aligned}
$$

where $\gamma \approx 0.577221$ (Euler-Mascheroni constant). An extension into small samples using the well-known Chi-Square distribution $\left(\chi_{n}^{2}\right)$ with $n$ degrees of freedom requires two coefficients computed as

$$
C_{1}=\mu_{M}-\sqrt{\frac{\sigma_{M}^{2} n}{2}} \text { and } C_{2}=\sqrt{\frac{\sigma_{M}^{2}}{2 n}} \text {, and }
$$

finally the Moran-Darling test statistic is

$$
T(\theta)=\left(M_{n}(\theta)-C_{1}+k / 2\right) / C_{2},
$$

where the term $k / 2$ is a bias correction based on the number of fitted distribution parameters $k$. The null hypothesis that the fitted distribution is correct is to be rejected if $T(\theta)$ exceeds a critical value from $\chi_{n}^{2}$. Compared to Cramér-von Mises (fig. 4-1), Moran-Darling places more weight on observations in the tails of the distribution.

Figure 4-2. Definition of goodness-of-fit tests (measures) for Akaike Information Criterion and Moran-Darling and association to methods of maximum likelihood and maximum product of spacings after Asquith (2016), Cheng and Stephens (1989), Dey and others (2016), and references therein. 


\section{Appendix 4 References Cited}

Anderson, T.W., 1962, On the distribution of the two-sample Cramér-von Mises Criterion: Annals of Mathematical Statistics. Institute of Mathematical Statistics: v. 33, no. 3, p. $1148-1159$.

Asquith, W.H., 2016, lmomco-L-moments, trimmed L-moments, L-comoments, censored L-moments, and many distributions: R package version 2.2.5 (September 9, 2016), accessed February 21, 2017, at http://cran.r-project.org/web/ packages/lmomco/index.html.

Cheng, R.C.H., and Stephens, M.A., 1989, A goodness-offit test using Moran's statistic with estimated parameters: Biometrika, v. 76, no. 2, p. 385-392.

Csörgö, S., and Faraway, J.J., 1996, The exact and asymptotic distributions of Cramér-von Mises statistics: Journal of the Royal Statistical Society, Series B, v. 58, p. 221-234.
Dey, D.K., Roy, Dooti, and Yan, Jun, 2016, Univariate extreme value analysis, chap 1 of Dey, D.K., and Yan, Jun, eds., Extreme value modeling and risk analysis - Methods and applications: Boca Raton, Fla., CRC Press, p. 1-22.

Faraway, J.J., Marsaglia, George, Marsaglia, John, and Baddeley, Adrian, 2015, goftest-Classical goodness-of-fit tests for univariate distributions: R package version 1.0-4, accessed February 21, 2017, at https://cran.r-project.org/ package $=$ goftest.

Hollander, Myles, and Wolfe, D.A., 1973, Nonparametric statistical methods: New York, John Wiley, 503 p.

Marsaglia, George, Tsang, W.W., and Wang, Jingbo, 2003, Evaluating Kolmogorov's distribution: Journal of Statistical Software, v. 8, no. 18, 4 p. 


\section{Appendix 5. Primer on Probability Distributions Applicable to This Study in the Context of L-moments}

This appendix defines and summarizes the probability density, cumulative distribution, and quantile functions of six three-parameter and four or more parameter (high parameter) probability distributions considered for this study. The parameterization of distributions by the same name can vary subtly between sources. In addition, some sources might present a distribution with a different number of parameters (usually one more or one less) than used for this study. For example, the Weibull distribution is a distinct three-parameter distribution here but is shown as a two-parameter version under the same name in Evans and others (2000).

The core mathematics of the six three-parameter distributions in context of L-moments are available in Hosking (1990), Hosking and Wallis (1997), Stedinger and others (1993) and extensions to the high-parameter distributions are available in Asquith (2007), Asquith (2011a,b), Asquith (2014), and Karian and Dudewicz (2011). Readers are directed to the research packages by Asquith (2016) [R package lmomco] and Hosking $(2015 \mathrm{a}, \mathrm{b})$ [R packages 1 mom and
lmomREA] that describe computation of L-moments in the $\mathrm{R}$ language ( $\mathrm{R}$ Core Team, 2016). Another useful package is by Karvanen (2016) [R package Lmoments].

The six three-parameter distributions (generalized extreme value, generalized logistic, generalized normal [lognormal], generalized Pareto, Pearson type III, and Weibull) are defined in figures 5-1 through 5-6. These distributions are of primary interest for this study.

The high-parameter distributions are acknowledged and briefly demonstrated for this study. As a general rule, the mathematics of higher-parameter distributions is considerably more complex than that of the three-parameter distributions. Two four-parameter distributions are considered, the asymmetric exponential power distribution and the Kappa distribution, defined in figures 5-7 and 5-8. The asymmetric exponential power distribution does not suffer from multiple solution complexities like the generalized lambda distribution (Asquith, 2007; Karian and Dudewicz, 2011). Lastly, the fiveparameter Wakeby distribution is defined in figure 5-9. 


\section{Generalized Extreme Value Distribution}

The generalized extreme value (GEV) distribution is a common distribution in applications involving extreme value analysis of natural phenomena. The two-parameter Gumbel distribution is a special case of the GEV for shape parameter $\kappa=0$. The distribution functions for parameters $\xi$ (location), $\alpha$ (scale, $\alpha>0$ ), and $\kappa$ (shape, $\kappa>-1)$ are

$$
\begin{aligned}
& f(x)=\alpha^{-1} \exp [-(1-\kappa) Y-\exp (-Y)], \text { and } \\
& F(x)=\exp [-\exp (-Y)]
\end{aligned}
$$

where

$$
Y= \begin{cases}-\kappa^{-1} \log [1-\kappa(x-\xi) / \alpha] & \text { if } \kappa \neq 0, \text { and } \\ (x-\xi) / \alpha & \text { if } \kappa=0,\end{cases}
$$

and

$$
x(F)= \begin{cases}\xi+\alpha\left(1-[-\log (F)]^{\kappa}\right) / \kappa & \text { if } \kappa \neq 0, \text { and } \\ \xi-\alpha \log [-\log (F)] & \text { if } \kappa=0 .\end{cases}
$$

The ranges of the distribution are

$$
\begin{array}{cl}
-\infty<x \leq \xi+\alpha / \kappa & \text { if } \kappa>0, \\
-\infty<x<\infty & \text { if } \kappa=0, \text { and } \\
\xi+\alpha / \kappa \leq x<\infty & \text { if } \kappa<0 .
\end{array}
$$

The L-moments are

$$
\begin{aligned}
\lambda_{1} & =\xi+\alpha[1-\Gamma(1+\kappa)] / \kappa, \\
\lambda_{2} & =\alpha\left(1-2^{-\kappa}\right) \Gamma(1+\kappa) / \kappa, \\
\tau_{3} & =2\left(1-3^{-\kappa}\right) /\left(1-2^{-\kappa}\right)-3, \text { and } \\
\tau_{4} & =\frac{5\left(1-4^{-\kappa}\right)-10\left(1-3^{-\kappa}\right)+6\left(1-2^{-\kappa}\right)}{\left(1-2^{-\kappa}\right)},
\end{aligned}
$$

where $\Gamma(a)$ is the complete gamma function and is $\Gamma(a)=\int_{0}^{\infty} t^{a-1} \exp (-t) \mathrm{d} t$.

Fitted Distribution Nomenclature for this Report

A GEV distribution has three parameters. In the same ordering as described above, a GEV having arbitrary parameters $\xi=4.6, \alpha=0.18$, and $\kappa=0.14$ is written as " $\mathrm{GEV}(4.6,0.18,0.14)$ " for precision.

Figure 5-1. Mathematical definitions and related details for the three-parameter generalized extreme value distribution after Asquith (2011a,b; 2016) and Hosking and Wallis (1997) and references therein. 


\section{Generalized Logistic Distribution}

The generalized logistic (GLO) distribution likely is not as frequently used in hydrology as the generalized extreme value (GEV), generalized normal (GNO), or Pearson type III (PE3), but represents an informative upper bounds of L-skew and L-kurtosis for many earth-system data. The distribution functions for parameters $\xi$ (location), $\alpha$ (scale, $\alpha>0$ ), and $\kappa$ (shape, $-1<k<1$ ) are

$$
\begin{aligned}
& f(x)=\frac{\alpha^{-1} \exp [-(1-\kappa) Y]}{[1+\exp (-Y)]^{2}}, \text { and } \\
& F(x)=1 /[1+\exp (-Y)]
\end{aligned}
$$

where

$$
Y= \begin{cases}-\kappa^{-1} \log [1-\kappa(x-\xi) / \alpha] & \text { if } \kappa \neq 0, \text { and } \\ (x-\xi) / \alpha & \text { if } \kappa=0,\end{cases}
$$

and

$$
x(F)= \begin{cases}\xi+\alpha\left(1-[(1-F) / F]^{\kappa}\right) / \kappa & \text { if } \kappa \neq 0, \text { and } \\ \xi-\alpha \log [(1-F) / F] & \text { if } \kappa=0 .\end{cases}
$$

The ranges of the distribution are

$$
\begin{array}{cl}
-\infty<x \leq \xi+\alpha / \kappa & \text { if } \kappa>0, \\
-\infty<x<\infty & \text { if } \kappa=0, \text { and } \\
\xi+\alpha / \kappa \leq x<\infty & \text { if } \kappa<0 .
\end{array}
$$

The L-moments are

$$
\begin{aligned}
\lambda_{1} & =\xi+\alpha[1 / \kappa-\pi / \sin (\kappa \pi)], \\
\lambda_{2} & =\alpha \kappa \pi / \sin (\kappa \pi), \\
\tau_{3} & =-\kappa, \text { and } \\
\tau_{4} & =\left(1+5 \kappa^{2}\right) / 6,
\end{aligned}
$$

and the relation between $\tau_{3}$ and $\tau_{4}$ is

$$
\tau_{4}=\frac{1+5\left(\tau_{3}\right)^{2}}{6} .
$$

The parameters are

$$
\begin{aligned}
\kappa & =-\tau_{3}, \\
\alpha & =\frac{\lambda_{2} \sin (\kappa \pi)}{\kappa \pi}, \text { and } \\
\xi & =-\lambda_{1}-\alpha\left(\frac{1}{\kappa}-\frac{\pi}{\sin (\kappa \pi)}\right) .
\end{aligned}
$$

\section{Fitted Distribution Nomenclature for this Report}

A GLO distribution has three parameters. In the same ordering as described above, a GLO having arbitrary parameters $\xi=4.6, \alpha=0.18$, and $\kappa=-0.14$ is written as " $\mathrm{GLO}(4.6,0.18,-0.14)$ " for precision.

Figure 5-2. Mathematical definitions and related details for the three-parameter generalized logistic distribution after Asquith (2011a,b; 2016) and Hosking and Wallis (1997) and references therein. 


\section{Generalized Normal Distribution}

The generalized normal (GNO) distribution accommodates nonzero skewness and retains the normal as a special case. The GNO is lauded as equivalent to the three-parameter log-normal distribution (LN3) but avoids logarithmic transformation of the data prior to computation of sample statistics. The distribution functions for parameters $\xi$ (location), $\alpha$ (scale, $\alpha>0$ ), and $\kappa$ (shape) are

$$
\begin{aligned}
& f(x)=\frac{\exp \left(\kappa Y-Y^{2} / 2\right)}{\alpha \sqrt{2 \pi}}, \\
& F(x)=\Phi(Y), \text { and } \\
& x(F) \text { has no explicit analytical form, }
\end{aligned}
$$

where $\Phi(Y)$ is the cumulative distribution function of the standard normal distribution and $Y$ is

$$
Y= \begin{cases}-\kappa^{-1} \log [1-\kappa(x-\xi) / \alpha] & \text { if } \kappa \neq 0, \text { and } \\ (x-\xi) / \alpha & \text { if } \kappa=0 .\end{cases}
$$

The ranges of the distribution with bounds $\eta$ are

$$
\begin{array}{cl}
-\infty<x \leq \xi+\alpha / \kappa & \text { if } \kappa>0, \\
-\infty<x<\infty & \text { if } \kappa=0, \text { and } \\
\xi+\alpha / \kappa \leq x<\infty & \text { if } \kappa<0 .
\end{array}
$$

The first two L-moments are

$$
\lambda_{1}=\xi+\frac{\alpha}{\kappa}\left[1-\exp \left(\kappa^{2} / 2\right)\right] \text { and } \quad \lambda_{2}=\frac{\alpha}{\kappa}\left[\exp \left(\kappa^{2} / 2\right)\right][1-2 \Phi(-\kappa / \sqrt{2})] .
$$

There are no simple expressions for $\lambda_{3}, \lambda_{4}$, and $\lambda_{5}$.

The GNO is the LN3 because for $x>0$ and $\lambda_{3}>0$, the LN3 has the same distribution functions with the substitution of $Y$ for the following

$$
Y=\frac{\log (x-\zeta)-\mu_{\log }}{\sigma_{\log }}
$$

where $\zeta$ is the lower bounds (real space) for which $\zeta<\lambda_{1}-\lambda_{2}, \mu_{\log }$ is the arithmetic mean in log-space, and $\sigma_{\log }$ is the standard deviation in $\log$-space. The parameter equalities, by letting $\eta=\exp \left(\mu_{\log }\right)$, are

$$
\xi=\zeta+\eta \quad \text { and } \quad \alpha=\eta \sigma_{\log } \quad \text { and } \quad \kappa=-\sigma_{\log }
$$

The parameters of the LN3 in terms of the parameters of the GNO, by letting $\eta=\lambda_{1}-\zeta$, are

$$
\sigma_{\log }=\sqrt{2} \times \Phi^{(-1)}\left(0.5\left[1+\lambda_{2} / \eta\right]\right) \quad \text { and } \quad \mu_{\log }=\log (\eta)-0.5 \sigma_{\log }^{2},
$$

for a known bounds $\zeta$ and, by letting $\eta=\alpha / \sigma_{\log }$, are

$$
\sigma_{\log }=-\kappa \quad \text { and } \quad \mu_{\log }=\log (\eta) \quad \text { and } \quad \zeta=\xi-\eta,
$$

for an unknown bounds $\zeta$.

\section{Fitted Distribution Nomenclature for this Report}

A GNO distribution has three parameters. In the same ordering as described above, a GNO having arbitrary parameters $\xi=4.6, \alpha=0.18$, and $\kappa=-0.10$ is written as " $\mathrm{GNO}(4.6,0.18,-0.10)$ " for precision.

Figure 5-3. Mathematical definitions and related details for the three-parameter generalized normal (three-parameter log-normal) distribution after Asquith (2011a,b; 2016) and Hosking and Wallis (1997) and references therein. 


\section{Generalized Pareto Distribution}

The generalized Pareto (GPA) distribution likely is not as frequently used in hydrology as the generalized extreme value (GEV), generalized normal (GNO), or Pearson type III (PE3), but represents an informative lower bounds of L-skew and L-kurtosis for many earth-system data. The distribution functions for parameters $\xi$ (location), $\alpha$ (scale, $\alpha>0$ ), and $\kappa$ (shape, $\kappa>-1$ ) are

$$
\begin{aligned}
& f(x)=\alpha^{-1} \exp [-(1-\kappa) Y], \text { and } \\
& F(x)=1-\exp (-Y),
\end{aligned}
$$

where

$$
Y= \begin{cases}-\kappa^{-1} \log [1-\kappa(x-\xi) / \alpha] & \text { if } \kappa \neq 0, \text { and } \\ (x-\xi) / \alpha & \text { if } \kappa=0,\end{cases}
$$

and

$$
x(F)= \begin{cases}\xi+\alpha\left[1-(1-F)^{\kappa}\right] / \kappa & \text { if } \kappa \neq 0, \text { and } \\ \xi-\alpha \log (1-F) & \text { if } \kappa=0 .\end{cases}
$$

The ranges of the distribution are

$$
\begin{array}{ll}
\xi<x \leq \xi+\alpha / \kappa & \text { if } \kappa>0, \text { and } \\
\xi \leq x<\infty & \text { if } \kappa \leq 0 .
\end{array}
$$

The L-moments are

$$
\begin{aligned}
\lambda_{1} & =\xi+\alpha /(1+\kappa), \\
\lambda_{2} & =\alpha /[(1+\kappa)(2+\kappa)], \\
\tau_{3} & =(1-\kappa) /(3+\kappa), \text { and } \\
\tau_{4} & =(1-\kappa)(2-\kappa) /[(3+\kappa)(4+\kappa)] .
\end{aligned}
$$

The parameters for a known $\xi$ are

$$
\begin{aligned}
& \kappa=\left[\left(\lambda_{1}-\xi\right) / \lambda_{2}\right]-2, \text { and } \\
& \alpha=(1+\kappa)\left(\lambda_{1}-\xi\right),
\end{aligned}
$$

and the relation between $\tau_{3}$ and $\tau_{4}$ is

$$
\tau_{4}=\frac{\tau_{3}\left(1+5 \tau_{3}\right)}{5+\tau_{3}},
$$

and the parameters for an unknown $\xi$ are

$$
\begin{aligned}
& \kappa=\left(1-3 \tau_{3}\right) /\left(1+\tau_{3}\right), \\
& \alpha=(1+\kappa)(2+\kappa) \lambda_{2}, \text { and } \\
& \xi=\lambda_{1}-(2+\kappa) \lambda_{2} .
\end{aligned}
$$

\section{Fitted Distribution Nomenclature for this Report}

A GPA distribution has three parameters. In the same ordering as described above, a GPA having arbitrary parameters $\xi=4.6, \alpha=0.40$, and $\kappa=0.55$ is written as "GPA $(4.6,0.40,0.55)$ " for precision.

Figure 5-4. Mathematical definitions and related details for the three-parameter generalized Pareto distribution after Asquith (2011a,b; 2016) and Hosking and Wallis (1997) and references therein. 


\section{Pearson Type III Distribution}

The Pearson type III (PE3) distribution is a three-parameter distribution and is a widely used probability distribution in the hydrologic sciences. The product moments are explicit parameters, which greatly simplifies comparisons between parameter estimates between product moments and L-moments. The distribution functions for parameters $\mu$ (arithmetic mean, location), $\sigma$ (standard deviation, scale), and $\gamma$ (skew, shape), but expressed with alternative parameters $\xi$ (location), $\beta$ (scale, $\beta>0$ ), and $\alpha$ (shape, $\alpha>0$ ) are

$$
\begin{aligned}
& f(x)= \begin{cases}\beta^{-\alpha}(x-\xi)^{\alpha-1} \exp \left(-Y_{1}\right) / \Gamma(\alpha) & \text { if } \gamma>0, \\
\beta^{-\alpha}(\xi-x)^{\alpha-1} \exp \left(-Y_{2}\right) / \Gamma(\alpha) & \text { if } \gamma<0, \text { and } \\
\varphi((x-\mu) / \sigma) / \sigma & \text { if } \gamma=0,\end{cases} \\
& F(x)= \begin{cases}G\left(\alpha, Y_{1}\right) / \Gamma(\alpha) & \text { if } \gamma>0, \\
1-G\left(\alpha, Y_{2}\right) / \Gamma(\alpha) & \text { if } \gamma<0, \text { and } \\
\Phi((x-\mu) / \sigma) & \text { if } \gamma=0,\end{cases}
\end{aligned}
$$

$x(F)$ has no explicit analytical form,

where

$$
Y_{1}=(x-\xi) / \beta \quad \text { and } \quad Y_{2}=(\xi-x) / \beta
$$

and where $G(a, b)$ is the incomplete gamma function, $\Gamma(a)$ is the complete gamma function, $\varphi(a)$ is the probability density function of the standard normal distribution (mean of zero and standard deviation of unity), $\Phi(a)$ is the cumulative distribution function of the standard normal distribution. The relations between the product moments and the three alternative parameters for $\gamma \neq 0$ are

$$
\alpha=4 / \gamma^{2} \text { and } \beta=\sigma|\gamma| / 2 \text { and } \xi=\mu-2 \sigma / \gamma \text {. }
$$

The incomplete gamma function $G(a, b)$ is $G(a, b)=\int_{0}^{b} t^{a-1} \exp (-t) \mathrm{d} t$ and the complete gamma function $\Gamma(a)$ is $\Gamma(a)=\int_{0}^{\infty} t^{a-1} \exp (-t) \mathrm{d} t$.

The ranges of the distribution are

$$
\begin{aligned}
\xi \leq x<\infty & \text { if } \gamma>0, \\
-\infty<x<\infty & \text { if } \gamma=0 \text { (normal distribution), and } \\
-\infty<x \leq \xi & \text { if } \gamma<0 .
\end{aligned}
$$

The L-moments are

$$
\begin{aligned}
\lambda_{1} & =\xi+\alpha \beta \text { and } \lambda_{2}=\pi^{-1 / 2} \beta \Gamma(\alpha+1 / 2) / \Gamma(\alpha), \text { and } \\
\tau_{3} & =6 I_{1 / 3}(\alpha, 2 \alpha)-3,
\end{aligned}
$$

where $I_{x}(p, q)$ denotes the incomplete beta function ratio

$$
I_{x}(p, q)=\frac{\Gamma(p+q)}{\Gamma(p) \Gamma(q)} \int_{0}^{x} t^{p-1}(1-t)^{q-1} \mathrm{~d} t,
$$

which also is the same as the cumulative distribution function of the Beta distribution.

\section{Fitted Distribution Nomenclature for this Report}

A PE3 distribution has three parameters. In the same ordering as described above, a PE3 having arbitrary parameters $\mu=4.6, \sigma=0.18$, and $\gamma=0.60$ is written as "PE3(4.6, 0.18, 0.60)" for precision.

Figure 5-5. Mathematical definitions and related details for the three-parameter Pearson type III distribution after Asquith (2011a,b; 2016) and Hosking and Wallis (1997) and references therein. 


\section{Weibull Distribution}

The Weibull (WEI) distribution is a three-parameter version for this investigation, whereas, some authors implement only a two-parameter version. The distribution functions for parameters $\zeta$ (location), $\beta$ (scale), and $\delta$ (shape) are

$$
\begin{aligned}
& f(x)=\delta Y^{\delta-1} \exp \left(-Y^{\delta}\right) / \beta, \\
& F(x)=1-\exp \left(-Y^{\delta}\right), \text { and } \\
& x(F)=\beta[-\log (1-F)]^{1 / \delta}-\zeta,
\end{aligned}
$$

where

$$
Y=(x-\zeta) / \beta .
$$

The range of the distribution is

$$
\zeta \leq x<\infty .
$$

The distribution is a reverse generalized extreme value (GEV) distribution. As result, algorithms for a GEV can be used implementation of the Weibull. The relations between the GEV parameters $(\xi, \alpha, \kappa)$ are

$$
\begin{aligned}
\kappa & =1 / \delta, \\
\alpha & =\beta / \delta, \text { and } \\
\xi & =\zeta-\beta .
\end{aligned}
$$

\section{Fitted Distribution Nomenclature for this Report}

A WEI distribution has three parameters. In the same ordering as described above, a WEI having arbitrary parameters $\zeta=-3.9, \beta=0.40$, and $\delta=2.1$ is written as "WEI $(-3.9,0.40,2.1)$ " for precision.

Figure 5-6. Mathematical definitions and related details for the three-parameter Weibull distribution after Asquith (2011a,b; 2016) and Hosking and Wallis (1997) and references therein. 


\section{Asymmetrical Exponential Power Distribution}

The four-parameter asymmetric exponential power (AEP4) distribution was introduced by others to obtain a flexible distribution with potential applications in stochastic modeling. The distribution functions for parameters $\xi$ (location), $\alpha$ (scale, $\alpha>0$ ), $\kappa$ (shape $1, \kappa>0$ ), $h$ (shape $2, h>0$ ) are

$$
\begin{aligned}
& f(x)=\frac{\kappa h}{\alpha\left(1+\kappa^{2}\right) \Gamma(1 / h)} \exp \left[-\left(\kappa^{\operatorname{sign}(x-\xi)}(|x-\xi| / \alpha)\right)^{h}\right], \\
& F(x)= \begin{cases}{\left[\kappa^{2} /\left(1+\kappa^{2}\right)\right] G\left([(\xi-x) /(\alpha \kappa)]^{h}, 1 / h\right)} & \text { for } x<\xi, \\
1-\left[1 /\left(1+\kappa^{2}\right)\right] G\left([\kappa(x-\xi) / \alpha]^{h}, 1 / h\right) & \text { for } x \geq \xi, \text { and }\end{cases} \\
& x(F)= \begin{cases}\xi-\alpha \kappa\left[G^{(-1)}\left(\left[1+\kappa^{2}\right] F / \kappa^{2}, 1 / h\right)\right]^{1 / h} & \text { for } F<F(\xi), \text { and } \\
\xi+(\alpha / \kappa)\left[G^{(-1)}\left(\left[1+\kappa^{2}\right](1-F), 1 / h\right)\right]^{1 / h} & \text { for } F \geq F(\xi),\end{cases}
\end{aligned}
$$

where $\Gamma(a)$ is the complete gamma function and is $\Gamma(a)=\int_{0}^{\infty} t^{a-1} \exp (-t) \mathrm{d} t, G(Z, a)$ is the upper tail of the incomplete gamma function and is $G(a, b)=\int_{0}^{b} t^{a-1} \exp (-t) \mathrm{d} t$, and $G^{(-1)}(Z, a)$ is the inverse of the upper tail of the incomplete gamma function. The AEP4 subsumes the normal distribution at $\kappa=1$ and $h=2$, and the range of the distribution is $-\infty<x<\infty$.

Only the first three L-moments are shown here for brevity. The first two L-moments are

$$
\begin{aligned}
& \lambda_{1}=\xi+\alpha(1 / \kappa-\kappa) \frac{\Gamma(2 / h)}{\Gamma(1 / h)}, \text { and } \\
& \lambda_{2}=-\frac{\alpha \kappa(1 / \kappa-\kappa)^{2} \Gamma(2 / h)}{\left(1+\kappa^{2}\right) \Gamma(1 / h)}+2 \frac{\alpha \kappa^{2}\left(1 / \kappa^{3}+\kappa^{3}\right) \Gamma(2 / h) I_{1 / 2}(1 / h, 2 / h)}{\left(1+\kappa^{2}\right)^{2} \Gamma(1 / h)},
\end{aligned}
$$

where $I_{1 / 2}(1 / h, 2 / h)$ is the cumulative distribution of the Beta distribution $I_{m}(a, b)$, this function is also the normalized incomplete beta function and is

$$
I_{m}(a, b)=\int_{0}^{m} t^{a-1}(1-t)^{b-1} \mathrm{~d} t \times[1 / \beta(a, b)],
$$

where $\beta(a, b)$ is the complete beta function and is $\beta(a, b)=\int_{0}^{1} t^{a-1}(1-t)^{b-1} \mathrm{~d} t$. The third L-moment is $\lambda_{3}=A_{1}+A_{2}+A_{3}$ where the $A_{i}$ are

$$
\begin{aligned}
& A_{1}=\frac{\alpha(1 / \kappa-\kappa)\left(\kappa^{4}-4 \kappa^{2}+1\right) \Gamma(2 / h)}{\left(1+\kappa^{2}\right)^{2} \Gamma(1 / h)}, \\
& A_{2}=-6 \frac{\alpha \kappa^{3}(1 / \kappa-\kappa)\left(1 / \kappa^{3}+\kappa^{3}\right) \Gamma(2 / h) I_{1 / 2}(1 / h, 2 / h)}{\left(1+\kappa^{2}\right)^{3} \Gamma(1 / h)}, \text { and } \\
& A_{3}=6 \frac{\alpha\left(1+\kappa^{4}\right)(1 / \kappa-\kappa) \Gamma(2 / h) \Delta}{\left(1+\kappa^{2}\right)^{2} \Gamma(1 / h)},
\end{aligned}
$$

where $\Delta$ is

$$
\Delta=\frac{1}{\beta(1 / h, 2 / h)} \int_{0}^{1 / 2} t^{1 / h-1}(1-t)^{2 / h-1} I_{(1-t) /(2-t)}(1 / h, 3 / h) \mathrm{d} t .
$$

\section{Fitted Distribution Nomenclature for this Report}

An AEP4 distribution has four parameters. In the same ordering as described above, a AEP4 having arbitrary parameters $\xi=4.2, \alpha=0.18, \kappa=0.75$, and $h=1.15$ is written as "AEP4(4.2, $0.18,0.75,1.25$ )" for precision.

Figure 5-7. Mathematical definitions and related details for the four-parameter asymmetric exponential power distribution after Asquith (2011a,b; 2014; 2016) and references therein. 


\section{Kappa Distribution}

The Kappa (KAP) distribution is of particular interest to L-moments, because if $h=-1$, the distribution is the generalized logistic distribution (GLO); if $h=0$, it is the generalized extreme value (GEV); and if $h=1$, it is the generalized Pareto (GPA). The distribution functions for parameters $\xi$ (location), $\alpha$ (scale), $\kappa$ (shape1), $h$ (shape2) subject to the constraints that $h \geq 0$ and $\kappa>-1$ or if $h<0$ and $-1<\kappa<-1 / h$ are

$$
\begin{aligned}
f(x) & =\alpha^{-1}[1-\kappa(x-\xi) / \alpha]^{1 / \kappa-1} \times F^{1-h}, \\
F(x) & =\left[1-h(1-\kappa(x-\xi) / \alpha)^{1 / \kappa}\right]^{1 / h}, \text { and } \\
x(F) & =\xi+\frac{\alpha}{\kappa}\left[1-\left(\frac{1-F^{h}}{h}\right)^{\kappa}\right] .
\end{aligned}
$$

The ranges of the distribution $x_{L} \leq x \leq x_{U}$ are

$$
\begin{aligned}
& x_{L}= \begin{cases}\xi+\alpha\left(1-h^{-\kappa}\right) / \kappa & \text { if } h>0, \\
\xi+\alpha / \kappa & \text { if } h \leq 0 \text { and } \kappa<0, \text { and } \\
-\infty & \text { if } h \leq 0 \text { and } \kappa \geq 0,\end{cases} \\
& x_{U}= \begin{cases}\xi+\alpha / \kappa & \text { if } \kappa>0, \text { and } \\
\infty & \text { if } \kappa \leq 0 .\end{cases}
\end{aligned}
$$

The L-moments are

$$
\begin{aligned}
\lambda_{1} & =\xi+\alpha\left(1-g_{1}\right) / \kappa, \\
\lambda_{2} & =\alpha\left(g_{1}-g_{2}\right) / \kappa, \\
\tau_{3} & =\left(-g_{1}+3 g_{2}-2 g_{3}\right) /\left(g_{1}-g_{2}\right), \text { and } \\
\tau_{4} & =\left(-g_{1}+6 g_{2}-10 g_{3}+5 g_{4}\right) /\left(g_{1}-g_{2}\right),
\end{aligned}
$$

where the $g_{r}$ for $r \in 1,2,3,4$ is

$$
g_{r}= \begin{cases}r \Gamma(1+\kappa) \Gamma(r / h) /\left[h^{1+\kappa} \Gamma(1+\kappa+r / h)\right] & \text { if } h>0, \text { and } \\ r \Gamma(1+\kappa) \Gamma(-\kappa-r / h) /\left[(-h)^{1+\kappa} \Gamma(1-r / h)\right] & \text { if } h<0,\end{cases}
$$

where $\Gamma(a)$ is the complete gamma function and is

$$
\Gamma(a)=\int_{0}^{\infty} t^{a-1} \exp (-t) \mathrm{d} t .
$$

\section{Fitted Distribution Nomenclature for this Report}

A KAP distribution has four parameters. In the same ordering as described above, a KAP having arbitrary parameters $\xi=4.2, \alpha=0.13, \kappa=0.32$, and $h=-0.27$ is written as " $\mathrm{KAP}(4.2,0.13,0.32,-0.27)$ " for precision. However, the KAP could not be fit to the data used (tables 1-2 and 1-3), and this notation thus is absent in (unneeded for) this report.

Figure 5-8. Mathematical definitions and related details for the four-parameter Kappa distribution after Asquith (2007; 2011a,b; 2016) and Hosking and Wallis (1997) and references therein. 


\section{Wakeby Distribution}

The Wakeby (WAK) distribution is a wildly flexible distribution because it has five parameters. The distribution is attractive because it is fit to four or five L-moments depending on whether $\xi$ is either known or unknown. The distribution functions for parameters $\xi$ (location), $\alpha$ (scale1), $\gamma$ (scale2), $\beta$ (shape1), $\delta$ (shape2) are

$$
f(x)=\alpha(1-F)^{\beta-1}+\gamma(1-F)^{-\delta-1},
$$

$F(x)$ has no explicit analytical form, and

$$
x(F)=\xi+\frac{\alpha}{\beta}\left[1-(1-F)^{\beta}\right]-\frac{\gamma}{\delta}\left[1-(1-F)^{-\delta}\right],
$$

where constraints of the parameters are

$$
\begin{array}{r}
\beta+\delta>0 \quad \text { or } \beta=\gamma=\delta=0, \\
\text { if } \alpha=0 \text { then } \beta=0, \\
\text { if } \gamma=0 \text { then } \delta=0 \text {, and } \\
\gamma \geq 0 \text { and } \alpha+\gamma \geq 0 .
\end{array}
$$

The range of the distribution is $\xi \leq x \leq x_{U}$ where the upper limit is

$$
x_{U}= \begin{cases}\infty & \text { if } \delta \geq 0 \text { and } \gamma>0, \text { and } \\ \xi+\alpha / \beta-\gamma / \delta & \text { if } \delta<0 \text { or } \gamma=0 .\end{cases}
$$

The L-moments of moment order $r$ for $r \leq 3$ are defined for $\delta<1$

$$
\begin{aligned}
& \lambda_{1}=\xi+\frac{\alpha}{(1+\beta)}+\frac{\gamma}{(1-\delta)}, \\
& \lambda_{2}=\frac{\alpha}{(1+\beta)(2+\beta)}+\frac{\gamma}{(1-\delta)(2-\delta)}, \text { and } \\
& \lambda_{3}=\frac{\alpha(1-\beta)}{(1+\beta)(2+\beta)(3+\beta)}+\frac{\gamma(1+\delta)}{(1-\delta)(2-\delta)(3-\delta)} .
\end{aligned}
$$

and the L-moments for $r>3$ are

$$
\begin{gathered}
\lambda_{4}=\frac{\alpha(1-\beta)(2-\beta)}{(1+\beta)(2+\beta)(3+\beta)(4+\beta)}+\frac{\gamma(1+\delta)(2+\delta)}{(1-\delta)(2-\delta)(3-\delta)(4-\delta)}, \text { and } \\
\lambda_{5}=\frac{\alpha(1-\beta)(2-\beta)(3-\beta)}{(1+\beta)(2+\beta)(3+\beta)(4+\beta)(5+\beta)}+ \\
\frac{\gamma(1+\delta)(2+\delta)(3+\delta)}{(1-\delta)(2-\delta)(3-\delta)(4-\delta)(5-\delta)} .
\end{gathered}
$$

Parameter estimation requires complex numerical routines.

\section{Fitted Distribution Nomenclature for this Report}

A WAK distribution has five parameters. In the same ordering as described above, a WAK having arbitrary parameters $\xi=3.9, \alpha=1.9, \gamma=7.5, \beta=0.15$, and $\delta=-0.05$ is written as "WAK $(3.9,1.9,7.5,0.15,-0.05)$ " for precision.

Figure 5-9. Mathematical definitions and related details for the five-parameter Wakeby distribution after Asquith (2007; 2011a,b; 2016) and Hosking and Wallis (1997) and references therein. 


\section{Appendix 5 References Cited}

Asquith, W.H., 2007, L-moments and TL-moments of the generalized lambda distribution: Computational Statistics and Data Analysis, v. 51, no. 9, p. 4484-4496.

Asquith, W.H., 2011a, Distributional analysis with L-moment statistics using the $\mathrm{R}$ environment for statistical computing: Texas Tech University, Ph.D. dissertation, accessed June 3, 2016, at https://ttu-ir.tdl.org/ttu-ir/handle/2346/ETDTTU-2011-05-1319.

Asquith, W.H., 2011b, Distributional analysis with L-moment statistics using the R environment for statistical computing: CreateSpace ISBN 978-1463508418. [Print-on-demand; reprinting of Asquith, 2011a, with errata.]

Asquith, W.H., 2014, Parameter estimation for the 4-parameter asymmetric exponential power distribution by the method of L-moments using R: Computational Statistics \& Data Analysis, v. 71, p. 955-970.

Asquith, W.H., 2016, lmomco-L-moments, trimmed L-moments, L-comoments, censored L-moments, and many distributions: R package version 2.2.5 (September 9, 2016), accessed February 21, 2017, at http://cran.r-project.org/web/ packages/lmomco/index.html.

Evans, Merran, Hastings, N.A.J., and Peacock, B.J., 2000, Statistical distributions (3d ed.): New York, John Wiley, $221 \mathrm{p}$.

Hosking, J.R.M., 1990, L-moments—Analysis and estimation of distributions using linear combinations or order statistics: Journal of Royal Statistical Society, series B, v. 52, no. 1, p. $105-124$.
Hosking, J.R.M., and Wallis, J.R., 1997, Regional frequency analysis-An approach based on L-moments: Cambridge, Cambridge University Press, 224 p.

Hosking, J.R.M., 2015a, lmom-L-moments: R package version 2.5 (February 2, 2015), accessed February 21, 2017, at http://cran.r-project.org/package=lmom.

Hosking, J.R.M., 2015b, lmomRFA-Regional frequency analysis using L-moments: $\mathrm{R}$ package version 3.0-1 (February 2, 2015): Accessed February 21, 2017, at http:// cran.r-project.org $/$ package $=$ lmomRFA.

Karian, Z.A., Dudewicz, E.J., 2011, Handbook of fitting statistical distributions with R: Boca Raton, Fla., CRC Press, 1,672 p.

Karvanen, Juha, 2016, Lmoments-L-moments and quantile mixtures: R package version 1.2-3 (February 22, 2016), accessed February 21, 2017, at https://cran.r-project.org/ web/packages/Lmoments/index.html.

R Core Team, 2016, R-A language and environment for statistical computing, version 3.2.4: Vienna, Austria, R Foundation for Statistical Computing.

Stedinger, J.R., Vogel, R.M., and Foufoula-Georgiou, Efi, 1993, Frequency analysis of extreme events, chap. 18 of D.A. Maidment, ed., Handbook of hydrology: New York, McGraw-Hill, p. 18.1-18.66. 
